\title{
ANÁliSE AMBIENTAL E TÉCNICA PARA A OBTENÇÃO DE NANOCRISTAIS DE CELULOSE DE BAGAÇO DA CANA-DE- AÇÚCAR APLICADOS EM NANOCOMPÓSITOS
}

\author{
ROSINEIDE MIRANDA LEÃO
}

TESE DE DOUTORADO EM CIÊNCIAS MECÂNICAS DEPARTAMENTO DE ENGENHARIA MECÂNICA

FACULDADE DE TECNOLOGIA

\section{UNIVERSIDADE DE BRASÍLIA}


UNIVERSIDADE DE BRASÍLIA

FACULDADE DE TECNOLOGIA

DEPARTAMENTO DE ENGENHARIA MECÂNICA

\begin{abstract}
ANÁliSE AMBIENTAL E TÉCNICA PARA A OBTENÇÃO DE NANOCRISTAIS DE CELULOSE DE BAGAÇO DA CANA-DEAÇÚCAR APLICADOS EM NANOCOMPÓSITOS
\end{abstract}

ROSINEIDE MIRANDA LEÃO

ORIENTADOR: PROF ${ }^{\mathrm{a}}$ DR $^{\mathrm{a}}$ SANDRA MARIA DA LUZ

TESE DE DOUTORADO EM CIÊNCIAS MECÂNICAS

PUBLICAÇÃO: ENM. DM - 38

BRASÍLIA/DF: AGOSTO 2016 
UNIVERSIDADE DE BRASÍLIA

FACULDADE DE TECNOLOGIA

DEPARTAMENTO DE ENGENHARIA MECÂNICA

\begin{abstract}
ANÁliSE AMBIENTAL E TÉCNICA PARA A OBTENÇÃO DE NANOCRISTAIS DE CELULOSE DE BAGAÇO DA CANA-DEAÇÚCAR APLICADOS EM NANOCOMPÓSITOS ROSINEIDE MIRANDA LEÃO
\end{abstract}

TESE SUBMETIDA AO DEPARTAMENTO DE ENGENHARIA MECÂNICA DA FACULDADE DE TECNOLOGIA DA UNIVERSIDADE DE BRASÍLIA COMO PARTE DOS REQUISITOS NECESSÁRIOS PARA A OBTENÇÃO DO GRAU DE DOUTOR EM ENGENHARIA MECÂNICA

APROVADO POR:

Prof $^{\mathrm{a}}$. Dra Sandra Maria da Luz (Faculdade do Gama/UnB) (Orientadora)

Prof. Dr Ademir Jose Zattera (Departamento de Polímeros/UCS) (Examinador externo)

Prof. Dr Thiago Oliveira Rodrigues (Departamento de Engenharia Florestal/UnB) (Examinador externo)

$\overline{\text { Prof. Dr Eder Lima de Albuquerque (Departamento de Engenharia Mecânica/UnB) }}$ (Examinador interno)

Prof. Dr Leonardo Fonseca Valadares (Embrapa Agroenergia)

(Examinador externo)

BRASÍLIA/DF, 22 DE AGOSTO DE 2016 


\section{F ICHA CATALOGRÁFICA}

\section{LEÃO, ROSINEIDE MIRANDA}

Análise Ambiental e Técnica para a Obtenção de Nanocristais de Celulose de Bagaço da Cana-de-Açúcar Aplicados em Nanocompósitos. [DISTRITO FEDERAL] 2016. xv, 194p., 210 x 297 mm (ENMC/FT/UnB, Doutor, Ciências Mecânicas, 2016).

Tese de Doutorado Universidade de Brasília. Faculdade de Tecnologia.

Departamento de Engenharia Mecânica
1. Bagaço de cana-de-açúcar
2. Avaliação de ciclo de vida
3. Nanocristais de celulose
4. Nanocompósitos
I. ENM/FT/UnB
II. Título (série)

\section{REFERÊNCIA BIBLIOGRÁFICA}

LEÃO, ROSINEIDE MIRANDA (2016). Análise Ambiental e Técnica para a Obtenção de Nanocristais de Celulose de Bagaço da Cana-de-Açúcar Aplicados em Nanocompósitos. Tese de Doutorado em Ciências Mecânicas, Publicação ENM. DM - 38/2016. Departamento de Engenharia Mecânica, Universidade de Brasília, Brasília - DF, 194p.

\section{CESSÃO DE DIREITOS}

NOME DO AUTOR: Rosineide Miranda Leão

TÍTULO: Análise Ambiental e Técnica para a Obtenção de Nanocristais de Celulose de Bagaço da Cana-de-Açúcar Aplicados em Nanocompósitos.

GRAU: Doutor

ANO: 2016.

É concedido à Universidade de Brasília permissão para reproduzir cópias desta Tese de Doutorado e para emprestar ou vender tais cópias somente para propósitos acadêmicos e científicos. O autor reserva outros direitos de publicação e nenhuma parte dessa Tese de Doutorado pode ser reproduzida sem autorização por escrito do autor.

Rosineide Miranda Leão rosemirandaleao@gmail.com 
"Poís é o senhor dá sabedoría, De sua boca procedem o conhecimento e o discernimento". Provérbios 2:6 


\section{AGRADECIMENTOS}

Primeiramente a Deus, por tudo;

A minha mãe Altair, pelo amor e dedicação;

Aos meus irmãos Roneide, Marli e Idalino José pelo carinho e paciência;

Aos meus sobrinhos Cássio, Maurício, Lucas e Bruna pelo apoio e compreensão;

A minha orientadora Sandra Maria da Luz, pela paciência, confiança, apoio e cuja dedicação fez com que a realização deste trabalho fosse possível;

Ao meu supervisor no exterior, João Manuel Luís Lopes Maia, pela confiança em mim depositada;

Aos meus amigos: Gabriela, Micheline, Ângela, Luiz, Janaine, Alair, Vitor, Lia Raquel, Marcelo, Kelly, Isabel, Adriana, Leia, Eva Claúdia, Paula Bertuoli, Mateus, Renan, Jéssica, Selma, pelo companheirismo, amizade e motivação;

Aos professores Doutores Jorge Luiz Ferreira, Ademir José Zattera, Andreia Costa, Maria Del Pilar Hidalgo, Gustavo Cueva, Patrícia Braga, Eliane Noronha, José Francisco Júnior, Carlos André e a Mercedes Maria Bustamante pela confiança em mim depositada;

Aos técnicos Margarete Lima, Nuno Dias, Ingrid Gracielle Silva, Fabio Nakamura, Francisco, Damiani, Maria Regina Silva; Paula e Yuri Dias, pelo apoio na realização dos experimentos;

Ao departamento de Biologia: Laboratório de Microscopia de Varredura Eletrônica e a Microscopia Eletrônica de Transmissão. Departamento de biologia celular, enzimologia, bioquímica, ecologia e limnologia, Departamento Geologia e biofísica;

A Case Western Reserve University, ao departamento de Macromolecular Science \& Engineering em Cleveland - Ohio, por permitirem o uso de suas instalações e equipamentos.

Ao Laboratório de polímeros (LPOL), da Universidade de Caxias de Sul;

A Usina Ester que forneceu as fibras de bagaço de cana-de-açúcar;

Ao decanato de Pós Graduação (DPP), REUNI e FAP-DF, pelo apoio financeiro.

À Capes, CNPq e Petrobras, pelo apoio financeiro que tornou viável a realização deste trabalho. 


\section{RESUMO}

O setor de cana no Brasil vem crescendo desde o início da década de 2000, obtendo uma produção anual de cerca de 654 milhões de toneladas em 2015, tornando o bagaço um importante resíduo agroindustrial. Esse fato leva a utilização de bagaço como fonte para a obtenção de nanocristais de celulose. Portanto, o presente estudo tem como objetivo obter nanocristais de celulose de forma técnica e ambiental que possam ser utilizados em nanocompósitos. Nanocristais de celulose podem ser extraídos por vários métodos, assim, a Avaliação do Ciclo de Vida (ACV) apresenta-se como a metodologia mais indicada para investigar quais as formas mais viáveis de obtenção. Para isso, o inventário dos sistemas englobou a produção de cana-de-açúcar e dos nanocristais. Insumos, energia e processos auxiliares como transporte e uso de combustível também foram quantificados. A unidade funcional adotada foi de $1 \mathrm{~kg}$ de nanocristais de celulose. Inicialmente, foram utilizados doze cenários para extração dos nanocristais de celulose que envolveu condições experimentais da literatura abrangendo pré-tratamento e hidrólise. Essas condições permitiram isolar os nanocristais de celulose, como também a composição química do bagaço e de cada fase de tratamento. Assim, as fibras e os nanocristais de celulose foram caracterizados por um conjunto de técnicas (microscopia eletrônica de varredura MEV; microscopia eletrônica de transmissão MET; microscopia de força atômica MFA; espectroscopia de infravermelho com transformada de Fourier FTIR, difração de Raios-X e análises térmicas). Depois da obtenção dos nanocristais de celulose, nanocompósitos de acrilonitrila butadieno estireno (ABS) reforçados com 0,5, 1,0 e 1,5\% de nanocristais de celulose foram obtidos por extrusão. Além disso, a influência do teor de nanocristais de celulose nos nanocompósitos foi estudada por difração de Raios-X,TGA análise termogravimétrica, DSC calorimetria exploratória diferencial e DMA análise dinâmicomecânica, ensaios mecânicos, análise estatística, MEV e reologia. Os resultados mostraram que em todos os cenários, na fase de pré-tratamento e na produção dos nanocristais, houve uma grande contribuição para os impactos ambientais devido à quantidade de produtos químicos utilizados e, especialmente, ao consumo elevado de água e energia. A composição química do bagaço em massa foi de $39 \%$ de celulose, $21 \%$ de lignina e $27 \%$ de hemicelulose. Entretanto, a caracterização por MEV mostrou que o tratamento mudou a morfologia das fibras, bem como o aumento da rugosidade da superfície. A caracterização por MET mostrou o cumprimento em torno de 44-300 nm e o diâmetro de $10-30 \mathrm{~nm}$. A caracterização por MFA mostrou a morfológia dos cristalitos e aglomerados de nanocristais. A análise de FTIR identificou claramente nos espectros, picos em 890-1364 $\mathrm{cm}^{-1}$ típico de celulose I. E, finalmente a análise de difração raios-X mostrou aumento da cristalinidade com sucessivos tratamentos, resultando em uma cristalinidade de $67 \%$ para os nanocristais. Difração de raios-X mostram diminuição do ângulo para os nanocompósitos, comprovando a dispersão da carga na matriz. As curvas TGA mostraram que a inserção dos nanocristais provocou uma estabilidade térmica intermediária para os nanocompósitos, e as curvas DSC para os nanocompósitos mostraram eventos térmicos semelhantes ao ABS. As curvas DMA mostraram aumento do módulo de armazenamento dos nanocompósitos. A adição dos nanocristais de celulose ao $\mathrm{ABS}$, alterou as propriedades do polímero, comprovado estatisticamente. Assim, dependendo da aplicação, dos nanocompósitos terá um desempenho de maior, tração; flexão; impacto, estabilidade; viscosidade ou em termos ambientais.

Palavras-chave: Bagaço de cana-de-açúcar, nanocristais de celulose, avaliação de ciclo de vida, nanocompósitos. 


\begin{abstract}
The sugarcane sector in Brazil has been growing since the beginning of the 2000s, obtaining a annual production of about 654 million tonnes in 2015, making sugarcane an important agricultural residue, may generate many applications. This fact carries the use of exceeding bagasse as a source to obtain cellulose nanocrystals. Therefore, the present study aims to obtain cellulose nanocrystals technical and environmental that can be used in nanocomposites. Nanocrystals cellulose can be extracted by various methods, so the Life Cycle Assessment (LCA) is presented as the most appropriate methodology to investigate what the most viable forms of obtainment. For that, inventory of the systems involved the sugarcane and nanocrystals production. Inputs, energy and auxiliary processes such as transportation and fuel use also were quantified. The functional unit used was $1 \mathrm{~kg}$ of cellulose nanocrystals. Initially, were used twelve scenarios for extraction of cellulose nanocrystals that involved experimental conditions of the literature including pre-treatment and hydrolysis. These conditions allowed isolation of cellulose nanocrystals, as well as, the chemical composition of the bagasse and of each treatment phase. The fibers and cellulose nanocrystals were characterized by a range of technical (scanning electron microscopy SEM, transmission electron microscopy TEM, atomic force microscopy AFM; infrared spectroscopy Fourier transform FTIR, X-ray diffraction and thermal analysis). After obtaining of the cellulose nanocrystals, nanocomposites of acrylonitrile butadiene styrene (ABS) reinforced with $0.5,1.0$ and $1.5 \%$ cellulose nanocrystals were obtained by extrusion. Furthermore, the influence of cellulose nanocrystals content in the nanocomposites was studied by (X-ray diffraction, TGA-thermogravimetric analysis, DSCdifferential scanning calorimetry and DMA-dynamic mechanical analysis), mechanical testing, SEM and rheology. The results showed that in all scenarios in the pre-treatment phase and nanocrystals production was there was a great contribution to that contributed to environmental impacts due amounts chemicals used, and especially the high consumption of water and energy. The chemical composition of the bagasse mass was $39 \%$ of cellulose, $21 \%$ of hemicellulose and $27 \%$ of lignin. However, the SEM characterization showed that the treatment changed the morphology of the fibers, as well as, increased surface roughness. The TEM characterization showed lenght around 44-300 $\mathrm{nm}$ and a diameter of 10-30 nm. The AFM characterization showed the morphology of the crystallites and agglomerates. The FTIR spectra analysis clearly identified, band in $890-1364 \mathrm{~cm}^{-1}$ characteristic of cellulose I. And, finally X-ray diffraction analysis showed that the crystallinity increased with successive treatments, resulting in nanocrystals with crystallinity, about $67 \%$. X-rays show decreased angle for nanocomposites, showing the load dispersion in the matrix. The TGA curves showed that the insertion of the nanocrystal caused a intermediate in thermal stability for the nanocomposite, and the DSC curves for nanocomposites showed thermal events similar to the ABS. The DMA curves showed increased storage modulus of the nanocomposites. The addition of the cellulose nanocrystals to ABS occurs alteration in polymer properties, statistically confirmed. Thus, depending on the application, each material will have a performance tensile higher; flexural; impact, stability; viscosity or environmental.
\end{abstract}

Keywords: Sugarcane bagasse, cellulose nanocrystals, evaluation of life cycle, nanocomposites. 


\section{SUMÁRIO}

\section{CAPÍTULO I}

1 INTRODUÇÃO

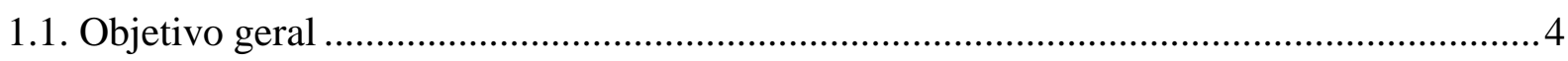

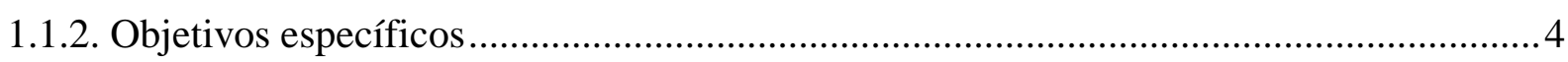

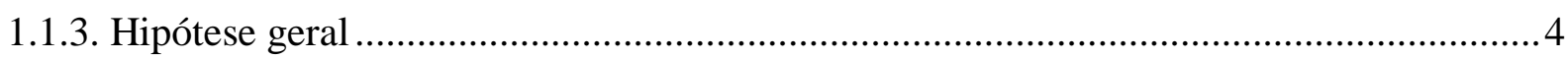

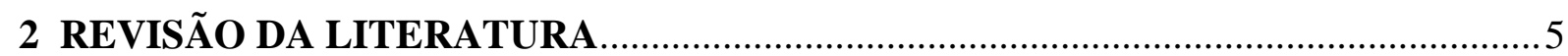

2.1. BAGAÇO DE CANA-DE-AÇÚCAR E A COMPOSIÇÃO DAS FIBRAS

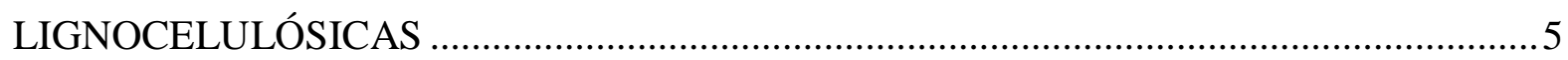

2.2. Tratamento de biomassa vegetal para separação dos materiais lignocelulósicos..............14

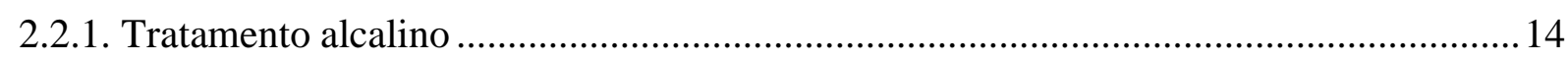

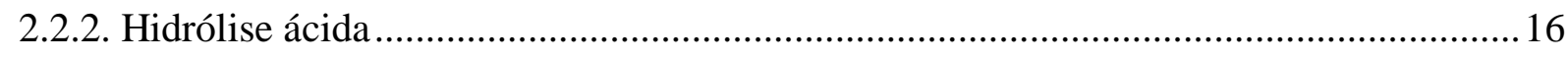

2.2.3. Os nanocristais de celulose e suas aplicações ............................................................ 18

2.3. AVALIAÇÃO DO CICLO DE VIDA (ACV) APLICADA AO DESENVOLVIMENTO

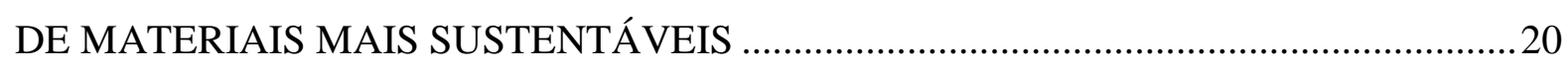

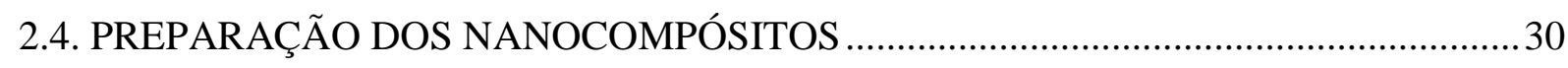

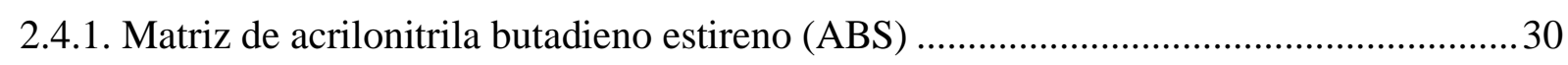

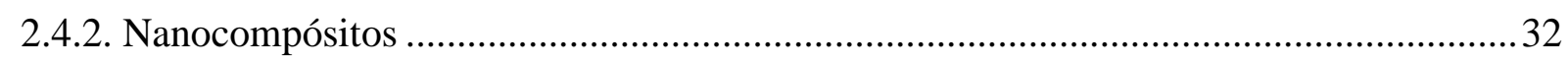

2.5. CARACTERIZAÇÃO DOS NANOCRISTAIS E NANOCOMPÓSITOS DE

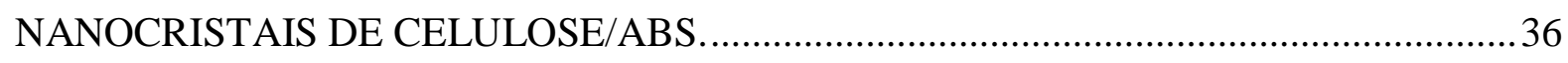

\section{CAPÍTULO II}

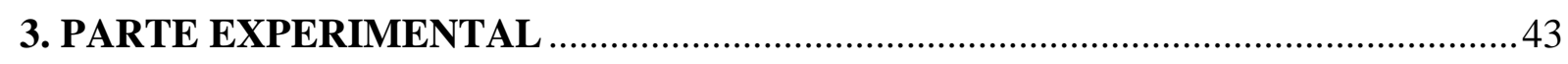

3.1. CARACTERIZAÇÃO DAS FIBRAS DE BAGAÇO DE CANA-DE-AÇÚCAR ...........44

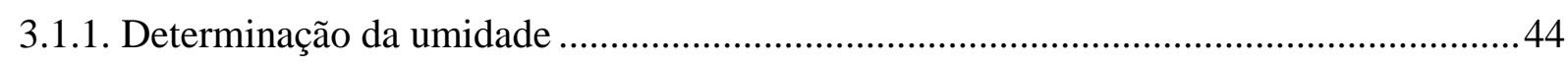

3.1.2. Teor de extrativos das fibras de bagaço de cana-de-açúcar com acetona.......................44

3.1.3. Caracterização química das fibras de bagaço de cana-de-açúcar: holocelulose, celulose lignina...... .45

3.2. OBTENÇÃO E CARACTERIZAÇÃO DAS FIBRAS E DOS NANOCRISTAIS DE CELULOSE A PARTIR DAS FIBRAS DE BAGAÇO DE CANA-DE-AÇÚCAR..............46 
3.3. AVALIAÇÃO DO CICLO DE VIDA (ACV) DA EXTRAÇÃO DOS NANOCRISTAIS DE CELULOSE A PARTIR DE BAGAÇO DE CANA-DE-AÇÚCAR

3.4. CARACTERIZAÇÃO DAS FIBRAS E DOS NANOCRISTAIS DE CELULOSE POR FTIR, DIFRAÇÃO DE RAIOS-X, MEV, MET, MFA, TGA/DTG, DSC.

3.6. CARACTERIZAÇÃO TÉRMICA, MECÂNICA, MORFOLÓGICAS E ANÁLISE DOS NANOCOMPÓSITOS E ANÁLISE REOMÉTRICA

\section{CAPÍTULO III}

\section{RESULTADOS E DISCUSSÃO}

4.1. AVALIAÇÃO DO IMPACTO AMBIENTAL DOS PROCESSOS DE OBTENÇÃO DOS NANOCRISTAIS DE CELULOSE.

4.1.1. Impacto ambiental da fase de produção dos nanocristais do sistema.....

4.2. CARACTERIZAÇÃO DAS FIBRAS DE BAGAÇO DE CANA-DE-AÇÚCAR IN NATURA.

4.3. CARACTERIZAÇÃO MORFOLÓGICAS DAS FIBRAS E DOS NANOCRISTAIS DE CELULOSE

4.3.1. Caracterização das fibras e dos nanocristais de celulose por difração de raios-X 79

4.3.2. Caracterização das fibras e dos nanocristais de celulose por FTIR 84

4.4. CARACTERIZAÇÃO POR MICROSCOPIA 86

4.3.1. Caracterização das fibras, das holocelulose e das $\alpha$-celuloses por (MEV) 86

4.3.2. Caracterização dos NCC por microscopia eletrônica de transmissão (MET) .90

4.3.3. Caracterização dos NCC por microscopia de força atômica (MFA) . .92

4.5. CARACTERIZAÇÃO TÉRMICA DAS FIBRAS

4.5.1. Caracterização das fibras, nanocristais de celulose, holocelulose e $\alpha$-celuloses a partir da análise térmica e TGA/FTIR acoplado. .93

4.5.2. Caracterização das fibras por calorimetria exploratória diferencial (DSC) 100 
4.6. OBTENÇÃO DOS NANOCOMPÓSITOS E CARACTERIZAÇÃO POR ANÁLISES TÉRMICAS, MORFOLÓGICA, ENSAIOS MECÂNICOS ANÁLISE ESTATÍSTICA E

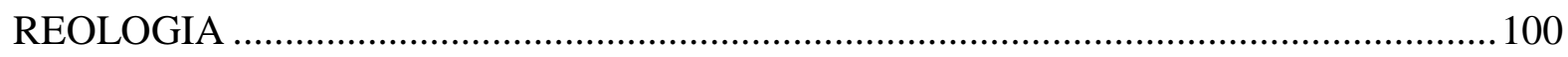

4.6.1. Descrição dos processos de obtenção dos nanocompósitos ........................................ 100

4.6.2. Caracterização dos nanocompósitos a partir das análises térmicas .............................. 101

4.6.3. Caracterização dos nanocompósitos e NCC por calorimetria exploratória diferencial

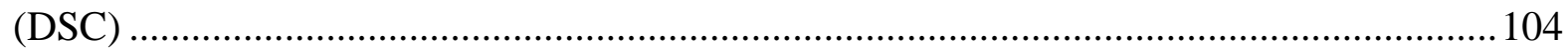

4.6.4. Caracterização dos nanocompósitos por análise dinâmica mecânica (DMA) .............. 106

4.7. MORFOLOGIA E INTERFACE DOS NANOCOMPÓSITOS DE NANOCRISTAIS DE CELULOSE/ABS

4.8. PROPRIEDADES MECÂNICAS DOS NANOCOMPÓSITOS DE NANOCRISTAIS

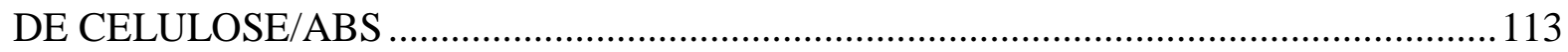

4.8.1. Resistência à tração dos nanocompósitos de nanocristais de celulose/ABS .................113

4.8.2. Resistência à flexão dos nanocompósitos de nanocristais de celulose/ABS ................ 117

4.8.3. Resistência ao impacto dos nanocompósitos de nanocristais de celulose/ABS ...........118

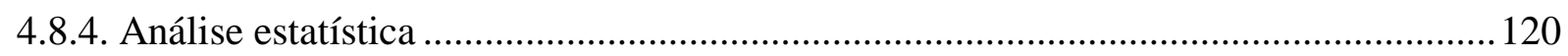

4.8.5. Raios-X dos nanocompósitos de nanocristais de celulose/ABS ................................... 123

4.8.6. Reometria de Placas paralelas dos nanocompósitos de nanocristais de celulose/ABS.124

\section{CAPÍTULO IV}

5. CONCLUSÕES.

6. PERSPECTIVAS FUTURAS E RECOMENDAÇÕES 


\section{LISTA DE TABELAS}

Tabela 2.1. Solubilidade dos componentes dos materiais lignocelulósicos

Tabela 2.2. Condições de hidrólise para a obtenção de nanocristais a partir da celulose de diferentes fontes naturais.

Tabela 2.3. Caracterização dos nanocristais de celulose a partir de diferentes fontes 18

Tabela 2.4. Propriedades físicas da matriz de ABS GP 35.

Tabela 3.1. Sequências de tratamentos para as fibras de bagaço de cana de açúcar e extração dos nanocristais de celulose

Tabela 3.2. Materiais incluídos nas entradas e saídas do estudo de ACV, considerando $1 \mathrm{~kg}$ de nanocristal de celulose

Tabela 4.1. Rendimento das fases de obtenção dos NCC

Tabela 4.2. Composição química do bagaço in natura e depois de cada fase de tratamento...79

Tabela 4.3. Índice de cristalinidade das fases de obtenção dos NCC

Tabela 4.4. Índice de cristalinidade das holocelulose e $\alpha$-celulose: bagaço de cana (BC); bagaço pré-tratados (BPT); polpa branqueada (PB)

Tabela 4.5. Grupos funcionais dos espectros de infravermelho dos materiais lignocelulósicos

Tabela 4.6. Perda de massa a diferentes temperaturas e picos de temperatura de degradação do bagaço in natura e das fibras tratadas

Tabela 4.7. Dados das curvas DSC das fibras não tratadas, tratadas e nanocristais de celulose

Tabela 4.8. Perda de massa nanocompósitos de nanocristais de celulose/ABS dos processos V e IX e ABS puro em atmosfera de $\mathrm{N}_{2}$ 104

Tabela 4.9. Dados das curvas DSC dos nanocompósitos de nanocristais de celulose/ABS dos processos V e IX. 105

Tabela 4.10. Temperatura de transição vítrea (Tg) do ABS e dos nanocompósitos de nanocristais de celulose/ABS dos processos V e IX

Tabela 4.11. Propriedades mecânicas de flexão dos nanocompósitos de nanocristais de celulose/ABS dos processos V e IX 118

Tabela 4.12. Espaçamento basal dos nanocristais e nanocompósitos de nanocristais de celulose/ABS dos processos V e IX 124 


\section{LISTA DE FIGURAS}

Figura 2.1. Composição quimica do bagaço de cana-de-açúcar..............................................5

Figura 2.2. Representação de algumas estruturas de unidades químicas que constituem a

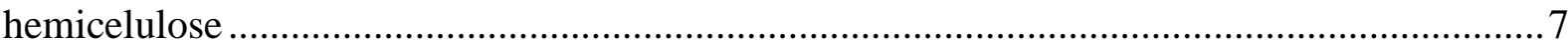

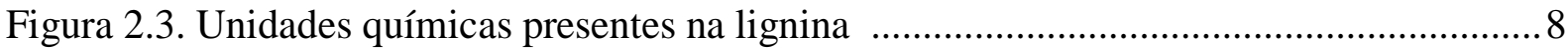

Figura 2.4. Representação da cadeia linear da celulose .........................................................10

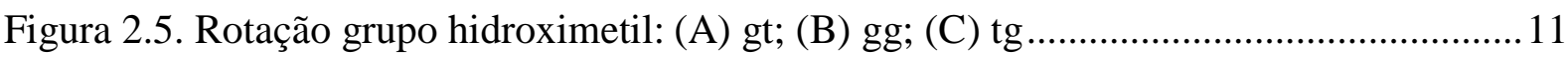

Figura 2.6. Ligação de hidrogênio para o (A) celulose I; (B) celulose II.............................. 12

Figura 2.7. Obtenção de diferentes tipos de celulose ............................................................13

Figura 2.8. Cela unitária monoclínica da celulose I de fibra de rami .....................................14

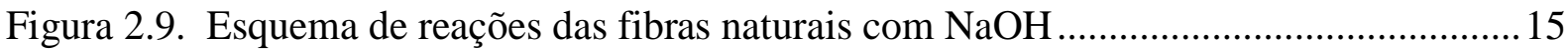

Figura 2.10. Mecanismo de hidrólise da celulose catalisada por ácido sulfúrico ...................16

Figura 2.11. Representação da remoção da hemicelulose e lignina .......................................20

Figura 2.12. Etapas da avaliação do ciclo de vida.................................................................21

Figura 2.13. As categorias de impacto e suas implicações no meio ambiente ........................2 24

Figura 2.14. Características e a fórmula estrutural do Acrilonitrila butadieno estireno...........31

Figura 2.15. Nanocompósitos com diferentes matrizes, segundo a literatura recente..............34

Figura 2.16. Diferença entre a distribuição e a dispersão.........................................................35

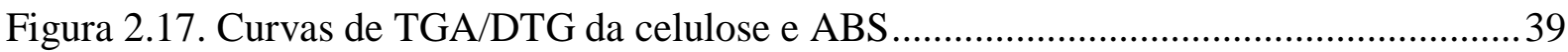

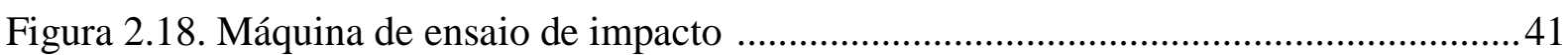

Figura 3.1. Fluxograma esquemático da metodologia empregada neste trabalho ...................43

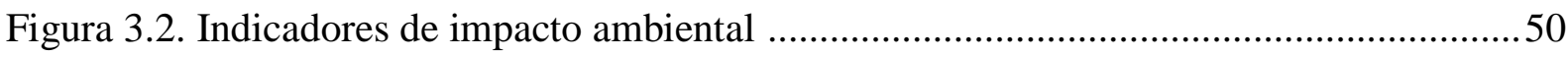

Figura 3.3. Fronteiras do sistema estudado para os diferentes cenários de obtenção de nanocristais do bagaço de cana-de-açúcar............................................................................51

Figura 3.4. Entradas e saídas do processo de obtenção dos nanocristais ................................53

Figura 3.5. Corpo de prova submetido a ensaio de tração. A seta indica o sentido da aplicação

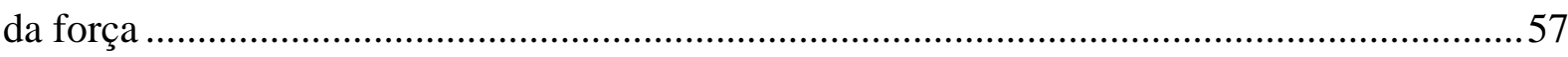

Figura 3.6. Corpo de prova submetido a ensaio de flexão em 3 pontas .................................58

Figura 4.1. Volume total da água consumida em cada rota de obtenção de NCC ..................61

Figura 4.2. Percentual de consumo total de água nas etapas de pré-tratamento e hidrólise .....62

Figura 4.3. Consumo de enrgia elétrica MJ/kg NCC para cada processo ...............................66 
Figura 4.4. Os potenciais de impactos ambientais na fase de produção: potencial de aquecimento global 68

Figura 4.5. Os potenciais de impactos ambientais na fase de produção: potencial de acidificação

Figura 4.6. Os potenciais de impactos ambientais na fase de produção: potencial de eutrofização 71

Figura 4.7. Imagens estereomicroscópio $(20$ x) de bagaço de cana (BC); bagaço pré-tratados (BPT); polpa branqueada (PB); nanocristais de celulose (NCCV); e nanocristais de celulose (NCCIX) dos processos V e IX 75

Figura 4.8. Difratogramas de raios X: bagaço de cana (BC); bagaço pré-tratados (BPT); polpa branqueada $(\mathrm{PB})$; nanocristais de celulose (NCCV); e nanocristais de celulose (NCCIX). ....80 Figura 4.9. Difratogramas de raios X: (bagaço de cana (BC); bagaço pré-tratados (BPT); polpa branqueada $(\mathrm{PB})$.

Figura 4.10. Espectros de FTIR das fibras de bagaço de cana (BC); bagaço pré-tratados (BPT); polpa branqueada (PB); nanocristais de celulose (NCCV); e nanocristais de celulose (NCCIX) dos processos V e IX.

Figura 4.11. Micrografias obtidas em MEV das fibras de $\mathrm{BC}$ in natura

Figura 4.12. Micrografias obtidas em MEV do processo V: (A e B) bagaço pré-tratados; (C e D) polpa branqueada 88

Figura 4.13. Micrografias obtidas em MEV do processo IX: (A e B) bagaço pré-tratados; (C e D) polpa branqueada. 89

Figura 4.14. Micrografias obtidas em MEV das fibras holocelulose e $\alpha$-celulose: bagaço de cana (BC); bagaço pré-tratados (BPT); polpa branqueada (PB) dos processos V e IX 90 Figura 4.15. Microscopia eletrônica de transmissão dos nanocristais de celulose a partir de bagaço de cana-de-açúcar 91

Figura 4.16. Distribuição de tamanho das nanopartículas dos nanocristais de celulose .92 Figura 4.17. Microscopia força atômica dos nanocristais de celulose a partir de bagaço de cana-de-açúcar . 93

Figura 4.18. Comportamento das curvas de degradação térmica das fibras de bagaço de canade-açúcar (BC); Bagaço pré-tratado (BPT); Polpa branqueada (PB); Nanocristais (NCCV); Nanocristais (NCCIX)

Figura 4.19. Espectro característico dos gases liberados durante a pirólise em uma temperatura de $400^{\circ} \mathrm{C}$ das fibras de bagaço de cana-de-açúcar (BC); Bagaço pré-tratado 
(BPT); Polpa branqueada (PB); Nanocristais (NCCV); Nanocristais (NCCIX) dos processos V e IX

Figura 4.20. Comportamento das curvas de degradação térmica: (A) holocelulose; (B) $\alpha$ celulose; (C) lignina; Bagaço pré-tratado (BPT); Polpa branqueada (PB) dos processo V e IX

Figura 4.21. Corpos de prova de tração e flexão (A) NCC 1,5\%/ABS processo V; (B) ABS 101

Figura 4.22. Comportamento das curvas de degradação térmica dos nanocompósitos nanocristais de celulose/ABS: (A) NCC0,5\%/ABS; (B) NCC1,5\%/ABS dos processos V e IX.

Figura 4.23. Curva DSC para os nanocompósitos de nanocristais de celulose/ABS dos processos V e IX. 106

Figura 4.24. Módulo de armazenamento (E') para o ABS e os nanocompósitos de nanocristais de celulose/ABS dos processos V e IX 108

Figura 4.25. Módulo de armazenamento (E") para o ABS e os nanocompósitos de nanocristais de celulose/ABS do processo V e IX

Figura 4.26. Tan $\delta$ do ABS e dos nanocompósitos de nanocristais de celulose/ABS dos processos V e IX.

Figura 4.27. Micrografias obtidas dos nanocompósitos de nanocristais de celulose/ABS: (A) ABS; (B) NCCV0,5\%/ABS;. (C) NCCV1,5\%/ABS; (D) NCCIX1,5\%/ABS dos processos V e IX 112

Figura 4.28. Comportamento das curvas de resistência à tração versus deformação de nanocompósitos de nanocristais de celulose/ABS dos processos V e IX

Figura 4. 29. MóduloYoung versus nancompósitos de nanocristais de celulose/ABS dos processos V e IX. 116

Figura 4.30. Resistência ao impacto dos nancompósitos de nanocristais de celulose/ABS dos processos V e IX. 119

Figura 4.31. Propriedades físicas dos nanocompósitos pelo teste Dunnet 121

Figura 4.32. Média da resistência a a tração, flexão e impacto por grupo; Teor de NCC em relação a concentração 122

Figura 4.33. Média do módulo elástico tração (A) e flexão (B) 123

Figura 4.34. Viscosidade complexa versus frequência angular do ABS puro e dos nancompósitos de nanocristais de celulose/ABS dos processos V e IX. 127 
Figura 4.35. Módulo de armazenamento $\left(\mathrm{G}^{\prime}\right)$ versus frequência angular do ABS puro e dos nanocompósitos de nanocristais de celulose/ABS dos processos V e IX............................. 128 


\section{LISTA DE ABREVIAÇÕES}

ABS: Acrilonitrila butadieno estireno

ACV: Avaliação de ciclo de vida

AICV: Avaliação de impacto de ciclo de vida

BPTV/ BPTIX: Bagaço pré-tratados do processo V ou processo IX

$\mathrm{C}_{14} \mathrm{H}_{8} \mathrm{O}_{2}$ : Antraquinona

$\mathrm{C}_{2} \mathrm{H}_{4} \mathrm{O}_{2}$ : Ácido acético

$\mathrm{CO}_{2}$ : Dióxido de carbono

D: Diâmetro

DBO: Demanda bioquímica de oxigênio

DMA: Análise dinâmico-mecânica

DQO: Demanda química de oxigênio

DRX: Difração de raios-X

DSC: Calorimetria exploratória diferencial

DTG: Derivada termogravimétrica

E": Módulo de perda

E': Módulo de armazenamento

E: Módulo de elasticidade

FTIR: Espectroscopia no infravermelho com transformada de Fourier

G": Módulo de perda

G': Módulo de armazenamento

$\mathrm{H}_{2} \mathrm{O}_{2}$ : Peróxido de hidrogênio

$\mathrm{H}_{2} \mathrm{SO}_{4}$ : Ácido sulfúrico

$\mathrm{HNO}_{3}$ : Ácido nítrico

ICr: Índice de cristalinidade

ICV: Inventário do ciclo de vida

L/D: Razão de aspecto

L: Comprimento

MET: Microscopia eletrônica de transmissão

MEV: Microscopia eletrônica de varredura 
MFA: Microscopia de força atômica

MPa: Mega Pascal

$\mathrm{NaClO}_{2}$ : Clorito de sódio

$\mathrm{NaOH}$ : Hidróxido sódio

NCC: Nanocristais de celulose

NCCV/ NCCIX: Nanocristais de celulose do processo V ou processo IX

PBV/PBIX: Polpa branqueada do processo $\mathrm{V}$ ou processo IX

$\mathrm{PO}_{4}$ : Fosfato

$\mathrm{SO}_{2}$ : Dióxido de enxofre

Tan $\delta:$ Tan delta

$\mathrm{T}_{\mathrm{g}}$ : Temperatura de transição vítrea

TGA: Análise termogravimétrica

$\mathrm{T}_{\text {onset: }}$ Temperatura onset

$\mathrm{T}_{\text {pico: }}$ Temperatura do pico

$\Delta \mathrm{H}:$ Entalpia

$\varepsilon$ : Elongação até a ruptura

$\eta$ : Viscosidade

$\sigma:$ Resistência à tração

$\omega$ : Frequência 


\section{CAPÍTULO I \\ 1. INTRODUÇÃO}

A produção de nanocompósitos reforçados com fibras naturais tem crescido continuamente nos últimos anos, em substituição de outros reforços, como por exemplo, fibra de vidro. Em busca de uma nova alternativa, visando materiais que ofereçam vantagens ao meio ambiente, é crescente a pesquisa na utilização de nanocristais de celulose como reforço de polímeros, devido principalmente à sua alta rigidez, transparência, baixo custo, reciclabilidade e baixa densidade. Os nanocompósitos podem ser definidos como compósitos constituídos por reforços que possuem pelo menos uma de suas dimensões na escala nanométrica. Esses novos materiais garantem qualidade e satisfação em diversas áreas como no emprego em filmes, peças, medicina, embalagens, revestimentos entre outras inúmeras aplicações. A cada ano, novos materiais vêm sendo elaborados e aprimorados, assegurando sua utilização para diversos fins e promovendo o desenvolvimento sustentável no mundo.

Este trabalho envolverá duas principais fases, a primeira relacionada à obtenção do nanocristal e a segunda, relacionada a obtenção e avaliação de nanocompósitos de ABS reforçados com os nanocristais de celulose. A literatura propõe inúmeros tratamentos físicos e químicos para a obtenção de nanocristais de celulose que seguem as sequências pré-tratamento, branqueamento e hidrólise. Esses tratamentos têm por objetivo remover os resíduos, óleos, extrativos ou outros elementos presentes nas fibras, como lignina e hemicelulose, podendo contribuir para uma celulose purificada e facilitar a obtenção dos nanocristais de celulose. Entretanto, um dos principais desafios relacionados à obtenção dos nanocristais de celulose pode ser o elevado impacto ambiental devido ao alto consumo de água e energia no processo. No entanto, a fim de obter nanocristais de celulose comercialmente competitivos e de baixo custo são necessários processos energeticamente eficientes e com menor impacto ambiental.

Neste trabalho, vários métodos de obtenção de nanocristais foram propostos e o impacto ambiental dos processos foi medido pela avaliação de ciclo de vida, utilizando o software GaBi. Esta é uma importante ferramenta que quantifica as emissões e impactos locais, regionais e globais. Essa análise de portão ao portão poderá proporcionar a escolha dos métodos que menos agridem o meio ambiente. O objetivo desse estudo é avaliar os impactos ambientais decorrentes 
de diversos processos de obtenção de nanocristais de celulose a partir de bagaço-de-cana. A função do sistema foi à obtenção de insumo renovável para aplicação em nanocompósitos.

Assim, os resultados de uma ACV visam quantificar os impactos ambientais potenciais de um sistema de produto ao longo do ciclo de vida, ajudando a identificar oportunidades de melhoria e indicar opções mais sustentáveis a partir de comparações e análise do processo. Além da avaliação ambiental, os nanocristais foram caracterizados por meio das técnicas de microscopia eletrônica de varredura (MEV), microscopia eletrônica de transmissão (MET), microscopia de força atômica (MFA), espectroscopia de infravermelho, difração de raios-x e análises térmicas. Estas técnicas poderão fornecer informações sobre a morfologia, dimensões, estabilidade térmica e cristalinidade em cada fase dos tratamentos. Deste modo, além do impacto ambiental, poder-se-á estudar a viabilidade técnica dos nanocristais para aplicação em nanocompósitos.

Vale ressaltar, a dificuldade na preparação de nanocompósitos com nanocristais de celulose, devido à sua tendência à aglomeração e formação de ligações de hidrogênio. Dessa forma, a maior parte dos trabalhos relatados na literatura se refere a polímeros hidrofílicos, onde essa tendência é minimizada. A literatura mostra a preparação dos nanocompósitos utilizando diferentes solventes e agentes interfaciais, contribuindo assim, com o aumento do impacto ambiental. O presente trabalho reflete um esforço na busca pela utilização dos nanocristais de celulose como agente de reforço para uma matriz de ABS, visando explorar plenamente o potencial dessas estruturas obtidas a partir de resíduos agrícolas. Assim, a fim de minimizar o impacto ambiental, o reforço e a matriz serão colocados diretamente na extrusora sem qualquer agente de acoplamento interfacial.

Esta tese está estruturada em 4 capítulos - Capítulo I: Introdução; objetivo; hipótese e revisão da literatura: envolvendo a descrição e conceitos relacionados ao bagaço de cana-deácucar e a composição das fibras lignocelulósicas; tratamento de biomassa vegetal para separação dos materiais lignocelulósicos (tratamento alcalino e hidrólise ácida); nanocristais de celulose e sua aplicação; avaliação do ciclo de vida aplicada ao desenvolvimento de materiais mais sustentáveis (a ferramenta da ACV; definição objetivo e escopo; inventário do ciclo de vida; avaliação do ciclo de vida; interpretação); preparação dos nanocompósitos; matriz de acrilonitrila butadieno estireno; nanocompósitos; caracterização dos nanocristais e 
nanocompósitos (FTIR; Difração de raios-X; MEV; MET; MFA) dos materiais; caracterização térmica (TGA/DTG/DSC/DMA); propriedades mecânicas e reologia.

Capítulo II: Parte experimetal: envolvendo a metodologia empregada para a caracterização das fibras de bagaço de cana-de-açúcar (determinação de umidade; teor de extrativos); caracterização química das fibras de bagaço de cana-de-açúcar (hemicelulose, lignina e hemicelulose); obtenção e caracterização das fibras e dos nanocristais de celulose a partir das fibras de bagaço de cana-de-açúcar (pré-tratamentos das fibras de bagaço de cana-deaçúcar seguido de hidrólise); avaliação do ciclo de vida (ACV) da extração de nanocristais de celulose a partir de bagaço de cana-de-açúcar (objetivo e escopo; aquisição e qualidade dos dados; descrição do sistema e dados de inventário); caracterização das fibras e nanocristais de celulose (FTIR; Difração de raios-X; MEV; MET; MFA; TGA/DSC); obtenção dos nanocompósitos (processamento em extrusora de dupla rosca); caracterização térmica, mecânica, morfológica e reologica dos nanocompósitos (TGA/DSC/DMA; tração; flexão e impacto; MEV e reometria de placas paralelas).

Capítulo III: Resultados e discussão: Mostra os resultados e a discussão relacionada a avaliação do impacto ambiental dos processos de obtenção dos nanocristais de celulose: impactos ambientais da fase agrícola do sistema e produção dos nanocristais; caracterização das fibras de bagaço de cana-de-açúcar in natura; caracterização morfológica das fibras e dos nanocristais de celulose por (Difração de raios-X; FTIR; MEV; MET; MFA); caracterização térmica das fibras; nanocristais de celulose; holocelulose e $\alpha$-celulose; obtenção dos nanocompósitos e caracterização por (análises térmicas, morfológicas, ensaios mecânicos e reologia).

Capítulo IV: Conclusões e recomendações: apresenta as conclusões do trabalho e sugestão para trabalhos futuros. 


\subsection{OBJETIVO}

\subsubsection{Objetivo geral}

O objetivo principal deste trabalho é investigar a melhor combinação entre aspecto técnico e ambiental para a produção nanocristais de celulose tecnicamente viável e com menor impacto ambiental que possam ser utilizados em nanocompósitos.

\subsubsection{Objetivos específicos}

- A partir da análise do consumo de água, energia e impactos ambientais dos processos de obtenção dos nanocristais de celulose.

- Analisar os processos de obtenção de nanocristais de celulose e seus efeitos sobre as propriedades dos nanocristais de celulose.

- Avaliar as propriedades dos nanocompósitos obtidos a partir dos nanocristais de celulose.

\subsubsection{Hipótese geral}

A hipótese geral deste trabalho consiste em uma técnica viável para produção de NCC (nanocristais de celulose) com baixo impacto ambiental. 


\section{REVISÃO DA LITERATURA}

\subsection{O BAGAÇO DE CANA-DE-AÇÚCAR E A COMPOSIÇÃO DAS FIBRAS LIGNOCELULÓSICAS}

O Brasil é um dos maiores produtores de cana, tornando assim o bagaço um resíduo agroindustrial muito abundante. O bagaço de cana é um resíduo produzido em grandes quantidades todos os anos pelas indústrias de açúcar e álcool, e é usado principalmente como combustível para alimentar a usina sucroalcooleira. Este resíduo pode ser utilizado em várias aplicações mais nobres, podendo citar como exemplo a utilização das fibras desses materiais lignocelulósicos como reforço em compósitos ou nanocompósitos poliméricos (MANDAL; CHAKRABARTY, 2011).

Vários processos e produtos têm sido relatados na utilização do bagaço como matériaprima para aplicações industriais (LEÃO et al., 2016c). Na literatura, vários estudos com diferentes técnicas têm sido utilizadas para obtenção de nanocristais de celulose (MANDAL; CHAKRABARTY, 2011; MULINARI et al., 2009; CAMPOS et al., 2013; TEIXEIRA et al., 2011; LI et al., 2012; GILFILLAN et al., 2014). O bagaço da cana-de-açúcar é constituído por celulose, hemicelulose, lignina, gorduras e ceras, sílica e outros elementos como pode ser observado na Figura 2.1 (MULINARI et al., 2009; LUZ et al., 2010).

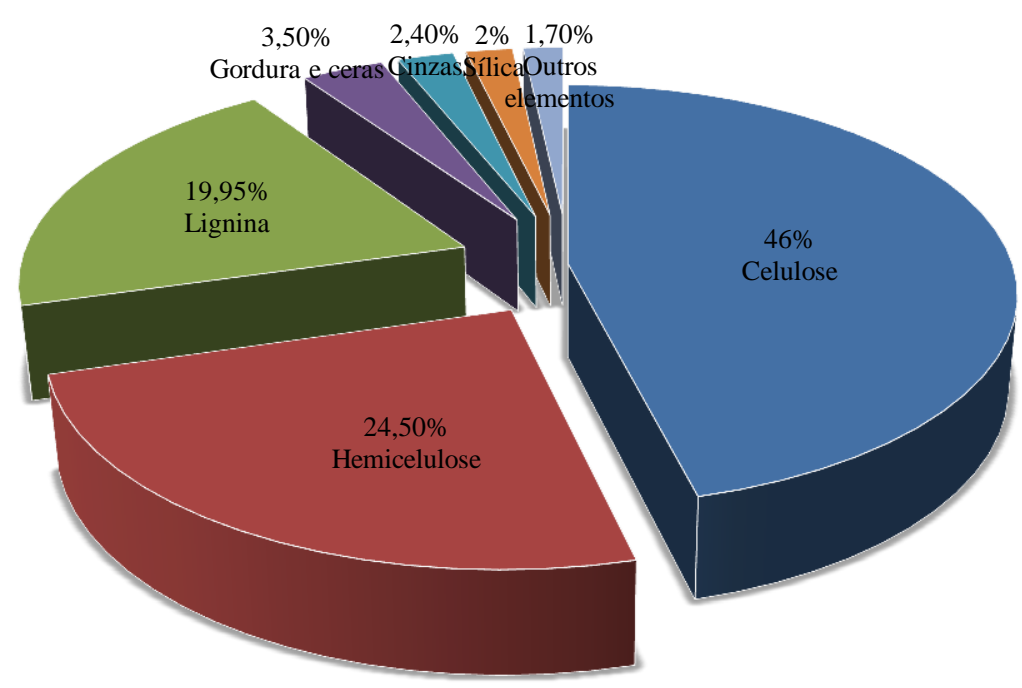

Figura 2.1: Composição química do bagaço de cana-de-açúcar (MULINARI et al., 2009). 
As fibras naturais podem ser chamadas também de fibras lignocelulósicas, são ricas em lignina, hemicelulose e celulose, podendo ser usadas em diversas aplicações, dependendo da sua composição e propriedades físicas. Estes componentes têm sido alvo de vários estudos, e apontam como a grande aposta para a solução do problema energético mundial, como também em seu aproveitamento para obtenção de novos materiais (VERARDI et al., 2005; BRÍGIDA et al., 2010).

Os materiais lignocelulósicos também são constituídos por pequenas porcentagens de extrativos, proteínas, amido, materiais inorgânicos, pectinas, carboidratos simples, terpenos, alcalóides, saponinas, polifenólicos, gomas, resinas, gorduras e graxas, entre outros que podem ser extraídas com solventes orgânicos ou até mesmo com água, dependendo de sua polaridade e solubilidade (KUMAR et al., 2011; VERARDI et al., 2005; LIU et al., 2010).

Existem várias tecnologias para a utilização das fibras naturais, através da conversão biológica, mecânica e/ou química. Em particular, os processos químicos e térmicos são amplamente considerados como métodos promissores para a utilização das fibras naturais (SABA et al., 2014). Os materiais lignocelulósicos in natura, devido às suas propriedades, não admitem fácil acessibilidade aos seus componentes. Vários fatores comprometem a hidrólise dos resíduos lignocelulósicos, por exemplo, a porosidade do material, a cristalinidade da celulose e os elevados teores de lignina e hemicelulose (MAURYA et al., 2015).

O termo hemicelulose é usado para os polissacarídeos que ocorrem normalmente integrados à celulose, dentro das paredes celulares. A hemicelulose é constituída por diversos monossacarídeos polimerizados, como pentoses (xilose e arabinose), hexoses (galactose, glucose e manose) e ácidos urônicos (ácidos 4-O- e resíduos de ácido galactorônico). Além disso, a hemicelulose é amorfa e possui baixa massa molecular. (PALMQVIST; HAHN-HAGERDAL, 2000). A fórmula metil glucurônico mínima das pentoses e hexoses são respectivamente, $\mathrm{C}_{5} \mathrm{H}_{8} \mathrm{O}_{4}$ e $\mathrm{C}_{6} \mathrm{H}_{10} \mathrm{O}_{5}$ (XU et al., 2013). Algumas destas estruturas estão representadas na Figura 2.2. 

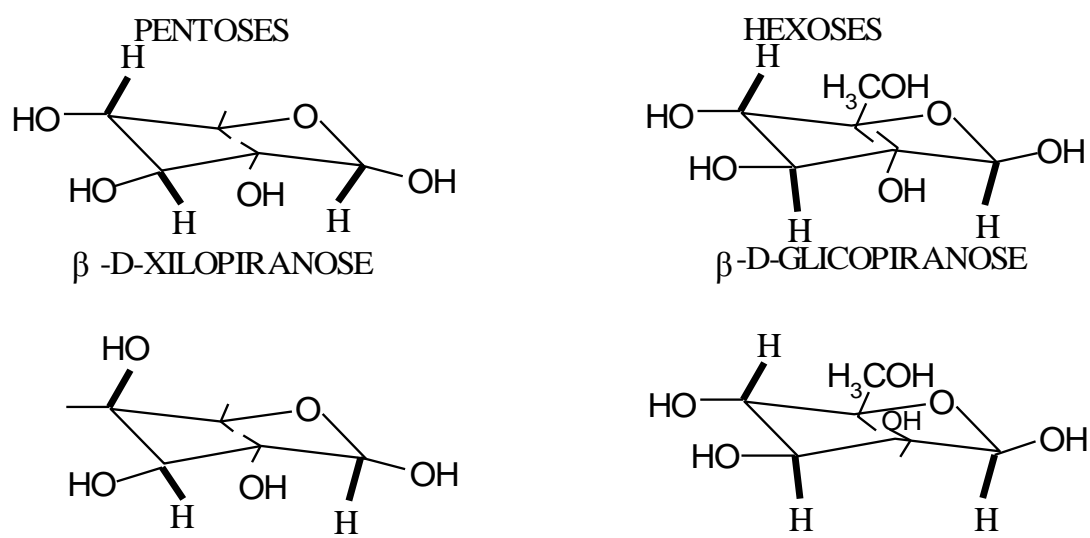

$\alpha$-L-ARABINOPIRANOSE

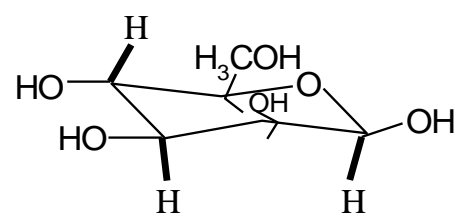

$\beta$-D-MANOPIRANOSE

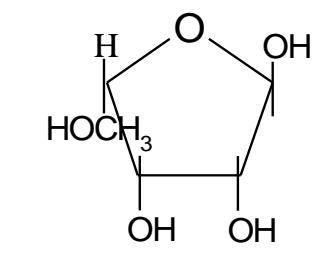

$\alpha$-L-ARABINOFURANOSE

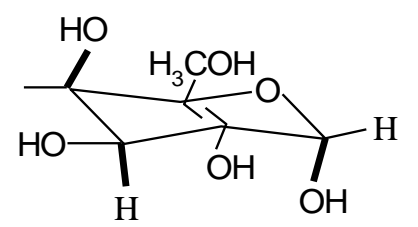

$\alpha$-D-GALACTOPIRANOSE

Figura 2.2. Representação de algumas estruturas de unidades químicas que constituem a hemicelulose (PALMQVIST; HAHN-HAGERDAL, 2000).

Suas estruturas proporcionam cadeias laterais que interagem espontaneamente com a celulose, dando estabilidade e flexibilidade à fibra. A hemicelulose é hidrofílica devido à estrutura contendo hidroxila e o grupo acetil, portanto, é solúvel em solução álcali e é facilmente hidrolisada em ácidos (KUMAR et al., 2011; ROSLI et al., 2013).

A lignina é um polímero complexo de estrutura amorfa, com elementos aromáticos e alifáticos, que se integram a celulose e hemicelulose durante a constituição da parede celular dos vegetais e tem como objetivo atribuir rigidez à estrutura da planta, que influencia diretamente nas propriedades mecânicas, morfologia, flexibilidade e na taxa de hidrólise da fibra natural (ROSLI et al., 2013).

A lignina está presente nos materiais lignocelulósicos, atuando como material adesivo, como agente de enriquecimento e ainda como barreira dificultando a degradação enzimática e/ou microbiana da parede celular. A lignina possui uma alta porção de não carboidrato encontrada na parede celular das plantas. Quimicamente, ela se difere da celulose e da hemicelulose, é mais complexa, pois possui ligações cruzadas, tem estrutura macromolecular tridimensional e é composta a partir de unidades fenólicas (MADSEN, 2004). 
A lignina e a hemicelulose juntas formam uma matriz em volta da celulose, e assim penetram nos sítios desocupados entre as moléculas de celulose na região amorfa, colaborando com o aumento na rigidez do vegetal. A eficácia de adesão entre as fibras de celulose e a lignina é aumentada pela existência de ligações covalentes entre as cadeias de lignina e as propriedades da celulose e da hemicelulose (SILVA et al., 2009; SIRÓ; PLACKETT, 2010).

Segundo Santos et al. (2011), este biopolímero é constituído por três unidades distintas da família do éter fenil. O isolamento e a sua plastificação são dificultados devido à sua complexidade química. Unidades monoméricas usualmente encontradas em ligninas estão representadas na Figura 2.3.
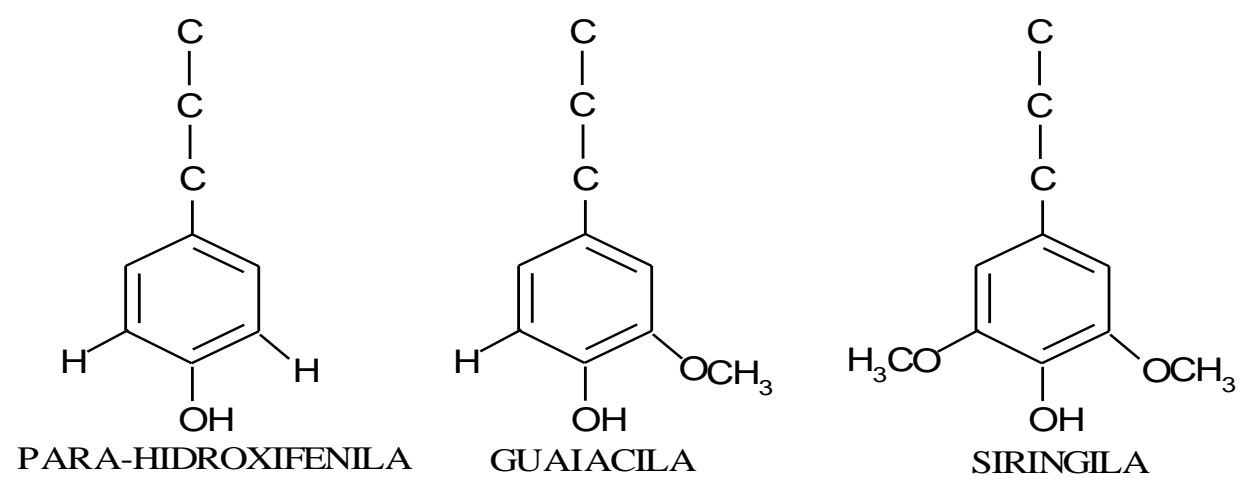

Figura 2.3. Unidades químicas presentes na lignina (SANTOS et al., 2011).

Os extrativos são compostos químicos de baixa massa molar encontrados na parede celular dos vegetais, geralmente constituídos a partir de graxas, ácidos graxos, álcoois graxos, fenóis, esteróides, resinas, ceras, óleos, fitoesteróis, resinas ácidas, taninos, terpenos e flavonóides, e outros tipos de compostos orgânicos. Estas substâncias se dividem na forma de monômeros, dímeros e polímeros. Embora possua baixo teor de extrativos quando comparados com os demais componentes, sua presença pode implicar na seleção da madeira para determinados fins. Os extrativos de cor ou voláteis dão valor estético ao material e os compostos aromáticos impedem o ataque da madeira por fungos e insetos (LI et al., 2012; SILVÉRIO et al., 2006; MAURYA et al., 2015). Algumas reações químicas e solubilidade da hemicelulose, lignina e extrativos podem ser observadas na Tabela 2.1. 
Tabela 2.1. Solubilidade dos componentes dos materiais lignocelulósicos (KLOCK, 2005).

\begin{tabular}{l|l}
\hline Componentes & Características \\
\hline Celulose & $\begin{array}{l}\text { Insolúvel em água, mas é solúvel em ácido forte. A celulose cristalina não } \\
\text { é solúvel em ácido fraco, somente a celulose amorfa. }\end{array}$ \\
Hemicelulose & $\begin{array}{l}\text { Solúvel em ácido fraco e insolúvel em água. } \\
\text { Lignina }\end{array}$ \\
Ex parcialmente solúvel em ácido fraco e solúvel em base forte. \\
\hline
\end{tabular}

E por último, destaca-se a celulose e sua presença nos materiais lignocelulósicos. A estrutura das plantas é formada por paredes celulares primárias e secundárias. As paredes primárias e secundárias diferem no arranjo das cadeias de celulose. Na parede primária as fibras são constituídas de cadeias em todas as direções dentro do plano. A parede secundária é constituída por três camadas, S1, S2, S3 e lúmen. As células são separadas por meio de lamelas. Na camada S1 as lamelas são finas, assim, o arranjo das fibrilas é helicoidal (espiral). Na camada S2 as cadeias de celulose são agrupadas em microfibrilas paralelas, formando um arranjo mais denso e alinhadas com o eixo da fibra. A camada S3 possui pequenas quantidades de celulose, sendo constituída principalmente de xilana. As fibras lignocelulósicas possuem aproximadamente 40 - 45\% de celulose localizada predominantemente na parede secundária. A celulose distingue-se dos extrativos pela sua insolubilidade em água e solventes orgânicos, a hemicelulose em solução alcalina e a lignina pela sua resistência a agentes oxidantes e suscetibilidade a hidrólise por ácidos (FENGEL; WEGENER, 2003; KONTTURI et al., 2005).

A celulose é composta por longas cadeias lineares com um grande número de grupos de hidroxila, numa conformação termodinamicamente preferencial, com elevado grau de polimerização, e está presente em todas as fibras naturais. A celulose é um polímero natural, constituído por unidades de D-glicose, sendo formada por unidade repetitiva, as quais estão covalentemente ligadas através de funções acetais entre o grupo $\mathrm{OH}$ equatorial do átomo de carbono 4 (C4) e o átomo de carbono 1 (C1), ou seja, é composta por duas moléculas de glicose eterificadas por ligações $\beta$-1,4-glicosídicas, que é, em princípio, a maneira na qual a celulose é biogeneticamente formada (KUMAR et al., 2011; YANG et al., 2015; SILVA et al., 2009; ROSLI et al., 2013; PANTHAPULAKKAL; SAIN, 2012; JIANG; HSIEH, 2013; HUG et al., 2012; ENDES et al., 2013). A celulose possui cadeia reta formada por ligações $\beta$ para construção de fibras com alta força de tensão. A configuração $\beta$ permite que a celulose forme cadeias retas e 
longas (STRYER, 2010). A fórmula molecular empírica da celulose é $\left(\mathrm{C}_{6} \mathrm{H}_{11} \mathrm{O}_{5}\right)_{\mathrm{n}}$, que por hidrólise dá origem a unidades estruturais de glicose (SUMMERSCALES et al., 2010; OKAMURA et al., 1991; HOSOYA; SAKAKI, 2014; MOON et al., 2011). A representação da cadeia linear da celulose, formada por unidades consecutivas de celobiose pode ser vista na Figura 2.4.

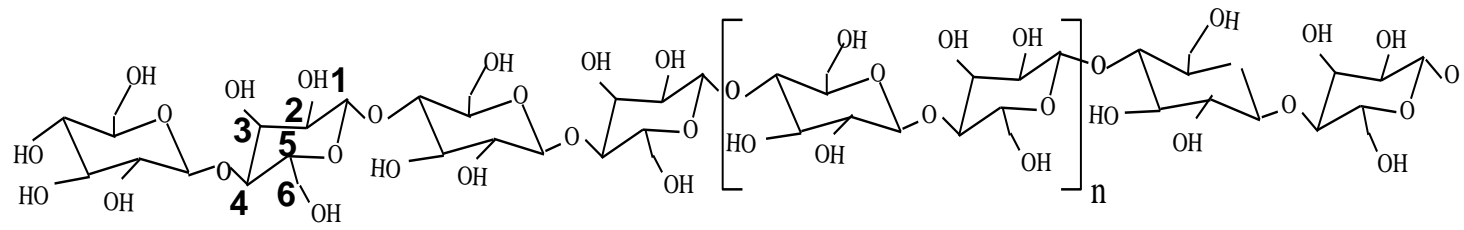

Figura 2.4. Representação da cadeia linear da celulose (SUMMERSCALES et al., 2010).

Esta unidade repetitiva, conhecida como celobiose, contém seis grupos hidroxila que estabelecem interações do tipo ligações de hidrogênio intra e intermoleculares (KUMAR et al., 2009). As ligações intramoleculares ocorrem entre grupos de hidroxila de uma mesma cadeia e auxiliam na manutenção da rigidez da cadeia de celulose, enquanto que as intermoleculares ocorrem entre grupos de hidroxila de uma cadeia adjacente e conservam as cadeias rígidas e compactas (OH YOUN et al., 2005; MOON et al., 2011; FENGEL; WEGENER, 2003). Dessa forma, cada glicose relaciona-se com a seguinte por uma rotação de $180^{\circ}$, e o átomo de oxigênio do anel de cada uma estabelece uma ligação de hidrogênio com o carbono 3-OH da seguinte e as fibrilas são formadas por cadeias paralelas (STRYER, 2010). Portanto, os grupos das hidroxilas $(\mathrm{OH})$ são responsáveis pelo comportamento físico e químico da celulose, constituindo dois tipos de ligações de hidrogênio, em função do seu posicionamento na unidade glicosídica (OH YOUN et al., 2005; FENGEL; WEGENER, 2003).

Um parâmetro chave para a estrutura da celulose é o comportamento de rotação do grupo hidroximetil. Este possui três conformações rotaméricas de baixa energia para o substituinte do anel piranose, definidos por três letras (tg: trans-gauche; gg: gauche-gauche e gt: gauche-trans), referentes aos estados trans-gauche os ângulos diedros O5-C5; C6-O6 e C4-C5; C6-O6, respectivamente. A unidade monomérica da celulose, a glicose, tem em solução aquosa uma preferência para conformação gg do grupo hidroximetil, seguido por gt, enquanto que tg se apresenta em menor quantidade (BERGENSTRÅHLE et al., 2010). Segundo O'Sullivan (1997), 
a celulose I possui uma conformação tg e a celulose II possui uma conformação gt ao longo das cadeias.

O padrão das ligações de hidrogênio é diferente para os diferentes tipos de celulose e as propriedades mecânicas, também são diferentes (AKERHOLM et al., 2004; NISHIYAMA et al., 2003; KONTTURI et al., 2005). Deste modo, existem dois padrões diferentes de ligação de hidrogênio, padrão A e B, que são caracterizados por duas ligações de hidrogênio intramoleculares. Essas ligações de hidrogênio só podem estar presentes (em conformação de ligação glicosídica normalmente encontrada em cristais de celulose) se o grupo hidroximetil está na conformação tg. A razão para a diferença de estabilidade entre estes três é a relativa proximidade do oxigênio e do substituinte carbono (BERGENSTRÅHLE et al., 2010; O'SULLIVAN, 1997). A Figura 2.5 mostra uma representação das três posições de rotação mais prováveis do grupo hidroximetil:

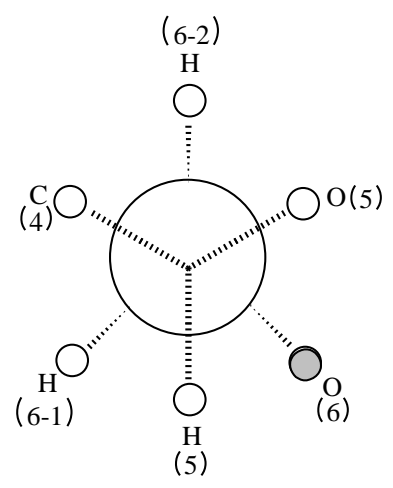

(a)

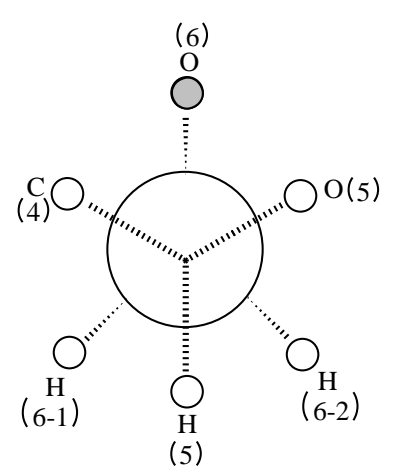

(b)

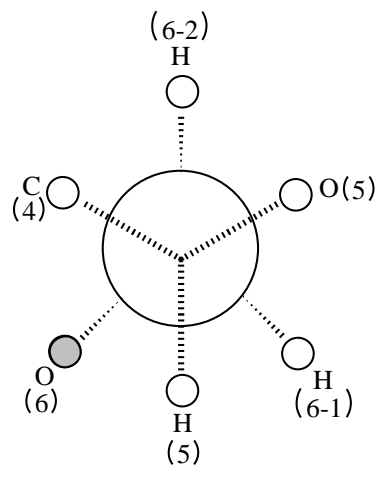

(c)

Figura 2.5: Rotação do grupo hidroximetil: (a) gt; (b) gg; (c) tg (adaptado O'SULLIVAN, 1997).

O estudo das orientações hidroximetil, ligações de hidrogênio intra e intercadeia, foram sugeridos para celulose I e II. A celulose I tem duas ligações de hidrogênio intramoleculares em $(\mathrm{O}) 5-(\mathrm{O} 3-\mathrm{H})$ e $(\mathrm{O} 2-\mathrm{H})-(\mathrm{O}) 6$ e uma intercadeia entre as ligações de hidrogênio em $(\mathrm{O}) 6-(\mathrm{O}) 3$, como mostrado na Figura 2.6. A celulose II é relatada como tendo intercadeia de ligação de hidrogênio no $(\mathrm{O} 3-\mathrm{H})-(\mathrm{O}) 5$, e uma ligação de hidrogênio intermolecular em $(\mathrm{O} 6-\mathrm{H})-(\mathrm{O}) 2$ para as cadeias do centro $(\mathrm{O} 6-\mathrm{H})-(\mathrm{O}) 3$. Ou seja, a diferença entre a celulose I e II está em relação às 
ligações de hidrogênio entre as cadeias (O'SULLIVAN, 1997; KONTTURI et al., 2005; FENGEL; WEGENER, 2003).

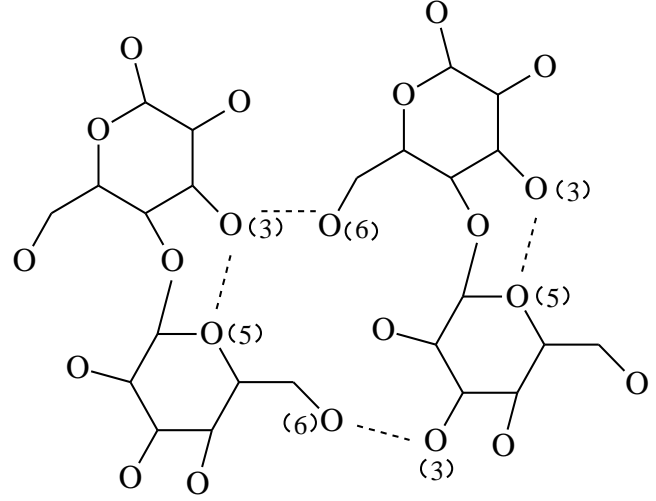

(a)

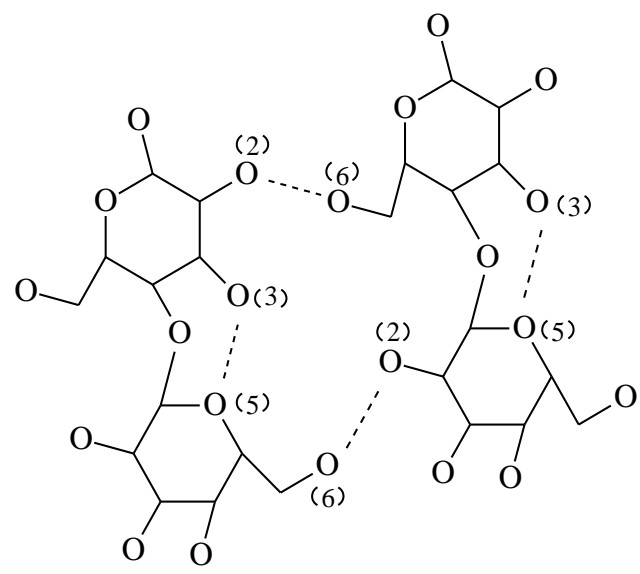

(b)

Figura 2.6: Ligação de hidrogênio para o (A) celulose I; (B) celulose II (O'SULLIVAN, 1997).

A diferença entre as ligações de hidrogênio formadas é uma das principais influências no grau de polimerização que gerará celulose do tipo I, II, III, IV, com diferentes estruturas cristalinas e microcristalinas, conforme a Figura 2.7. A celulose forma uma estrutura microcristalina com regiões de alta ordem (regiões cristalinas), e regiões de baixa ordem (regiões amorfas). A celulose tipo I é de ocorrência natural (KADLA; GILBERT, 2000; ZUGENMAIER, et al., 2001; LAVOINE et al., 2012; BLEDSKI; GASSAN, 1999).

Segundo OH YOUN et al. (2005) a transformação da celulose I em celulose II esta dentro dos domínios cristalinos. A celulose II pode ser obtida a partir do tratamento da celulose I com hidróxido de sódio aquoso (mercerização), como é feito para a formação de filmes de fibras ou através de tratamento ácido. Celulose II é o polimorfo majoritário na indústria de processamento de celulose, sendo formada a partir de regeneração ou mercerização (WYMAN et al., 2005; NISHIYAMA et al., 2003; OUDIANI et al., 2011; MOON et al., 2011; OGEDA; PETRI, 2010). Segundo O' Sullivan (1997), a celulose III é obtida por meio de tratamento da celulose com hidróxido de amônia líquida a $-80^{\circ} \mathrm{C}$ e da subsequente evaporação de amônia. Os espectros de 
infravermelho da celulose III preparada a partir de celulose I e II são diferentes, assim como difrações de raios-X. Portanto, a celulose III obtida a partir de celuloses I e II, é indicada pelas celuloses III $_{\text {I }}$ IIII II, respectivamente. Celulose IV é obtida a partir da celulose III aquecendo em glicerol a $260^{\circ} \mathrm{C}$. Existem duas formas de obter a celulose IV, dependendo do material de partida III I $_{\text {I }}$ ou IIII resultando em (IV I $_{\text {e }}$ IV $_{\text {III }}$ (OKAMURA et al., 1991; MOON et al., 2011). A celulose I e II tem célula unitária monoclínica com dimensões específicas: a) 7,9 $\AA$; b) $8,35 \AA$; c) 10,3 e y) $96^{\circ}$; a) 7,93 $\AA$; b) $9,18 \AA$; c) 10,3 $\AA$; e y) $62^{\circ}$, respectivamente (BLEDSKI; GASSAN, 1999; MOON et al., 2011).

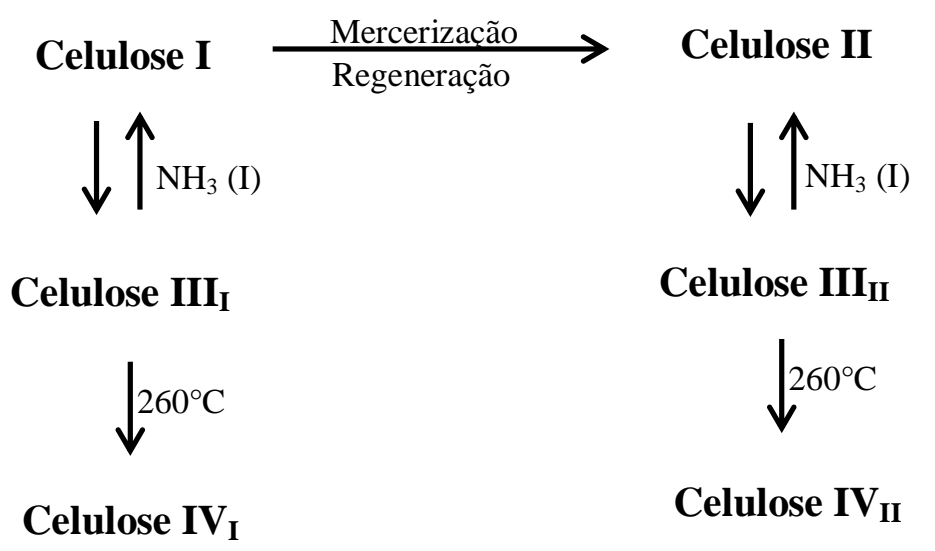

Figura 2.7: Obtenção de diferentes tipos de celulose (OH YOUN et al., 2005).

Tradicionalmente, um material cristalino é aquele no qual os átomos estão situados em um arranjo que se repete ou que é periódico ao longo de grandes distâncias atômicas, ou seja, os átomos se posicionam em um padrão tridimensional repetitivo, no qual cada átomo está ligado aos seus átomos vizinhos mais próximos. A disposição atômica em sólidos cristalinos indica que pequenos grupos de átomos formam um padrão repetitivo. Assim, as estruturas cristalinas, são convenientemente subdivididas em pequenas entidades que se repetem, conhecidas como células unitárias. A célula unitária é utilizada para representar a simetria da estrutura cristalina, onde todas as posições dos átomos no cristal podem ser geradas mediante translações proporcionais às distâncias inteiras da célula unitária ao longo de cada uma das suas arestas. Desta forma, a célula unitária apresenta uma unidade estrutural básica ou um bloco de construção básica da estrutura 
cristalina e determina a estrutura cristalina em virtude da sua geometria e das posições dos íons ou moleculas em forma de esferas rígidas (CALLISTER, 2012).

A célula unitária possui dimensões bem definidas conforme a Figura 2.8. No caso da celulose existem mais de uma forma alomórfica, isto é, não há uma dimensão única para a célula unitária (LIMA; BORSALI, 2004). A celulose I, celulose nativa, é à base da estrutura cristalina da cela unitária encontrada nas fibras celulósicas (CHERIAN et al., 2011). Devido às ligações de hidrogênio, a celulose adquire uma forte tendência em formar cristais. $\mathrm{O}$ grau de cristalinidade da celulose altera de acordo com sua origem e processamento. A celulose de algodão possui cadeias mais ordenadas, apresentando cristalinidade de aproximadamente 70\%; a palha de arroz 68\%; a madeira 71\%; e o bagaço da cana de açúcar 52\% (MAMLEEV et al., 2007; LI et al., 2012; FENGEL; WEGENER, 2003).

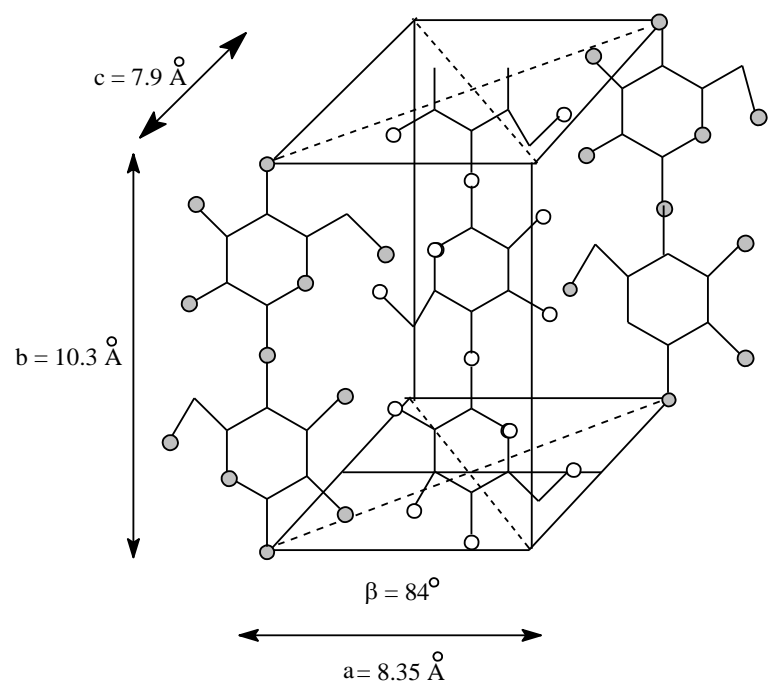

Figura 2.8: Cela unitária monoclínica da celulose I da fibra de rami (adptado BLEDSKI; GASSAN, 1999).

\subsection{Tratamento de biomassa vegetal para separação dos materiais lignocelulósicos}

\subsubsection{Tratamento alcalino}

No tratamento alcalino, as substâncias lignocelulósicas se rompem, ou seja, dissolve hemicelulose e lignina por hidrólise de ésteres, ocorrendo inchaço da celulose (ARSÈNEA et al., 
2013). O hidróxido de sódio tem um papel muito importante nos tratamentos químicos, como por exemplo, ativa as hidroxilas da celulose, transformando-as em alcóxidos e ainda aumenta a acessibilidade do reagente ao interior das fibras (LEÃO et al., 2016b). A parede secundária é a mais espessa e a mais importante destes componentes. A parede secundária é, na verdade, a seção da fibra que predomina depois da polpação química do material lignocelulósico. $\mathrm{O}$ esquema de reações das fibras naturais com hidróxido de sódio é mostrado na Fiqura 2.9 (KONTTURI et al., 2005).

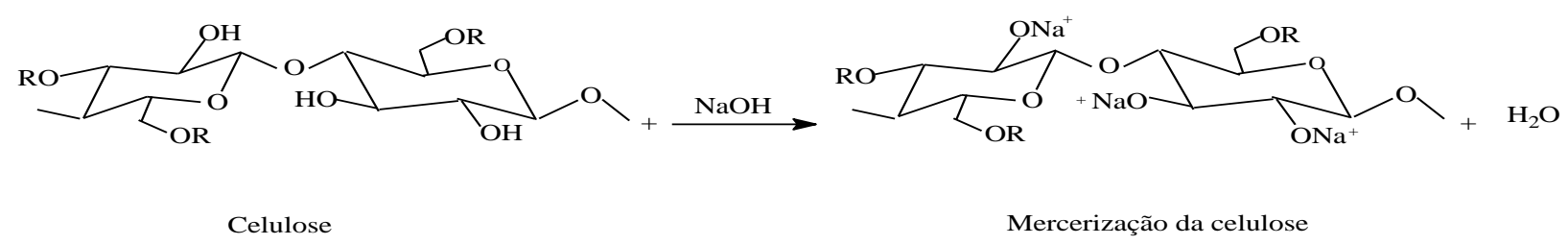

Figura 2.9: Esquema de reações das fibras naturais com $\mathrm{NaOH}$ (KONTTURI et al., 2005).

$\mathrm{Na}$ literatura diversos materiais lignocelulósicos foram tratados em meio alcalino, obedecendo diferentes concentrações, podendo citar: fibra de bagaço de cana-de-açúcar com solução de $\mathrm{NaOH}$ 17,5\% (m/v) (MANDAL; CHAKRABARTY, 2011), casca de arroz com solução de $\mathrm{NaOH} 4 \%$ (m/v) (JOHAR et al., 2012), fibra de bagaço de cana-de-açúcar com solução de $\mathrm{NaOH}$ 5\% (m/v) (TEIXEIRA et al., 2011) e curauá e bagaço de cana-de-açúcar com solução de $\mathrm{NaOH}$ 5\% (m/v) (CAMPOS et al., 2013).

Após o tratamento alcalino ou polpação, as polpas são geralmente branqueadas antes da utilização. O branqueamento pode ser baseado na remoção de lignina, com o cloro, dióxido de cloro, oxigênio, ozônio ou peróxido de hidrogênio (KONTTURI et al., 2005; KALIA et al., 2011; ROSA et al., 2012; FAHMA et al., 2010; MORÁN et al., 2008).

A separação dos componentes dos materiais lignocelulósicos é um dos principais obstáculos na utilização dos recursos renováveis de forma eficiente. No entanto, tal separação é obrigatória para sua utilização no campo nanotecnológico e das várias tecnologias de prétratamento para o isolamento dos nanocristais de celulose (ABRAHAMA et al., 2011). 


\subsubsection{Hidrólise ácida}

Os nanocristais são obtidos a partir de hidrólise ácida após pré-tratamentos iniciais, este procedimento é realizado por um período de tempo e temperatura controlados. Este processo remove parte da celulose amorfa, deixando cristais únicos e bem definidos num estado de suspensão coloidal. Nanocristais de celulose são obtidos principalmente por meio de hidrólise ácida, com ácidos fortes, tais como ácido sulfúrico ou ácido clorídrico o que leva a nanocristais variando entre 100 e $400 \mathrm{~nm}$ de comprimento e cerca de $10 \mathrm{~nm}$ de diâmetro. Os nanocristais de celulose são obtidos na forma de bastonetes, altamente cristalinos (KARGARZADEH et al., 2012).

O ácido sulfúrico é frequentemente empregado, pois gera uma solução coloidal estável, provocada pela repulsão eletrostática entre os nanocristais, causada pela carga superficial negativa obtida da substituição dos grupos de hidroxila por grupos sulfatos, após hidrólise. Esta inserção de cargas negativas na superfície das partículas confere estabilidade à suspensão, uma vez que o uso de ácido clorídrico geraria suspensões instáveis que tenderiam a sofrer aglomeração por não apresentarem esta carga superficial. Portanto, a força eletrostática do $\mathrm{HCl}$ não é o suficiente para causar repulsão entre as partículas, resultando na aglomeração (ARAKI, WADA et al., 1998; CORRÊA et al., 2010; TEIXEIRA et al., 2011; LIU.et al., 2010; DUFRESNE, 2010). Outros ácidos podem ser usados, como por exemplo, ácido bromídrico misturado com ácido acético e ácido nítrico. Estes são capazes de hidrolisar a celulose a nanocristais, sem esterificação das superfícies como no caso do ácido sulfúrico, podendo apresentar melhores rendimentos (JIANG; HSIEH, 2013).

Ao tratar a celulose com ácido sulfúrico $\left(\mathrm{H}_{2} \mathrm{SO}_{4}\right)$, há sulfonação de grupos de hidroxilas por íons sulfato. Além disso, a inserção de grupos sulfato produz uma carga negativa sobre a superfície dos cristais conforme a Figura 2.10 (KARGARZADEH et al., 2012; FAHMA et al., 2010).

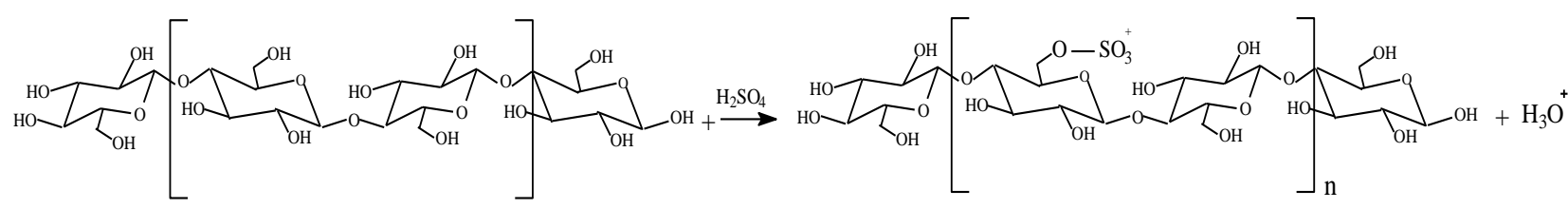

Figura 2.10. Mecanismo de hidrólise da celulose catalisada por ácido sulfúrico (FAHMA et al., 2010). 
A estabilidade desta suspensão é devido à repulsão eletrostática entre os grupos sulfato negativo sobre a superfície dos nanocristais (TEIXEIRA et al., 2011; DUFRESNE, 2010). A atuação do ácido na cadeia de celulose pode implicar no ataque das ligações glicosídicas ( $\beta$ 1-4) que é susceptível a hidrólise ácida, por íons hidrônio e à separação dos componentes das fibras (ARSÈNEA et al., 2013; ZAINI et al., 2013). A Tabela 2.2 apresenta um resumo das condições de hidrólise adotadas em diferentes literaturas utilizadas para a obtenção de nanocristais a partir da celulose de diferentes fontes.

Tabela 2.2: Condições de hidrólise para a obtenção de nanocristais a partir da celulose de diferentes fontes.

\begin{tabular}{lccccl}
\hline \multicolumn{1}{c}{ Origem da celulose } & $\begin{array}{c}\text { Concentração } \\
\mathrm{H}_{2} \mathrm{SO}_{4}(\%)\end{array}$ & $\begin{array}{c}\text { Temperatura } \\
\left({ }^{\circ} \mathrm{C}\right)\end{array}$ & $\begin{array}{c}\text { Tempo } \\
(\mathrm{min})\end{array}$ & $\begin{array}{c}\text { Centrifugação } \\
(\mathrm{rpm})\end{array}$ & Referências \\
\hline Casca de arroz & 64 & 25 & 60 & 3.000 & ROSA et al., (2012) \\
Fibra de coco & 64 & 45 & 180 & 10.000 & ROSA et al., (2010) \\
Kenaf & 65 & 45 & 120 & 10.000 & KARGARZADEH et al., (2012) \\
Algodão & 60 & 45 & 60 & 13.000 & MORAIS et al., (2013) \\
Bagaço de cana-de-açúcar & 64 & 45 & 60 & 12.000 & KUMAR et al., (2014) \\
\hline
\end{tabular}

As regiões cristalinas e amorfas estão presentes em fibras de celulose em proporções que variam dependendo das espécies das plantas. Por essa razão, as características (designadamente as dimensões) de nanocristais de celulose dependem em grande parte da matéria-prima. Deste modo, as dimensões dos nanocristais de celulose são influenciadas pelas condições de hidrólise ou pré-tratamento (MORAIS et al., 2013; ZAINI et al., 2013; BECK-CANDANEDO et al., 2005). Assim, os nanocristais de celulose podem apresentar alta razão de aspecto (comprimento/diâmetro), o que lhes confere boa capacidade de reforço por permitir uma transferência da tensão da matriz para a carga. Deste modo, a concentração do ácido, tempo de hidrólise e a temperatura podem determinar o tamanho dos nanocristais como também o índice de cristalinidade ( $\mathrm{ICr}$ ) e o rendimento dos nanocristais de celulose conforme a Tabela 2.3 (ABDUL KHALIL et al., 2012). Além destas características, existe o interesse econômico, pois eles podem ser preparados a partir de uma grande variedade de fontes renováveis, incluindo resíduos agrícolas como o bagaço de cana-de-açúcar, casca de arroz e palha de milho. Neste contexto apresenta como uma alternativa de preparar nanocompósitos ambientalmente amigáveis 
(MESQUITA et al., 2010; EL MIRI et al., 2015; NAHLA et al., 2015; PRACELLA et al., 2014).

Tabela 2.3: Características de nanocristais de celulose obtidos a partir de diferentes fontes.

\begin{tabular}{lcccl}
\hline Fibras naturais & $\begin{array}{c}\text { Diâmetro } \\
(\mathrm{nm})\end{array}$ & $\begin{array}{c}\text { Comprimento } \\
(\mathrm{nm})\end{array}$ & $\begin{array}{c}\mathrm{ICr} \\
(\%)\end{array}$ & \multicolumn{1}{c}{ Referências } \\
\hline Kenaf & 11 & 124 & 80 & KARGARZADEH et al., 2012 \\
Sisal & 22 & 220 & 75 & MORÁN et al., 2008 \\
Bagaço & 8 & 255 & 70 & TEIXEIRA et al., 2011 \\
Casca de arroz & 6,7 & 166 & 90 & JIANG; HSIEH, 2013 \\
\hline
\end{tabular}

\subsubsection{Os Nanocristais de Celulose e suas Aplicações}

São vários os termos conhecidos para nomear os nanoestruturas de celulose, como por exemplo, nanowhiskers de celulose (NWC), nanocristais de celulose (NCC), nanofibrilas de celulose (NFC), celulose microfibrilada (MFC) ou nanocelulose (NC). Portanto, a definição do nome vai depender do tamanho e do seu método de extração (KUMAR et al., 2014; BRITO et al., 2012). O nanocristal de celulose é um bionanomaterial com muitas propriedades promissoras. Segundo Li et al. (2013), a sua comercialização em 2020 poderá chegar em 600 bilhões de dólares, assim é de suma importância avaliar seu impacto ambiental, pois é importante endereçar os impactos ambientais dos produtos a fim de melhorar constantemente os processos produtivos. Assim, a nanocelulose pode ser dividida em duas formas: nanofibras e nanocristais (ARVIDSSON et al., 2015). Segundo Arvidsson et al. (2015), nanofibras de celulose consistem em ambas as regiões amorfa e cristalina, já os nanocristais de celulose consistem em uma estrutura cristalina.

KUMAR et al. (2014), definiram os NCCs como sendo partículas de celulose em forma de agulha que tem, pelo menos, uma dimensão igual ou inferior a $100 \mathrm{~nm}$ com natureza altamente cristalina. Pela definição de BRINCHI et al. (2013), os NCC são formados por partículas semelhantes a uma haste rígida com comprimento entre 100 nm e vários micrômetros, respectivamente. Onde as partículas são constituídas de $100 \%$ de celulose e a cristalinidade variando entre 54 a $88 \%$. 
Nanocristal de celulose é um substrato único de escala nanométrica natural, no qual pode ser extraído a partir da parede celular de fibras lignocelulósicas utilizando diferentes métodos, que incluem a mecânica, químico-mecânico e técnicas enzimáticas. Os nanocristais de celulose incluem os grupos de cadeias de celulose, os quais estão ligados entre si por ligações de hidrogênio. Devido à elevada área superficial, altamente cristalina, natureza renovável, baixo custo, baixa densidade, transparência, alta rigidez e excelentes propriedades mecânicas, os nanocristais de celulose têm um grande potencial para ser utilizado em várias aplicações, incluindo produtos biomédicos, cosméticos, produto farmacêuticos, componentes de eletrônicos, espumas, aerogéis e têxteis e usados como agentes de enchimento em materiais nanocompósitos de alta performance (PICKERING et al., 2016; JONOOBI et al., 2010; PRACELLA et al., 2014; COCCIA et al., 2014; KUMAR et al., 2014; MORAIS et al., 2013; BRITO et al., 2012; MOON et al., 2011; LUONG et al., 2011; KUMAR et al., 2013). As desvantagens dos nanocristais de celulose reportadas pela literatura são a elevada hidrofilicidade e a baixa estabilidade térmica $\left(\sim 200^{\circ} \mathrm{C}\right)$ e consequentemente baixa temperatura de processamento (BEZERRA et al., 2015; SIRÓ; PLACKETT, 2010;).

O uso de partículas de pequenas dimensões como reforço em nanocompósitos de alta performance tem despertado muito interesse. Na última década, os esforços foram direcionados para obtenção de nanocristais de celulose a partir de fibras naturais. A celulose de bagaço de cana-de-açúcar foi utilizada devido a sua abundância (o Brasil é o maior produtor desta fibra) e seu baixo teor de lignina (HELBERT et al., 1996; EL MIRI et al., 2015).

No entanto, a fim de obter nanocristais de celulose comercialmente competitivos, fontes de baixo custo, bem como processos energeticamente eficientes são necessários (JONOOBI et al., 2012). Vários processos foram utilizados para extrair nanocristais de celulose a partir da biomassa, como por exemplo, polpação alcalina com hidróxido de sódio, branqueamento com clorito de sódio e hidrólise com ácido sulfúrico conforme a Figura 2.11. Assim, tratamentos químicos seguidos de hidrólise ácida com tempo e temperatura controlados têm sido utilizados.

A produção de nanocristais de celulose tem sido realizada com diferentes tipos de biomassa, métodos, reagentes e cristalinidade: fibra de coco (etanol/benzeno; clorito de sódio; ácido acético; hidróxido de potássio, cristalinidade de 56\%) (FAHMA et al., 2010; KARGARZADEH et al., 2012; BRINCHI et al., 2013), madeira (etanol/benzeno; clorito de sódio; ácido acético; hidróxido de sódio; hidróxido de potássio; ácido sulfúrico, cristalinidade de 
69\%) (CHEN et al., 2011), casca de arroz (etanol/hexano; ácido acético; hidróxido de sódio; peróxido de hidrogênio; ácido nítrico; tetra-acetiletilenodiamina; ácido sulfúrico, cristalinidade de 79\%) (ROSA et al., 2012), sisal (etanol/tolueno; clorito de sódio; ácido acético; hidróxido de sódio; borato de sódio; peróxido de hidrogênio; ácido nítrico; bissulfeto de sódio; ácido sulfúrico, cristalinidade de 75\%) (MORÁN et al., 2008), bagaço de cana-de-açúcar (metanol/benzeno; clorito de sódio; ácido acético; hidróxido de sódio; hidróxido de potássio; ácido sulfúrico, cristalinidade de 72\%) (KUMAR et al., 2014).

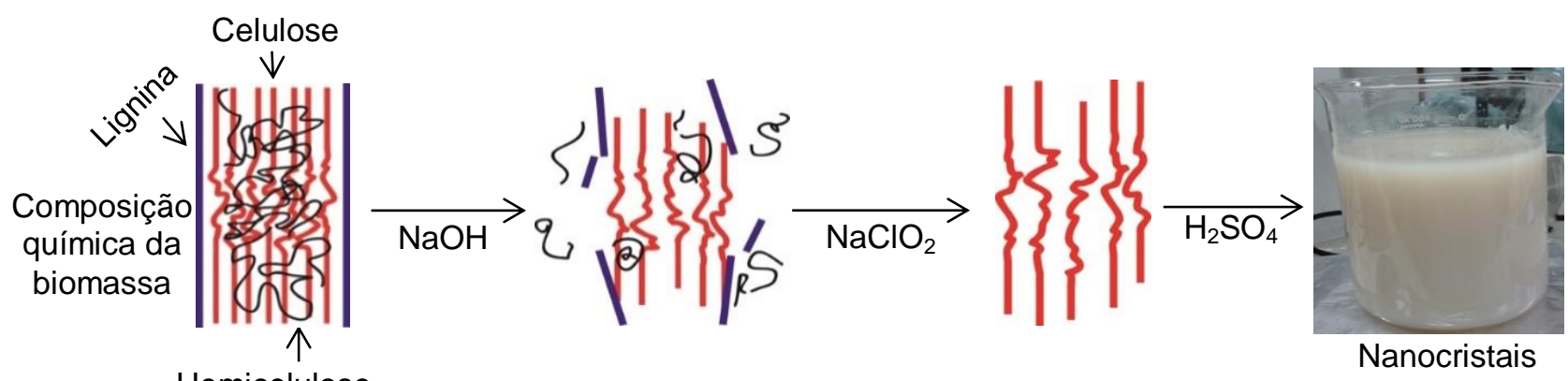

Figura 2.11: Representação da remoção da hemicelulose e lignina.

\subsection{AVALIAÇÃO DE CICLO DE VIDA (ACV) APLICADA AO DESENVOLVIMENTO DE MATERIAIS MAIS SUSTENTÁVEIS}

Nas últimas décadas verificou-se um grande interesse em substituir produtos à base de petróleo por produtos renováveis. À medida que a matriz de bioprodutos aumenta, assim também, aumenta o interesse de avaliar os impactos energéticos e ambientais desses produtos. A ACV tem sido aceita como um método útil para quantificar e avaliar as interferências ambientais de vários processos e produtos sobre o meio ambiente (WILLERS; RODRIGUES, 2014).

Os principais objetivos do conceito de ciclo de vida são: reduzir o uso de recursos (matérias-primas) e as emissões de produtos para o meio ambiente. De fato, a ACV tem contribuído para consolidar métodos de avaliar os impactos ambientais de produtos de um determinado sitema (LEMMET et al., 2012; WILLERS; RODRIGUES, 2014; RICKERBY; MORRISON, 2007). 


\section{A Ferramenta de ACV}

A Avaliação Ciclo de Vida é uma ferramenta que permite avaliar os impactos ambientais ou associado a um produto durante seu ciclo de vida, desde a obtenção da matéria-prima, passando pelo uso, até o descarte final, por meio da quantificação de entradas e saídas do sistema avaliado. Portanto, ACV é um método estruturado, abrangente e normatizado internacionalmente de acordo com as normas da ISO 14040/14044, conduzida pelas etapas de definição de objetivo e escopo, análise de inventário, avaliação de impacto e interpretação. A Figura 2.12 mostra as fases da ACV de forma esquemática (ILCD Handbook).

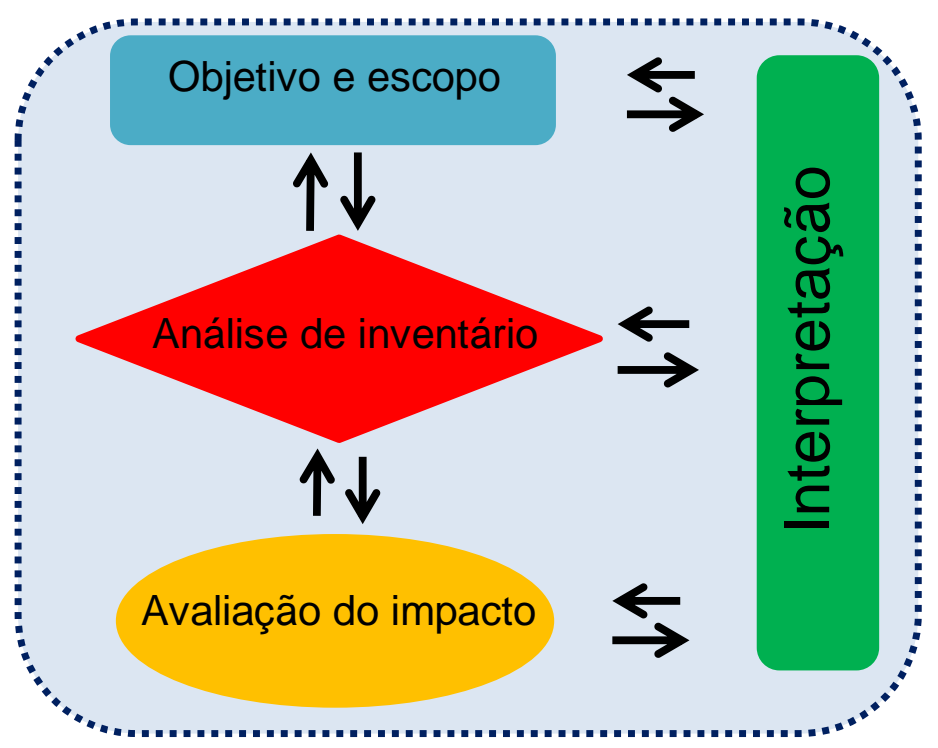

Figura 2.12: Etapas da avaliação do ciclo de vida.

Cada fase da avaliação de ciclo de vida pode ser compreendida nos seguintes pontos:

1. Objetivo e escopo: Esta fase define o objetivo e o escopo do estudo da ACV, envolvendo decisões sobre fronteiras do sistema a ser avaliado e a unidade funcional, estimativas e limitações e os métodos de alocação que serão usados, bem como categorias de impacto.

2. Análise de inventário: Nesta fase, todos os fluxos de entradas e saídas são levantados a fim de obter um perfeito balanço de massa e energia relacionado a consumo ou liberação de energia e materiais e emissões para o ar, água e solo. 
3. Avaliação do impacto: Esta avaliação determina os (potenciais) impactos ambientais causados no meio ambiente. Nessa fase, os dados de inventário são selecionados e atribuídos a categorias de impacto, ou seja, o método definido faz a conversão dos resultados do ICV (Inventário de Ciclo de Vida) em impactos ambientais. Assim, todos os parâmetros incluídos na categoria de impacto são somados e é obtido o resultado da categoria de impacto.

4. Interpretação: Nesta fase, os resultados obtidos nas fases de análise de inventário e de avaliação dos impactos são combinados e interpretados de acordo com os objetivos definidos (ROES et al., 2007; COLTRO, 2007).

\section{Definição objetivo e escopo}

A norma ISO 14044 (2006), ressalta que o objetivo de um estudo da ACV deve deixar clara a aplicação pretendida, as razões do estudo e o público-alvo e para quem se pretende comunicar os resultados do estudo. O propósito é fornecer uma referência para a qual as entradas e saídas são relacionadas. Esta referência é necessária para assegurar a comparabilidade de resultados da $\mathrm{ACV}$ para garantir que tais comparações sejam feitas numa base comum.

O escopo considera diversos fatores, tais como o sistema do produto a ser estudado, as funções do sistema ou produto, a unidade funcional, as fronteiras do sistema, procedimentos de alocação, metodologia de avaliação de impacto, forma de interpretação, suposições, limitações, qualidade de dados, análise crítica, e o formato do relatório o estudo, como também aspectos temporais, geográficos e tecnológicos. É nessa fase que se fazem as suposições e se definem as regras de corte devido aos diversos limites da pesquisa (tempo, custos, acesso aos dados, etc.). Todas as entradas e saídas do sistema são então baseadas na mesma unidade funcional que pode ser dada em massa, energia ou outra unidade deve ser claramente descrita (ISO 14044, 2006; WILLERS; RODRIGUES, 2014).

A unidade funcional deve apresentar a função de um sistema e todos os fluxos de entrada e saída dos processos. Portanto, a unidade funcional é a unidade de referência quantitativa onde todos os fluxos de entradas e saídas na ACV estão relacionadas. Em resumo, a unidade funcional relacionada deve ser definida e mensurável (ISO 14040, 2006; COLTRO, 2007). 
De acordo com a ISO 14040 (2006), a fronteira do sistema determina quais unidades de processo devem ser incluídas no estudo. A fronteira do sistema estabelece limites para o estudo, define todos os processos elementares do estudo. As fronteiras são estabelecidas, tais como fronteira entre o sistema técnico e ambiental ou início e o fim do sistema; delimitação da área em estudo (deve ser estabelecido geograficamente); perpesctiva de tempo do estudo; definição das atividades que consta no ciclo de vida do produto estudado que serão incluídas ou excluídas; distribuição da carga ambiental entre vários co-produtos.

\section{Inventário do Ciclo de Vida (ICV)}

O Inventário do Ciclo de Vida de um produto é a fase de coleta dos dados referentes aos fluxos de entrada e saída, onde está incluído o uso de recursos e liberações de emissões no ar, na água e no solo associados com o sistema, os quais determinarão os impactos resultantes da produção. Os dados a serem coletados são valores mensuráveis (massa, volume, energia, área, etc.) que terão relação direta com a unidade funcional. Trata-se da quantificação das matériasprimas, dos insumos auxiliares, consumos de água, reagentes químicos e energia, assim como emissões de poluentes em efluentes líquidos dos processos ligados a todo o ciclo de vida de um produto (ILCD Handbook, 2010). Deste modo, um critério de corte deve ser definido a fim de se estabelecer uma quantidade de fluxos de um processo a ser excluído sem que haja comprometimento da qualidade da ACV. Nessa fase é elaborado um fluxograma do sistema em estudo, de modo que as atividades ou processos que serão avaliados sejam bem definidos, bem como as fronteiras técnicas do mesmo. Assim, uma fração mínima a ser coletada deve ser claramente entendida e descrita no estudo (ISO 14040, 2006).

Segundo ISO 14040 (2006), a análise de inventário é iterativa, a coleta de dados faz com que os condutores de uma ACV conheçam mais sobre o sistema, o que pode levar à identificação de novos requisitos ou mesmo limitações para os dados. Desta forma, isso pode acarretar na necessidade de alterações nos procedimentos de coleta de dados para que os objetivos sejam alcançados como também pode ocorrer revisões de objetivo e/ou escopo em estudo. 


\section{Avaliação de impacto ciclo de vida (AICV)}

A fim de analisar os efeitos das cargas ambientais, a avaliação de impacto pode ser qualitativa ou quantitativa. Com base na norma ISO 14040 (2006), este processo deve consistir de seleção, classificação e caracterização de categorias de impactos (os dados do inventário são multiplicados por fatores de equivalência para cada categoria de impacto). Os dados gerados nas fases de análise de inventário são associados à avaliação do impacto ambiental, de modo que o significado do impacto ambiental seja avaliado de acordo com sua relevância, ou seja, os dados são interpretados em termos de seus impactos ambientais. Em relação ao nível de ação, as categorias de impacto podem ser divididas em de nível intermediário (midpoint) ou de nível final (endpoint) conforme a Figura 2.13 (WILLERS; RODRIGUES, 2014).

Portanto, a seleção das categorias de impacto baseia-se em três princípios: a completude, as categorias selecionadas devem relacionar todos os possíveis problemas ambientais do sistema; a independência, a categoria escolhida trata de um impacto ambiental exclusivo para evitar a dupla contagem; a validade, não deve haver dúvida sobre a contribuição de um fluxo a uma categoria de impacto (ROUSSEAUX, 2016).

Portanto, a escala geográfica de uma categoria pode ser global, quando se refere a todo o planeta; regional, quando aborda uma zona intermediária; e a local, quando se restringe a uma área específica.

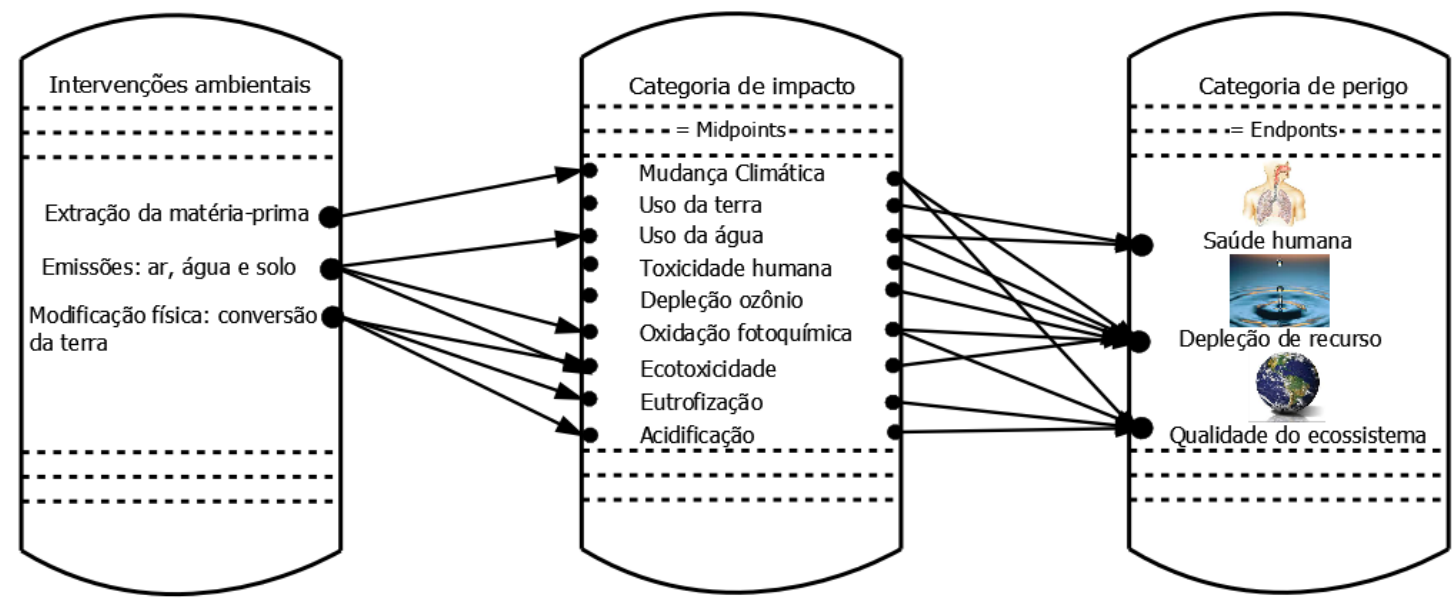

Figura 2.13: As categorias de impacto e suas implicações no meio ambiente (adaptado ILCD Handbook, 2010). 


\section{Potencial de aquecimento global}

O aquecimento global está relacionado à emissão de gases de efeito estufa como dióxido de carbono $\left(\mathrm{CO}_{2}\right)$, óxido nitroso $\left(\mathrm{N}_{2} \mathrm{O}\right)$, metano $\left(\mathrm{CH}_{4}\right)$, clorofluorcarbono (CFCs), hexafluoreto de enxofre $\left(\mathrm{SF}_{6}\right)$ hidroclorofluorcarbono ( $\left.\mathrm{HCFCs}\right)$ e brometo de metila $\left(\mathrm{CH}_{3} \mathrm{Br}\right)$ causando aumento da temperatura terrestre. As consequências estão entre o aumento da temperatura média global da terra e mudanças climáticas regionais inesperadas, comprometendo o ecossistema. De acordo com Cisneros (2016), a elevação da temperatura da superfície terrestre é a causa da possível redução de água nos mananciais do planeta.

O potencial de aquecimento global é dado em (kilograma equivalente de $\mathrm{CO}_{2}$ ) e esta categoria é de escala global (SHEN; PATEL, 2010; GHANTA et al., 2014; LUZ et al., 2010; NIELSEN et al., 2007). Esta é uma categoria que envolve uma série de mecanismos ambientais que afeta a Saúde Humana e o Ambiente Natural (EUROPEAN COMISSION, 2010).

\section{Energia}

O aumento do consumo de energia eleva a necessidade de expansão das duas maiores fontes de produção de energia: as usinas hidrelétricas que apresentam grande impacto ambiental e as termelétricas, que trabalham com queima de combustíveis fósseis.

O uso de energia é principalmente de origem fóssil, óleo, petróleo e carvão, e em menor volume, o gás natural. Desta forma, conclui-se que a solução para um dos maiores problemas globais deste século é a redução do uso de energia fóssil. Tendo como consequências aumento do efeito estufa que é um fenômeno natural de retenção de calor, mas tem se intensificado pelas ações antrópicas, através da emissão do dióxido de carbono (resultado da queima de combustíveis fósseis) gerando uma grande quantidade de gases na atmosfera. Por outro lado, é que a queima de biomassa provoca a liberação de dióxido de carbono na atmosfera, mas como este composto havia sido previamente absorvido pelas plantas que deram origem ao combustível, assim, o balanço de emissões de dióxido de carbono é nulo, neste caso específico (SHEN; PATEL, 2010; KAHN, 2016). 


\section{Uso da terra}

Esta categoria esta relacionada aos danos do ecossistema, devido à ocupação e transformação da terra, tais como produção agrícola, extração mineral e assentamentos humanos. Esta ocupação do solo indica a manutenção de uma área de um estado em particular em um determinado período de tempo. Portanto, a utilização da terra acarreta impactos nos recursos, na biodiversidade, nos serviços ecossistêmicos, entre outros aspectos. Podendo ter impactos locais ou regionais e são medidos em área ( $\mathrm{km}^{2}$, ha, etc.)/ano (EUROPEAN COMISSION, 2010).

\section{Uso da água}

De acordo com a norma ISO 14046 (2014), a avaliação da pegada hídrica apresenta algumas vantagens, como avaliar os potenciais de impactos ambientais relacionados com a água; identificar formas de reduzir potenciais impactos relacionados com a água de produtos ou processos em diferentes etapas do ciclo de vida; facilitar a eficiência da água e otimizar a gestão da água no produto ou processo, fornecer informações cientificamente consistente e confiáveis para relatar os resultados sobre a pegada de hídrica.

O termo "pegada hídrica" é um indicador do uso da água que considera o uso direto (por um consumidor ou produtor) ou indireto da água (abastecimento). Desta forma, a pegada hídrica pode ser considerada como um indicador abrangente da apropriação de recursos hídricos, com conceito tradicional e restrito de captação de água. A pegada hídrica de um produto é o volume de água utilizado para produzi-lo, ou seja, é a medida ao longo de toda cadeia produtiva. É um indicador multidimensional, que mostra os volumes de consumo de água por fonte e os volumes de poluição pelo tipo de poluição; todos os componentes de uma pegada hídrica total são especificados a geográfica e temporalmente (HOEKSTRA et al., 2011).

Portanto, a contabilização da pegada hídrica fornece informações espaciais e sobre o uso e a alocação equitativa e sustentável da água, além de formar uma boa base para a avaliação dos impactos ambientais, sociais e econômicos (HOEKSTRA et al., 2011).

De acordo com a Water Footprint Network (2016), a pegada hidríca é dividida em três tipos de água: água verde, água cinza e água azul ou pegada hidríca verde (PHverde), pegada hidríca cinza (PHcinza) e pegada hidríca azul (PHazul), conforme descrito a seguir: 
- Água verde: essa categoria refere-se à água doce em nível de bacia hidrográfica, incluindo a água da chuva e evaporação (ISO 1046, 2014; BAYART et al., 2010; STEPHAN et al., 2009; KOEHLER, 2008; WATER FOOTPRINT NETWORK, 2016).

- Água cinza: essa categoria refere-se ao uso da água a partir da superfície do solo. Ou seja, indica o consumo de qualquer superfície subterrânea, bem como no caso da produção agrícola particularmente e água de irrigação (ISO 1046, 2014; WATER FOOTPRINT NETWORK, 2016).

- Água azul: essa categoria refere-se à utilização total de água (água do rio + água do lago + água subterrânea e água da chuva) (ISO 1046, 2014; STEPHAN et al., 2009; WATER FOOTPRINT NETWORK, 2016).

\section{Toxicidade humana}

Esta categoria está relacionada com as atividades antrópicas que emitem subtâncias tóxicas a saúde humana por injeção ou inalação. Nesta categoria a medição é feita na antroposfera. O Potencial de toxicidade humana é expresso em quilogramas equivalentes de diclorobenzeno (DCB) (EUROPEAN COMISSION, 2010).

\section{Depleção do Ozônio}

$\mathrm{O}$ ozônio é formado e destruído pela luz solar e reações químicas (liberam $\mathrm{Cl}^{-}$e $\mathrm{Br}^{-}$que destroem a camada de ozônio) na estratosfera. A depleção do ozônio ocorre se a taxa de destruição do ozônio é aumentada devido a perdas resultantes das substâncias antropogênicas que persistem na atmosfera. Assim, a emissão antrópica de gases como o $\mathrm{CFC}, \mathrm{CH}_{3} \mathrm{Cl}, \mathrm{N}_{2} \mathrm{O}$, reage com o ozônio, formando o oxigênio e provocando um "buraco" que permite a passagem dos raios UVB (ultravioleta) que podem causar danos à saúde. O Potencial de Depleção do Ozônio (PDO) é expresso em quilogramas equivalentes de CFC-11 (clorofluorocarboneto ) e esta categoria é de escala global (EUROPEAN COMISSION, 2010).

\section{Oxidação fotoquímica}

A reação fotoquímica ocorre sob a influência dos raios ultravioletas, óxidos nitrosos $\left(\mathrm{NO}_{\mathrm{x}}\right)$ e compostos orgânicos votáteis $(\mathrm{COV})$ que reagem, produzindo oxidantes que causam o nevoeiro fotoquímico na troposfera. Este fato pode alterar o nicho ecológico de outros 
organismos vivos como também pode causar sérios danos à saúde humana. Esta categoria é expressa em quilograma equivalente de eteno $\left(\mathrm{C}_{2} \mathrm{H}_{4}\right)$, e sua ação pode ser local ou regional (EUROPEAN COMISSION, 2010).

\section{Ecotoxicidade}

Esta categoria compreende nos impactos de substâncias tóxicas nos ecossistemas terrestres e aquáticos. O Potencial de Ecotoxicidade é expresso em quilogramas equivalentes de diclorobenzeno (DCB) e sua ação pode ser ação local ou regional (EUROPEAN COMISSION, 2010).

\section{Potencial de acidificação}

O potencial de acidificação se caracteriza pela reação dos constituintes químicos com o ar, o solo e água formando ácidos. Esta categoria de impacto é baseada em emissões de óxidos de enxofre $\left(\mathrm{SO}_{2}\right)$, óxidos de nitrogênio $\left(\mathrm{NO}_{\mathrm{x}}\right)$, ácido hidroclorídrico $(\mathrm{HCl})$ e amônia $\left(\mathrm{NH}_{3}\right)$. Estes, retornam ao solo e aos corpos hídricos na forma de chuva ácida que causa a degradação de ambientes naturais e antrópicos. Podem causar danos diretos ao ambiente natural e artificial e indireto à saúde humana e aos recursos naturais. O potencial de acidificação é expresso em quilogramas equivalentes de $\mathrm{SO}_{2}$ e sua ação pode ser local ou regional (SHEN; PATEL, 2010; GHANTA et al., 2014; EUROPEAN COMISSION, 2010).

\section{Potencial de eutrofização}

A presença de macronutrientes nos ecossistemas, nitrogênio e fósforo, favorece o crescimento mais acentuado de espécies vegetais tanto terrestres quanto aquáticas. Portanto, pode ocorrer uma alteração significativa da composição da vegetação, seja em ambientes aquáticos ou terrestres. Na eutrofização aquática, os macronutrientes limitam o crescimento de algas, provocando a morte de peixes e na impossibilidade de consumo da água. A eutrofização terrestre é causada pela deposição de emissões atmosféricas de compostos nitrogenados, como óxido de nitrogênio (NO), dióxido de nitrogênio $\left(\mathrm{NO}_{2}\right)$, nitratos $\left(\mathrm{NO}_{3}\right)$ e amônia $\left(\mathrm{NH}_{3}\right)$. O fósforo é o limitante em sistemas de água doce e o nitrogênio é o limitante em água salgada. Potencial de eutrofização é expresso em quilogramas equivalentes de fosfato $\left(\mathrm{PO}_{4}^{-}\right)$e sua ação é local (EUROPEAN COMISSION, 2010; SHEN; PATEL, 2010; GHANTA et al., 2014). 


\section{Interpretação}

Nesta fase é feito um resumo dos resultados da análise de inventário e da avaliação de impactos obtidos no estudo. Na fase da interpretação deve incluir a identificação dos impactos ambientais, avaliação do estudo em relação a sua completeza, integridade, sensibilidade e consistência dos dados, bem como conclusões, limitações, incertezas, recomendações de melhorias com a finalidade de reduzir os impactos ambientais (COLTRO, 2007; COLTRO; KARASKI, 2015). Assim, a integridade do estudo visa garantir que todas as informações pertinentes estão completas, caso contrário, deve-se avaliar as fases anteriores (ICV e AICV) ou ajustar os objetivos e escopo do estudo. A sensibilidade dos resultados é determinado por meio de métodos quantitativos para avaliar o efeito das incertezas no estudo devido à qualidade das informações, às estimativas e às suposições realizadas ao longo do estudo (CHEHEBE, 1997).

\section{Estudos relacionados a ACV envolvendo materiais}

Muitos estudos vêm sendo realizados utilizando a ferramenta de avaliação de ciclo de vida e pode-se destacar nesses estudos as considerações sobre a reciclagem ou uso de materiais renováveis e seus respectivos impactos ambientais quando comparados a materiais sintéticos ou não reciclados. Vidal et al. (2009) aplicou a avaliação do ciclo de vida no estudo de materiais compósitos de termoplásticos (PP e HDPE) reciclados reforçados com casca de arroz e algodão, que são resíduos biodegradáveis de pouco valor econômico. Segundo Vidal et al. (2009), o impacto ambiental destes materiais é comparado com o impacto de polipropileno virgem e poliestireno de alta densidade. Pode-se ainda citar os estudos realizados por Bernier et al. (2012), aplicando a avaliação do ciclo de vida da lignina kraft para aplicações de polímeros e Roes et al. (2007), avaliaram os impactos ambientais e o custo de nanocompósitos de polipropileno.

Foram encontrados somente três artigos sobre a ACV aplicada a nanocristais de celulose (FIGUEIRÊDO et al., 2012; ARDIDSSON et al., 2015; LI et al., 2013). Arvidsson et al. (2015) avaliaram os impactos ambientais do berço ao portão por três rotas de produção de nanocristais a partir da polpa da madeira. As três rotas de produção foram: (1) enzimática, (2) carboximetilação e (3) sem pré-tratamento. Os resultados mostraram que os nanocristais produzidos através da rota 
carboximetilação mostraram maiores impactos ambientais, que pode ser explicado, devido à utilização de solventes de petróleo bruto. Figueiredo et al. (2012), avaliaram os impactos ambientais a partir da fibra de algodão e fibra de coco, os parâmetros foram: (consumo de água, reagentes, energia, e emissões para a água), e as categorias de impacto consideradas foram aquecimento global, o esgotamento da água, eutrofização e toxicidade humana. A comparação entre as fibras, a fibra de algodão mostrou menor consumo de energia e água gerando menores impactos ambientais (aquecimento global, toxicidade humana e eutrofização).

$\mathrm{O}$ efeito global dos nanocristais de celulose precisa ser avaliado por meio de uma metodologia que inclui todas as etapas do ciclo de vida (ROES et al., 2007). Assim, esta ferramenta permite identificar quais estágios do ciclo de vida têm contribuição mais significativa para o impacto ambiental do processo. Por meio da ACV é possível avaliar a implementação de melhorias ou alternativas para diminuir os impactos ambientais do processo ou do produto (MOURAD et al., 2007). Um dos desafios na realização da ACV sobre nanocristais de celulose incluem na indisponibilidade de dados, particularmente relacionados ao uso e as fases do fim de vida e da avaliação das categorias de impactos das nanopartículas.

\subsection{PREPARAÇÃO DOS NANOCOMPÓSITOS}

\subsubsection{Matriz de acrilonitrila butadieno estireno (ABS)}

O desenvolvimento dos compósitos de polímeros termoplásticos provém de vários benefícios, incluindo o potencial para reciclagem até o fim de vida do produto, bem como a compatibilidade entre as fases reforço/matriz (BLAKER et al., 2014). A literatura tem reportado vários nanocompósitos com diferentes matrizes (polímeros naturais e sintéticos): ácido poliláctico (SPINELLA et al., 2015); ABS (MA et al., 2015; GALVAN et al., 2011a); policarbonato (PANTHAPULAKKAL; SAIN, 2012) entre outros.

Acrilonitrila butadieno estireno (ABS), conforme a Figura 2.14, é um terpolímero amorfo (copolímero), que é composto com propriedades altamente equilibradas, sendo a acrilonitrila responsável pela resistência térmica e química; o butadieno responsável pela resistência ao impacto e alongamento; e o estireno, responsável pelo brilho, mobilidade e rigidez (RIMDUSIT et al., 2014). 


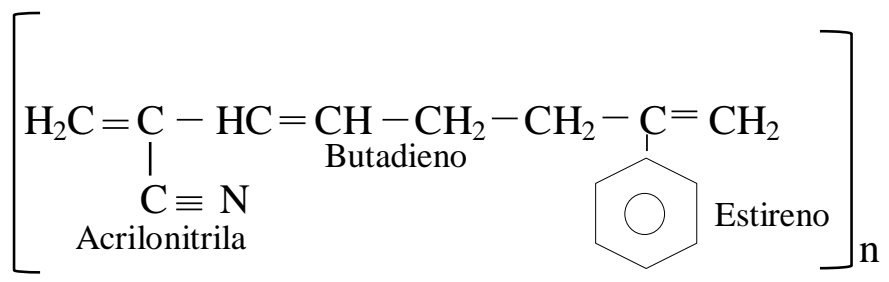

Figura 2.14: Características e a fórmula estrutural do acrilonitrila butadieno estireno.

Segundo Canevarolo Jr. (2006), o copolímero, por possuir dois ou mais "meros" diferentes na cadeia principal tendem a ter dificuldade de empacotamento e, portanto, apresentam baixa ou nenhuma cristalinidade. O ABS é um termoplástico amplamente aplicado na engenharia com propriedades únicas, como por exemplo, baixo custo, excelentes propriedades mecânicas e resistência química e de fácil processamento. Suas principais propriedades podem ser observadas na Tabela 2.4. O ABS é utilizado nas indústrias de telecomunicação, eletrônicos, eletrodomésticos e automotiva (em painéis de instrumentos, suportes de lâmpadas, revestimentos de colunas, maçanetas, suportes de espelhos, grades e guarnições decorativas e outras guarnições internas), principalmente, devido a sua resistência a solventes apolares (orgânicos) (CHRISSAFIS; BIKIARIS, 2011; ROCHA; SOARES, 2007; MA et al., 2015; BEYLER; HIRSCHLER, 2002; YU et al., 2012; SANCHEZ et al., 1999).

Tabela 2.4. Propriedades físicas da matriz de ABS GP 35 (BEYLER; HIRSCHLER, 2002).

\begin{tabular}{ll}
\hline Propriedade & Valores \\
\hline Índice de fluidez & $34 \mathrm{~cm}^{3} / 10 \mathrm{~min}$ \\
Densidade & $1,01-1,05 \mathrm{~g} / \mathrm{cm}^{3}$ \\
Módulo de tensão & $2300 \mathrm{MPa}$ \\
Alongamento no escoamento $50 \mathrm{~mm} / \mathrm{min}$ & $2,4 \%$ \\
Dureza & $99 \mathrm{MPa}$ \\
Resistência ao Impacto Izod a $23^{\circ} \mathrm{C}$ & $22 \mathrm{~kJ} / \mathrm{m}^{2}$ \\
Temperatura de distorção térmica HDT A $(1,80 \mathrm{MPa})$ & $94^{\circ} \mathrm{C}$ \\
Temperatura de distorção térmica HDT A $(0,45 \mathrm{MPa})$ & $99^{\circ} \mathrm{C}$ \\
\hline
\end{tabular}


Tradicionalmente, o ABS consiste de duas fases, em que o copolímero de SAN, composto pelo estireno e a acrilonitrila é a fase contínua, matriz, na qual está dispersa na fase elastomérica do butadieno. A fase butadieno possui uma camada de SAN enxertado (grafting) em sua superfície, o que permite a compatibilidade entre as duas fases. A preservação das propriedades de modificação de impacto do ABS, durante o processamento por fusão (por exemplo, extrusão, moldagem por injeção) e uso do produto (por exemplo, estabilidade para a luz UV). Esta fase é particularmente susceptível à oxidação, devido à presença de ligações duplas residuais. O grupo nitrila de cadeias vizinhas, sendo polar, se atraem e se ligam, deixando o ABS mais forte do que o poliestireno puro. Para a maioria das aplicações, o ABS pode ser usado entre temperaturas de até -20 a $80^{\circ} \mathrm{C}$ e as suas propriedades mecânicas variam com a temperatura (BLOM et al., 2006; CHRISSAFIS; BIKIARIS, 2011; BHASKAR et al., 2003; NEHER et al., 2014).

Segundo Yang et al., (2004), a degradação dos constituintes do ABS inicia-se em temperaturas distintas, sendo o butadieno a $340^{\circ} \mathrm{C}$, o estireno a $350^{\circ} \mathrm{C}$ e o acrilonitrila a $400^{\circ} \mathrm{C}$. A presença de uma fase elastomérica (butadieno) que é sensível à degradação termo-oxidativa torna-se um fator principal no desempenho final do ABS, isto porque sua degradação causa uma diminuição na aderência com a matriz SAN. Assim, pode surgir um concentrador de tensões, o que reduz sua resistência ao impacto e, consequentemente, sua tenacidade (YANG et al., 2004).

A quantidade de acrilonitrila é um dos principais critérios para definir as propriedades básicas do elastômero. Como por exemplo, a polaridade do agrupamento nitrila faz com que o elastômero apresente resistência a óleos e solventes à base de hidrocarbonetos e apresente também boa flexibilidade e resistência à abrasão. O butadieno é um monômero utilizado na produção de elastômeros de grande interesse econômico no mercado mundial. Esses elastômeros podem ter propriedades diferentes, em função de sua estrutura química e estereoquímica (ROCHA; SOARES, 2007). A literatura tem reportado nanocompósitos com ABS/argila (CHRISSAFIS; BIKIARIS, 2011); ABS/nanocristais por MA et al., (2015); e ABS/TiO $/$ /argila (MARTINS et al., 2012).

\subsubsection{Nanocompósitos}

Há muitas inovações no campo da nanotecnologia nos últimos anos. Mais de mil produtos foram disponíveis para os consumidores em 2009 e mais de dois mil produtos foram disponíveis no mercado em 2015. Isso pode ser explicado pelas propriedades promissoras das 
nanopartículas (que têm pelo menos uma dimensão 0,1 e $100 \mathrm{~nm}$ ) e nanoprodutos que incorporam tais partículas (FIGUEIREDO et al., 2012).

O desenvolvimento de novos materiais plásticos com menor impacto ambiental tem despertado interesse nos últimos anos. Os polímeros termoplásticos reforçados com fibras reduzem o custo de produção (KOWALCZYK et al., 2011). O desenvolvimento de polímeros se deve principalmente à capacidade da engenharia modificar os plásticos e combiná-los com outros componentes (enchimentos, fibras ou nanofibras, estabilizadores, plastificantes, etc.) que são incorporadas na sua estrutura para um melhor desempenho. As principais nanopartículas utilizadas atualmente são as nanoargilas, os nanocristais de celulose e nanotubos de carbono (ROES et al., 2007; CHERIAN et al., 2011).

Assim, o interesse em nanocompósitos tem aumentado nos últimos anos devido o potencial associado com os novos grupos de materiais. Os nanocompósitos são definidos como compósitos com reforço em escala nanométrica $(<100 \mathrm{~nm})$, ou seja, pelo menos uma das fases consiste em escala nanométrica (CAMARGO et al., 2009; SIRÓ; PLACKETT, 2010; DUFRESNE, 2010; LAVOINE et al., 2012; YU et al., 2012). A definição de material contendo nanopartículas tem aumentado significativamente para incluir uma variedade de sistemas que têm pelo menos uma dimensão em escala nanométrica (1-100 nm) (CHENG et al., 2011; FORTUNATI et al., 2015). Já MARIANO et al. (2014), definem os nanocompósitos como um material sólido multifásico onde uma das fases tem um, dois, ou três dimensões em escala nanômétrica, que é inferior a $100 \mathrm{~nm}$.

Muitos trabalhos estão apresentando resultados com polímeros hidrofílicos (naturais ou sintéticos) para melhorar a dispersão e explorar o seu potencial, como também polímeros hidrofóbicos (sintéticos) conforme a Figura 2.15 (PANTHAPULAKKAL; SAIN, 2012; DUFRESNE, 2013; EL MIRI et al., 2015; MA et al., 2015; HASSAN et al., 2014; CHERIAN et al., 2011; DUFRESNE et al., 2010; FORTUNATI et al. 2015; CORRÊA et al., 2014; SPINELLA et al., 2015; MOON et al., 2011; POUR et al. 2014). 


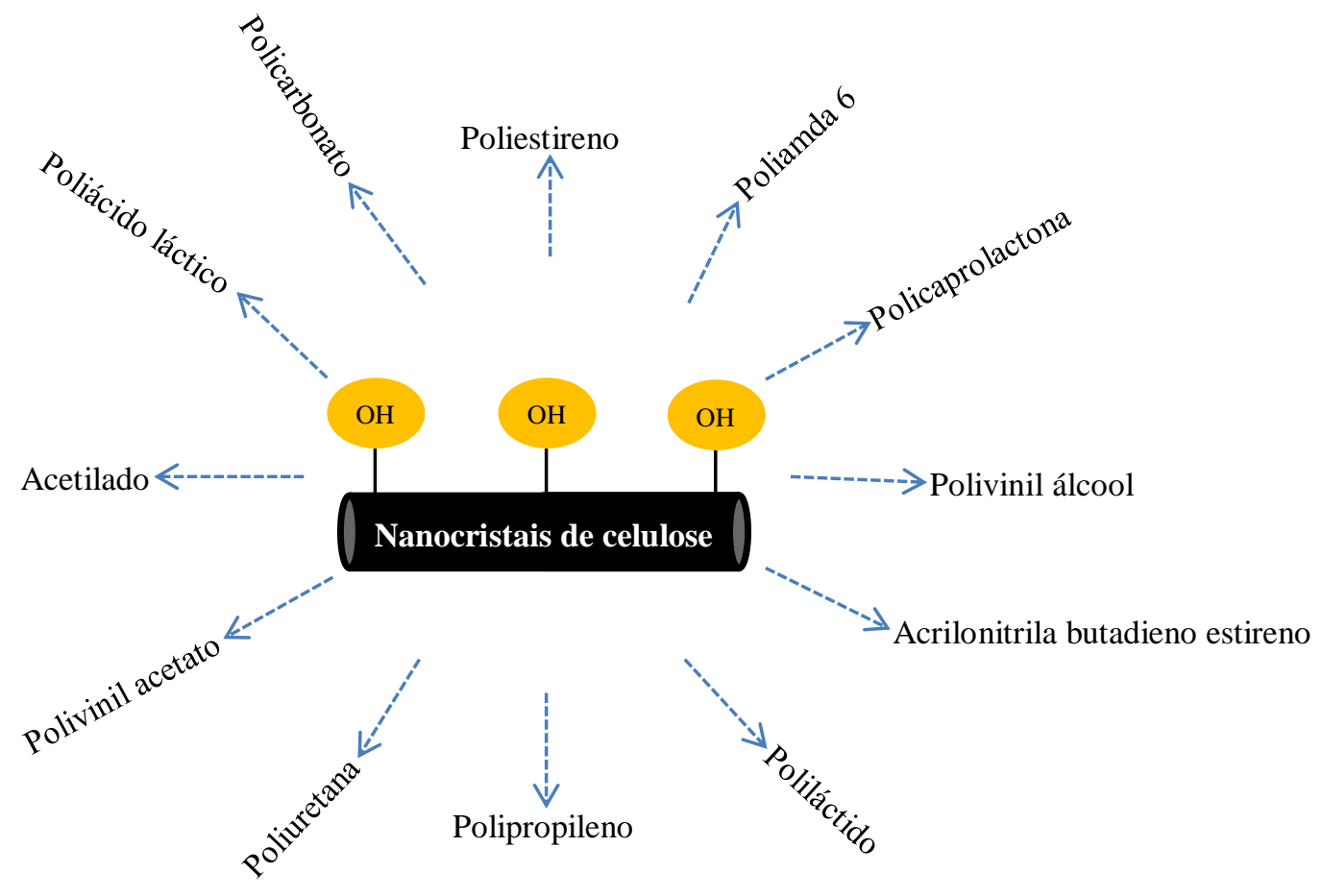

Figura 2.15: Nanocompósitos com diferentes matrizes, segundo a literatura recente.

Nanocompósitos possuem propriedades únicas, por causa do tamanho nanométrico, quando se compara os nanocompósitos com os compósitos convencionais, os nanocompósitos possuem a vantagem pelo baixo teor de carga. Os plásticos reforçados com nanocristais de celulose têm vantagens mecânicas, são melhores que os plásticos convencionais usados na automotiva, sendo 30\% mais leve e 3-4 vezes mais forte do que os plásticos atualmente utilizados na automotiva. São mais resistentes a danos causados pelo calor e produtos químicos (COCCIA et al., 2014).

As propriedades dos nanocompósitos tem relação com a pobre ou boa dispersão dos nanocristais de celulose na matriz. Uma má distribuição da nanocarga na matriz pode atuar como concentrador de tensões, podendo até agir negativamente nas propriedades do material. A distribuição está associada com a homogeneidade da amostra enquanto que a dispersão descreve a aglomeração conforme a Figura 2.16 (SCHADLER, 2003). 


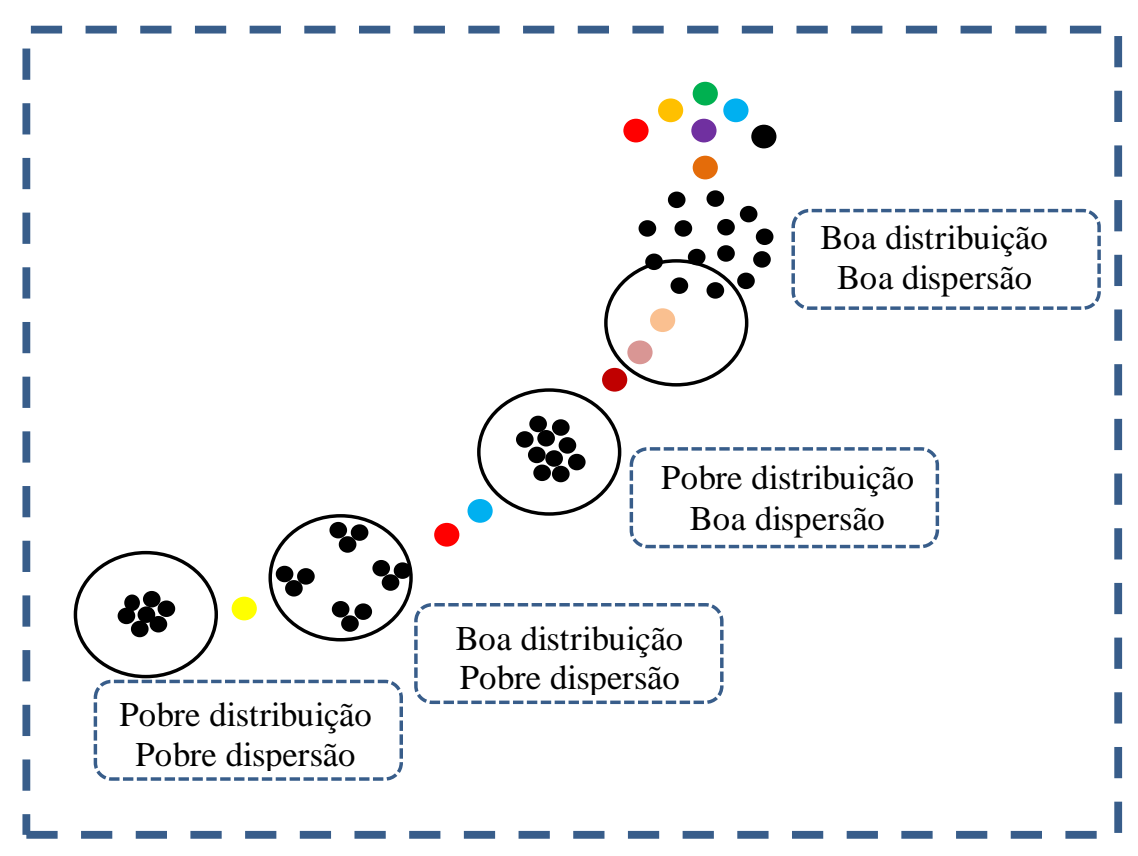

Figura 2.16: Diferença entre a distribuição e a dispersão (SCHADLER, 2003).

A modificação física por surfactante comercial pode ser uma estratégia para melhorar a dispersão dos nanocristais com solventes orgânicos e, consequentemente no polímero usado (FORTUNATI et al., 2015). A produção dos nanocompósitos com nanocristais de celulose para diversas aplicações é relativamente nova. Uma ampla gama de nanocompósitos tem sido investigada na utilização das nanofibras/nanocristais, mas existem vários problemas, tais como a dispersão dos nanocristais na matriz polimérica, especialmente quando são hidrofóbicos. Frequentemente, os métodos de obtenção usados são "casting"/evaporação, "master batch" e fusão (CHENG et al., 2011; SIRÓ; PLACKETT, 2010). A maioria das técnicas de processamento usado para preparar nanocompósitos poliméricos reforçados com nanocristais de celulose são principalmente restrito para método de processamento úmido, tais como "casting"/ evaporação, o que tem sido extensivamente reportado na literatura. A principal vantagem desta estratégia baseia-se no fato que preserva o estado de dispersão das nanopartículas em meio líquido. No entanto, isso limita o número de matrizes poliméricas que podem ser utilizadas em associação com os nanocristais de celulose. Além disso, este procedimento não é ecológico (uso de solvente), não é industrial e nem economicamente viável (MARIANO et al., 2014; EL MIRI et al., 2015). 
MA et al. (2015), utilizaram o método "master batch" que proporcionou uma maneira simples de aplicar nanocristais de celulose como reforço em uma matriz hidrofóbica (ABS). Primeiro foi preparado o "master batch" com alto teor nanocristais. O método "master batch" tem como objetivo melhorar dispersão, a estabilidade térmica e a compatibilidade entre NCC/ABS (nanocompósitos de nanocristais de celulose/ABS). Depois, os nanocompósitos foram obtidos pela mistura do master batch, o ABS e poli (estireno-co-anidrido maleico) utilizando uma extrusora de dupla rosca.

Peltola et al. (2006) utilizaram o método de fusão, aplicando uma extrusora-dupla rosca co-rotativos (ZSK 25 Werner Pfleiderer) para obter os nanocompósitos/ nanoargila. As definições da temperatura foram $170,170,170,180,180,180$ e $185^{\circ} \mathrm{C}$, respectivamente. Foram utilizadas as velocidades de parafuso de 200, 500, $1000 \mathrm{rpm}$, obtendo aumento de 10-20\% no módulo de tração em relação PP puro. Este método é o mais utilizado por não usar solvente e pela facilidade de preparo. Na obtenção de nanocompósitos, a chave para a obtenção de propriedades ótimas é a dispersão/distribuição das nanocargas na matriz polimérica. Este método é industrial, é ecológico e economicamente viável. No entanto, estas técnicas de processamento convencionais são raramente empregadas para a preparação de nanocompósitos poliméricos reforçados com nanocristais de celulose. Isto é atribuído pela incompatibilidade inerente e problemas de estabilidade térmica. Portanto, a natureza hidrofílica de celulose faz com que a aglomeração seja irreversível durante a secagem e a agregação em matrizes apolares podendo causar formações de ligações de hidrogênio adicionais entre nanopartículas (MARIANO; KISSI; DUFRESNE, 2014).

\subsection{CARACTERIZAÇÃO DOS NANOCRISTAIS E NANOCOMPÓSITOS DE NANOCRISTAIS DE CELULOSE/ABS}

\section{Caracterização por espectroscopia de infravermelho com transformada de Fourier (FTIR) das fibras e nanocristais}

A espectroscopia de infravermelho com transformada de Fourier é uma técnica de análise muito utilizada para colher espectros de infravermelho com maior rapidez (PICOLLI et al., 2006). Esta técnica é empregada para determinar de forma qualitativa e quantitativa 
características de ligações em moléculas orgânicas ou inorgânicas em amostras sólidas, líquidas ou gasosas (KING et al., 2002).

Por meio da análise de FTIR é possível identificar as bandas de absorção de energia específicas para cada ligação química, como também os grupos funcionais de cada material, pois cada grupo absorve em frequência característica de radiação na região do infravermelho (PICOLLI et al., 2006). Muitos trabalhos na literatura vêm aplicando essa técnica para a caracterização de materiais lignocelulósicos para avaliar a eficiência dos tratamentos (JIANG; HSIEH, 2013; MORAIS et al., 2013; ABRAHAM et al., 2011; LI et al., 2012; PRACELLA et al., 2014).

\section{Caracterização por difração de raios-X (DRX) dos materiais}

A difração de raios- $X$ utiliza o espalhamento coerente da radiação $X$, por estruturas organizadas (cristais), permitindo realizar estudos morfológicos em materiais, determinando sua estrutura cristalina e sua fração (percentual) cristalina. Macromoléculas e polímeros podem formar cristais da mesma forma que compostos inorgânicos e minerais (NETO et al., 2007a). Muitos trabalhos na literatura vêm aplicando essa técnica para avaliar, principalmente, o índice de cristalinidade dos materiais (CHERIAN et al., 2011; KUMAR et al., 2014; JIANG; HSIEH, 2013; MORAIS et al., 2013; ABRAHAM et al., 2011; LI et al., 2012; ARRIETA et al., 2014).

\section{Caracterização por microscopia (MEV/MET/MFA) dos materiais}

O microscópio eletrônico de varredura (MEV) é um instrumento utilizado para estudar a microestrutura e morfologia em materiais sólidos (MALISKA, 2009). Em compósitos, pode ser usada para avaliar os aspectos das fibras como comprimento, distribuição, adesão entre fibras e matriz e caracterização morfológica das fibras "in natura" ou tratadas. Muitos trabalhos na literatura vêm aplicando essa técnica para a caracterização morfológica de fibras, nanocompósitos e compósitos (JIANG; HSIEH, 2013; NAHLA et al., 2015; ABRAHAM et al., 2011; MANDAL; CHAKRABARTY, 2011; KOWALCZYK et al., 2011; PRACELLA et al., 2014).

O microscópio eletrônico de transmissão (MET) é uma técnica que fornece informações em nível superficial ou atômico, como por exemplo, morfologia (tamanho e forma dos 
constituintes da amostra), composição química, informações cristalográficas e as interrelações destas características com as propriedades macroscópicas e de interesse tecnológico dos materiais. A aplicação mais comum está na simples obtenção de imagens da microestrutura e padrões de sistemas cristalinos (CORREA, 2007a). Muitos trabalhos na literatura vêm aplicando esta técnica para conhecer, principalmente, o comprimento e diâmetro das nanopartículas (JIANG; HSIEH, 2013; MORAIS et al., 2013; LI et al., 2012; MANDAL; CHAKRABARTY, 2011; ARRIETA et al., 2014).

A microscopia de força atômica (MFA) é um dos melhores métodos para caracterizar os nanocristais de celulose, porque pode-se obter informações sobre o diâmetro, comprimento e forma dos nanocristais de celulose (EL MIRI et al., 2015). Muitos trabalhos na literatura vêm aplicando essa técnica para conhecer principalmente a superfície, o comprimento e diâmetro do material (JIANG; HSIEH, 2013; NAHLA et al., 2015; MANDAL; CHAKRABARTY, 2011; FRONE et al., 2013; ARRIETA et al., 2014).

\section{Caracterização por análise térmica (TGA/DTG/DSC/DMA) dos materiais}

A análise térmica abrange um grupo de técnicas, onde as propriedades físicas de uma substância e/ou de seus produtos de reação são medidas em função da temperatura e/ou tempo, enquanto essa substância é submetida a um controle de temperatura programado (ARAUJO et al., 2006).

A investigação térmica por TGA e DSC tem sido realizada para identificar modificações químicas e físicas em materiais poliméricos, lignocelulósicos, entre outros materiais. Algumas das alterações físicas têm sido determinadas por meio de DSC como cristalização, ponto de fusão, capacidade calorífica e calor de reação. As mudanças químicas podem ser polimerização, oxidação e degradação térmica ou oxidativa. A técnica de TGA tem sido utilizada na caracterização de degradação térmica ou estabilidade térmica que o material apresenta quando submetido a uma variação de temperatura (KUMAR et al., 2011). Os módulos dinâmicos de armazenamento e perda e amortecimento (tan $\delta$ ), gerados pela aplicação de ensaios dinâmicomecânicos em função da temperatura (DMA), são determinados, como também a energia de ativação necessária para as moléculas começarem a se movimentar (Tg) (MOTHÉ; MIRANDA, 2009). 
A análise termogravimétrica é uma técnica na qual a diferença de massa de uma amostra (perda ou ganho) é determinada em função da temperatura e/ou tempo, enquanto a amostra é submetida a uma variação de temperatura programada (SILVA et al., 2007; HATAKEYAMA; LIU, 2000). A análise termogravimétrica (TGA) e a sua derivada (DTG) fornecem informações sobre a natureza e a extensão da degradação do material. Em trabalhos recentes, essa técnica foi empregada no estudo da caracterização das fibras e polímeros para conhecer a temperatura de degradação da celulose, hemicelulose, lignina, extrativos e ABS conforme a Figura 2.17 (MOTHÉ; MIRANDA, 2009; MA et al., 2015).
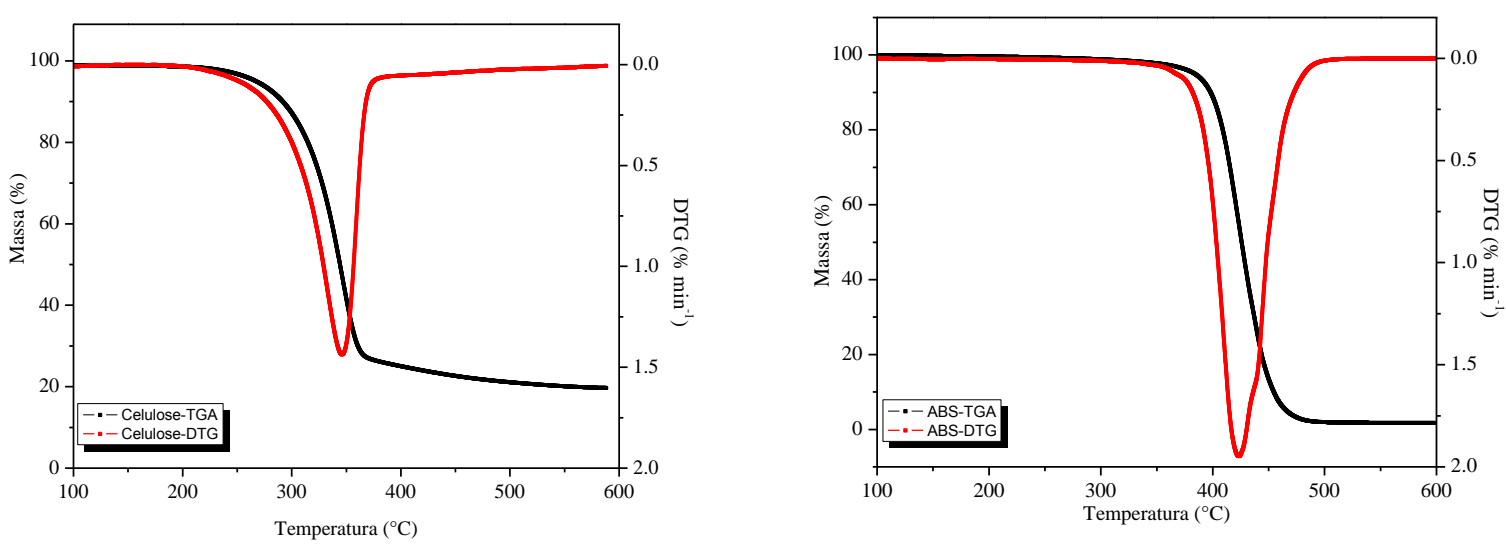

Figura 2.17: Curvas de TGA/DTG da celulose e ABS.

A interface entre TGA/FTIR proporciona a capacidade de monitorar a evolução de gases em tempo real das amostras. Dessa forma, foi utilizado um instrumento de interface Thermo Scientific TGA/FTIR, esta integração permite que os gases provenientes da TGA sejam conduzidos através de uma linha de transferência aquecida. Os gases passam por dentro de uma célula de fluxo da interface TGA-IR, onde os espectros de infravermelho são recolhidos. A célula de gás é niquelada, célula de gás de alumínio, $100 \mathrm{~mm}$ de comprimento e volume interno de $23 \mathrm{~mL}$ com janelas de $\mathrm{KBr}$, capaz de suportar temperaturas de até $325^{\circ} \mathrm{C}$. A linha de transferência de vidro revestido de aço inoxidável é conectada diretamente ao tubo do forno TGA, proporcionando uma passagem de gases totalmente inerte para a célula de gás. Yang et al. (2007), utilizou esta técnica para determinar os componentes voláteis da celulose, hemicelulose e e lignina. 
Em trabalhos recentes, essa técnica foi utilizada com objetivo de conhecer os picos de temperatura das entalpias envolvidas nos processos para as fibras, nanocristais de celulose e para os nanocompósitos de nanocristais de celulose/ABS (MOTHÉ; MIRANDA, 2009; MORAIS et al., 2013; ABRAHAM et al., 2011; LI et al., 2012; MANDAL; CHAKRABARTY, 2011; KOWALCZYK et al., 2011; PRACELLA et al., 2014; FRONE et al., 2013; ARRIETA et al., 2014).

A DMA é uma técnica que tem sido amplamente usada para caracterização de polímeros através da detecção dos processos de relaxação, tanto macroscópico como molecular, por apresentar sensibilidade superior (por volta de três ordens de grandeza) quando comparada com as técnicas convencionais de análise térmica. Está técnica fornece informações sobre as propriedades viscoelásticas, podendo ser usadas de três modos de cargas: compressão, tração e cisalhamento. Por meio dessa técnica, pode-se obter informações sobre o módulo elástico ( $\left.E^{\prime}\right)$, o módulo de dissipação viscosa (E") e do amortecimento mecânico ( $\left.\tan \delta=E^{\prime \prime} / E^{\prime}\right)$ de um material, quando sujeito a uma solicitação mecânica. Todos os polímeros são viscoelásticos, isto é, apresentam quando deformados um comportamento simultâneo dos matérias elásticos e plásticos (CANEVAROLO, 2007). As propriedades viscoelásticas são dependentes do tempo (ou frequência) e da temperatura. Muitos trabalhos na literatura vêm aplicando essa técnica para conhecer o comportamento dos polímeros (KOWALCZYK et al., 2011; MOTHÉ; MIRANDA, 2009; PRACELLA et al., 2014).

\section{Propriedades mecânicas}

Os resultados de ensaios de tração e flexão são obtidos por meio das curvas do tipo tensão versus deformação. Os ensaios são realizados por meio de aplicação de uma solicitação ao material sob condições controladas, geralmente deformação a velocidade constante, até a ruptura do material (CANTO; PESSAN, 2007; NETO, 2007b). E para medir a carga aplicada continuamente é utilizado a célula de carga e para as elongações é utilizado um extensômetro (CALLISTER, 2012)

A partir das informações obtidas, estas são usadas na pesquisa e no desenvolvimento dos materiais por caracterização quantitativa. É importante ressaltar que a resistência de uma amostra 
depende de sua capacidade de suportar uma carga sem deformação ou ruptura (HIBBELER, 2010).

Nos ensaios de flexão, as curvas obtidas são do tipo tensão sob flexão e deformação sob flexão (CANTO; PESSAN, 2007; NETO, 2007b). A resistência à flexão é a máxima tensão de flexão sofrida pelo corpo de prova durante teste de flexão ASTM D 790 (2003). Muitos trabalhos na literatura vêm aplicando essas técnicas para conhecer as propriedades mecânicas dos materiais poliméricos (NAHLA et al., 2015; FORTUNATI et al., 2015).

Os ensaios de impacto estão relacionados com a carga aplicada, como um impacto instantâneo de um martelo de pêndulo balanceado que é liberado de uma posição elevada que se encontra a uma altura fixa (h). O corpo de prova fica posicionado na base, com a liberação do martelo, uma aresta em forma de faca montada sobre o pêndulo atinge e fratura o corpo de prova exatamente no entalhe, que atua como um ponto de concentração de tensões para este impacto de alta velocidade. O pêndulo continua, elevando-se até uma altura máxima (h'), que é inferior a (h) e a absorção de energia, é determinada partir da diferença entre (h) e (h'), representa uma medida da energia do impacto conforme a Figura 2.18 (CALLISTER, 2012).

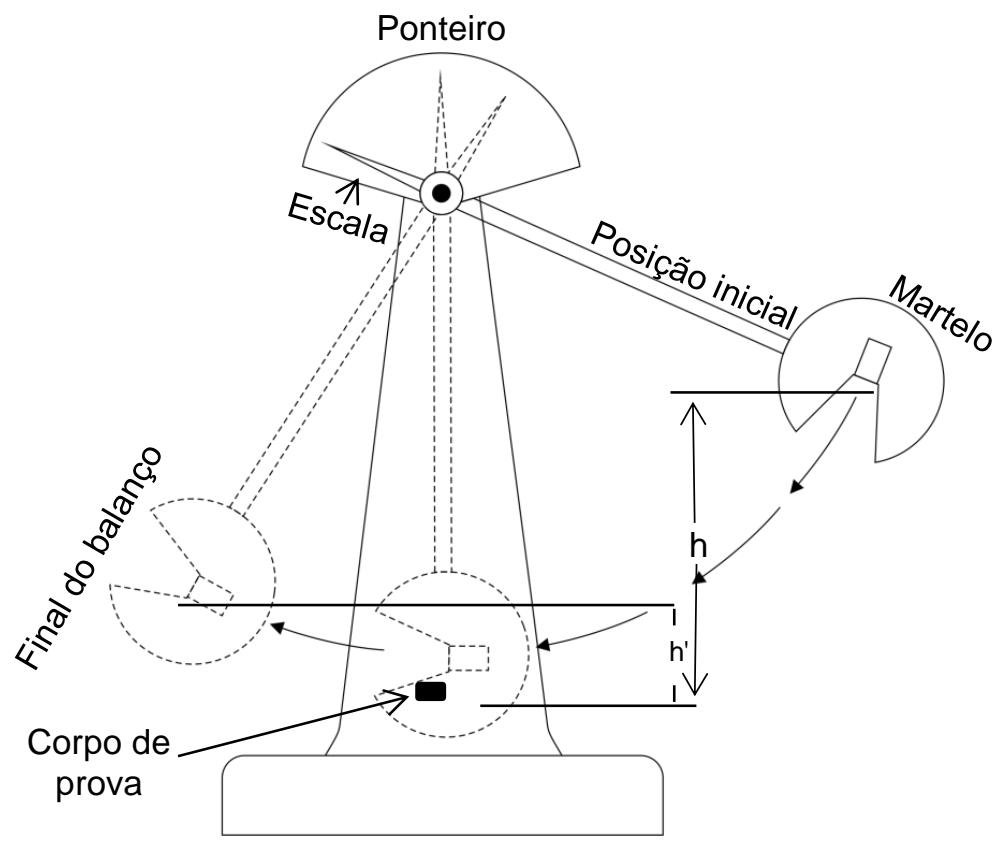

Figura 2.18: Máquina de ensaio de impacto (CALLISTER, 2012). 


\section{Reologia}

O fluxo de sistemas de polímeros (fusão e solução) tem fascinado a reologia nos últimos anos. Estes sistemas apresentam geralmente propriedades viscoelásticas, deste modo, têm atraído à atenção dos pesquisadores (BARNES, 2000). Portanto, é de suma importância avaliar o comportamento viscoelástico de materiais poliméricos, não apenas como forma de se obter condições otimizadas de processamento, mas também, para conhecer valiosas informações sobre o mecanismo de escoamento e seu efeito sobre a morfologia e as propriedades mecânicas (GUIMARÕES et al., 2003).

Esta técnica estuda o fluxo e a deformação dos materiais. Para este estudo, são aplicadas tensões ou deformações do material e suas respostas são analisadas. Ou seja, as relações entre tensão e deformação constituem as chamadas equações reológicas de estado, que representam as propriedades reológicas do material. Este tipo de técnica permite estudar a estrutura microscópica de sistemas poliméricos com maior precisão, além de estudar processamento destes materiais. Durante o processamento de polímeros fundidos encontramos fluxos de cisalhamento, ou seja, dentro da matriz da extrusora, nas cavidades de um molde de injeção e na calandragem.

Deste modo, se as taxas de cisalhamento forem baixas nestes processos, estes reômetros permitirão simular o comportamento dos mesmos sob mesmas condições. A temperatura é o parâmetro que mais influencia as propriedades reológicas dos polímeros (BRETAS; SCURACCHIO, 2007). Muitos trabalhos na literatura vêm aplicando essa técnica para conhecer propriedades reológicas de nanocompósitos poliméricos. Os valores de viscosidade complexa $\left(\eta^{*}\right)$, módulo de armazenamento $\left(G^{\prime}\right)$, módulo de perda $\left(G^{\prime \prime}\right)$, foram calculados por meio de um programa específico do equipamento (LI et al., 2012; JIN, et al. 2015; GUIMARÕES et al., 2003). 


\section{CAPÍTULO 2}

\section{PARTE EXPERIMENTAL}

O fluxograma da Figura 3.1 descreve de maneira geral todas as etapas de obtenção e caracterização dos materiais desenvolvidos. A seguir, será descrito detalhadamente cada procedimento experimental empregado. A fibra de bagaço de cana-de-açúcar utilizada no trabalho foi gentilmente fornecida pela Usina Ester (classificadas em tipo B3 > $15 \mathrm{~mm}$ e medula < $3 \mathrm{~mm}$ (pó)) localizada em Cosmópolis - SP. O ABS (Terluran GP 35 com fluidez de $34 \mathrm{~g} / 10$ ') utilizado como matriz neste trabalho foi gentilmente fornecido pela Universidade de Caxias do Sul.

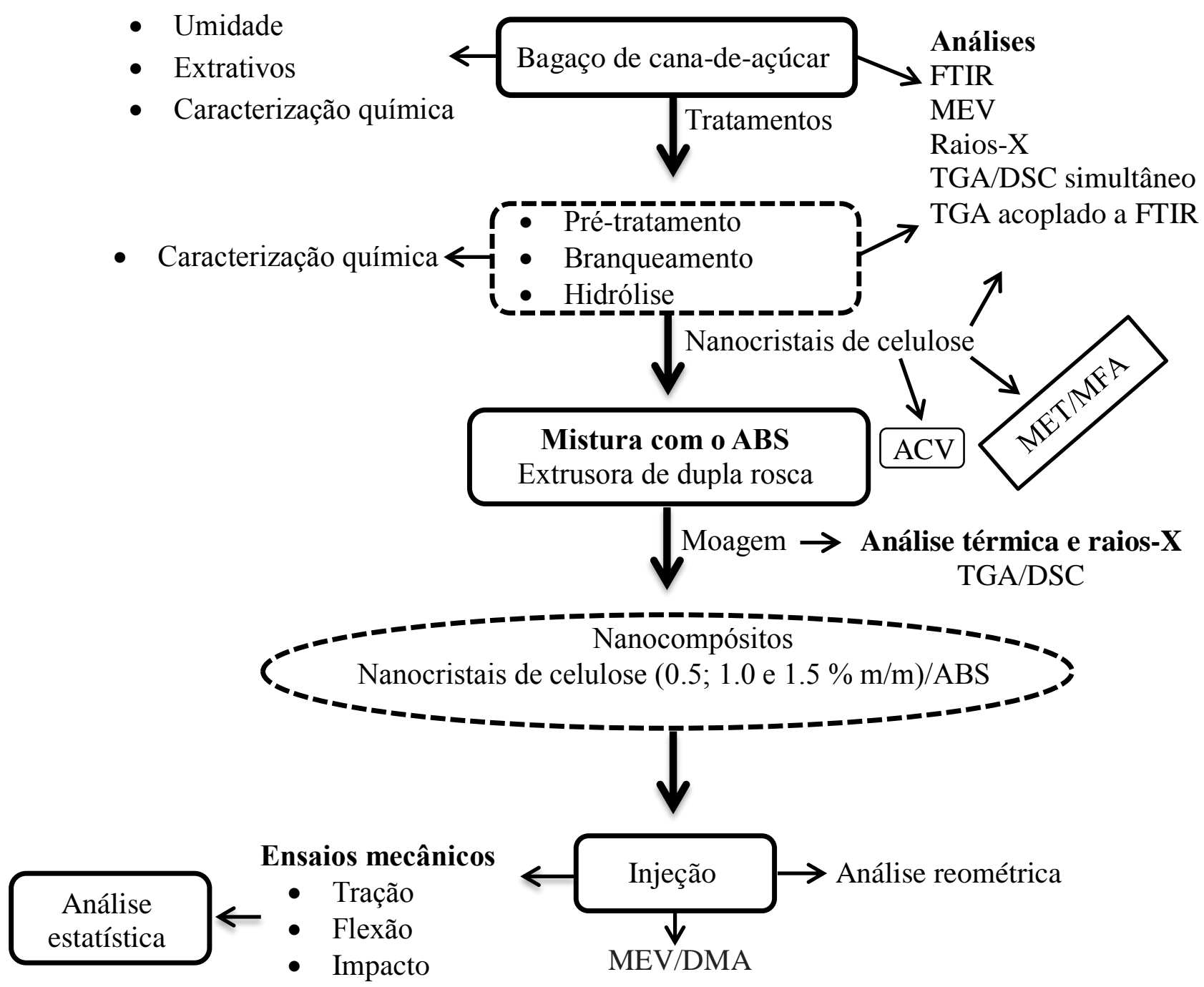

Figura 3.1: Fluxograma esquemático da metodologia empregada neste trabalho. 


\subsection{CARACTERIZAÇÃO DAS FIBRAS DE BAGAÇO DE CANA-DE-AÇÚCAR}

As amostras para determinação dos teores de umidade e extrativos foram preparadas de acordo com a norma ABNT (NBR 6923), em triplicata. O bagaço de cana-de-açúcar e as fibras de cada fase de tratamento foram preparadas de acordo com a norma ASTM 2 ASTM M e ASTM C, em duplicata, para determinar a composição química (celulose, hemicelulose e lignina), realizado na faculdade do Gama - UnB (Laboratório de tecnologias em biomassa) (MORAIS; ROSA; MARCONCINI, 2010).

\subsubsection{Determinação de umidade}

Primeiramente as fibras de bagaço de cana-de açúcar foram mantidas ao ar livre por 7 dias. Logo depois, colocaram-se em um pesa filtro cerca de $2 \mathrm{~g}$ de fibra. Posteriormente as fibras foram secas em estufa a uma temperatura de $105^{\circ} \mathrm{C}$ por 24 horas. Após resfriadas em dessecador, as fibras foram pesadas até massa constante. $\mathrm{O}$ teor de umidade de equilíbrio foi calculado utilizando a equação 3.1.

$$
\text { Umidade (TU\%) }=\frac{P_{a r}-P_{e s t}}{P_{a r}} \times 100,
$$

Onde $\mathrm{P}_{\mathrm{ar}}$ é o peso das fibras em temperatura ambiente; $\mathrm{P}_{\text {est }}$ é o peso das fibras após secagem em estufa e TU é o teor de umidade.

\subsubsection{Teor de extrativos das fibras de bagaço de cana-de-açúcar}

Pesou-se $2 \mathrm{~g}$ de fibras que foram submetidas à extração com acetona por Soxhlet. As amostras foram extraídas por aproximadamente $4 \mathrm{~h}$ e, logo depois foram levadas à estufa para secagem a $105^{\circ} \mathrm{C}$ por $24 \mathrm{~h}$, até peso constante. $\mathrm{O}$ teor de extrativos foi calculado pela equação 3.2 .

$$
\text { Extrativos }(\mathrm{TE} \%)=\frac{\mathrm{MRE}-\mathrm{MRRS}}{\mathrm{MA}} \times 100,
$$


Onde MA é a massa da amostra, MRE, a massa do conjunto recipiente/extrativos; MRRS, massa do conjunto recipiente/resíduo de solvente e TE é o teor de extrativos.

\subsubsection{Caracterização química das fibras de bagaço de cana-de-açúcar: hemicelulose, celulose e lignina}

Holocelulose: Em um Erlenmeyer de $500 \mathrm{~mL}$ foi colocado cerca de $3 \mathrm{~g}$ de bagaço de cana-deaçúcar, $120 \mathrm{~mL}$ de água destilada e uma barra magnética para a agitação. Acrescentou-se no Erlenmeyer 2,5 g de clorito de sódio com pureza de $80 \%$ e $1 \mathrm{~mL}$ de ácido acético glacial com pureza $\geq 99,85 \%$. O conjunto foi tampado e colocado em banho de glicerina a temperatura constante de $70 \pm 2{ }^{\circ} \mathrm{C}$ por uma hora. Após este tempo foi adicionado $2,5 \mathrm{~g}$ de clorito de sódio e $1 \mathrm{~mL}$ de ácido acético glacial. Aguardou-se por mais uma hora e adicionou-se uma nova etapa de 2,5 g de clorito de sódio e $1 \mathrm{~mL}$ de ácido acético glacial, prosseguindo com o aquecimento em banho de glicerina por mais 3 horas, totalizando no final 5 horas de aquecimento. Após este tempo, colocou-se este conjunto em banho de gelo por 30 minutos. Logo depois, filtrou-se e lavou-se (até pH neutro). Seguindo a metodologia da ASTM 2, o conjunto foi levado à estufa a $105 \pm 2{ }^{\circ} \mathrm{C}$ por 18 horas. $\mathrm{O}$ teor de holocelulose foi calculado seguindo a equação 3,3 .

$$
\text { Holocelulose }(\mathrm{TH} \%)=\frac{\mathrm{MFC}-\mathrm{MF}}{\mathrm{MA}} \times 100 \text {, }
$$

Onde MFC é a massa do funil seco + holocelulose, MF, massa do funil seco; MA, massa da amostra e TH é o teor de holocelulose.

$\alpha$-celulose: Cerca de $1 \mathrm{~g}$ de holocelulose seca foi colocado em um almofariz e adicionou $15 \mathrm{~mL}$ de solução de $\mathrm{NaOH} 17.5 \%$ (m/v). Após 2 min de espera, a amostra foi triturada por 8 min. Á mistura foi então adicionado $40 \mathrm{~mL}$ de água destilada e transferiu-se o conteúdo para o funil, logo depois, filtrou e lavou (até $\mathrm{pH}$ neutro) depois foram colocados na estufa a $105 \pm 2{ }^{\circ} \mathrm{C}$ por 18 horas, de acordo com a norma ASTM tipo M. O teor de celulose foi calculado seguindo a equação 3.4 .

$$
\text { celulose }(\mathrm{T} \alpha \%)=\frac{\mathrm{MFC}-\mathrm{MF}}{\mathrm{MAH}} \times 100
$$


Onde MFC é a massa funil seco + massa da $\alpha$-celulose; MF, massa funil seco, MAH, massa da holocelulose e T $\alpha$ é o teor de $\alpha$-celulose.

Lignina: Cerca de $1 \mathrm{~g}$ de amostra seca, foi colocada em um almofariz e adicionou-se $17 \mathrm{~mL}$ de uma solução de $\mathrm{H}_{2} \mathrm{SO}_{4}$ a $72 \%(\mathrm{~m} / \mathrm{m})$ e resfriado 10 a $15^{\circ} \mathrm{C}$. Após 15 min de agitação com pistilo, aguardou por 24 horas. Logo depois, adicionou-se $306 \mathrm{~mL}$ de água destilada e o conteúdo foi transferido para um balão de fundo redondo de $500 \mathrm{~mL}$ conectado a um condensador simples, e manteve-se sob aquecimento e refluxo por $4 \mathrm{~h}$. A amostra foi então filtrada, lavada (até pH neutro) e levada à estufa a $105 \pm 2{ }^{\circ} \mathrm{C}$ por 3 horas de acordo com a norma ASTM tipo C. O teor de lignina segue a equação 3.5 .

$$
\text { Lignina }(\mathrm{TL} \%)=\frac{\mathrm{MFC}-\mathrm{MF}}{\mathrm{MA}} \times 100,
$$

Onde MFC é a massa funil seco + massa da lignina, MF, massa funil seco; MA, massa da amostra e TL é o teor de lignina.

\subsection{OBTENÇÃO E CARACTERIZAÇÃO DAS FIBRAS E DOS NANOCRISTAIS DE CELULOSE A PARTIR DAS FIBRAS DE BAGAÇO DE CANA-DE-AÇÚCAR}

Este método fundamenta-se na obtenção dos nanocristais a partir das fibras de bagaço de cana-de-açúcar, comparando diversas metodologias da literatura: tratamento alcalino, branqueamento e hidrólise ácida realizado na faculdade do Gama - UnB (Laboratório de tecnologias em biomassa) e caracterização das fibras e nanocristais de celulose por FTIR, difração de raios-X, MET, MEV, MFA, TGA/DSC e TGA/FTIR (ROSA et al., 2010; CAMPOS et al., 2013; TEIXEIRA et al., 2011; BRÍGIDA et al., 2010; JONOOBI; MATHEW; OKSMAN, 2012; MORAIS et al., 2013).

\section{Pré-tratamentos das fibras de bagaço de cana-de-açúcar seguido de hidrólise ácida}

As fibras foram pré-tratadas, seguidas de branqueamento (realizado sob duas formas: um estágio de branqueamento ou quatro estágios de branqueamento), conforme a Tabela 3.1. 
Tabela 3.1: Sequências de tratamentos para as fibras de bagaço de cana-de-açúcar e a extração dos nanocristais de celulose.

\begin{tabular}{|c|c|c|c|c|}
\hline Processos & Amostras & Condições & Resultados & Siglas \\
\hline \multirow{3}{*}{ 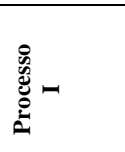 } & $\begin{array}{l}\text { Fibras de bagaço de cana-de- } \\
\text { acúcar }\end{array}$ & $\mathrm{NaOH} 5 \%(\mathrm{~m} / \mathrm{v}) ; 80^{\circ} \mathrm{C} / 1 \mathrm{~h}$ & Bagaço pré-tratado & BPTI \\
\hline & Pré-tratamento do bagaço & $\begin{array}{l}\mathrm{NaClO}_{2} 1 \%(\mathrm{~m} / \mathrm{v})+10 \text { gotas }\left(\mathrm{C}_{2} \mathrm{H}_{4} \mathrm{O}_{2}\right) \\
90^{\circ} \mathrm{C} / 1 \mathrm{~h} \text { (quatro estágios de branqueamento) }\end{array}$ & Polpa branqueada & PBI \\
\hline & Polpa branqueada & $\mathrm{H}_{2} \mathrm{SO}_{4} 64 \%(\mathrm{~m} / \mathrm{m}) ; 45^{\circ} \mathrm{C} / 1 \mathrm{~h}$ hidrólise ácida & Nanocristais de celulose & $\mathrm{NCC} 1$ \\
\hline \multirow{3}{*}{ 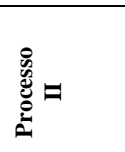 } & $\begin{array}{l}\text { Fibras de bagaço de cana-de- } \\
\text { açúcar }\end{array}$ & $\mathrm{NaOH} 5 \%(\mathrm{~m} / \mathrm{v}) ; 80^{\circ} \mathrm{C} / 1 \mathrm{~h}$ & Bagaço pré-tratado & BPTII \\
\hline & Pré-tratamento do bagaço & $\begin{array}{l}\mathrm{NaClO}_{2} 1 \%(\mathrm{~m} / \mathrm{v})+10 \text { gotas }\left(\mathrm{C}_{2} \mathrm{H}_{4} \mathrm{O}_{2}\right) \\
90^{\circ} \mathrm{C} / 1 \mathrm{~h} \text { (um estágio de branqueamento) }\end{array}$ & Polpa branqueada & PBII \\
\hline & Polpa branqueada & $\mathrm{H}_{2} \mathrm{SO}_{4} 64 \%(\mathrm{~m} / \mathrm{m}) 45^{\circ} \mathrm{C} / 30 \mathrm{~min}$ hidrólise ácida & Nanocristais de celulose & NCCII \\
\hline \multirow{3}{*}{ 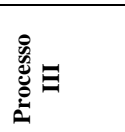 } & $\begin{array}{l}\text { Fibras de bagaço de cana-de- } \\
\text { açúcar }\end{array}$ & $\begin{array}{l}\mathrm{NaClO}_{2} 2 \%(\mathrm{~m} / \mathrm{v})+10 \text { gotas }\left(\mathrm{C}_{2} \mathrm{H}_{4} \mathrm{O}_{2}\right) \text { temperatura ambiente } \\
\text { /4h (quatro estágios de branqueamento) }\end{array}$ & Bagaço pré-tratado & BPTIII \\
\hline & Pré-tratamento do bagaço & $\mathrm{NaOH} 4 \%(\mathrm{w} / \mathrm{v}) ;$ ) temperatura ambiente $/ 4 \mathrm{~h}$ & Polpa branqueada & PBIII \\
\hline & Polpa branqueada & $\mathrm{H}_{2} \mathrm{SO}_{4} 64 \%(\mathrm{~m} / \mathrm{m}) 45^{\circ} \mathrm{C} / 30 \mathrm{~min}$ hidrólise ácida & Nanocristais de celulose & NCCIII \\
\hline \multirow{3}{*}{ 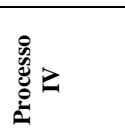 } & $\begin{array}{l}\text { Fibras de bagaço de cana-de- } \\
\text { açúcar }\end{array}$ & $\begin{array}{l}\mathrm{NaClO}_{2} 2 \%(\mathrm{~m} / \mathrm{v})+10 \text { gotas }\left(\mathrm{C}_{2} \mathrm{H}_{4} \mathrm{O}_{2}\right) \\
90^{\circ} \mathrm{C} / 1 \mathrm{~h} \text { (quatro estágios de branqueamento) }\end{array}$ & Bagaço pré-tratado & \\
\hline & Pré-tratamento do bagaço & $\mathrm{NaOH} 2 \%(\mathrm{~m} / \mathrm{v}) ; 80^{\circ} \mathrm{C} / 1 \mathrm{~h}$ & Polpa branqueada & PBIV \\
\hline & Polpa branqueada & $\mathrm{H}_{2} \mathrm{SO}_{4} 64 \%(\mathrm{~m} / \mathrm{m}) 45^{\circ} \mathrm{C} / 30 \mathrm{mim}$ hidrólise ácida & Nanocristais de celulose & NCCIV \\
\hline \multirow{3}{*}{ 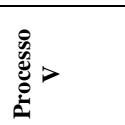 } & $\begin{array}{l}\text { Fibras de bagaço de cana-de- } \\
\text { açúcar }\end{array}$ & $\begin{array}{l}\mathrm{NaClO}_{2} 2 \%(\mathrm{~m} / \mathrm{v})+10 \text { gotas }\left(\mathrm{C}_{2} \mathrm{H}_{4} \mathrm{O}_{2}\right) \\
90^{\circ} \mathrm{C} / 1 \mathrm{~h} \text { (um estágio de branqueamento) }\end{array}$ & Bagaço pré-tratado & BPTV \\
\hline & Pré-tratamento do bagaço & $\mathrm{NaOH} 2 \%(\mathrm{~m} / \mathrm{v}) ; 80^{\circ} \mathrm{C} / 1 \mathrm{~h}$ & Polpa branqueada & PBV \\
\hline & Polpa branqueada & $\mathrm{H}_{2} \mathrm{SO}_{4} 64 \%(\mathrm{~m} / \mathrm{m}) 45^{\circ} \mathrm{C} / 30 \mathrm{~min}$ hidrólise ácida & Nanocristais de celulose & $\mathrm{NCCV}$ \\
\hline \multirow{4}{*}{ 递市 } & $\begin{array}{l}\text { Fibras de bagaço de cana-de- } \\
\text { açúcar }\end{array}$ & $\mathrm{NaOH} 5 \%(\mathrm{~m} / \mathrm{v}) ; 80^{\circ} \mathrm{C} / 1 \mathrm{~h}$ & Bagaço pré-tratado & BPTVI \\
\hline & Pré-tratamento do bagaço & $\begin{array}{l}\mathrm{NaClO}_{2} 3.3 \%(\mathrm{~m} / \mathrm{v})+10 \text { gotas }\left(\mathrm{C}_{2} \mathrm{H}_{4} \mathrm{O}_{2}\right) \\
90^{\circ} \mathrm{C} / 1 \mathrm{~h} \text { (quatro estágios de branqueamento) }\end{array}$ & Polpa branqueada & PBVI \\
\hline & & $\mathrm{HNO}_{3}(1 \mathrm{M}) ; 80^{\circ} \mathrm{C} / 1 \mathrm{~h}$ & & NCCVI \\
\hline & Polpa branqueada & $\mathrm{H}_{2} \mathrm{SO}_{4} 64 \%(\mathrm{~m} / \mathrm{m}) ; 45^{\circ} \mathrm{C} / 1 \mathrm{~h}$ - hidrólise ácida & Nanocristais de celulose & \\
\hline \multirow{4}{*}{ 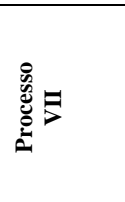 } & $\begin{array}{l}\text { Fibras de bagaço de cana-de- } \\
\text { açúcar }\end{array}$ & $\mathrm{NaOH} 5 \%(\mathrm{~m} / \mathrm{v}) ; 80^{\circ} \mathrm{C} / 1 \mathrm{~h}$ & Bagaço pré-tratado & BPTVII \\
\hline & Pré-tratamento do bagaço & $\begin{array}{l}\mathrm{NaClO}_{2} 3.3 \%(\mathrm{~m} / \mathrm{v})+10 \text { gotas }\left(\mathrm{C}_{2} \mathrm{H}_{4} \mathrm{O}_{2}\right) \\
90^{\circ} \mathrm{C} / 1 \mathrm{~h} \text { (um estágio de branqueamento) }\end{array}$ & Polpa branqueada & PBVII \\
\hline & & $\mathrm{HNO}_{3}(1 \mathrm{M}) ; 80^{\circ} \mathrm{C} / 1 \mathrm{~h}$ & & NCCVII \\
\hline & Polpa branqueada & $\mathrm{H}_{2} \mathrm{SO}_{4} 64 \%(\mathrm{~m} / \mathrm{m}) ; 45^{\circ} \mathrm{C} / 1 \mathrm{~h}$ - hidrólise ácida & Nanocristais de celulose & \\
\hline \multirow{3}{*}{ 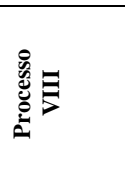 } & $\begin{array}{l}\text { Fibras de bagaço de cana-de- } \\
\text { açúcar }\end{array}$ & $\mathrm{NaOH} 5 \%(\mathrm{~m} / \mathrm{v}) ; 80^{\circ} \mathrm{C} / 1 \mathrm{~h}$ & Bagaço pré-tratado & BPTVIII \\
\hline & Pré-tratamento do bagaço & $\begin{array}{l}\mathrm{NaClO}_{2} 3.3 \%(\mathrm{~m} / \mathrm{v})+10 \text { gotas }\left(\mathrm{C}_{2} \mathrm{H}_{4} \mathrm{O}_{2}\right) \\
90^{\circ} \mathrm{C} / 1 \mathrm{~h} \text { (quatro estágios de branqueamento) } \\
\mathrm{HNO} 3(0.05 \mathrm{M}) ; 80^{\circ} \mathrm{C} / 1 \mathrm{~h}\end{array}$ & Polpa branqueada & PBVIII \\
\hline & Polpa branqueada & $\mathrm{H}_{2} \mathrm{SO}_{4} 64 \%(\mathrm{~m} / \mathrm{m}) ; 45^{\circ} \mathrm{C} / 30 \mathrm{~min}$ - hidrólise ácida & Nanocristais de celulose & NCCVIII \\
\hline \multirow{3}{*}{ 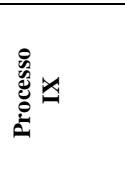 } & $\begin{array}{l}\text { Fibras de bagaço de cana-de- } \\
\text { açúcar }\end{array}$ & $\mathrm{NaOH} 5 \%(\mathrm{~m} / \mathrm{v}) ; 80^{\circ} \mathrm{C} / 1 \mathrm{~h}$ & Bagaço pré-tratado & BPTIX \\
\hline & Pré-tratamento do bagaço & $\begin{array}{l}\mathrm{NaClO}_{2} 3.3 \%(\mathrm{~m} / \mathrm{v})+10 \text { gotas }\left(\mathrm{C}_{2} \mathrm{H}_{4} \mathrm{O}_{2}\right) \\
90^{\circ} \mathrm{C} / 1 \mathrm{~h}(\text { um estágio de branqueamento }) \\
\mathrm{HNO}(0.05 \mathrm{M}) ; 80^{\circ} \mathrm{C} / 1 \mathrm{~h}\end{array}$ & Polpa branqueada & PBIX \\
\hline & Polpa branqueada & $\mathrm{H}_{2} \mathrm{SO}_{4} 64 \%(\mathrm{~m} / \mathrm{m}) ; 45^{\circ} \mathrm{C} / 30 \mathrm{~min}$ - hidrólise ácida & Nanocristais de celulose & NCCIX \\
\hline \multirow{3}{*}{ 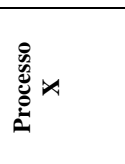 } & $\begin{array}{l}\text { Fibras de bagaço de cana-de- } \\
\text { açúcar }\end{array}$ & $\begin{array}{l}\mathrm{NaOH} 25 \%(\mathrm{~m} / \mathrm{v})+\mathrm{C}_{14} \mathrm{H}_{8} \mathrm{O}_{2} 19.37 \%(\mathrm{~m} / \mathrm{m}) 80^{\circ} \mathrm{C} / 3.5 \mathrm{~h}- \\
\text { antraquinona }\end{array}$ & Bagaço pré-tratado & BPTVX \\
\hline & Pré-tratamento do bagaço & $\begin{array}{l}\mathrm{H}_{2} \mathrm{O}_{2} 30 \%(\mathrm{~m} / \mathrm{v})+\mathrm{NaOH} 0.1 \%(\mathrm{~m} / \mathrm{v}) \\
90^{\circ} \mathrm{C} / 1 \mathrm{~h} \text { (quatro estágios de branqueamento) }\end{array}$ & Polpa branqueada & PBX \\
\hline & Polpa branqueada & $\mathrm{H}_{2} \mathrm{SO}_{4} 64 \%(\mathrm{~m} / \mathrm{m}) ; 45^{\circ} \mathrm{C} / 30 \mathrm{~min}$ - hidrólise ácida & Nanocristais de celulose & NCCX \\
\hline \multirow{4}{*}{ 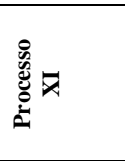 } & $\begin{array}{l}\text { Fibras de bagaço de cana-de- } \\
\text { açúcar }\end{array}$ & $\begin{array}{l}\mathrm{NaOH} 25 \%(\mathrm{~m} / \mathrm{v})+\mathrm{C}_{14} \mathrm{H}_{8} \mathrm{O}_{2} 19.37 \%(\mathrm{~m} / \mathrm{m}) 80^{\circ} \mathrm{C} / 3.5 \mathrm{~h}- \\
\text { antraquinona }\end{array}$ & Bagaço pré-tratado & BPTVXI \\
\hline & Pré-tratamento do bagaço & $\mathrm{H}_{2} \mathrm{O}_{2} 30 \%(\mathrm{~m} / \mathrm{v})+\mathrm{NaOH} 0.1 \%(\mathrm{~m} / \mathrm{v})$ & Polpa branqueada & PBXI \\
\hline & & $90^{\circ} \mathrm{C} / 1 \mathrm{~h}$ (um estágio de branqueamento) & & NCCXI \\
\hline & Polpa branqueada & $\mathrm{H}_{2} \mathrm{SO}_{4} 64 \%(\mathrm{~m} / \mathrm{m}) ; 45^{\circ} \mathrm{C} / 30 \mathrm{~min}$ - hidrólise ácida & Nanocristais de celulose & \\
\hline \multirow{4}{*}{ 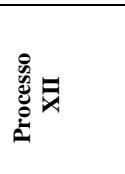 } & $\begin{array}{l}\text { Fibras de bagaço de cana-de- } \\
\text { açúcar }\end{array}$ & $\begin{array}{l}\mathrm{NaOH} 25 \%(\mathrm{~m} / \mathrm{v})+\mathrm{C}_{14} \mathrm{H}_{8} \mathrm{O}_{2} 19.37 \%(\mathrm{~m} / \mathrm{m}) 80^{\circ} \mathrm{C} / 3.5 \mathrm{~h} \\
\text { antraquinona }\end{array}$ & Bagaço pré-tratados & BPTVXII \\
\hline & Pré-tratamento do bagaço & $\mathrm{H}_{2} \mathrm{O}_{2} 11 \%(\mathrm{~m} / \mathrm{v})$ & Polpa branqueada & PBXII \\
\hline & & $90^{\circ} \mathrm{C} / 1 \mathrm{~h}$ (um estágio de branqueamento) & & NCCXII \\
\hline & Polpa branqueada & $\mathrm{H}_{2} \mathrm{SO}_{4} 64 \%(\mathrm{~m} / \mathrm{m}) ; 45^{\circ} \mathrm{C} / 30 \mathrm{~min}$ - hidrólise ácida & Nanocristais de celulose & \\
\hline
\end{tabular}


As fibras foram pré-tratadas, seguidas de branqueamento (realizado sob duas formas: um estágio de branqueamento ou quatro estágios de branqueamento) com os seguintes reagentes: hidróxido de sódio $(\mathrm{NaOH})$; clorito de sódio $\left(\mathrm{NaClO}_{2}\right)$ acrescido de ácido acético glacial $\left(\mathrm{C}_{2} \mathrm{H}_{4} \mathrm{O}_{2}\right)$; ácido nítrico $\left(\mathrm{HNO}_{3}\right) ; \mathrm{NaOH}$ acrescido de antraquinona $\left(\mathrm{C}_{14} \mathrm{H}_{8} \mathrm{O}_{2}\right)$; peróxido de hidrogênio $\left(\mathrm{H}_{2} \mathrm{O}_{2}\right)$ acrescido de $\mathrm{NaOH}$; e peróxido de hidrogênio $\left(\mathrm{H}_{2} \mathrm{O}_{2}\right)$. Logo depois, as fibras foram lavadas com água destilada para retirar o excesso dos reagentes (a verificação foi feita com papel de indicador de $\mathrm{pH}$ até $\mathrm{pH}$ neutro). As fibras foram secas à temperatura ambiente, seguidas de estufa a $80^{\circ} \mathrm{C}$ por $24 \mathrm{~h}$.

Para a hidrólise ácida, utilizou-se uma solução de ácido sulfúrico na proporção de 1:10 $(\mathrm{m} / \mathrm{v})$. A reação de hidrólise foi interrompida com a adição de água gelada. O ácido sulfúrico foi removido com a fase aquosa, após centrifugação (7830 rpm, 20 minutos a $\left.4^{\circ} \mathrm{C}\right)$, usando uma centrífuga (Thermo Scientific Heraeus MEGAFUGE 16R). Depois o pH foi ajustado com uma solução a 0,05 $\mathrm{M}$ de $\mathrm{NaOH}$. A suspensão coloidal de nanocristais foi submetida a um processo de liofilização, em câmara liofilizadora (Termofisher, Modelo Micromoduly YO-115) até total sublimação da água e peso constante. Todas as amostras foram analisadas em um estereomicroscópio manual Leica modelo S8APO, com $75 \mathrm{~cm}$ de distância de trabalho apocromático de até 80x.

Observação: Foram avaliados os impactos ambientais dos dozes processos realizados. Mas, somente dois melhores processos foram escolhidos para a reprodução para caracterização e aplicação em materiais nanocompósitos como reforço do ABS. Ou seja, aqueles processos que apresentaram menores impactos ambientais. Algumas amostras foram lavadas com água destilada pura e outras com solução a $0,05 \mathrm{M}$ de $\mathrm{NaOH}$, dependendo do $\mathrm{pH}$, até o pH neutro.

\subsection{AVALIAÇÃO DO CICLO DE VIDA (ACV) DA EXTRAÇÃO DE NANOCRISTAIS DE CELULOSE A PARTIR DE BAGAÇO DE CANA-DE-AÇÚCAR}

\section{Objetivo e escopo}

A modelagem dos processos de obtenção dos nanocristais foi facilitada pelo software GaBi Education 6.0. Realizou-se o presente estudo seguindo os preceitos e requisitos da norma internacional ISO 14044, 2006. Com este propósito, o estudo de ACV foi realizado com base em dados primários a partir dos experimentos realizados e também com base em dados secundários, 
a partir de uma revisão da literatura existente neste domínio quando os dados primários não foram suficientes para completar o estudo.

O objetivo deste estudo foi avaliar os impactos ambientais decorrentes de diversos processos de obtenção de nanocristais de celulose a partir de bagaço-de-cana. Este estudo justifica-se pela necessidade de maior conhecimento sobre os impactos associados às atividades de obtenção dos nanocristais de celulose. Os resultados permitirão quantificar tais impactos e atribuí-los às diferentes fases dos processos.

A unidade funcional adotada foi a produção de $1 \mathrm{~kg}$ de nanocristais de celulose.

A função do sistema em estudo foi à obtenção de nanocristais de celulose para aplicação em nanocompósitos.

Fluxo de referência foi delimitado de forma que todos os dados secundários e primários coletados se relacionassem a medida de componentes e operações necessárias para atender à função do sistema.

As fronteiras do sistema foram estabelecidas contemplando a cadeia produtiva dos principais insumos necessários aos processos de extração até a obtenção dos nanocristais (existentes na base de dados). Tratou-se de uma avaliação do "portão ao portão". A avaliação abordou impactos ambientais associados com a produção dos nanocristais de celulose desde a preparação do solo, o plantio da cana e colheita "berço" (dados secundários) até a obtenção dos nanocristais de celulose "portão" (dados primários). Os processos de obtenção dos nanocristais de celulose podem ser divididos em três fases principais: 1) tratamento alcalino; 2) branqueamento e 3) hidrólise ácida.

Os dados relacionados ao consumo de água (ISO 14046, 2014; WATER FOOTPRINT NETWORK, 2016), energia (IPCC, 2016), reagentes e resíduos foram contabilizados para cada subprocesso da extração de nanocristais de celulose, utilizando-se dados primários dos experimentos realizados. Alguns processos auxiliares como a produção de insumos, energia, combustível, foram utilizados a partir de dados já disponíveis na base de dados GaBi.

Os equipamentos (banho-maria, estufa, agitador mecânico, chapa de aquecimento centrifuga, liofilizador) funcionam com energia elétrica proveniente da rede administrada pela companhia de eletricidade estadual.

A metodologia Centre of Environmental Science (CML) 2001, atualizada em novembro de 2010, foi utilizada para avaliar as categorias de impacto. Para efeito de comparação, foram 
consideradas as mesmas categorias de impacto de Arvidsson et al. (2015) e Figueirêdo et al. (2012) potencial de aquecimento global (PAG), potencial de acidificação (PA), potencial de eutrofização (PE), água e energia disponível na base de dados GaBi Education 6.0 conforme a Figura 3.2.

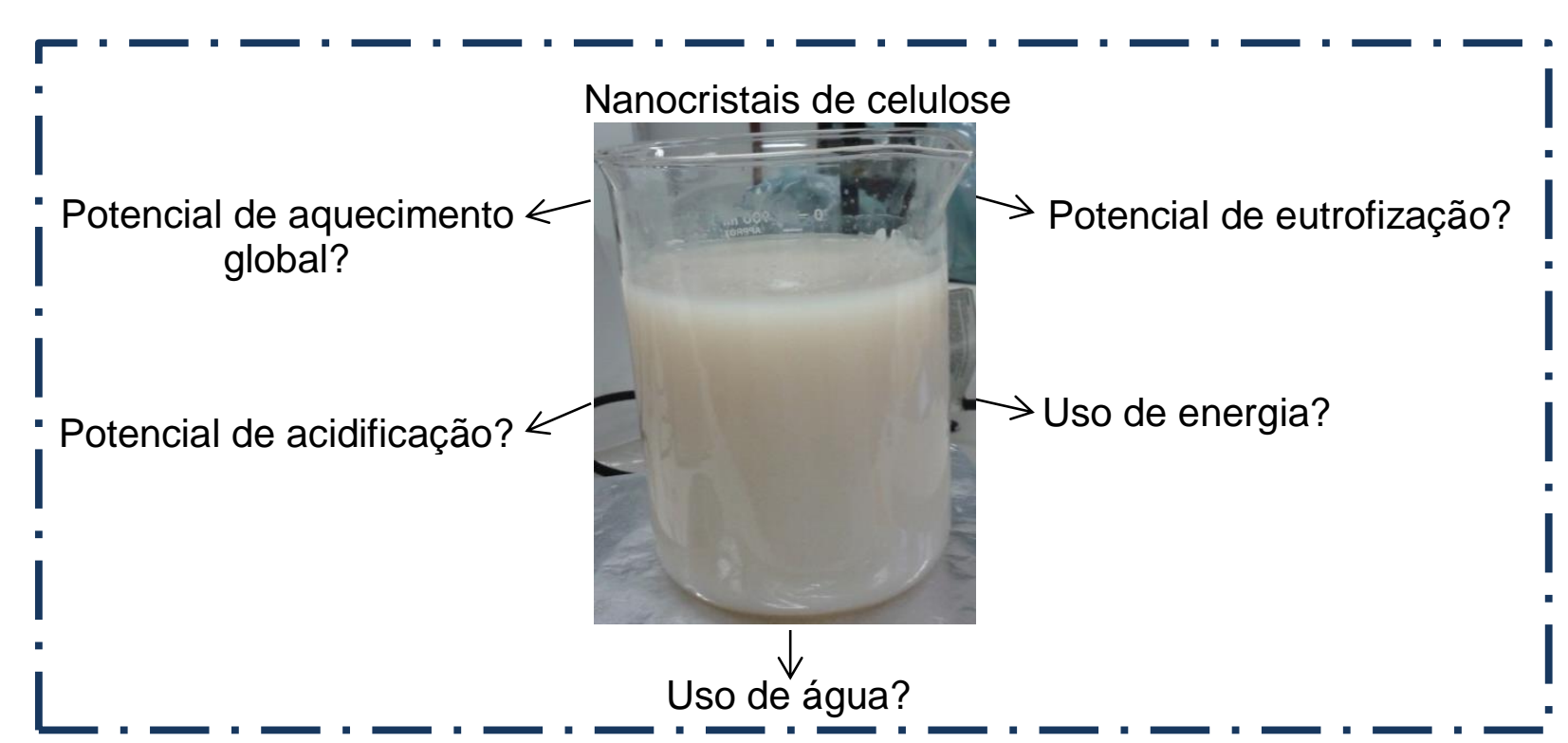

Figura 3.2: Indicadores de impacto ambiental.

\section{Descrição do sistema e dados de inventário}

O inventário contemplou os seguintes aspectos de entrada do sistema: cultivo, colheita, moagem, consumo de água, reagentes químicos, energia e transporte, assim, como emissões de poluentes até o portão da indústria dos nanocristais de celulose. As emissões em efluentes líquidos foram avaliadas considerando os seguintes parâmetros: DQO (demanda química de oxigênio) e DBO (demanda biológica de oxigênio).

Baseados nos estudos realizado pela Silva; Luz (2012), eles consideram na avaliação da fase agrícola as seguintes etapas: preparo do solo, plantio das mudas, defensivos agrícolas contra ervas daninhas e fertirrigação. A colheita foi realizada sem queima. Após a colheita a cana segue para o processamento nas usinas, esse transporte é feito geralmente por caminhões de diferentes capacidades de carga. O principal resultado obtidos neste estudo foi a mitigação de $\mathrm{CO}_{2}$ em $3,8 \times 10^{3} \mathrm{~kg}$ de $\mathrm{CO}_{2}$ eq. 
Os autores consideraram em suas análises, o preparo da cana começa no processo de extração do caldo, que depois de tratado e concentrado será direcionado para a produção de açúcar ou etanol. O processo de extração consiste na separação física do caldo da cana (bagaço). Dessa forma, o bagaço é derivado da moagem da cana-de-açúcar e é o maior subproduto da indústria sucroalcooleira (SILVA; LUZ, 2012)

Após a colheita da cana, esta chega à usina com certa quantidade de impurezas, ocorrendo à lavagem deste material. Depois, inicia-se o processo de extração do caldo, que depois de tratado e concentrado será direcionado para a produção de açúcar ou para a produção de etanol. O processo de extração consiste na separação física do caldo da cana de sua fibra (SILVA; LUZ, 2012). O resíduo da moagem é o bagaço, que é direcionado para um depósito ou indústria. A fase de obtenção de nanocristais foi compreendida pelos processos de produção dos nanocristais com pré-tratamento, branqueamento e hidrólise, conforme a Figura 3.3.

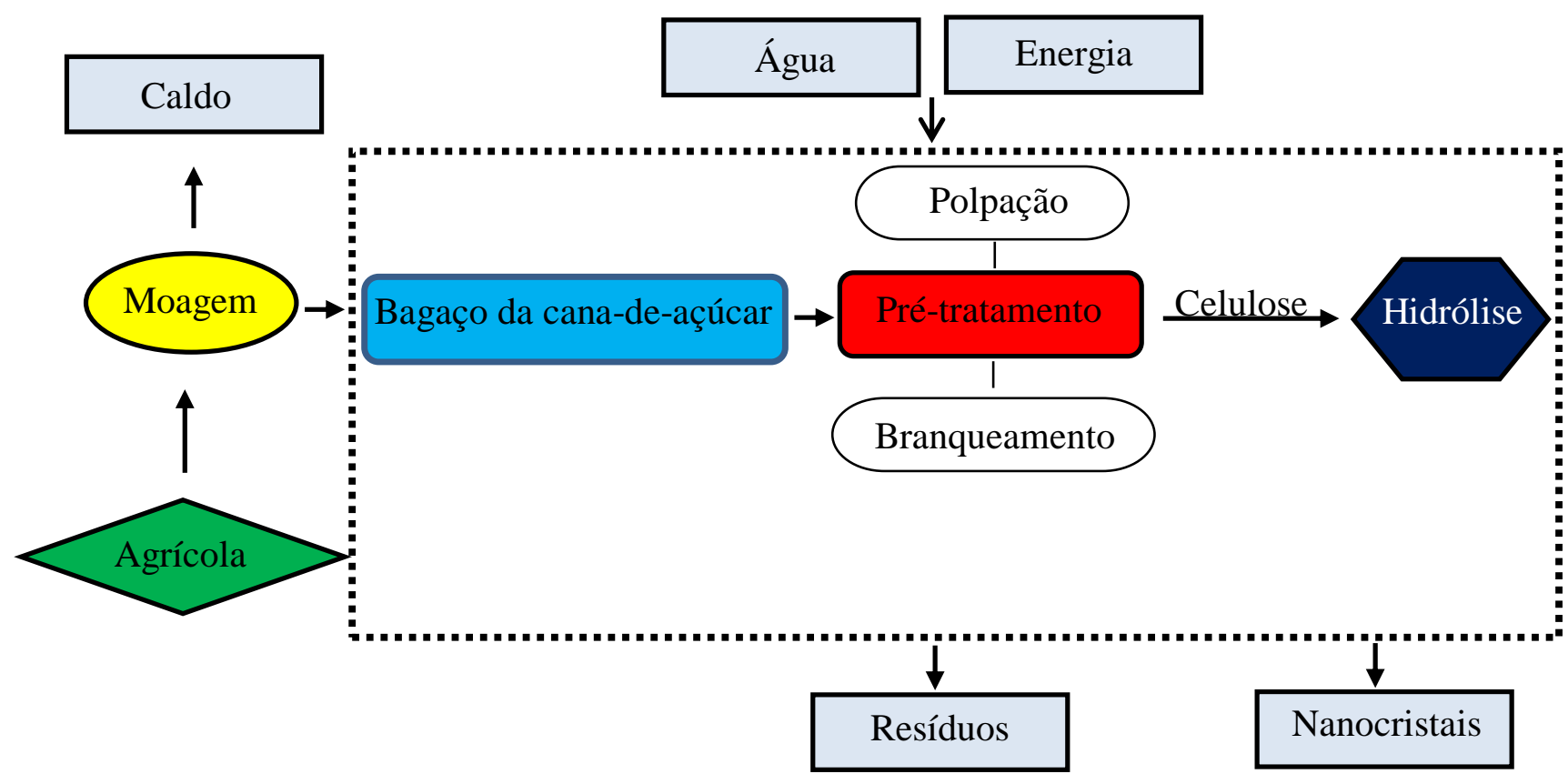

Figura 3.3: Fronteiras do sistema estudado para os diferentes cenários de obtenção de nanocristais do bagaço de cana-de-açúcar.

Assim, foram apresentadas as quantidades de matéria-prima, insumos, água e energia das entradas do processo e as saídas nanocristais, evaporação para o ar, água e resíduos, conforme Tabela 3.2. 
Tabela 3.2: Materiais incluídos nas entradas e saídas do estudo de ACV, considerando a produção de $1 \mathrm{~kg}$ de nanocristal de celulose.

\begin{tabular}{|c|c|c|c|c|c|c|c|c|c|c|c|c|}
\hline \multicolumn{13}{|c|}{ ENTRADAS } \\
\hline Processos & $\begin{array}{c}\text { Bagaço } \\
(\mathrm{kg})\end{array}$ & $\begin{array}{c}\mathrm{NaClO}_{2} \\
(\mathrm{~kg})\end{array}$ & $\begin{array}{c}\mathrm{C}_{2} \mathrm{H}_{4} \mathrm{O}_{2} \\
(\mathrm{~kg})\end{array}$ & \multicolumn{2}{|c|}{$\begin{array}{c}\mathrm{NaOH} \\
(\mathrm{kg})\end{array}$} & $\begin{array}{c}\mathrm{HNO}_{3} \\
(\mathrm{~kg})\end{array}$ & \multicolumn{2}{|c|}{$\begin{array}{c}\mathrm{H}_{2} \mathrm{O}_{2} \\
(\mathrm{~kg})\end{array}$} & $\begin{array}{c}\mathrm{H}_{2} \mathrm{SO}_{4} \\
(\mathrm{~kg})\end{array}$ & $\begin{array}{c}\text { Água } \\
\text { destilada } \\
\text { (L) }\end{array}$ & $\begin{array}{c}\text { Água } \\
\text { (L) }\end{array}$ & $\begin{array}{r}\text { Energia } \\
(\mathbf{k W h})\end{array}$ \\
\hline $\mathrm{I}$ & 0,09 & 0,08 & 0,55 & \multicolumn{2}{|c|}{$1,0 \times 10^{3}$} & - & \multicolumn{2}{|c|}{-} & $3,2 \times 10^{3}$ & $6,3 \times 10^{5}$ & $4,8 \times 1^{6}$ & 0,57 \\
\hline II & 0,09 & 2,20 & 1,40 & \multicolumn{2}{|c|}{0,01} & - & \multicolumn{2}{|c|}{-} & 0,03 & $4,6 \times 10^{4}$ & $3,3 \times 1^{5}$ & 0,38 \\
\hline III & 0,57 & 0,94 & 3,20 & \multicolumn{2}{|c|}{0,47} & - & \multicolumn{2}{|c|}{-} & 0,01 & $2,4 \times 10^{4}$ & $1,8 \times 1^{5}$ & 0,48 \\
\hline IV & 0,48 & 0,16 & 0,55 & \multicolumn{2}{|c|}{0,01} & - & \multicolumn{2}{|c|}{ - } & 0,01 & $1,5 \times 10^{4}$ & $1,1 \times 1^{5}$ & 0,50 \\
\hline $\mathrm{V}$ & 0,13 & 0,14 & 0,48 & \multicolumn{2}{|c|}{0,10} & - & \multicolumn{2}{|c|}{-} & 0,32 & $6,3 \times 10^{3}$ & $4,8 \times 1^{4}$ & 0,37 \\
\hline VI & 0,40 & 0,30 & 0,50 & \multicolumn{2}{|c|}{0,45} & 28,60 & \multicolumn{2}{|c|}{ - } & 0,01 & $1,8 \times 10^{4}$ & $2,1 \times 1^{5}$ & 0,59 \\
\hline VII & 0,52 & 0,01 & 2,70 & \multicolumn{2}{|c|}{0,58} & 37,00 & \multicolumn{2}{|c|}{-} & 0,01 & $9,4 \times 10^{3}$ & $2,2 \times 1^{5}$ & 0,44 \\
\hline VIII & 8,90 & 0,13 & 0,24 & \multicolumn{2}{|c|}{6,60} & 4,20 & \multicolumn{2}{|c|}{ - } & 0,20 & $2,1 \times 10^{3}$ & $2,1 \times 1^{4}$ & 0,52 \\
\hline IX & 0,11 & 4,40 & 0,07 & \multicolumn{2}{|c|}{5,20} & 3,30 & \multicolumn{2}{|c|}{ - } & 0,16 & $1,0 \times 10^{3}$ & $1,4 \times 1^{4}$ & 0,34 \\
\hline $\mathrm{X}$ & 0,57 & - & - & \multicolumn{2}{|c|}{0,02} & - & \multicolumn{2}{|c|}{1142,80} & 0,01 & $1,9 \times 10^{4}$ & $1,5 \times 1^{5}$ & 0,52 \\
\hline XI & 0,26 & - & - & \multicolumn{2}{|c|}{$1,1 \times 10^{3}$} & - & \multicolumn{2}{|c|}{488,89} & 0,06 , & $4,4 \times 10^{4}$ & $3,1 \times 1^{5}$ & 0,68 \\
\hline XII & 0,18 & - & - & \multicolumn{2}{|c|}{0,75} & - & \multicolumn{2}{|c|}{90,90} & 0,47 & $3,3 \times 10^{3}$ & $2,4 \times 1^{4}$ & 0,33 \\
\hline \multicolumn{13}{|c|}{ SAÍDAS } \\
\hline & I & II & III & IV & $\mathbf{V}$ & VI & VII & VIII & IX & $\mathbf{X}$ & XI & XII \\
\hline $\mathrm{NCC}(\mathrm{kg})$ & 1,0 & 1,0 & 1,0 & 1,0 & 1,0 & 1,0 & 1,0 & 1,0 & 1,0 & 1,0 & 1,0 & 1,0 \\
\hline $\operatorname{Ar}(\mathrm{kg})$ & $1,6 \times 10^{4}$ & $1,1 \times 10^{3}$ & $2,5 \times 10^{3}$ & $2,0 \times 10^{3}$ & 0,05 & $4,8 \times 10^{3}$ & 0,03 & 0,03 & 0,21 & $5,8 \times 10^{4}$ & $1,4 \times 10^{5}$ & 0,23 \\
\hline Água (L) & $5,4 \times 10^{6}$ & $3,7 \times 10^{5}$ & $2,0 \times 10^{5}$ & $1,2 \times 10^{5}$ & $5,3 \times 10^{4}$ & $2,2 \times 10^{5}$ & $2,2 \times 10^{4}$ & $2,2 \times 10^{4}$ & $1,5 \times 10^{4}$ & $1,1 \times 10^{5}$ & $2,1 \times 10^{5}$ & $2,7 \times 10^{4}$ \\
\hline Resíduos (L) & $5,0 \times 10^{3}$ & 0,04 & 0,03 & 0,02 & 0,56 & 0,02 & 0,04 & 0,44 & 0,29 & $1,5 \times 10^{3}$ & $2,2 \times 10^{3}$ & 0,02 \\
\hline
\end{tabular}

Assim, os processos principais foram: preparo da cana, extração do caldo e obtenção do bagaço; e obtenção dos nanocristais (pré-tratamento e hidrólise). Processos auxiliares: transporte, tratamento da água, captação da água, desmineralização da água e uso de diesel. Desse modo, as entradas (matéria-prima, reagentes, água e energia) e as saídas (nanocristais de celulose, emissões para o ar, água e resíduos) seguem conforme Figura 3.4. 

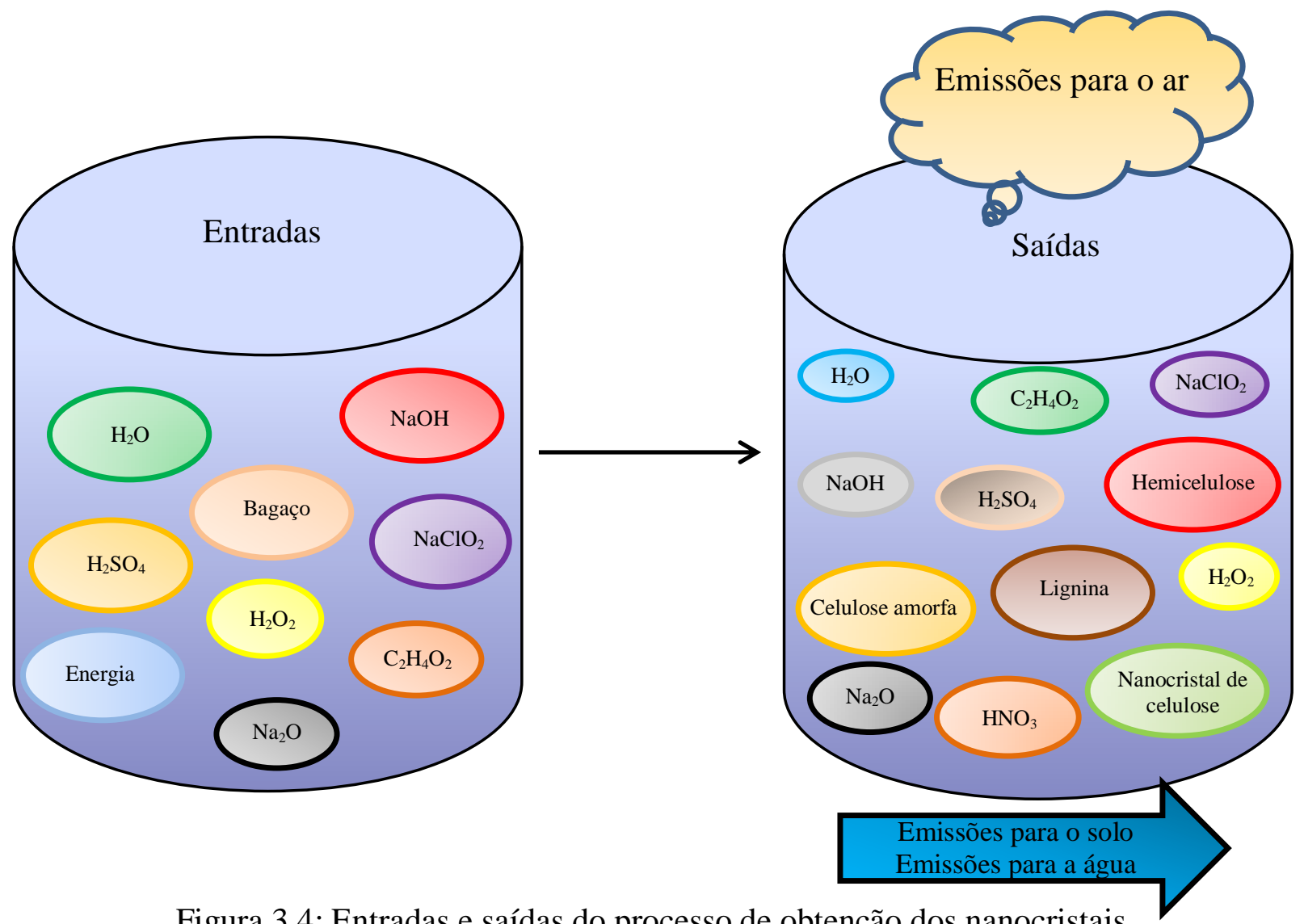

Figura 3.4: Entradas e saídas do processo de obtenção dos nanocristais.

\subsection{CARACTERIZAÇÃo das FibRAS E NANOCRISTAIS DE CELULOSE POR FTIR, RAIOS-X, MEV, TEM, MFA,TGA/DSC}

Caracterização das fibras e dos nanocristais de celulose por espectroscopia de infravermelho com transformada de Fourier (FTIR)

Antes das análises, as amostras foram secas em um dessecador sob vácuo durante 4 dias. O equipamento empregado para esta análise foi um espectrofotômetro Nicolet iS10 da Thermo Scientific, disponível na Faculdade do Gama/UnB (Laboratório de Análise Instrumental). As amostras foram analisadas na região do infravermelho entre $4000-400 \mathrm{~cm}^{-1}$ com intervalos de $4 \mathrm{~cm}^{-1}$ e 128 scans. 


\section{Caracterização das fibras e dos nanocristais de celulose por difração de Raios-X (XRD)}

Para as análises de difração de raios-X foram realizadas utilizando um difratômetro marca RIGAKU modelo ULTIMAIV, disponível no Departamento de Geologia (Laboratório de DRX) no modo de reflexão com um ângulo incidente de $1.54 \AA$, radiação de CuKa, sob $2 \theta$ de 5 a $50^{\circ}$ e velocidade de varredura $3 \% \mathrm{~min}^{-1}$. O índice de cristalinidade das amostras foram determinados a partir do difratograma. O método empírico Segal et al., (1959) foi usado para obter o índice de cristalinidade das amostras ICr, como mostrado na equação (3.7):

$$
\operatorname{ICr}(\%)=\frac{I_{200}-I_{A M}}{I_{200}} \times 100,
$$

Onde: $\mathrm{I}_{200}$ : intensidade dos picos cristalino; $\mathrm{I}_{\mathrm{AM}}$ : intensidade do halo amorfo e $\mathrm{ICr}$ é índice de cristalinidade. O espaçamento basal foi calculado, conforme a Lei de Bragg $2 \mathrm{~d} \operatorname{sen} \theta=\mathrm{n} \lambda$

\section{Caracterização das fibras por microscopia eletrônica de varredura (MEV)}

As amostras dos materiais lignocelulósicos e a superfície dos nanocompósitos fraturados foram todos presas em um suporte com auxílio de fita de carbono e submetidas ao recobrimento metálico com platina com espessura de $8 \mathrm{~nm}$ sob atmosfera de argônio, usando o equipamento de recobrimento metálico da marca Balzers modelo SCD 050 Sputter Coater. Logo depois, as fibras foram analisadas utilizando um microscópio da marca JEOL modelo JSM - 7001F, disponível no Departamento de Biologia (Laboratório de Microscopia Eletrônica de Varredura da UnB). Foi utilizado um detector de elétrons secundários e o equipamento operou com uma aceleração de $15 \mathrm{kv}$. E para medir o diâmetro e o comprimento foi utilizado software ImageJ.

\section{Caracterização dos nanocristais de celulose por microscopia eletrônica de transmissão (MET)}

A técnica de microscopia eletrônica de transmissão (JEOL - JEM 2100) foi utilizada para a caracterização morfológica dos nanocristais de celulose, disponível no Departamento de Biologia (Laboratório de Microscopia Eletrônica de Transmissão da UnB). Os nanocristais foram diluídos em água, a suspensão aquosa foi colocada em um grid de carbono sobre cobre de 300 
mesh, seca a temperatura ambiente, seguido de aplicação de $2 \%(\mathrm{~m} / \mathrm{v})$ de acetato de uranila. Após a análise, as dimensões (comprimento/diâmetro) das amostras foram determinadas usando o programa ImageJ.

\section{Caracterização dos nanocristais de celulose por microscopia de força atômica (MFA)}

Um microscópio de força atômica modelo AFM 3100 com ponta de nitreto de silício $\left(\mathrm{Si}_{3} \mathrm{~N}_{4}\right)$ em modo de contato, foi utilizado para análise de amostras de nanocristais de celulose a partir de cana-de-açúcar, disponível no Departamento de Macromolecular (Laboratório de Microscopia de Força Atômica na Case Western Reserve University). Uma gota da suspensão diluída dos NCC foi depositada sobre a superfície da mica recém clivada e seca a temperatura ambiente.

\section{Caracterização das fibras e dos nanocristais de celulose por análise térmica simultânea TGA/DSC}

As amostras foram analisadas em um analisador térmico simultâneo da marca TA Instruments, disponível na Faculdade do Gama/UnB (Laboratório de Análise Instrumental). As amostras de 5-10 mg foram colocadas em um cadinho de alumina e analisadas na razão de aquecimento de $10{ }^{\circ} \mathrm{C} / \mathrm{min}^{-1}$ de temperatura ambiente a $600^{\circ} \mathrm{C}$ sob atmosfera de $\mathrm{N}_{2}$ (fluxo de 60 mL.min ${ }^{-1}$ ). A fim de avaliar a degradação dos componentes, as amostras de bagaço in natura e bagaços pré-tratados, polpas branqueadas e nanocristais foram analisadas por TGA acoplado a FTIR. A temperatura da interface Thermo Scientific entre TGA/FTIR foi definida como $200^{\circ} \mathrm{C}$ para a célula e $190^{\circ} \mathrm{C}$ para a linha de transferência do gás. As amostras foram analisadas na região do infravermelho entre $4000-400 \mathrm{~cm}^{-1}$ com intervalos de $4 \mathrm{~cm}^{-1}$ e 64 scans.

\subsection{OBTENÇÃO DOS NANOCOMPÓSITOS}

\subsubsection{Processamento em extrusora dupla rosca}

Os nanocristais de celulose e o ABS foram previamente secos em estufa a $80^{\circ} \mathrm{C}$ por $3 \mathrm{~h}$. Nanocristais e matriz foram adicionados lentamente ao funil de entrada da extrusora dupla rosca (marca MH Equipamentos modelo COR 20-32-LAB, diâmetro 20 mm e L/D 46), disponível na Universidade de Caxias do Sul - UCS (Laboratório de Polímeros). Misturas de ABS com 0,5; 
1,0 e $1,5 \%(\mathrm{~m} / \mathrm{m})$ de nanocristais passaram inteiramente pelo conjunto de roscas por 8 zonas de temperatura $\left(91,157,187,188,178,175,172\right.$ e $\left.179^{\circ} \mathrm{C}\right)$ a $120 \mathrm{rpm}$. Os fios extrudados foram granulados.

Os grânulos foram secos em estufa a $60^{\circ} \mathrm{C}$ por $3 \mathrm{~h}$ e foram injetados em molde contendo cavidades com dimensões específicas para ensaios mecânicos, utilizando a Injetora modelo LHS 150-80 Himaco Hidráulicos e Máquinas Ltda. Foram usadas três diferentes zonas de aquecimento com o seguinte perfil de temperatura: $140^{\circ} \mathrm{C} ; 160^{\circ} \mathrm{C}$ e $190^{\circ} \mathrm{C}$. A velocidade de rotação da rosca foi de $60 \mathrm{rpm}$ em molde com temperatura de $15^{\circ} \mathrm{C}$. Foram produzidos corpos de prova para realização de ensaios de tração, flexão e impacto.

\subsection{CARACTERIZAÇÃo TÉRMICA, MECÂNICA, MORFOLÓGICA DOS NANOCOMPÓSITOS E ANÁLISE REOMÉTRICA}

\section{Análise dinâmico-mecânica (DMA)}

Amostras retangulares de $30 \times 13 \times 3,5 \mathrm{~mm}$ foram usadas para as análises dinâmicomecânicas. Estes foram adquiridos a partir de corpos de prova de tração. $\mathrm{O}$ equipamento usado para o ensaio foi TA Instruments DMA Q800, disponível no Departamento de Macromolecular (Laboratório de Caracterização de Materiais na Case Western Reserve University), na frequência de $1 \mathrm{~Hz}$. Amplitude de oscilação de $20 \mu \mathrm{m}$ e constante de Poisson 0,35 foram usadas. As amostras foram presas entre garras a um dispositivo "dual cantilever", e receberam torque de 70 N.cm ${ }^{-1}$. As amostras foram analisadas entre 25 e $150^{\circ} \mathrm{C}$ com uma razão de aquecimento de $3^{\circ} \mathrm{C} \cdot \mathrm{min}^{-1}$.

\section{Tração}

Os corpos de prova foram analisados em equipamento EMIC DL 2000 da Universidade de Caxias do Sul (Laboratório de polímeros, equipado com garras pneumáticas, sob velocidade de $2 \mathrm{~mm} \cdot \mathrm{min}^{-1}$. Foi analisado para cada nanocompósito o mínimo de 5 corpos de prova, com dimensões de acordo com a norma ASTM D 638 (2003), com $13 \mathrm{~mm}$ de largura, $160 \mathrm{~mm}$ de comprimento e $2,7 \mathrm{~mm}$ de espessura, conforme a Figura 3.5. As propriedades mecânicas de resistência à tração, elongação até máxima tensão e módulo de elasticidade em tração foram determinadas. 


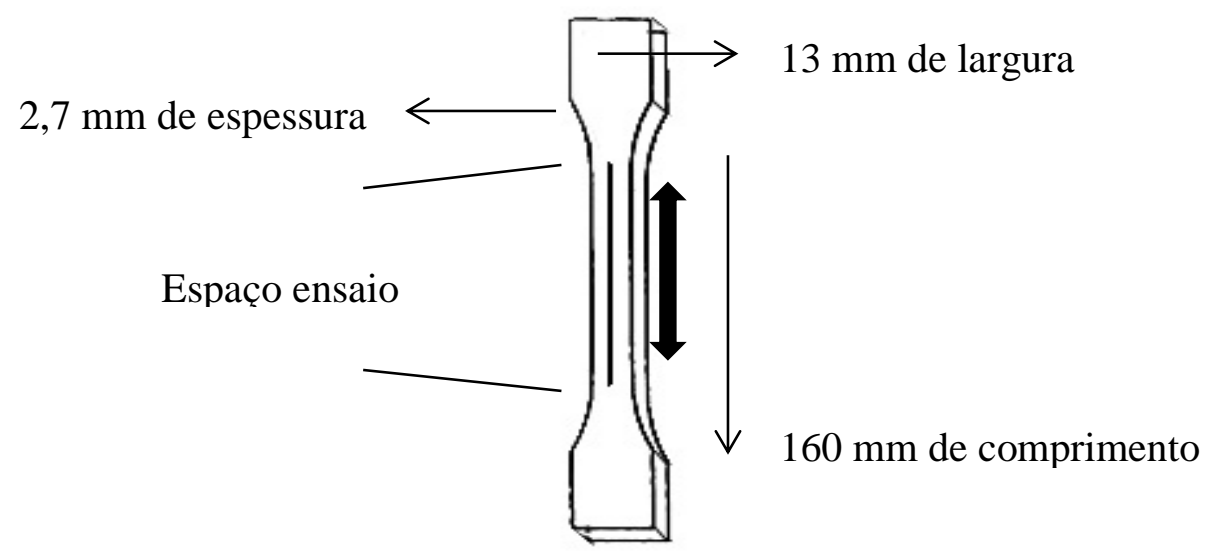

Figura 3.5: Corpo de prova submetido a ensaio de tração. A seta indica o sentido da aplicação da força (ASTM D 638).

\section{Flexão}

Os ensaios de flexão foram realizados sob a velocidade de $1,5 \mathrm{~mm} . \mathrm{min}^{-1}$ (disponível na Universidade de Caxias do Sul - Laboratório de polímeros). Foram analisados no mínimo 5 corpos de prova, com dimensões de acordo com a norma ASTM D 790 (2003), com 13 mm de largura, $130 \mathrm{~mm}$ de comprimento e $6,0 \mathrm{~mm}$ de espessura. O método de análise de flexão adotado foi o de 3 pontos, conforme a Figura 3.6. As propriedades mecânicas de resistência à flexão e módulo de elasticidade em flexão foram determinadas. 


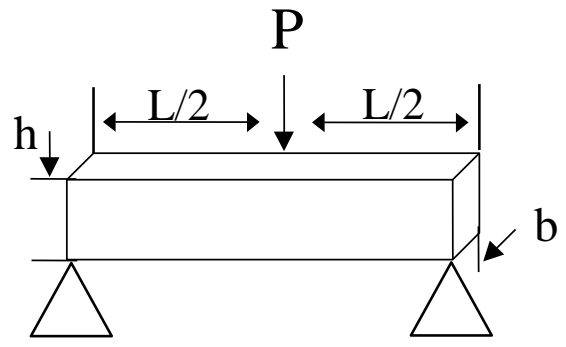

Figura 3.6: Corpo de prova submetido a ensaio de flexão em 3 pontos (ASTM D 790).

\section{Impacto}

Com o auxílio de uma máquina de impacto CEAST, ${ }^{1}$ (disponível na Universidade de Caxias do Sul - Laboratório de polímeros), os corpos de prova, em forma de barra com espessura de 3,2 $\mathrm{mm}$ e largura de $10,12 \mathrm{~mm}$ com entalhe, foram presos verticalmente pela parte inferior sofrendo um impacto 2,75 $\mathrm{J}$ de energia de um martelo instrumentado em forma de pêndulo. Os testes de impacto Izod foram realizados segundo norma ASTM D 256 a $23^{\circ} \mathrm{C}$ após 40 horas de sua moldagem por injeção e 48 horas após a realização do entalhe.

\section{Análise dos dados}

A análise estatística foi realizada pelo programa SPSS 20.0 através da comparação par a par do ABS com cada um dos nanocompósitos, por meio do teste de média de Dunnett. Estas amostras foram avaliadas pela análise de variância fatorial. Foi realizado o teste de Tukey B, onde foi observado se houve ou não diferença significativa entre os nanocompósitos e ABS. Todas as análises foram consideradas significativas ao nível de $\alpha=0,05$.

\section{Reometria de placas paralelas}

O ensaio de reometria de placas paralelas foi realizado com corpos de prova de tração com dimensões de 3,5 x 3,5 x 1,5 mm. O equipamento usado para os ensaios de reometria rotacional foi um reômetro oscilatório Anton Parr Physica MCR $101^{1}$ (disponível na Universidade de Caxias do Sul - Laboratório de polímeros), utilizando duas frequências uma 
baixa de $0,1 \mathrm{rad} / \mathrm{s}$ e uma alta de $300 \mathrm{rad} / \mathrm{s}$ para observar a viscosidade complexa com a deformação do material. 


\section{CAPÍTULO 3}

\section{RESULTADOS E DISCUSSÃO}

\subsection{AVALIAÇÃO DO IMPACTO AMBIENTAL DOS PROCESSOS DE OBTENÇÃO DOS NANOCRISTAIS DE CELULOSE}

Para se determinar os processos ideais para a obtenção de nanocristais de celulose foram avaliados os tratamentos propostos na Tabela 3.1. Conforme já mencionado, a avaliação foi feita do portão ao portão considerando o sistema descrito na Figura 3.2.

\subsubsection{Impactos ambientais da fase de produção dos nanocristais do sistema}

Pegada hídrica

A pegada hídrica de um produto está relacionada com quantidade de água que é consumida ou poluída em todas as fases de processamento da sua produção. Ao medir o volume da água consumida na produção e o volume de água necessário para assimilar poluentes são cumpridos os padrões de qualidade da água. Pode-se obter uma imagem de como um produto específico contribui para as preocupações crescentes na escassez de água e degradação da qualidade da água. Desta forma, o valor total da água consumida ou poluída é levado em conta na pegada hídrica do produto. A pegada hídrica do produto pode ajudar a identificar onde existem oportunidades para redução da pegada hídrica e melhorias na eficiência dos recursos (WATER FOOTPRINT NETWORK, 2016). Durante a fase de produção do NCC há três fases principais: polpação, branqueamento e hidrólise. Segundo Water Footprint Network, (2016), a pegada hídrica está dividida em três tipos, pegada hídrica verde (PHverde); pegada hídrica cinza (PHcinza) e a pegada hídrica azul (PHazul). Os resultados deste estudo relacionado com a pegada hídrica estão apresentados na Figura 4.1. 


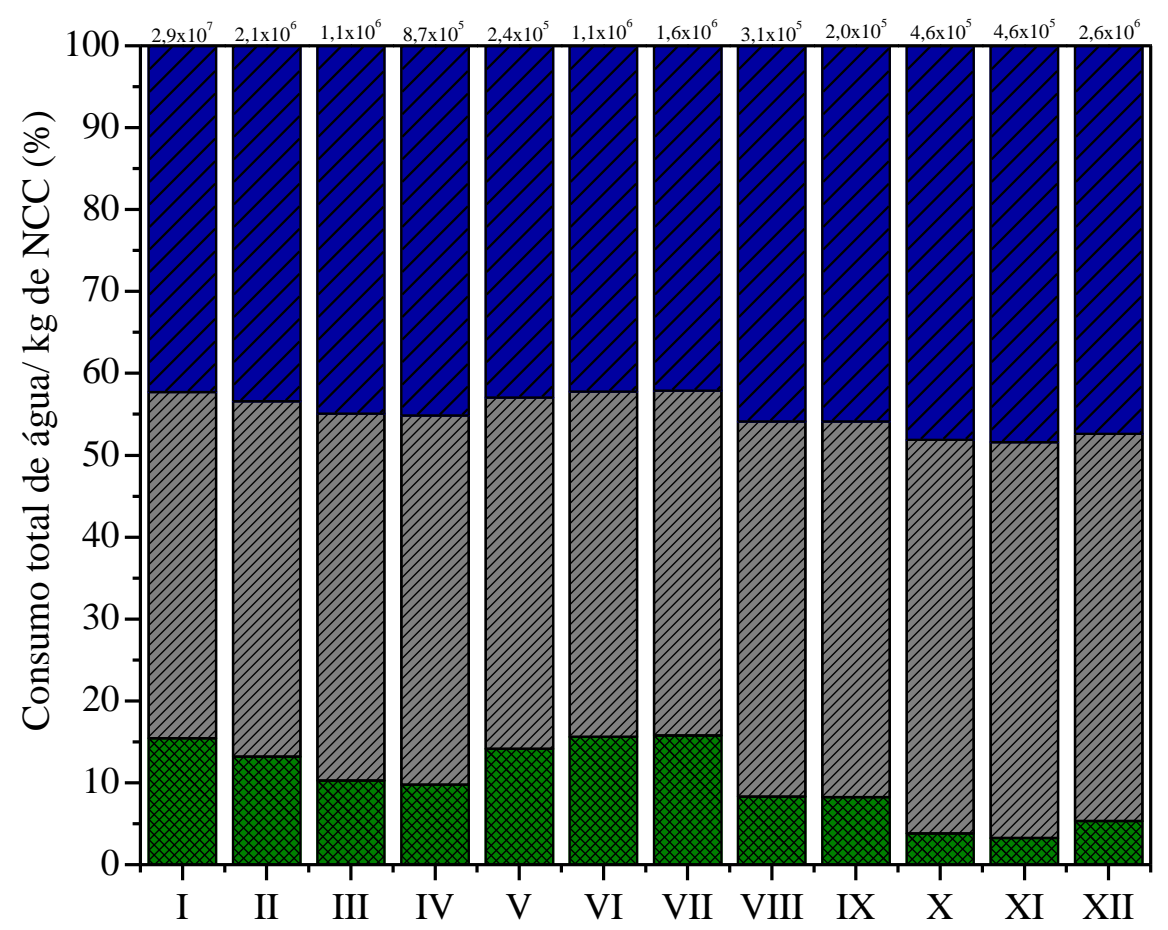

PHazul (Pegada hídrica azul) PHcinza (Pegada hídrica cinza) PHverde (Pegada hídrica verde)

I: $\mathrm{NaOH}_{5} 5 \% / \mathrm{NaClO}_{2} 1 \% / 4 x$; II: $\mathrm{NaOH} 5 \% / \mathrm{NaClO}_{2} 1 \% / 1 \mathrm{x}$; III: $\mathrm{NaClO}_{2} 2 \% / \mathrm{NaOH} 4 \% / 4 x$; IV: $\mathrm{NaCOl}_{2} 2 \% / \mathrm{NaOH}$ $2 \% / 4 x$; V: $\mathrm{NaClO}_{2} 2 \% / \mathrm{NaOH} 2 \% / 1 \mathrm{x}$; VI: $\mathrm{NaOH} 5 \% / \mathrm{NaClO}_{2} 3,3 \% / 4 x$; VII: $\mathrm{NaOH} 5 \% / \mathrm{NaClO}_{2} 3,3 \% / 1 \mathrm{x}$; VIII: $\mathrm{NaOH} 5 \% / \mathrm{NaClO}_{2} 3,3 \% / 4 x$; IX: $\mathrm{NaOH} 5 \% / \mathrm{NaClO}_{2} 3,3 \% / 1 \mathrm{x}$; X: $\mathrm{NaOH} 25 \% / \mathrm{H}_{2} \mathrm{O}_{2} 30 \% / 4 x ; \mathrm{XI}: \mathrm{NaOH} 25 \% / \mathrm{H}_{2} \mathrm{O}_{2}$ $30 \% / 1 x ; \mathrm{XII}: \mathrm{NaOH} 25 \% / \mathrm{H}_{2} \mathrm{O}_{2} 11 \% / 1 x$.

Figura 4.1: Volume total da água consumida em cada rota de obtenção NCC (WATER FOOTPRINT NETWORK, 2016).

Quando analisada as contribuições de cada fração da pegada hídrica observou-se que PHverde e PHcinza do processo de produção foi responsável por $60 \%$ do consumo total e a PHazul foi responsável por $45 \%$ conforme a Figura 4.1, evidenciando que há a utilização excessiva de água da rede. A água da rede, nesses casos, é utilizada para lavagem das fibras após os tratamentos e também em equipamento, no caso o banho-maria, mostrando assim que as ações para aumentar a eficiência do uso da água devem considerar o aprimoramento do tratamento dos efluentes (EMPINOTTI, 2013).

A PHazul está relacionada como o indicador de volume de água superficial e/ou subterrânea alocada durante o processo produtivo. Na sua contabilização é considerado o volume 
de água evaporada, o volume de água que não retorna ao corpo hídrico de origem e o volume de água que não retorna ao corpo hídrico de origem no mesmo período do qual foi captado (ex: represas, armazenamentos de água) e a PHcinza esta relacionada com a poluição da água que pode ser associado com a produção do produto (EMPINOTTI, 2013). A PHverde esta relacionado a quantidade de água da chuva alocado na produção agrícola e silvícola, referindo-se ao total da água que é evapotranspiração pelas plantas, água armazenada no solo, e mais a água incorporada no produto final.

\section{Pegada hídrica do pré-tratamento e hidrólise}

Avaliando-se as fases de pré-tratamento e hidrólise, verificou-se que o pré-tratamento foi responsável pelos maiores impactos ambientais de acordo com a Figura 4.2, atribuídos à pegada hídrica verde (PHverde); pegada hídrica cinza (PHcinza) e pegada hídrica azul (PHazul).

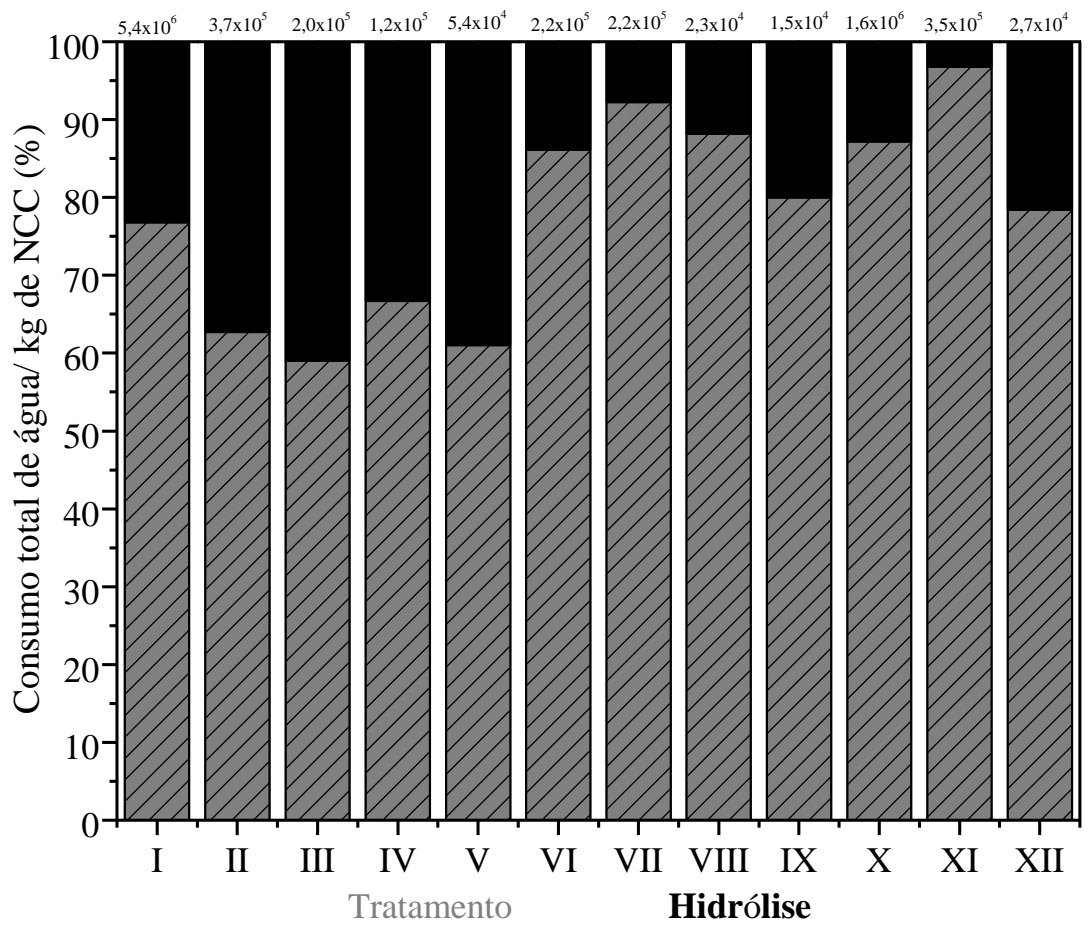

I: $\mathrm{NaOH}_{5} 5 \% / \mathrm{NaClO}_{2} 1 \% / 4 x$; II: $\mathrm{NaOH} 5 \% / \mathrm{NaClO}_{2} 1 \% / 1 x$; III: $\mathrm{NaClO}_{2} 2 \% / \mathrm{NaOH} 4 \% / 4 x ;$ IV: $\mathrm{NaCOl}_{2} 2 \% / \mathrm{NaOH}$ $2 \% / 4 x$; V: $\mathrm{NaClO}_{2} 2 \% / \mathrm{NaOH} 2 \% / 1 \mathrm{x}$; VI: $\mathrm{NaOH} 5 \% / \mathrm{NaClO}_{2} 3,3 \% / 4 \mathrm{x}$; VII: $\mathrm{NaOH} 5 \% / \mathrm{NaClO}_{2} 3,3 \% / 1 \mathrm{x}$; VIII: $\mathrm{NaOH} 5 \% / \mathrm{NaClO}_{2} 3,3 \% / 4 x$; IX: $\mathrm{NaOH} 5 \% / \mathrm{NaClO}_{2} 3,3 \% / 1 \mathrm{x}$; X: $\mathrm{NaOH} 25 \% / \mathrm{H}_{2} \mathrm{O}_{2} 30 \% / 4 x ; \mathrm{XI}: \mathrm{NaOH} 25 \% / \mathrm{H}_{2} \mathrm{O}_{2}$ $30 \% / 1 x ; \mathrm{XII}: \mathrm{NaOH} 25 \% / \mathrm{H}_{2} \mathrm{O}_{2} 11 \% / 1 x$.

Figura 4.2: Percentual de consumo total de água nas etapas de pré-tratamento e hidrólise. 
O volume total de água gasto na produção de nanocristais de celulose a partir do bagaço de cana para o processo I apresentou maior consumo de água com $5,4 \times 10^{6} \mathrm{~L}$ e o processo IX apresentou menor consumo de água com $1,5 \times 10^{4} \mathrm{~L}$ para cada $\mathrm{kg}$ de nanocristais (Tabela 4 apêndice A). Assim, no processo I entrou $4,8 \times 10^{6} \mathrm{~L}$ de água da torneira e $6,3 \times 10^{5} \mathrm{~L}$ de água destilada e saiu emissão para o ar $\left(1,6 \times 10^{4} \mathrm{~kg}\right)$, água contaminada $\left(5,4 \times 10^{6} \mathrm{~L}\right)$ e resíduos $(5,0$ $\mathrm{x} 10^{3} \mathrm{~kg}$ ). No processo IX entrou $1,4 \times 1^{4} \mathrm{~L}$ de água de água da torneira e $1,0 \times 10^{3} \mathrm{~L}$ de água destilada e saiu emissão para o ar $(0,21 \mathrm{~kg})$, água contaminada $\left(1,5 \times 10^{4} \mathrm{~L}\right)$ e resíduos $(0,29 \mathrm{~kg})$.

Assim, na fase de pré-tratamento demanda grande quantidade de água no banho-maria e na lavagem das fibras, até a neutralização do pH. A utilização de água em abundância, aliado à utilização de água destilada na lavagem e preparação das soluções químicas, acaba por representar a maior parte dos impactos ambientais da fase de produção dos nanocristais de celulose. O pré-tratamento envolveu lavagens das fibras com água e solução de hidróxido de sódio, ácido acético, ácido nítrico, peróxido de oxigênio e ácido sulfúrico esses insumos geram emissões para água que contribuiem com o aumento potencial de eutrofização (KOUNINA et al., 2013).

Assim, o processo I apresentou maior quantidade de água contaminada em relação ao processo IX, e consequentemente maior será o custo para limpar essa água para sua reutilização. $\mathrm{O}$ consumo de água é relativamente alto. $\mathrm{O}$ uso direto da água de lavagem seria uma forma de reduzir o consumo de água, e consequentemente diminuir o impacto dessa rota; e a filtração dos resíduos, para posterior utilizar os resíduos como fonte de energia, também seria uma forma de reduzir o impacto. Foi verificado que o processo IX apresentou menor consumo de água, devido as lavagens com solução de $\mathrm{NaOH}$. Este método seria também uma forma de reduzir.

Segundo Figueirêdo et al. (2012), o volume total de água gasto na produção dos nanocristais de celulose a partir da fibra de coco foi de $3,28 \times 10^{7} \mathrm{~L}$ e para a produção dos nanocristais de celulose a partir da fibra de algodão, o volume total de água gasto foi de $3,75 \times 10^{6} \mathrm{~L}$, para $1 \mathrm{~kg}$ de nanocristais em ambos os casos. $\mathrm{O}$ tratamento das fibras utilizado por Figueirêdo et al. (2012), foram: extração dos extrativos com água (duplicata), tratamento com $\mathrm{NaOH}$ (duplicata) seguido pelo branqueamento. Depois da hidrólise da celulose ocorreu a lavagem da suspensão por meio de diálise. Uma explicação para isso é que a composição química da fibra de coco que é composta por $28 \%$ de celulose, $19 \%$ de hemicelulose e $41 \%$ de 
lignina, ao contrário da fibra de algodão que apresenta 97\% de celulose, e o bagaço possui $39 \%$ celulose, $27 \%$ de hemicelulose e de lignina $21 \%$. A partir disso, percebe-se que na produção dos nanocristais de celulose a partir da fibra de coco exige-se um maior número de tratamentos devido à maior quantidade de lignina presente na fibra, e assim maior consumo de solvente, água e energia em relação ao bagaço, devido à necessidade de remoção da lignina (FIGUEIRÊDO et al., 2012; ROSA et al., 2010; LEÃO et al., 2015a). Apesar do bagaço apresentar menor quantidade de celulose que o algodão, o consumo de água na fabricação dos nanocristais de celulose foi menor, evidenciando que os tratamentos aplicados ao bagaço foram mais eficientes. Este valor elevado pode também ser explicado pelo baixo rendimento, o mesmo pode ser observado no processo I.

A fase da hidrólise gera muitos resíduos para a acidificação, desse modo, o processo I apresentou maior impacto ambiental, provocando assim aumento das emissões para o potencial de acidificação, principalmente em virtude da água de lavagem e solução com ácido $\left(\mathrm{H}_{2} \mathrm{SO}_{4}\right)$.

Portanto, nessa fase utiliza muita a água destilada. Deste modo, o processo de destilação convencional consiste em aquecer a água, em um recipiente fechado, até que entre em ebulição; esse vapor sofrerá condensação e retornará ao seu estado líquido, totalmente livre de impurezas e de minerais. Estes destiladores convencionais, usados em laboratórios de química, chegam a consumir até 48 litros de água para se obter 1 litro de água destilada. Estima-se que esse desperdício esteja numa faixa entre 30 e 40 litros de água de refrigeração, por cada litro de água destilada (COUTINHO et al., 2016). Assim, vale ressaltar os reagentes utilizados no tratamento da água, tais como (sulfato de alumínio; hidróxido de cálcio; carbonato de sódio; cloro; hipoclorito de sódio; fluoreto de sódio; hidróxido de sódio; sulfato de amônia; ácido sulfúrico; ácido clorídrico; sulfato de ferro III; cloreto de ferro entre outros) (CAESB, 2016) e a energia. Quando esses insumos são produzidos eles liberam $\mathrm{CO}_{2}$ entre outros acarretando aumento do potencial de aquecimento global e potencial de acidificação.

Assim, as análises dos resultados revelam diferenças no consumo da água, levando diferentes impactos ambientais, que pode ser explicada pela diferença nas quantidades de bagaço de cana-de-açúcar e nas concentrações dos reagentes em cada tratamento e o rendimento dos tratamentos aplicados influencia diretamente na quantidade de água utilizada para a produção de $1 \mathrm{~kg}$ de nanocristal. Quanto menor o rendimento dos tratamentos, proporcionalmente maior será o 
consumo de água na produção dos nanocristais. Tanto Arvidsson et al. (2015) como Figueirêdo et al. (2012) observaram o consumo intenso de água na produção dos nanocristais de celulose.

\section{Emissões}

Analisando-se os dados do inventário obtidos e descritos na Tabela 3.2, as quantidades de emissões para água para cada processo, conclui-se que os subprocessos de lavagem e hidrólise foram responsáveis pelos maiores volumes de resíduos. Dentre as emissões para a água avaliadas, as mais importantes foram: (DQO) e (DBO). Observou-se que o processo I apresentou maior DBO e consequente emissão para o potencial de eutrofização, com $0,06 \mathrm{~kg} \mathrm{PO}_{4}{ }^{-}$eq. $/ \mathrm{kg}$ de nanocristal. Isso pode ser explicado pela perda de material sólido na forma de fibra, descartada durante a filtração. Vale ressaltar, que as concentrações, a massa inicial do bagaço e os reagentes são diferentes, assim contribuindo para diferentes emissões (CAVALCANTI et al., 2010; FIGUEIRÊDO et al., 2012).

O processo I apresentou maior DQO, e consequentemente, maior emissão para potencial de eutrofização, com o equivalente a $0,13 \mathrm{~kg} \mathrm{PO}_{4}{ }^{-}$eq./ $\mathrm{kg}$ de nanocristal. A DQO é devida a grande quantidade de matéria orgânica e inorgânica na água, proveniente de produtos de degradação da fibra. Estas emissões foram decorrentes das etapas de polpação e branqueamento, em sua grande maioria, onde as concentrações, a massa inicial do bagaço e os reagentes são diferentes. Segundo Fengel; Wegener, (2003), na fase da hidrólise pode gerar lignina insolúvel, devido ao meio ácido, que poderiam precipitar durante o processo de hidrólise ou gerar produtos secundários. A hidrólise de lignina e hemicelulose gera açúcares e subprodutos (principalmente, difenóis, derivados de fenilpropano, cetonas, furfural e ácido acético) (OGEDA; PETRI, 2010).

\section{Energia}

Analisando os resultados do consumo de energia, verificou-se que o processo I foi o responsável pelo maior consumo de energia $\left(1,14 \times 10^{5} \mathrm{MJ} / \mathrm{kg}\right.$ de nanocristal) e o processo IX apresentou o menor consumo $\left(7,56 \times 10^{2} \mathrm{MJ} / \mathrm{kg}\right.$ de nanocristal), conforme a Figura 4.3 (Tabela 5 apêndice A). A energia requerida pelo processo I foi significativamente maior que a energia necessária para todos os outros processos. No processo I foi utilizado (banho-maria, estufa, chapa de aquecimento, centrífuga, bomba a vácuo, liofilozador); No processo IX foi utilizado 
(banho-maria, estufa, chapa de aquecimento, centrífuga, liofilozador). A fase de pré-tratamento foi a responsável pelo maior consumo de energia, devido a maior utilização de equipamento.

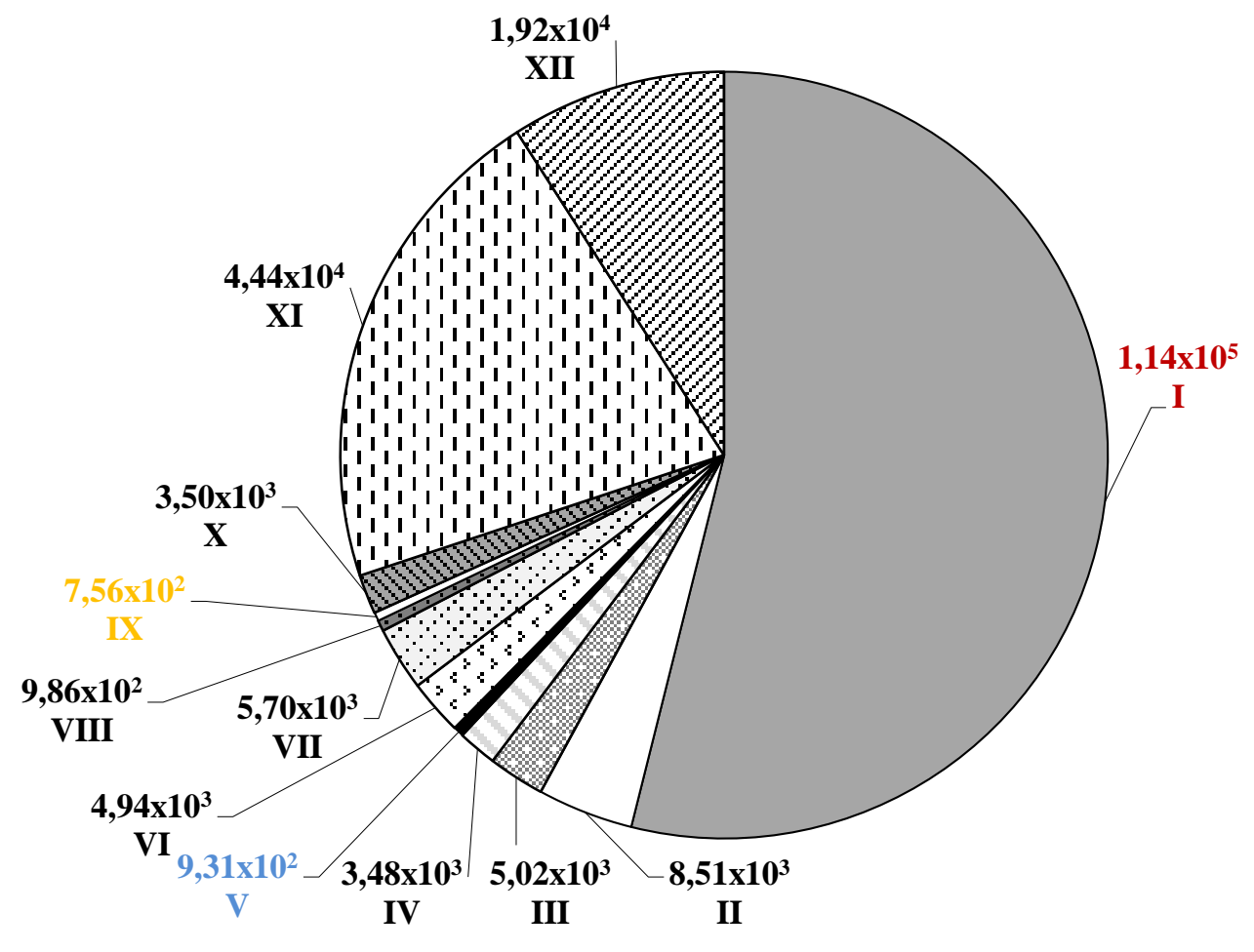

I: $\mathrm{NaOH}_{5} 5 \% / \mathrm{NaClO}_{2} 1 \% / 4 x$; II: $\mathrm{NaOH} 5 \% / \mathrm{NaClO}_{2} 1 \% / 1 \mathrm{x}$; III: $\mathrm{NaClO}_{2} 2 \% / \mathrm{NaOH} 4 \% / 4 x$; IV: $\mathrm{NaCOl}_{2} 2 \% / \mathrm{NaOH}$ $2 \% / 4 x$; V: $\mathrm{NaClO}_{2} 2 \% / \mathrm{NaOH} 2 \% / 1 \mathrm{x}$; VI: $\mathrm{NaOH} 5 \% / \mathrm{NaClO}_{2} 3,3 \% / 4 x$; VII: $\mathrm{NaOH} 5 \% / \mathrm{NaClO}_{2} 3,3 \% / 1 \mathrm{x}$; VIII: $\mathrm{NaOH} 5 \% / \mathrm{NaClO}_{2} 3,3 \% / 4 x$; IX: $\mathrm{NaOH} 5 \% / \mathrm{NaClO}_{2} 3,3 \% / 1 \mathrm{x}$; X: $\mathrm{NaOH} 25 \% / \mathrm{H}_{2} \mathrm{O}_{2} 30 \% / 4 x ; \mathrm{XI}: \mathrm{NaOH} 25 \% / \mathrm{H}_{2} \mathrm{O}_{2}$ $30 \% / 1 x ; \mathrm{XII}: \mathrm{NaOH} 25 \% / \mathrm{H}_{2} \mathrm{O}_{2} 11 \% / 1 x$.

Figura 4.3: Consumo de energia elétrica $\mathrm{MJ} / \mathrm{kg}$ NCC para cada processo.

Para diminuir o impacto dessa rota é necessário diminuir o uso de equipamento na fase de pré-tratamento ou utilizar resíduos (lignina) como fonte de energia, ou seja, produzir energia sem aumentar os níveis de dióxido de carbono e outros gases poluentes na atmosfera (SHEN; PATEL, 2010; KAHN, 2016).

Segundo Arvidsson et al. (2015), a energia requerida para destilação do etanol é aproximadamente $0,8 \mathrm{MJ} / \mathrm{kg}$ e para isopropanol $0,7 \mathrm{MJ} / \mathrm{kg}$. Juntos, o gasto de energia é muito menor que a energia requerida para obter $1 \mathrm{~kg}$ de nanocristais de celulose. O consumo de energia na produção da nanocristais de celulose, conforme estudo realizado por Figueirêdo et al. (2012), foi cerca de $1,80 \times 10^{3}$ a $1,60 \times 10^{4} \mathrm{MJ} / \mathrm{kg}$. Este elevado consumo de energia se deve 
principalmente a hidrólise com (120, 150 e 180 minutos). Para Gavankar et al. (2014), o consumo de energia contabilizado em seu estudo para a produção de nanotubos de carbono foi $\mathrm{de}$, aproximadamente, 100 a $10^{6} \mathrm{MJ} / \mathrm{kg}$. Este elevado consumo de energia se deve principalmente pela conversão do monóxido de carbono a alta pressão. Esse estudo a hidrólise foi de 30/60 minutos. Dessa forma, o consumo de energia para o processo IX foi muito menor que os resultados obtidos por Figueirêdo et al. (2012) e Gavankar et al. (2014), mostrando a competitividade desse material frente a outros produzidos comercialmente.

\section{Aquecimento global}

Analisando o potencial de aquecimento global, na Figura 4.4, o processo I consome muita água, energia e insumos. Assim, o processo I apresentou o maior potencial de aquecimento

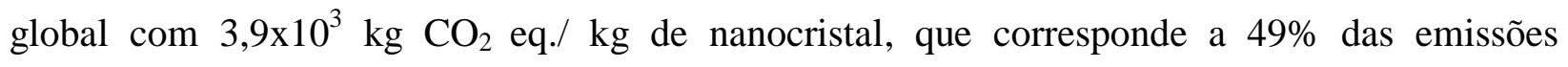
equivalentes de $\mathrm{CO}_{2}$, devido aos números elevados de consumo de água $\left(5,2 \times 10^{3} \mathrm{~kg} \mathrm{CO}_{2}\right.$ eq.), energia $\left(11,1 \mathrm{~kg} \mathrm{CO}_{2}\right.$ eq.) e insumos $\left(1,2 \times 10^{3} \mathrm{~kg} \mathrm{CO}_{2}\right.$ eq. $)$. Portanto, $5,4 \times 10^{6} \mathrm{~L}$ de água geraram $5,2 \times 10^{3} \mathrm{~kg} \mathrm{CO}$ eq./kg de nanocristal, de emissão para PAG. De acordo com Gonzalez; Veja (2016), a mudança climática (aumento da temperatura da terra ocorre evaporação da água dos rios) está afetando negativamente a disponibilidade de água em muitas regiões aumentando os riscos de escassez de água, como também o elevado consumo de reagentes para o tratamento da água, como mencionado anteriormente. Desse modo, a elevada pegada hídrica pode elevar o potencial de aquecimento global.

O processo IX apresentou menor potencial de aquecimento global com $13,7 \mathrm{~kg} \mathrm{CO}_{2}$ eq./ $\mathrm{kg}$ de nanocristal, que corresponde a $0,17 \%$ das emissões equivalentes de $\mathrm{CO}_{2}$, conforme a Figura 4.4 (Tabela 6 - apêndice A), devido menor consumo de água (16,6 $\mathrm{kg} \mathrm{CO}_{2}$ eq.), energia (8,0 $\mathrm{kg} \mathrm{CO}_{2}$ eq.) e insumos (16,1 kg CO 2 eq.). Portanto, $1,5 \times 10^{4} \mathrm{~L}$ de água geraram $16,6 \mathrm{~kg} \mathrm{CO}_{2}$ eq./kg de nanocristal, de emissão para PAG. Figueirêdo et al. (2012) apresentaram os estudos

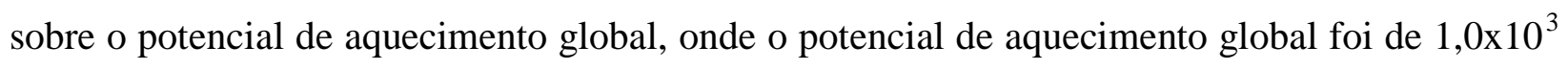
$\mathrm{kg} \mathrm{CO}_{2}$ eq. para obter $1 \mathrm{~kg}$ de nanocristais de celulose a partir da fibra de coco. De acordo com Figueirêdo et al. (2012), a produção e a distribuição de eletricidade é o principal responsável pelo impactos sobre as alterações climáticas e eutrofização em ambos os sistemas estudados. Para Khanna et al. (2008), a contribuição para o aquecimento global foi de 0,7 a $1,3 \times 10^{3} \mathrm{~kg} \mathrm{CO}_{2}$ eq. para a produção de $1 \mathrm{~kg}$ de nanofibras de carbono. 


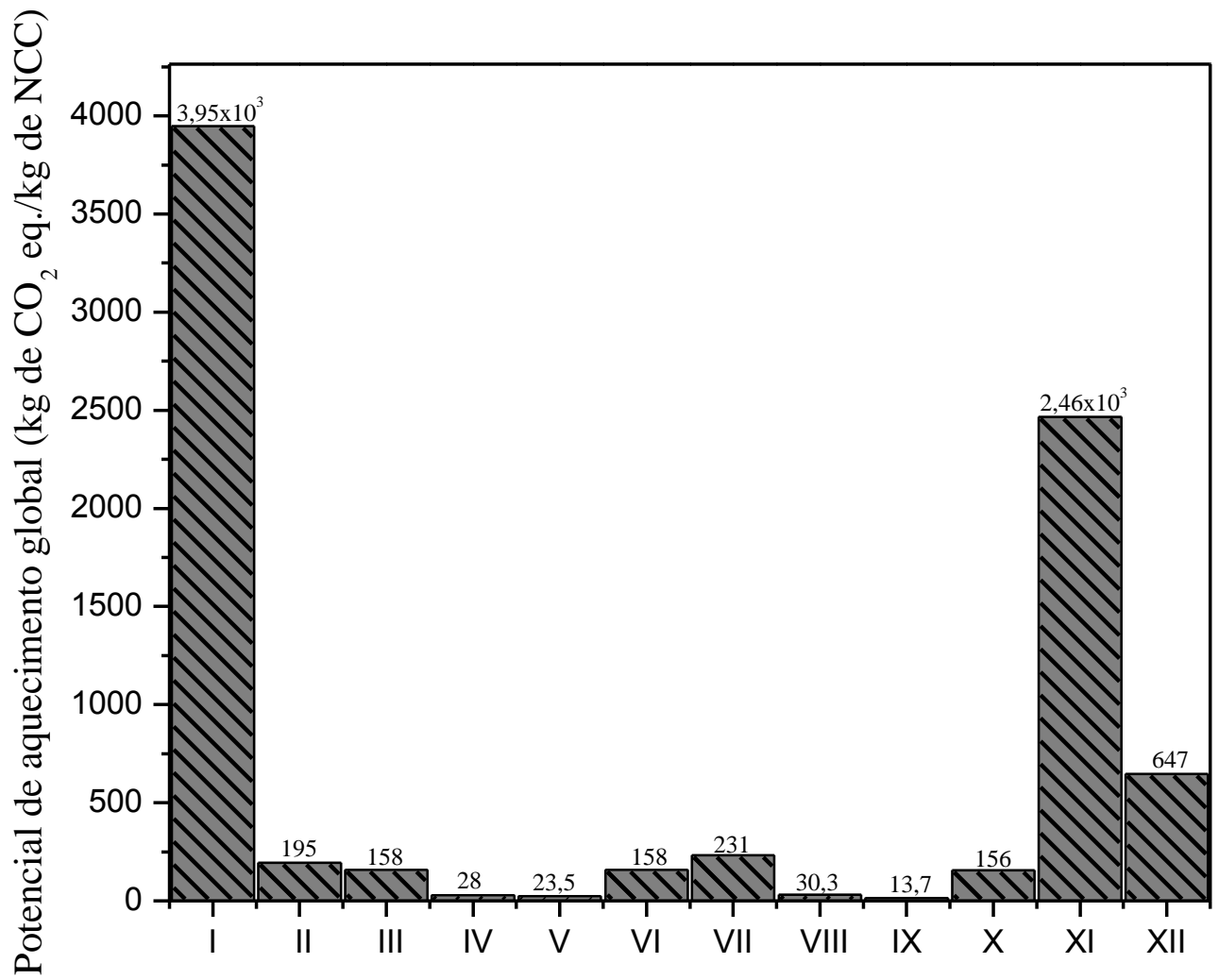

I: $\mathrm{NaOH}_{5} 5 \% / \mathrm{NaClO}_{2} 1 \% / 4 x$; II: $\mathrm{NaOH} 5 \% / \mathrm{NaClO}_{2} 1 \% / 1 x ;$ III: $\mathrm{NaClO}_{2} 2 \% / \mathrm{NaOH} 4 \% / 4 x ;$ IV: $\mathrm{NaCOl}_{2} 2 \% / \mathrm{NaOH}$ $2 \% / 4 x$; V: $\mathrm{NaClO}_{2} 2 \% / \mathrm{NaOH} 2 \% / 1 x$; VI: $\mathrm{NaOH} 5 \% / \mathrm{NaClO}_{2} 3,3 \% / 4 x$; VII: $\mathrm{NaOH} 5 \% / \mathrm{NaClO}_{2} 3,3 \% / 1 \mathrm{x}$; VIII: $\mathrm{NaOH} 5 \% / \mathrm{NaClO}_{2} 3,3 \% / 4 x$; IX: $\mathrm{NaOH} 5 \% / \mathrm{NaClO}_{2} 3,3 \% / 1 \mathrm{x} ; \mathrm{X}: \mathrm{NaOH} 25 \% / \mathrm{H}_{2} \mathrm{O}_{2} 30 \% / 4 x ; \mathrm{XI}: \mathrm{NaOH} 25 \% / \mathrm{H}_{2} \mathrm{O}_{2}$ $30 \% / 1 x ; \mathrm{XII}: \mathrm{NaOH} 25 \% / \mathrm{H}_{2} \mathrm{O}_{2} 11 \% / 1 x$.

Figura 4.4: Os potenciais de impactos ambientais na fase de produção: potencial de aquecimento global.

Desta forma, o potencial de aquecimento global do processo IX foi bem menor que os resultados obtidos por Figueirêdo et al. (2012) e Khanna et al. (2008), mostrando assim que o nanocristal de celulose obtido pelo processo IX tem boa performance ambiental comparado com os nanocristais obtidos pelos autores.

\section{Acidificação}

Avaliando-se o potencial de acidificação, verifica-se que a etapa de hidrólise gera resíduos para PA, assim, a fase da hidrólise apresentou maior contribuição quando comparada à 
fase de pré-tratamento, devido à grande quantidade de ácido $\left(\mathrm{H}_{2} \mathrm{SO}_{4}\right)$ e água destilada utilizada nesta fase.

O processo I consumiu muita água e ácido, e assim, contribuindo com maior potencial de acidificação com $26 \mathrm{~kg} \mathrm{SO}$ eq./ $\mathrm{kg}$ de nanocristal, que corresponde a $61 \%$ das emissões equivalentes de $\mathrm{SO}_{2}$ conforme a Figura 4.5. Este elevado consumo é devido a lavagem da suspensão até o pH neutro, que foi realizado com água destilada. No processo de lavagem sai água contaminada com hidróxido de sódio, ácido acético e ácido sulfúrico (15,0 kg $\mathrm{SO}_{2}$ eq.), dessa forma, esses elementos vão gerar insumos para PA, ou seja, a emissão para água causou

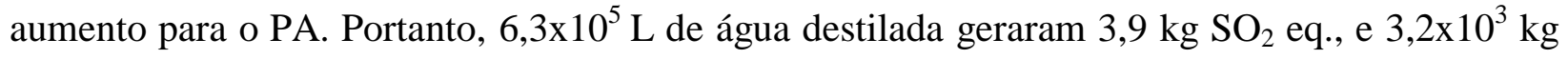
de $\mathrm{H}_{2} \mathrm{SO}_{4}$ geraram 14,2 $\mathrm{kg} \mathrm{SO}$ eq., de emissão para PA. E isso pode acarretar dano direto ao ambiente natural e artificial e indireto à saúde humana e aos recursos naturais EUROPEAN COMISSION, 2010; SHEN; PATEL, 2010; GHANTA et al., 2014).

O processo IX apresentou o menor potencial de acidificação, com 0,14 kg SO 2 eq./ kg de nanocristal, que corresponde a 0,43\% das emissões conforme a Figura 4.5 (Tabela 7 - apêndice A). No processo de lavagem sai água contaminada com hidróxido de sódio, ácido acético, ácido nítrico e ácido sulfúrico $\left(0,0413 \mathrm{~kg} \mathrm{SO}\right.$ eq.). Portanto, $1,0 \times 10^{3} \mathrm{~L}$ de água destilada geraram $0,0054 \mathrm{~kg} \mathrm{SO}$ eq., e 1,6x10 ${ }^{1} \mathrm{~kg}$ de $\mathrm{H}_{2} \mathrm{SO}_{4}$ geraram 0,0075 kg SO 2 eq., de emissão para PA. Este processo apresentou menor consumo de água, na lavagem da suspensão, que foi realizada com solução aquosa de hidróxido de sódio $(\mathrm{NaOH})$ a $0,05 \mathrm{M}$. Ou seja, quando se tem uma base $(\mathrm{NaOH})$ e um ácido $\left(\mathrm{H}_{2} \mathrm{SO}_{4}\right)$, uma substância, irá neutralizar as propriedades da outra, pois reagem quimicamente entre si e assim ocorrendo a neutralização, assim, levando o menor consumo de água nessa fase (RUSSEL, 2015).

Uma forma de reduzir a categoria de impacto dessa fase seria talvez utilizar ácido clorídrico ao invés de ácido sulfúrico. O ácido clorídrico é mais fácil de neutralizar, isso se deve, porque o $\mathrm{Pka}$ do $\mathrm{HCl}$ é menor do que $\mathrm{H}_{2} \mathrm{SO}_{4}$, assim o $\mathrm{HCl}$ reage com maior facilidade. Outra forma seria obter os nanocristais de celulose de forma mecânica, ou seja, utilizando um moinho micronizador, a partir da polpa branqueada e assim obtendo as nanopartículas. Jonoobi et al. (2012), desenvolveram um processo de micronização de polpa de celulose oriunda de resíduos da indústria de papel através do qual pode-se obter fibras em escala nanométrica sem a necessidade de utilizar produtos químicos. 


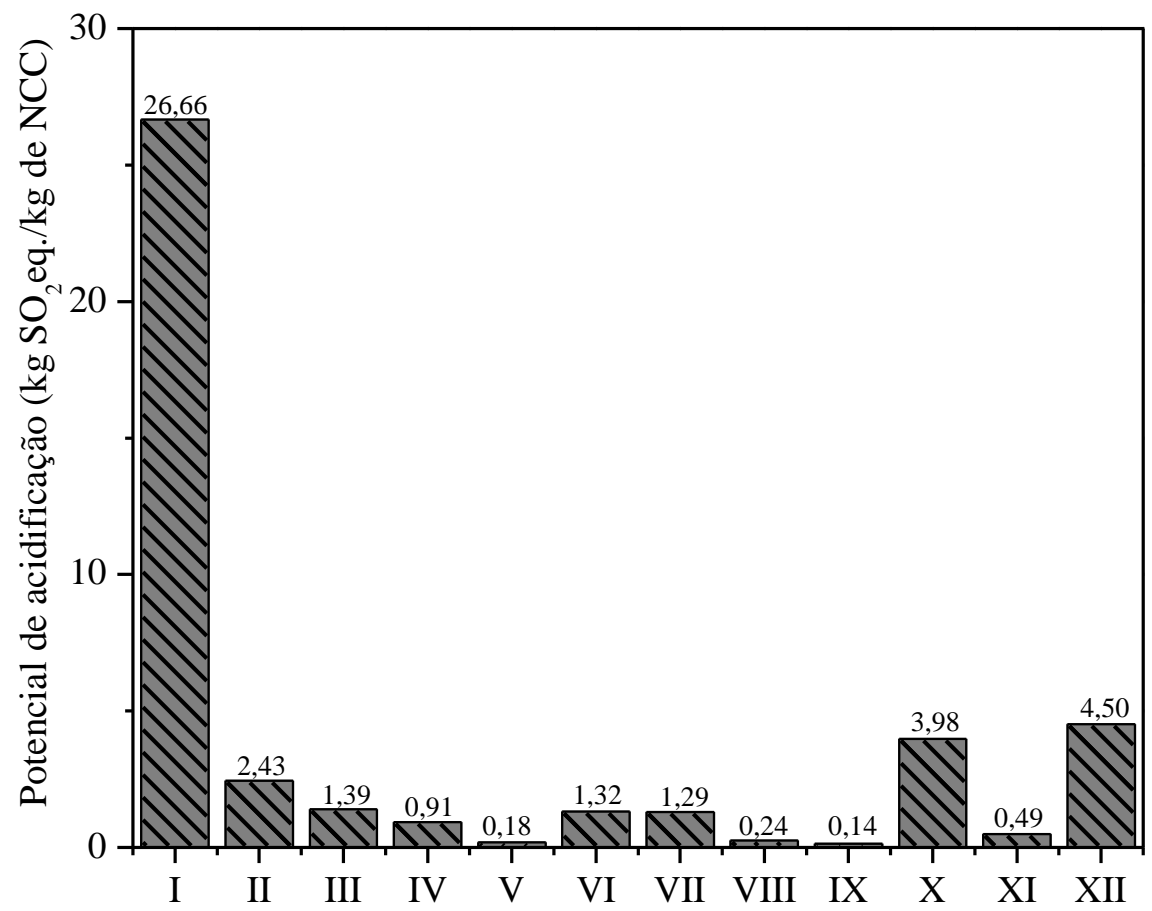

I: $\mathrm{NaOH}_{5} 5 \% / \mathrm{NaClO}_{2} 1 \% / 4 x$; II: $\mathrm{NaOH} 5 \% / \mathrm{NaClO}_{2} 1 \% / 1 \mathrm{x} ; \mathrm{III}: \mathrm{NaClO}_{2} 2 \% / \mathrm{NaOH} 4 \% / 4 x ; \mathrm{IV}: \mathrm{NaCOl}_{2} 2 \% / \mathrm{NaOH}$ 2\%/ 4x; V: $\mathrm{NaClO}_{2} 2 \% / \mathrm{NaOH} 2 \% / 1 \mathrm{x}$; VI: $\mathrm{NaOH} 5 \% / \mathrm{NaClO}_{2} 3,3 \% / 4 \mathrm{x}$; VII: $\mathrm{NaOH} 5 \% / \mathrm{NaClO}_{2} 3,3 \% / 1 \mathrm{x}$; VIII: $\mathrm{NaOH} 5 \% / \mathrm{NaClO}_{2} 3,3 \% / 4 x$; IX: $\mathrm{NaOH} 5 \% / \mathrm{NaClO}_{2} 3,3 \% / 1 x ; \mathrm{X}: \mathrm{NaOH} 25 \% / \mathrm{H}_{2} \mathrm{O}_{2} 30 \% / 4 x ; \mathrm{XI}: \mathrm{NaOH} 25 \% / \mathrm{H}_{2} \mathrm{O}_{2}$ $30 \% / 1 x$; XII: $\mathrm{NaOH} 25 \% / \mathrm{H}_{2} \mathrm{O}_{2} 11 \% / 1 x$.

Figura 4.5: Os potenciais de impactos ambientais na fase de produção: potencial de acidificação.

\section{Eutrofização}

Dentre os processos, o processo I apresenta o maior potencial de eutrofização, com $2,59 \mathrm{~kg} \mathrm{PO}{ }_{4}$ eq./ $\mathrm{kg}$ de nanocristal, que corresponde a $62 \%$ das emissões equivalentes de $\mathrm{PO}_{4}{ }^{-}$, devido à grande quantidade de insumos ( $\mathrm{NaOH} ; \mathrm{C}_{2} \mathrm{H}_{4} \mathrm{O}_{2}$ e $\mathrm{H}_{2} \mathrm{SO}_{4} 0,31 \mathrm{~kg} \mathrm{PO}{ }_{4}$ eq.) e água $(2,27$ $\mathrm{kg} \mathrm{PO}_{4}{ }^{-}$eq.), portanto, a emissão para água aumenta o PE. Portanto, $5,43 \times 10^{6} \mathrm{~L}$ de água geraram 2,27 kg de $\mathrm{PO}_{4}{ }^{-}$eq, de emissão para PE. O processo IX apresentou menor contribuição com 0.01 $\mathrm{kg} \mathrm{PO}_{4}{ }^{-}$eq./ $\mathrm{kg}$ de nanocristal, que corresponde a $0,47 \%$ das emissões equivalentes de $\mathrm{PO}_{4}{ }^{-}$, devido quantidade de insumos para água ( $\mathrm{NaOH} ; \mathrm{C}_{2} \mathrm{H}_{4} \mathrm{O}_{2} ; \mathrm{HNO}_{3}$ e $\mathrm{H}_{2} \mathrm{SO}_{4} 0,007 \mathrm{~kg} \mathrm{PO}_{4}{ }^{-}$eq.) e água $\left(0,003 \mathrm{~kg} \mathrm{PO}_{4}{ }^{-}\right.$eq.) conforme a Figura 4.6 (Tabela 8 - apêndice A). Portanto, $1,5 \times 10^{4} \mathrm{~L}$ de água geraram 0,007 $\mathrm{kg}$ de $\mathrm{PO}_{4}{ }^{-}$eq., de emissão para $\mathrm{PE}$. Desse modo, as lavagens podem 
acarretar emissões de nutrientes para a água, e com isso eleva o PE. Com relação às emissões de nutrientes, observou-se que a maior carga de nitrato foi proveniente do subprocesso de hidrólise. Avaliando os valores do fósforo e do nitrogênio, percebeu-se que a maior carga foi gerada no subprocesso de lavagem, que retiraram resíduos e parte da lignina das fibras. O nitrato, nitrogênio e o fósforo podem levar à eutrofização de corpos hídricos (CAVALCANTE et al., 2010; FIGUEIRÊDO et al., 2012). Isso pode acarretar alteração no meio e os macronutrientes pode limitar o crescimento de algas, provocando a morte de peixes e impossibilitando o consumo da água EUROPEAN COMISSION, 2010; SHEN; PATEL, 2010; GHANTA et al., 2014).

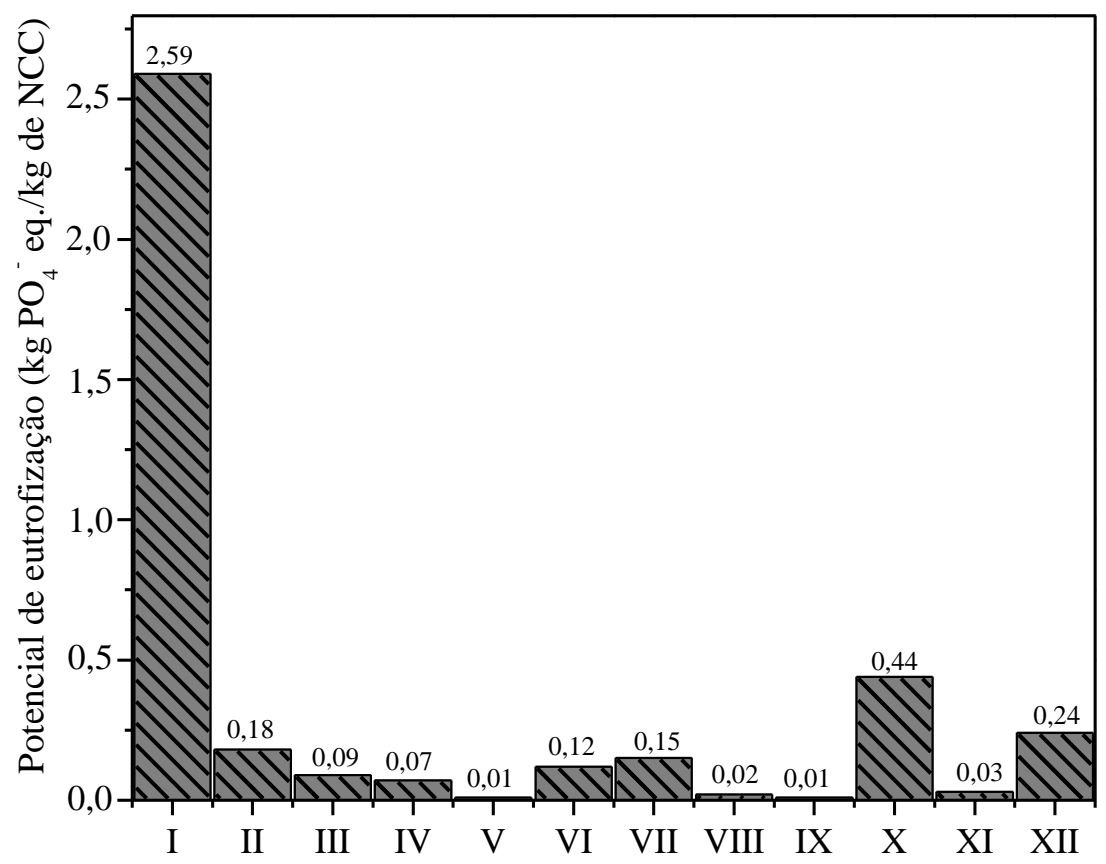

I: $\mathrm{NaOH}_{5} 5 \% / \mathrm{NaClO}_{2} 1 \% / 4 x$; II: $\mathrm{NaOH} 5 \% / \mathrm{NaClO}_{2} 1 \% / 1 x ;$ III: $\mathrm{NaClO}_{2} 2 \% / \mathrm{NaOH} 4 \% / 4 x ;$ IV: $\mathrm{NaCOl}_{2} 2 \% / \mathrm{NaOH}$ $2 \% / 4 x$; V: $\mathrm{NaClO}_{2} 2 \% / \mathrm{NaOH} 2 \% / 1 \mathrm{x}$; VI: $\mathrm{NaOH} 5 \% / \mathrm{NaClO}_{2} 3,3 \% / 4 x$; VII: $\mathrm{NaOH} 5 \% / \mathrm{NaClO}_{2} 3,3 \% / 1 \mathrm{x}$; VIII: $\mathrm{NaOH} 5 \% / \mathrm{NaClO}_{2} 3,3 \% / 4 x$; IX: $\mathrm{NaOH} 5 \% / \mathrm{NaClO}_{2} 3,3 \% / 1 \mathrm{x} ; \mathrm{X}$ : $\mathrm{NaOH} 25 \% / \mathrm{H}_{2} \mathrm{O}_{2} 30 \% / 4 x ; \mathrm{XI}$ : $\mathrm{NaOH} 25 \% / \mathrm{H}_{2} \mathrm{O}_{2}$ $30 \% / 1 x$; XII: $\mathrm{NaOH} 25 \% / \mathrm{H}_{2} \mathrm{O}_{2} 11 \% / 1 \mathrm{x}$.

Figura 4.6: Os potenciais de impactos ambientais na fase de produção: potencial de eutrofização 
Apesar da fase de pré-tratamento do processo IX apresentar maior concentração dos reagentes em relação ao processo I, foi compensado pelo rendimento conforme a Tabela $4.1 \mathrm{e}$ menor consumo de água, apresentando assim menor impacto em todas as categorias avaliadas. Estes resultados mostram que é necessário focar na melhora do rendimento em todas as fases. Segundo Wang et al. (2014), a temperatura de reação e tempo pode afetar o rendimento NCC. Para a celulose branqueada de eucalipto, em ácido sulfúrico com concentração entre 58-62\% $(\mathrm{m} / \mathrm{m})$ a uma temperatura de $50-60^{\circ} \mathrm{C}$ aumenta o rendimento do NCC com um tempo de reação entre 30 e 180 minutos e reduz a perda de açúcares. A literatura reporta baixo rendimento na obtenção dos nanocristais de celulose (com 45 min 6,8\% e com 60 min 4,9\%) (JIANG; HSIEH, 2013).

Vale ressaltar, que as análises dos resultados revelaram diferenças nos impactos ambientais, que pode ser explicada por: diferenças nas concentrações, diferença nas quantidades de bagaço de cana-de-açúcar e nos produtos finais; diferenças no consumo de energia e de água. $\mathrm{O}$ rendimento tem papel fundamental na contabilização dos impactos ambientais, pois rotas de tratamento que apresentem baixo rendimento em nanocristais de celulose, consequentemente, apresentam grandes impactos ambientais.

\section{Interpretação}

$\mathrm{Na}$ fase da produção dos nanocristais foi calculada a média para o PAG em torno de $671 \%$, assim, o processo I está com 488\% acima da média e o processo IX está com 97\% abaixo da média. Os principais contribuintes nessa fase foram energia, água e insumos. É muito importante reduzir o consumo principalmente de água, porque na produção da água emite $\mathrm{CO}_{2}$; $\mathrm{SO}_{2} ; \mathrm{PO}_{4}{ }^{-}$entre outros, e assim contribuindo com PAG, PA e PE.

Foi calculada a média para PA em torno de $3,64 \%$, o processo I está com $632 \%$ acima da média e o processo IX está com $94 \%$ abaixo da média. O principal contribuinte nessa fase foi ácido sulfúrico e água, portanto, o processo I consome muito ácido e água, esses elementos para a água gera aumento para o PA.

Foi calculada a média para PE em torno de 1,19\%, o processo I está com 119\% acima da média e o processo IX está com $94 \%$ abaixo da média. O principal contribuinte nessa fase foi insumos e água, portanto, esses insumos para a água gera aumento para o PE. 
O consumo de água e energia foi extensivamente elevado, este fator foi o que mais contribuiu para elevação das categorias de impacto local ou regional. Portanto, o consumo excessivo da água da rede interfere significativamente dentro do sistema, através das emissões equivalentes de fosfato, $\mathrm{SO}_{2}$ e $\mathrm{CO}_{2}$ contribui para o aumento do PE, PA e PAG.

\section{Limitações}

Deve-se buscar alternativas para melhorar desempenho ambiental e reduzir o uso de energia e água. $\mathrm{O}$ rendimento de todos os processos pode ser substancialmente melhorado com melhor controle de perda de fibra, especialmente durante a fase da hidrólise. Ainda, não há um equipamento eficiente para a lavagem dos nanocristais em grandes quantidades.

Como também, devem ser investigados equipamentos mais eficientes em termos energéticos, especialmente na fase de pré-tratamento, para reduzir a demanda de energia elétrica nestes processos.

\subsection{CARACTERIZAÇÃO DAS FIBRAS DE BAGAÇO DE CANA-DE-AÇÚCAR IN NATURA}

Conforme mencionado anteriormente, foram aplicados 12 processos distintos de tratamento químico para as fibras de bagaço de cana-de-açúcar. A Tabela 4.1 mostra os rendimentos de alguns processos, o rendimento para bagaço pré-tratado foi entre 36-97\% e o rendimento para a polpa branqueada foi entre $30-89 \%$, o baixo rendimento, provavelmente se deve a perda durante as fases de lavagens como também degradação dos componentes devido à concentração de álcali em alta temperatura. No tratamento alcáli a hemicelulose é hidrolisada (EL MIRI et al., 2015; MANDAL; CHAKRABARTY, 2011; FENGEL; WEGENER, 2003). 
Tabela 4.1: Rendimento das fases de obtenção dos NCC.

\begin{tabular}{cccc}
\hline Processos & $\begin{array}{c}\text { Bagaço pré-tratado } \\
(\boldsymbol{\%})\end{array}$ & $\begin{array}{c}\text { Polpa branqueada } \\
(\boldsymbol{\%})\end{array}$ & $\begin{array}{c}\text { Nanocristais } \\
(\boldsymbol{\%})\end{array}$ \\
\hline III & 86 & 58 & 8 \\
V & 83 & 44 & 8 \\
VI & 85 & 32 & 8 \\
VII & 97 & 30 & 11 \\
VIII & 61 & 43 & 68 \\
IX & 66 & 48 & 67 \\
X & 36 & 76 & 4 \\
XI & 36 & 89 & 9 \\
XII & 36 & 77 & 27 \\
\hline
\end{tabular}

III: $\mathrm{NaClO}_{2} 2 \% / \mathrm{NaOH} 4 \% / 4 x$; V: $\mathrm{NaClO}_{2} 2 \% / \mathrm{NaOH} 2 \% / 1 \mathrm{x}$; VI: $\mathrm{NaOH} 5 \% / \mathrm{NaClO}_{2} 3,3 \% / 4 \mathrm{x}$; VII: $\mathrm{NaOH}$ $5 \% / \mathrm{NaClO}_{2} 3,3 \% / 1 \mathrm{x}$; VIII: $\mathrm{NaOH} 5 \% / \mathrm{NaClO}_{2} 3,3 \% / 4 \mathrm{x}$; IX: $\mathrm{NaOH} 5 \% / \mathrm{NaClO}_{2} 3,3 \% / 1 \mathrm{x} ; \mathrm{X}: \mathrm{NaOH} 25 \% / \mathrm{H}_{2} \mathrm{O}_{2}$ $30 \% / 4 x$; XI: $\mathrm{NaOH} 25 \% / \mathrm{H}_{2} \mathrm{O}_{2} 30 \% / 1 x$; XII: $\mathrm{NaOH} 25 \% / \mathrm{H}_{2} \mathrm{O}_{2} 11 \% / 1 \mathrm{x}$.

O rendimento foi de 4-68\% para os nanocristais de celulose, ocorrendo perdas nas lavagens. A literatura reporta baixo rendimento na obtenção dos nanocristais de celulose (com 45 min 6,8\% e com 60 min 4,9\%) (JIANG; HSIEH, 2013). Segundo Wang et al. (2014), a temperatura de reação e tempo pode afetar o rendimento NCC, mas não podem afetar o rendimento máximo NCC para uma dada concentração de ácido. Uma forma de melhorar o rendimento seria fazer as lavagens dos $\mathrm{NCC}$ com $\mathrm{NaOH}$, como mostra o processo VIII e IX. Assim, analisando os processos, os processos V e o IX foram escolhidos para aplicação em nanocompósitos por apresentar melhor desempenho ambiental, comprovado pela ACV.

Na Figura 4.7 são apresentadas as imagens com um aumento de 20 vezes no estereomicroscópio do bagaço in natura (BC) e dos processos $\mathrm{V}\left(\mathrm{NaClO}_{2} 2 \% / \mathrm{NaOH} 2 \% / 1 \mathrm{x}\right)$ e IX $\left(\mathrm{NaOH} 5 \% / \mathrm{NaClO}_{2} 3,3 \% / 1 \mathrm{x}\right)$ de bagaços pré-tratados (BPT), polpas branqueadas (PB) e nanocristais de celulose (NCCV ou NCCIX) e no apêndice (B) estão apresentados os outros processos. A coloração inicial da fibra in natura foi marrom escuro, depois a coloração mudou de acordo com o tratamento. 

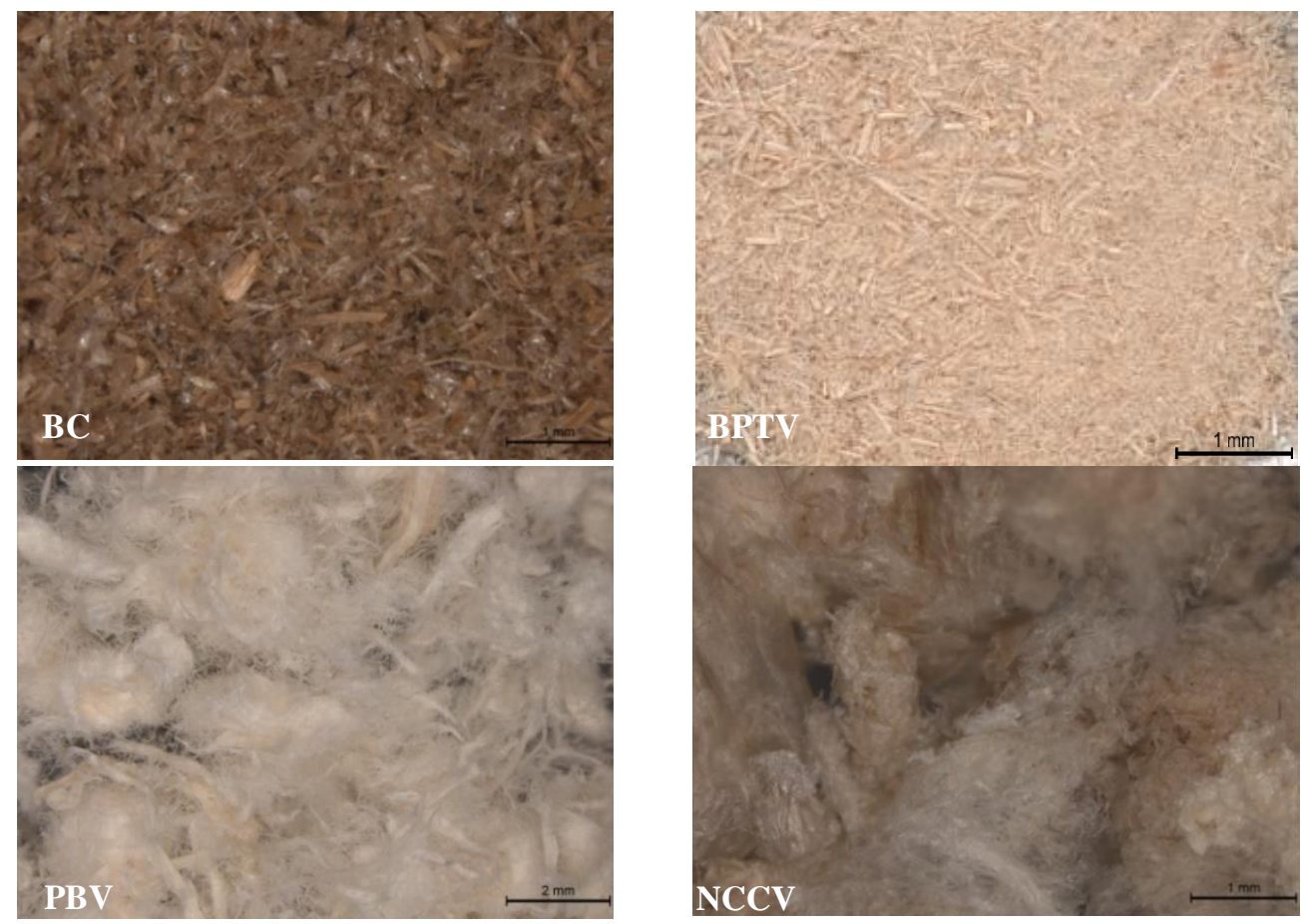

(A)
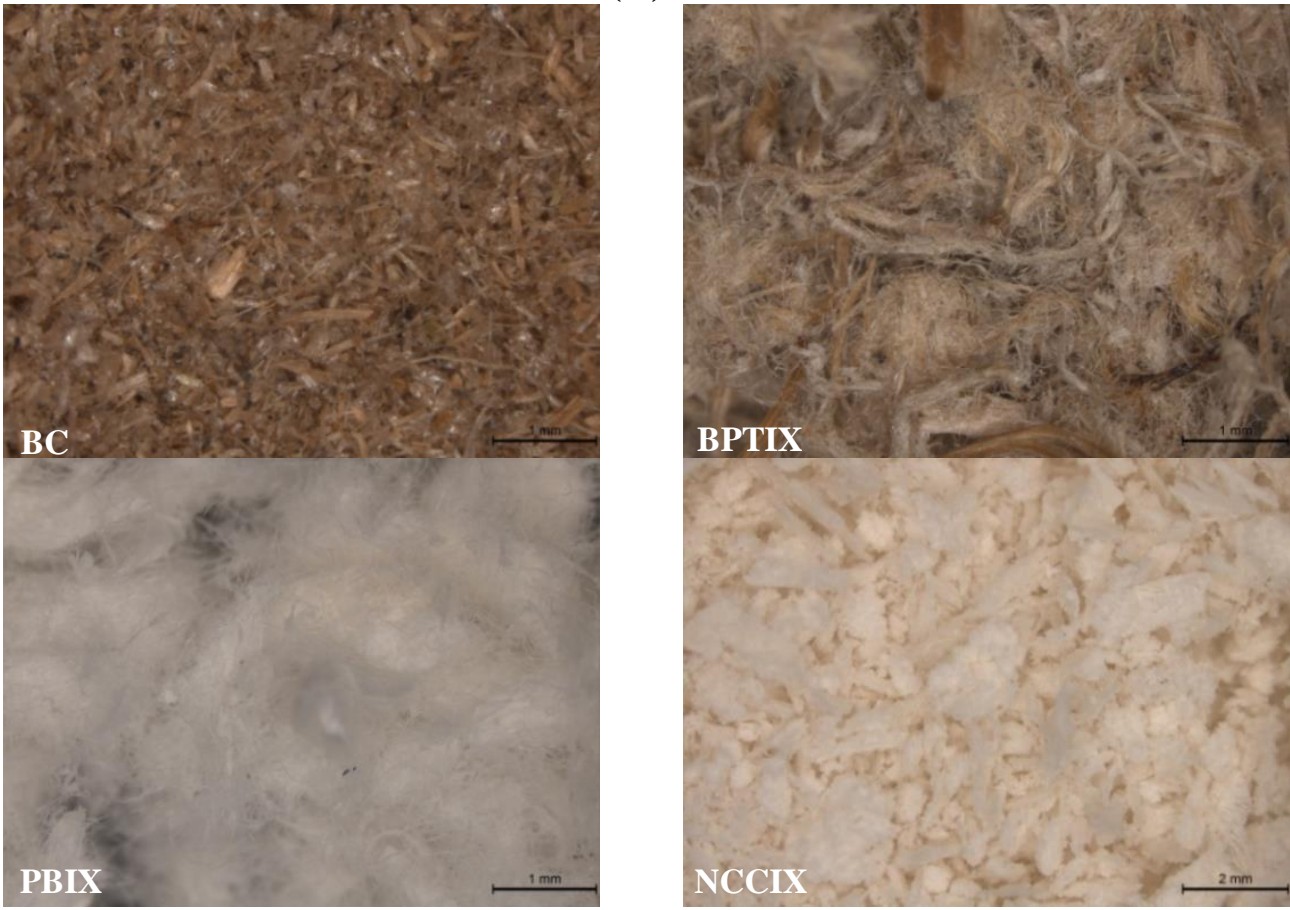

(B)

Figura 4.7. Imagens estereomicroscópio (20 vezes) de bagaço de cana (BC); bagaço pré-tratados (BPT); polpa branqueada (PB); nanocristais de celulose (NCCV); e nanocristais de celulose (NCCIX) dos processos V e IX. 
No pré-tratamento, a celulose apresentou coloração marrom clara com aspecto de algodão. Segundo Leão et al. (2015), a mudança de cor das fibras provavelmente está associada com a quebra da ligação química da lignina e extrativos durante o tratamento, ocorrendo desfibrilação parcial das fibras. Esta coloração pode estar relacionada com os produtos de degradação de açúcares que são gerados em temperatura elevadas de tratamento. $\mathrm{O}$ objetivo deste tratamento foi eliminar parcialmente componentes não celulósicos, resultando na celulose de bagaço pré-tratado (EL MIRI et al., 2015; MANDAL; CHAKRABARTY, 2011; FENGEL; WEGENER, 2003).

No branqueamento observou-se alteração na coloração da celulose, de marrom claro para branco, ou seja, purificação da celulose conforme a Figura 4.10. O branqueamento tem como objetivo a remoção da lignina residual (através da formação do complexo e despolimerização) e seus derivados para obtenção de um maior grau de pureza, levando as fibras celulósicas à coloração branca (PEREIRA et al., 2011; DUFRESNE, 2013; MANDAL; CHAKRABARTY, 2011; KARGARZADEH et al., 2012). Assim, nesta fase ocorreu a purificação das fibras celulósicas de qualquer impureza residual (lignina ou outras), ocorrendo oxidação dos grupos cromóforos presentes na lignina (PEREIRA et al., 2011; MOON et al., 2011). Este tratamento pode resultar em desfibrilação da celulose com também apresentar microfibrilas com um diâmetro menor conforme é mostrado no MEV (EL MIRI et al., 2015). A lignina reage com $\mathrm{NaClO}_{2}$ e dissolve, aumentando assim, a celulose pura, resultando em polpa branqueada (ABRAHAMA et al., 2011; ROSLI et al., 2013).

Portanto, esses tratamentos causam degradação da hemicelulose e a transformação da lignina pela alta temperatura e ação química. A hemicelulose tem uma estrutura amorfa, portanto, os reagentes químicos podem ter maior acesso do que na celulose. Assim, os residuos não celulósicos foram removidos ou parcialmente removidos após o branqueamento das fibras. A mercerização (tratamento alcalino) levou ao inchaço das fibras o que facilitou a quebra durante a hidrólise ácida (ABRAHAMA et al., 2011). Segundo FENGEL; WEGENER (2003), o comportamento das macromoléculas depende da concentração das soluções. Esta mudança está associada com as ligações de hidrogênio.

Na hidrólise observou-se uma suspensão coloidal (aspecto gelatinoso) apresentando uma coloração de marrom claro a branco. Essa fase visou à quebra das ligações intermoleculares, 
isolamento dos nanocristais de celulose. Ou seja, a hidrólise foi realizada em condições adequadas que permitiram a remoção dos domínios amorfos a partir da polpa branqueada, ocorrendo à clivagem das microfibrilas de celulose em dimensões nanométricas (EL MIRI et al., 2015; KARGARZADEH et al., 2012).

A determinação de umidade e extrativos foi somente realizada para o material in natura, Para os materiais obtidos nas fases de pré-tratamento das fibras, essa determinação é considerada insignificante dentro do desvio padrão das medidas quantitativas realizadas, uma vez que estas substâncias são removidas durante o pré-tratamento.

Como mencionado anteriormente, a fibra de bagaço foi caracterizada a fim de conhecer as características iniciais das fibras antes e depois de cada fase de tratamento até a obtenção dos nanocristais. Isto é importante, pois os resultados podem estar relacionados à composição inicial da fibra lignocelulósica. O teor de umidade de uma fibra lignocelulósica está relacionado com o seu teor de água presente na fibra, no caso da fibra de bagaço o valor encontrado experimentalmente foi de 7,8\% $\pm 0,03(\mathrm{~m} / \mathrm{m})$. Segundo Joseph et al. (1999), as fibras naturais são de natureza hidrofílica e o teor de umidade normalmente atinge de 8 a $13 \%(\mathrm{~m} / \mathrm{m})$. O teor de umidade de uma madeira é a relação entre o peso da água contida no seu interior (a madeira se expande) e o seu peso no estado completamente seco (madeira se contrai), expresso em porcentagem. Esta técnica baseia-se na perda por secagem em estufa e visa definir a quantidade de substâncias voláteis de qualquer natureza (FENGEL; WEGENER, 2003).

Para a determinação dos teores de extrativos, as amostras foram submetidas à extração com acetona. Nesta extração pode haver a remoção de pigmentos, corantes, taninos, flobafenos e estilbenos, entre outros (FENGEL; WEGENER, 2003). O teor de extrativos solúveis em acetona foi de 7,2\% $\pm 0,8(\mathrm{~m} / \mathrm{m})$. A acetona é polar, sendo assim, foram removidos os compostos polares da fibra de bagaço. De acordo com Silvério et al. (2006), os compostos solúveis em solventes orgânicos pertencem às classes dos ácidos e ésteres graxos, álcoois de cadeia longa, esteroides, compostos fenólicos e glicosídeos.

As análises do teor de celulose, lignina e hemicelulose foram utilizadas como parâmetro de comparação entre as eficiências dos métodos de tratamento, assim, verificando a quantidade de celulose em cada fase. A remoção dos constituintes é de suma importância para o controle da hidrólise. Desta forma, durante a hidrólise é necessário uma celulose pura, pois outros componentes poderiam dificultar a difusão do ácido até às regiões amorfas da celulose e poderia 
gerar lignina insolúvel, devido ao meio ácido, que poderia precipitar durante o processo de hidrólise ou gerar produtos secundários (FENGEL; WEGENER, 2003).

A Tabela 4.2 mostra os resultados das análises feitas para o bagaço in natura e para cada fase de tratamento do processo V e processo IX, mostrando elevado teor de celulose. Este resultado é esperado, na literatura há muitos trabalhos destacam a maior quantidade de celulose da fibra de cana-de-açúcar frente às outras fibras naturais fibra de coco (celulose $27 \%$, hemicelulose $19 \%$ e lignina 41\%) (LEÃO et al., 2015; CORRADINI et al., 2009). Os valores obtidos para composição química do bagaço in natura estão bem parecidos aos dados encontrados por REZENDE et al., (2011): celulose 35\% $\pm 0,9$; hemicelulose $24 \pm 0$,6; lignina 22 $\pm 0,1$. Analisando-se os resultados, foi possível observar que, de maneira geral, as fibras de bagaço de cana-de-açúcar possuem maior porcentagem de celulose e menor porcentagem de lignina e hemicelulose em sua composição, quando comparadas às fibras de coco. A literatura reporta que a constituição das fibras depende do tipo de solo, das condições climáticas, dos fertilizantes utilizados, do tipo de colheita das folhas, dos frutos e do caule dos vegetais (LEÃO et al., 2015; BLEDSKI; GASSAN, 1999; FENGEL; WEGENER, 2003). Segundo Leão et al. 2015), o balanço de massa não chegou a 100\% devido à presença de outros compostos de baixa massa molar, lignina solúvel e extrativos solúveis em diferentes solventes, que não puderam ser determinados nestas análises.

Foi possível observar que o pré-tratamento resultou na diminuição do teor de hemicelulose, lignina e o aumento do teor de celulose (PEREIRA et al., 2014), deste modo, ocorreu uma alteração definitiva na estrutura morfológica da fibra após o pré-tratamento. O tratamento alcáli remove a hemicelulose e o branqueamento remove a lignina residual. Estes resultados mostraram a suma importância do branqueamento na purificação da celulose antes da hidrólise (SANTOS et al., 2013).

Holocelulose é um termo aplicado para designar a celulose e hemicelulose obtidos após a remoção da lignina da fibra natural. Ou seja, uma deslignificação deve resultar na remoção total da lignina sem remoção dos polissacarídeos das fibras, sendo os polissacarídeos não celulósicos (hemicelulose) (KLOCK, 2005). Em resumo, a $\alpha$-celulose é a porção da holocelulose (celulose e hemicelulose) que é insolúvel em $\mathrm{NaOH} 17,5 \%(\mathrm{~m} / \mathrm{v})$ e a $\beta$-celulose é determinada como sendo a porção da celulose que é dissolvida em $\mathrm{NaOH}$ 17,5\% (m/v), mas, precipita quando a solução é neutralizada (HORVATH, 2006; HOOK et al., 2015). Assim, a celulose concentra a maior parte na 
$\alpha$-celulose, desse modo, o teor mais elevado de $\alpha$-celulose nas fibras de bagaço de cana é observado na polpa branqueada, isso ocorre por que durante o processo de fabricação kraft, a maior parte da lignina e da hemicelulose é dissolvida no estágio de deslignificação (VILA et al., 2011).

Tabela4.2: Composição química do bagaço in natura e das diferentes fases de tratamento.

\begin{tabular}{|c|c|c|c|c|}
\hline \multirow[b]{2}{*}{ In Natura } & \multicolumn{3}{|c|}{ Bagaço de cana-de-açúcar } & \multirow[b]{2}{*}{ Hemicelulose } \\
\hline & Holocelulose & $\alpha$-celulose & Lignina & \\
\hline & $67,2 \pm 1,2$ & $39,6 \pm 1,3$ & $21,8 \pm 1,3$ & $27,6 \pm 0,1$ \\
\hline & & \multicolumn{2}{|l|}{ Processo V } & \\
\hline Tratamentos & & $\alpha$-celulose & Lignina & Hemicelulose \\
\hline Bagaço pré-tratado & $72,7 \pm 0,25$ & $49,9 \pm 0,65$ & $16,7 \pm 0,55$ & $22,8 \pm 0,4$ \\
\hline \multirow[t]{2}{*}{ Polpa branqueada } & $84,6 \pm 0,56$ & $83,7 \pm 0,54$ & $3,3 \pm 0,93$ & $0,94 \pm 0,02$ \\
\hline & & \multicolumn{2}{|l|}{ Processo IX } & \\
\hline Tratamentos & & $\alpha$-celulose & Lignina & Hemicelulose \\
\hline Bagaço pré-tratado & $80,9 \pm 0,03$ & $68,9 \pm 0,28$ & $8,8 \pm 0,72$ & $11,6 \pm 0,32$ \\
\hline Polpa branqueada & $85,1 \pm 0,09$ & $84,8 \pm 0,42$ & $2,9 \pm 0,08$ & $0,32 \pm 0,33$ \\
\hline
\end{tabular}

\subsection{CARACTERIZAÇÃO MORFOLÓGICA DAS FIBRAS E DOS NANOCRISTAIS DE CELULOSE}

Os materiais lignocelulósicos, nas suas formas naturais ou resultados de algum processo de caráter físico ou químico, são constituídos por uma grande quantidade de partículas as quais podem ser de diferentes formas e tamanhos, e terem características físicas específicas. Visando obter um aproveitamento mais eficiente destes materiais, isso requer um conhecimento das características físico-químicas destes materiais tais como caracterizações por difração de raios-X, FTIR; MEV, MET, MFA, TGA/DSC e TGA/FTIR.

\subsubsection{Caracterização das fibras e dos nanocristais de celulose por difração de raios-x}

A análise por difração de raios-X permitiu a caracterização da microestrutura dos materiais cristalinos. Todos os processos (bagaços pré-tratados, polpas branqueadas e nanocristais de celulose), mostraram uma estrutura típica de celulose I verificado pela presença dos picos em torno de $22^{\circ}$ e $15^{\circ}$ o que representa o plano cristalográfico $(110 ; 200)$, conforme a Figura 4.8. De acordo com a literatura, picos nessas regiões indica que a celulose extraída do bagaço pode ser considerada como uma estrutura cristalina típica de celulose I (ZHOU et al., 2012; ZAINI et al., 2013; ROSA et al., 2012; KARGARZADEH et al., 2012; YU et al., 2012; 
LIU et al., 2010; SANTOS et al., 2013; SILVERIO et al., 2013; HUG et al., 2012; GUIMARÕES et al., 2009). De acordo com MA et al. (2011), nos difratogramas da celulose I os picos são apresentados a $16,39^{\circ}$ e $22,53^{\circ}$ para os planos (110) e (200); e para a celulose II os picos são apresentados a $19,8^{\circ}$ e $22,0^{\circ}$ para os planos (110) e (200). Portanto, não foi observado celulose II neste trabalho.

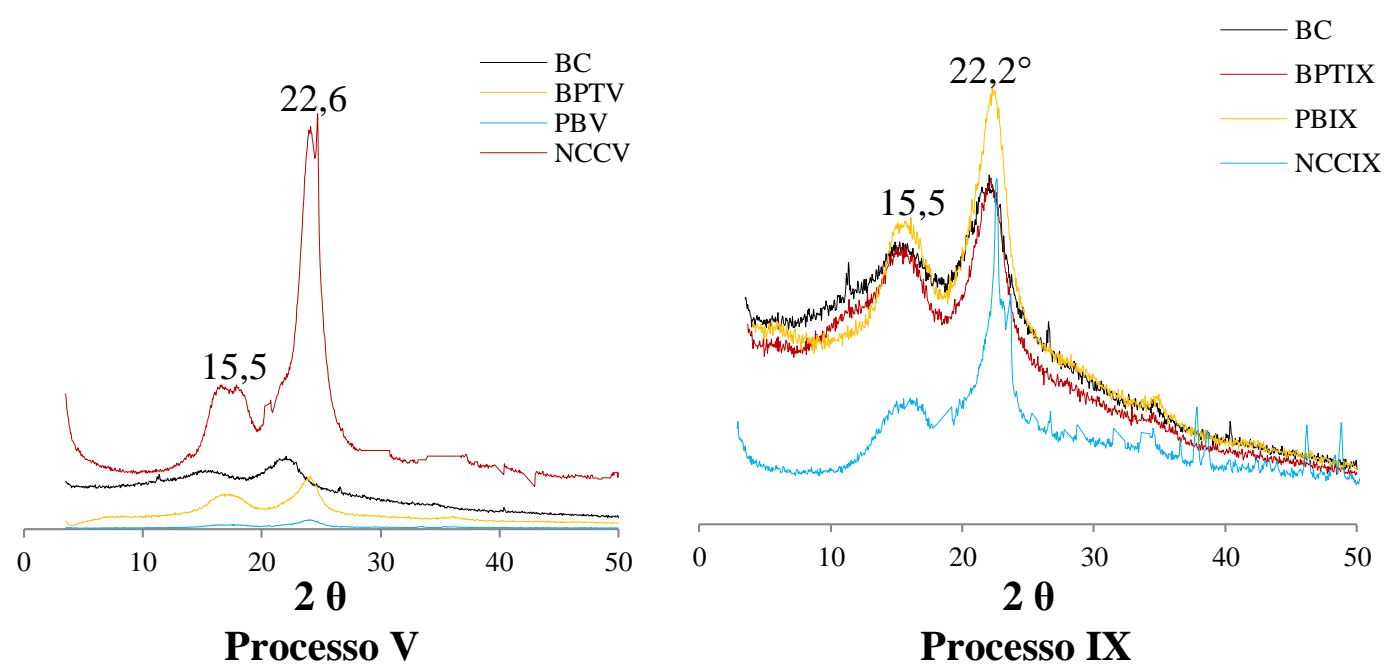

Processo V $\left(\mathrm{NaClO}_{2} 2 \% / \mathrm{NaOH} 2 \% / 1 \mathrm{x}\right)$; e processo IX ( $\left.\mathrm{NaOH} 5 \% / \mathrm{NaClO}_{2} 3,3 \% / 1 \mathrm{x}\right)$.

Figura 4.8: Difratogramas de raios X: bagaço de cana (BC); bagaço pré-tratados (BPT); polpa branqueada (PB); nanocristais de celulose (NCCV); e nanocristais de celulose (NCCIX).

A celulose presente em fibras brutas é a celulose I e após tratamento alcalino, ocorre à transformação para a celulose II (conforme a Figura 2.6). É relatado que a transformação cristalina das fibras naturais ocorre com uma concentração álcali de até $32 \%(\mathrm{~m} / \mathrm{v})$ e neste trabalho foi utilizado uma concentração máxima de $\mathrm{NaOH} 5 \%(\mathrm{~m} / \mathrm{v})$. Portanto, quanto menor concentração álcali, menor é a acessibilidade à molécula de celulose, e assim limitando a transformação da celulose (ABRAHAM et al., 2011). A grande diferença entre celulose I e II surge a partir das ligações de hidrogênio entre as cadeias, a celulose II tem orientação antiparalela entre as moléculas devido às mudanças que ocorrem nas suas ligações de hidrogênio. Isso tem uma influência direta sobre a estrutura da rede cristalina de celulose. Os nanocristais de celulose do tipo II exibem geralmente uma estabilidade térmica maior do que nanocristais de celulose do tipo I. Os nanocompósitos reforçados com nanocristais de celulose do tipo II também 
têm maior resistência à tração e maiores alongamentos do que aqueles reforçados com nanocristais de celulose do tipo I (HENRIQUE et al., 2013).

O índice de cristalinidade do bagaço de cana-de-açúcar, bagaços pré-tratados, polpas branqueadas e nanocristais de celulose de todos os processos (I-XII) são mostrados na Tabela 4.3. O índice de cristalinidade para o bagaço de cana-de-açúcar foi de 17\%, e os bagaços prétratados apresentaram cristalinidade de 19-49\%. Nesta fase ocorreu um aumento do grau da cristalinidade significativo. Isso pode ser devido à clivagem e à perda de uma grande parte da hemicelulose e dissolução da lignina, aumentando assim a fração de celulose que é semicristalina (PICKERING et al., 2016; ZAINI et al., 2013). Nas polpas branqueadas, a cristalinidade variou de $26-51 \%$. Nesta fase ocorreu a remoção remanescente da lignina, intensificando a clivagem da celulose das cadeias moleculares da região amorfa (PICKERING et al., 2016; ZAINI et al., 2013). Os nanocristais de celulose apresentaram cristalinidade de 51-67\% usando o método Segal et al., (1959). Segundo FENGEL; WEGENER, (2003), a hidrólise ácida provoca aumento da cristalinidade.

Tabela 4.3: Índice de cristalinidade das fases de obtenção NCC.

\begin{tabular}{cccc}
\hline Processos & $\begin{array}{c}\text { Bagaço pré-tratado } \\
(\boldsymbol{\%})\end{array}$ & $\begin{array}{c}\text { Polpa branqueada } \\
(\boldsymbol{\%})\end{array}$ & $\begin{array}{c}\text { Nanocristais } \\
(\boldsymbol{\%})\end{array}$ \\
\hline I & 21 & 26 & 52 \\
II & 21 & 30 & 61 \\
III & 16 & 45 & 56 \\
IV & 19 & 26 & 54 \\
V & 19 & 31 & 67 \\
VI & 21 & 42 & 61 \\
VII & 21 & 39 & 63 \\
VIII & 34 & 34 & 51 \\
IX & 34 & 51 & 65 \\
X & 49 & 48 & 53 \\
XI & 49 & 40 & 51 \\
XII & 49 & 43 & \\
\hline
\end{tabular}


Existem alguns parâmetros que influenciam nas propriedades dos nanocristais de celulose tais como, pré-tratamentos, concentração do ácido, tempo e temperatura. Os valores obtidos para o índice da cristalinidade estão bem parecidos aos dados encontrados na literatura. Comparativamente, o índice de cristalinidade em trabalhos recentes foi em torno de: 52\% para a celulose de cana-de-açúcar (LI et al., 2012); 37\% para a cana-de-açúcar in natura; 47\% para a celulose bruta e 56\% para a celulose branqueada (PEREIRA et al., 2011); Em outro trabalho $63 \%$ para a celulose de cana-de-açúcar purificada e $72 \%$ para os nanocristais de celulose obtidos a partir da cana-de-açúcar (KUMAR et al., 2014); 68\% para os nanocristais de celulose obtidos a partir da cana-de-açúcar (KUMAR et al., 2013). O maior índice de cristalinidade foi confirmado $64 \%$ para algodão e $90 \%$ para a nanocelulose a partir das fibras de algodão (MORAIS et al., 2013). Segundo ZAINI et al. (2013), a baixa cristalinidade dos nanocristais pode estar relacionada com o ataque do ácido sobre região cristalina do nanocristais.

O percentual da cristalinidade aumenta na sequência bagaço > bagaços pré-tratados > polpa branqueada > nanocristais de celulose, ou seja, foi observado que o grau de cristalinidade aumenta significativamente depois dos tratamentos (álcali, branqueamento e hidrólise) (MANDAL; CHAKRABARTY, 2011; KARGARZADEH et al., 2012; SILVERIO et al., 2013; SANTOS et al., 2013). O aumento da cristalinidade pode ser atribuído a dois fatores: remoção de parte da região amorfa e o rearranjo das regiões cristalinas em uma estrutura mais ordenada (ROSLI et al., 2013; SANTOS et al., 2013; LAVORATTI et al., 2016). Segundo MORÁN et al. (2008), nesses processos pode ter uma pequena quantidade ou nenhuma hemicelulose remanescente. SANTOS et al. (2013) observaram que durante a hidrólise ácida pode ocorrer a remoção parcial do domínio cristalino.

A análise por difração de raios-X do bagaço in natura e de todas as fases de tratamento (holocelulose e $\alpha$-celulose), também mostraram uma estrutura típica de celulose I verificado pela presença dos picos em torno de $15^{\circ}$ e $22^{\circ}$ o que representa o plano cristalográfico (110; 200) conforme a Figura 4.9. É possível verificar que independente do tratamento, os picos apresentaram as mesmas características, ou seja, típica de celulose pura. pura. 


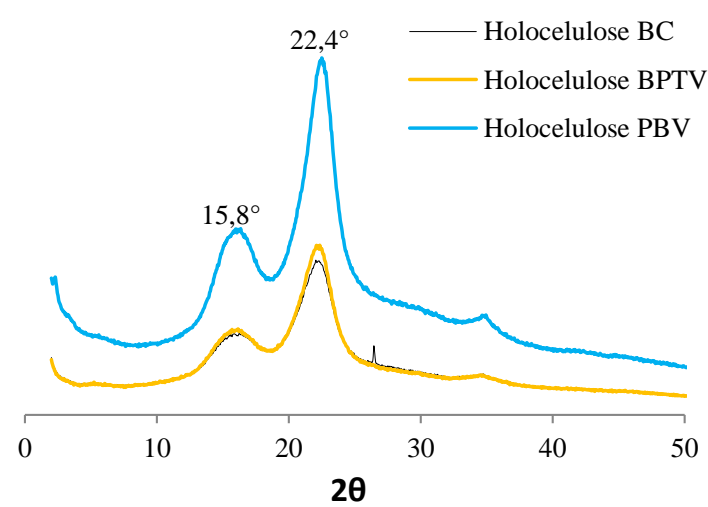

Processo V

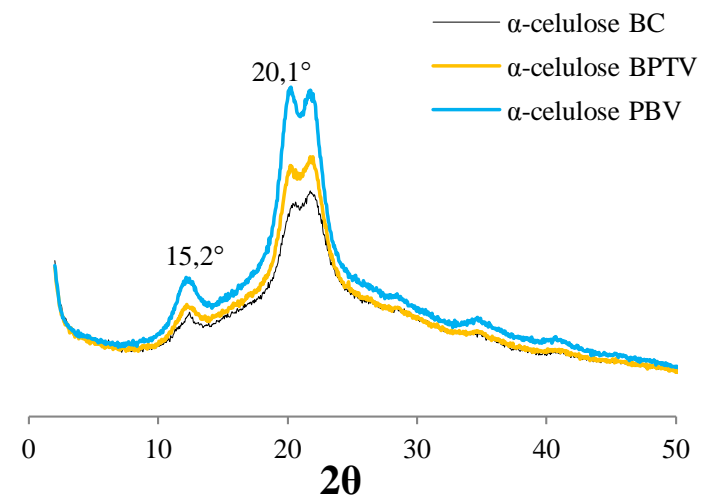

Processo V

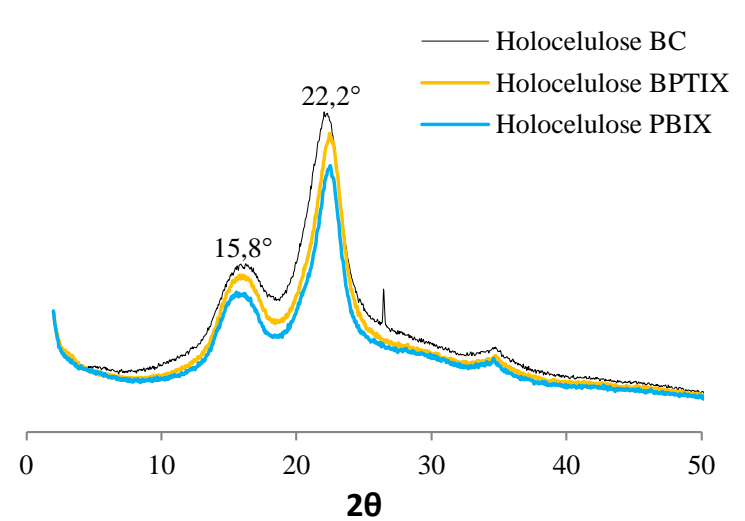

Processo IX

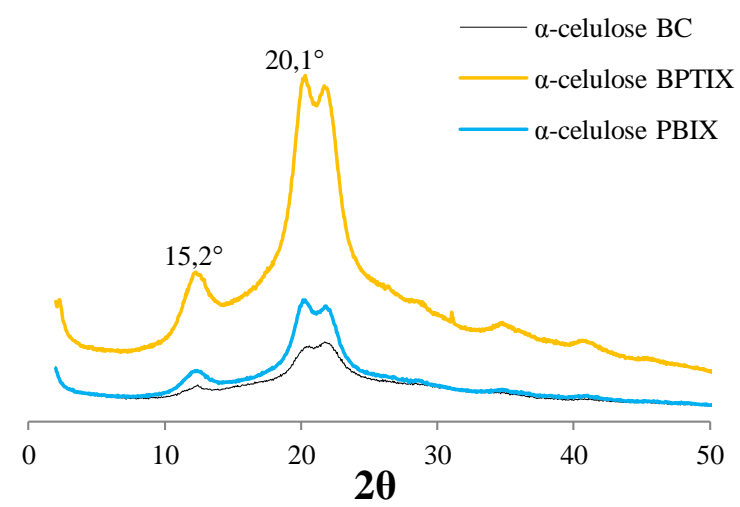

Processo IX

Figura 4.9: Difratogramas de raios X: bagaço de cana (BC); bagaço pré-tratados (BPT); polpa branqueada $(\mathrm{PB})$.

Para avaliar a eficiência de cada fase de tratamento, foi realizada a técnica de difração de raios-x, assim verificando o índice de cristalinidade da holocelulose e $\alpha$-celulose do processo $\mathrm{V}$ e IX. O percentual da cristalinidade da holocelulose ficou em torno de $47-51 \%$ e a $\alpha$-celulose ficou em torno de 53-57\%, confirmado assim a eficiência do tratamento, e consequentemente a remoção dos constituintes não celulósicos. É possível verificar que independente do tratamento, o percentual de cristalinidade não apresentou diferença significativa entre cada fase de tratamento conforme a Tabela 4.4. 
Tabela 4.4: Índice de cristalinidade das holocelulose e $\alpha$-celulose: bagaço de cana (BC); bagaço pré-tratados (BPT); polpa branqueada (PB).

\begin{tabular}{cccccc}
\hline \multicolumn{5}{c}{ Processo V (\%) } \\
\hline Holo BC & Holo BPT & Holo PB & $\alpha$-celulose BC & $\alpha$-celulose BPT & $\alpha$-celulose PB \\
\hline 47,8 & 49,5 & 51,2 & 53,0 & 57,7 & 57,4 \\
\hline \multicolumn{5}{c}{ Processo IX (\%) } \\
\hline Holo BC & Holo BPT & Holo PB & $\alpha$-celulose BC & $\alpha$-celulose BPT & $\alpha$-celulose PB \\
\hline 47,8 & 47,4 & 49,1 & 53,0 & 56,4 & 57,9 \\
\hline
\end{tabular}

\subsubsection{Caracterização das fibras e dos nanocristais de celulose por FTIR}

Os produtos de reação das modificações químicas foram analisados por espectroscopia na região do infravermelho. A Figura 4.10 e o apêndice $\mathrm{C}$ apresentam os espectros das fibras in natura, bagaço pré-tratados, polpa branqueada e os nanocristais na região entre $400 \mathrm{a} 1800 \mathrm{~cm}^{-1}$.

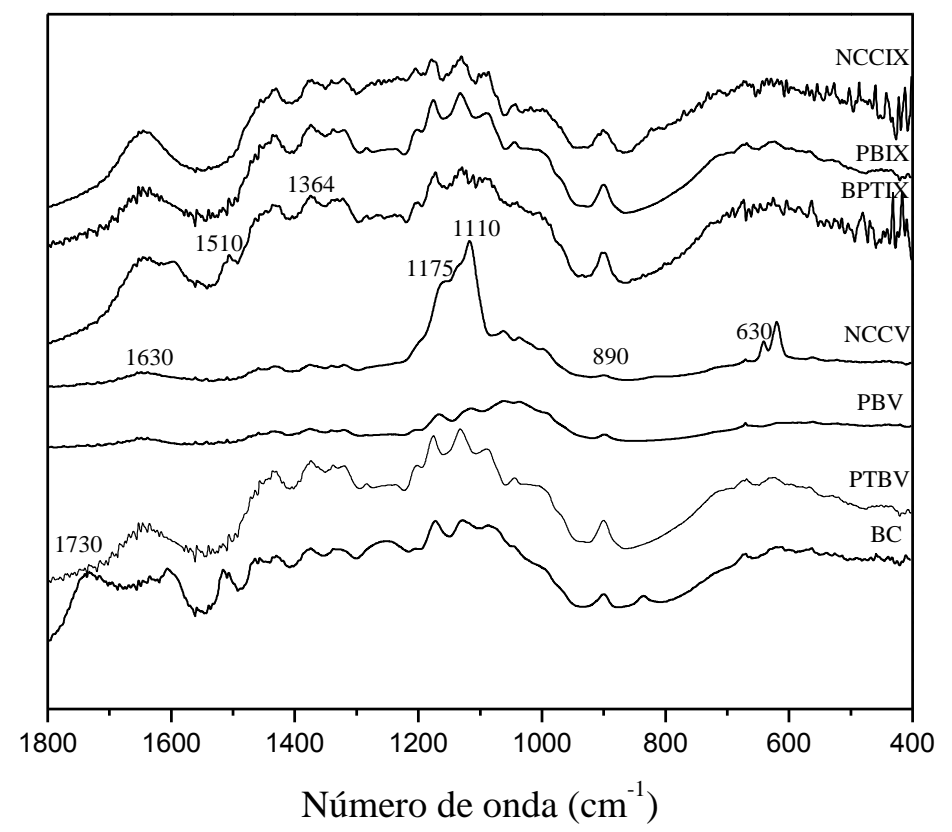

Processo V $\left(\mathrm{NaClO}_{2} 2 \% / \mathrm{NaOH} 2 \% / 1 \mathrm{x}\right)$; e processo IX $\left(\mathrm{NaOH} 5 \% / \mathrm{NaClO}_{2} 3,3 \% / 1 \mathrm{x}\right)$.

Figura 4.10. Espectros de FTIR das fibras de bagaço de cana (BC); bagaço pré-tratados (BPT); polpa branqueada (PB); nanocristais de celulose (NCCV); e nanocristais de celulose (NCCIX) dos processos V e IX. 
O material lignocelulósico é composto por alcanos, ésteres, aromáticos, cetonas e álcoois com diferentes grupos funcionais contendo oxigênio e hidroxilas (ADEL et al., 2010; ABRAHAMA et al., 2011).

A banda presente na região do infravermelho entre $1730 \mathrm{~cm}^{-1}$ é devido à presença do grupo carbonila na estrutura do bagaço de cana-de-açúcar conforme o espectro. Os grupos carbonila, estiramento da ligação $\mathrm{C}=\mathrm{O}$, podem estar presentes no grupo acetil da hemicelulose ou ligação éster do grupo ácido carboxílico da lignina e/ou hemicelulose. Este pico está presente somente na fibra in natura. Após os tratamentos este pico desaparece, confirmando assim, a remoção da hemicelulose e da lignina. Portanto, o tratamento com $\mathrm{NaOH} / \mathrm{NaClO}_{2}$, a lignina é removida, aumentando assim, o grau de cristalinidade comprovado pelo raios-X (HERRERAFRANCO; VALADEZ-GONZÁLEZ, 2005; JONOOBI et al., 2009; SANTOS et al., 2013; SILVERIO et al., 2013; NG et al., 2015; HENRIQUE et al., 2013; KARGARZADEH et al., 2012).

A ligação O-H relacionada à água absorvida, foi evidenciada na região de $1630 \mathrm{~cm}^{-1}$ (HUG et al., 2012; LU; HSIEH et al., 2012). Segundo Abrahama et al. (2011), a água absorvida das moléculas da celulose é muito difícil de extrair, devido a interação celulose-água. Foi evidenciado nos espectros de bagaço e bagaços pré-tratados (menos intenso) um pico na região $1510 \mathrm{~cm}^{-1}$ que pode ser devido à vibração $\mathrm{C}=\mathrm{C}$ do anel aromático e presença associada de lignina. A ausência deste pico confirma o efeito do tratamento e a purificação da celulose (JONOOBI et al., 2009; KUMAR et al., 2014; SILVERIO et al., 2013; LU; HSIEH et al., 2012; HENRIQUE et al., 2013). A banda em 1175-1110 $\mathrm{cm}^{-1}$ corresponde ao estiramento assimétrico da ligação C-O-C de celulose. Essas bandas estão associadas às estruturas de celulose $\mathrm{C}-\mathrm{O}, \mathrm{C}-\mathrm{C}$, estruturas de anéis aromáticos e deformação vibracional dos grupos C-H, C-CO e C-CH (HUG et al., 2012; NG et al., 2015; KARGARZADEH et al., 2012).

O pico na região $890-1364 \mathrm{~cm}^{-1}$ é devido às ligações glicosídicas simétricas C-H e vibracional do grupo C-O-C da celulose (NG et al., 2015). Foi evidenciado um aumento da intensidade do pico em todos os espectros, indicando uma maior exposição da celulose devido à remoção do material amorfo pelos tratamentos químicos, mostrando também o teor significativo de celulose I (KUMAR et al., 2014; SILVERIO et al., 2013; JOHAR et al., 2012). Segundo Kumar et al. (2014), estes espectros de nanocristais são constituídos por estrutura cristalina típica 
de celulose I, enquanto o teor de celulose amorfa é insignificante. As bandas entre $650-615 \mathrm{~cm}^{-1}$ são originadas pelas vibrações de $\mathrm{O}-\mathrm{H}$ da celulose. A Tabela 4.5 apresenta os grupos funcionais do espectro de infravermelho (KHAN et al., 2012). Foram confirmadas mudanças significativas entre as fibras de bagaços pré-tratados, polpas branqueadas e nanocristais pelos espectros de infravermelho, MEV, difração de raios-X e também análise térmica.

Tabela 4.5: Grupos funcionais dos espectros de infravermelho dos materiais lignocelulósicos.

\begin{tabular}{ll}
\hline \multicolumn{1}{c}{ Grupos funcionais } & Número de onda $\left(\mathbf{c m}^{-1}\right)$ \\
\hline Estiramento das ligações de hidrogênio intramolecular da celulose I (O-H) & 3427 \\
Estiramento (C-H) & 2920 \\
Estiramento vibracional das ligações acetil e éster da lignina e hemicelulose & 1730 \\
Associado com o anel aromático presente na lignina e hemicelulose ou absorção de água & $1638-1593$ \\
Vibração C=C do anel aromático & 1507 \\
Ligação C-H & 1458 \\
Ligação C-H & 1369 \\
Estiramento assimétrico da ligação C-O-C da celulose, hemicelulose e lignina. & 1168 \\
Banda C-O-C éter glicosídica & $1111-1152$ \\
Associado com as ligações glicosídica da $\beta$-celulose & 891 \\
Vibrações de O-H fora do plano & $650-615$ \\
\hline
\end{tabular}

\subsection{CARACTERIZAÇÃO POR MICROSCOPIA}

\subsubsection{Caracterização das fibras e nanocristais de celulose, holocelulose e $\alpha$-celulose por (MEV)}

As fibras naturais são formadas por células alongadas, entrelaçadas e o seu entrelaçamento é, em parte, responsável por algumas propriedades e características como densidade, tensão, módulo e alongamento na ruptura. É muito importante conhecer a morfologia da estrutura interna das fibras naturais e a sua composição química para entender a sua influência nas características dos nanocompósitos e, também, na escolha dos tratamentos químicos. As propriedades químicas e físicas das fibras se diferem para diferentes tratamentos químicos (ALBINANTE et al., 2013; FENGEL; WEGNER, 2003).

O efeito do tratamento na superfície das fibras de bagaço de cana-de-açúcar foi analisado em um microscópio eletrônico de varredura. As Figuras 4.11 a 4.13 e o apêndice D comparam as micrografias das fibras de bagaço da cana-de-açúcar in natura em relação os tipos de tratamentos 
de acordo com a Tabela 3.1. As micrografias das fibras in natura nas Figuras 4.11 (A) e (B) mostram as superfícies rugosas das fibras cobertas por camadas de ceras, partículas globulares, pectinas e extrativos, além dos constituintes amorfos como lignina e hemicelulose (FENGEL; WEGNER, 2003), apresentando um diâmetro de aproximadamente $93 \pm 20,6$ нm.
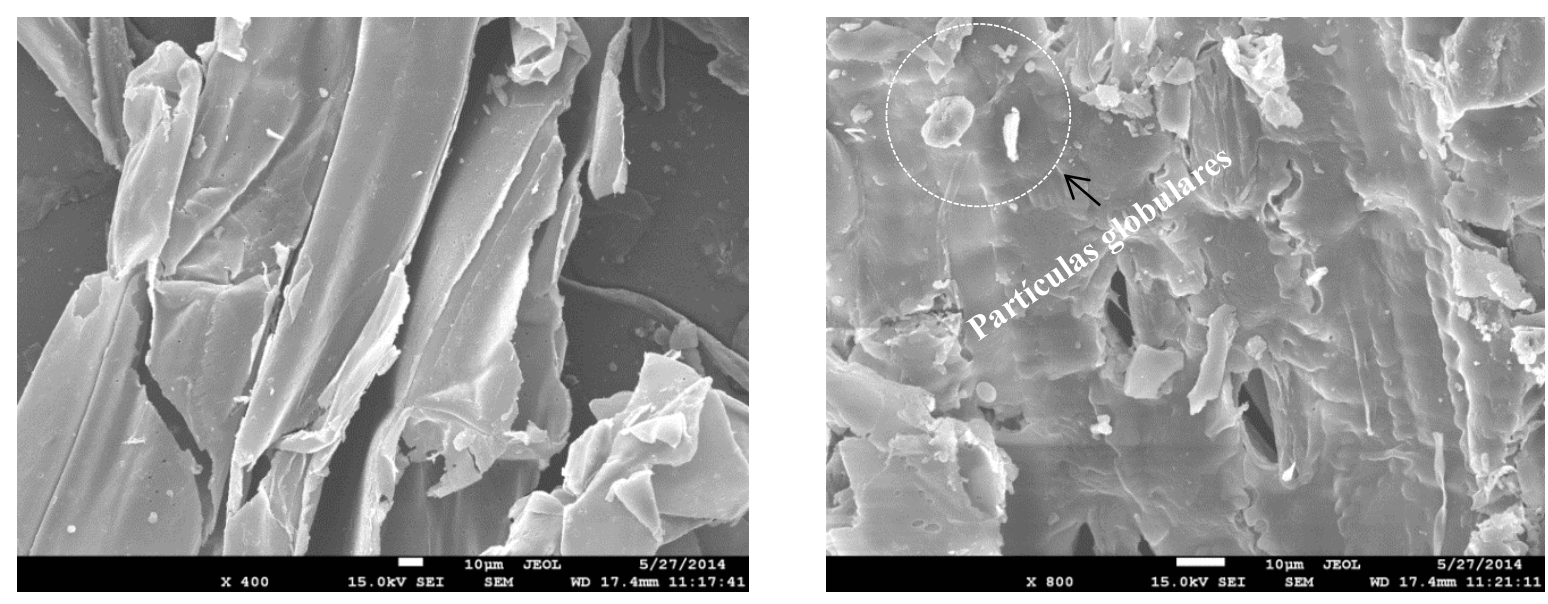

Figura 4.11. Micrografias obtidas em MEV das fibras de bagaço in natura.

As micrografias das fibras tratadas com solução de $\mathrm{NaClO}_{2}$ resultando no bagaço prétratados, foram apresentadas nas Figuras 4.12 (A) a (B), onde foi observado a rugosidade das fibras e ainda originou uma desagregação das fibras em microfibrilas, que visualmente tornou as fibrilas mais expostas, isto é, neste tratamento ocorre a quebra das ligações de hidrogênio que unem as cadeias de celulose, conferindo uma superfície mais rugosa que auxilia no ancoramento mecânico (REZENDE et al., 2010). As micrografias das fibras de celulose branqueada foram apresentadas nas Figuras 4.12 (C) a (D), segundo Kumar et al. (2014), nas fases de tratamentos o diâmetro e tamanho das fibrilas de celulose podem ser reduzidas devido à remoção da região amorfa da celulose semicristalina, a celulose obtida após o branqueamento apresentou um diâmetro de $16 \pm 4,9 \mu \mathrm{m}$. Ou seja, este tratamento removeu os constituintes não celulósicos, que cobre a superfície externa da parede celular das fibras, ocorrendo despolimerização da celulose e expondo comprimento das fibras ou das fibrilas. Entretanto, a adição de hidróxido de sódio a fibra promove a ionização do grupo da hidroxila, transformando-as em alcóxidos e ainda aumentando a acessibilidade do reagente ao interior das fibras. Assim, ocorreu a solubilização de hemicelulose e da lignina, além de alterar a cristalinidade da celulose. A hemicelulose é solúvel em baixas concentrações de álcali e, nessas condições, a lignina sofre hidrólise básica 
(ALBINANTE et al., 2013; LI et al., 2007; MOON et al., 2011; SIRÓ; PLACKETT, 2010; CHERIAN et al., 2011). Portanto, quando a hemicelulose e lignina são removidas, a textura do elemento celulósico é chamada de fibrila (FENGEL; WEGNER, 2003; ROSLI et al., 2013).
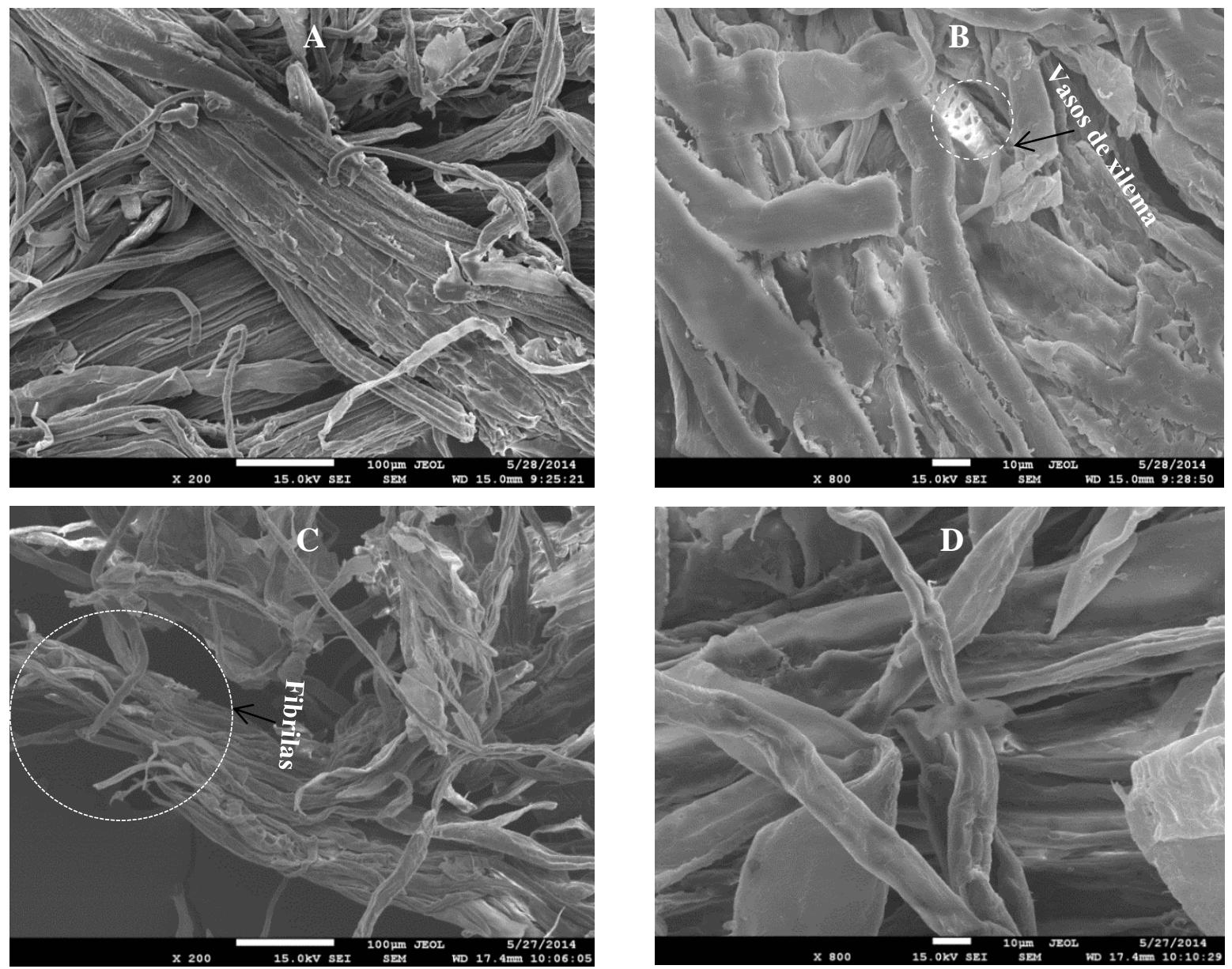

Figura 4.12: Micrografias obtidas em MEV do processo V: (A e B) bagaço pré-tratados; (C e D) polpa branqueada.

As micrografias das fibras tratadas com solução $\mathrm{NaOH}$ resultando no bagaço prétratados; foram apresentadas nas Figuras 4.13 (A) a (B) onde foi possível observar a desintegração parcial das fibras, provavelmente devido à remoção de uma parte da hemicelulose e lignina, que interliga as fibrilas de celulose. $\mathrm{O}$ tratamento $\mathrm{NaOH}+\mathrm{NaClO}_{2}$ causou o isolamento direto da celulose a partir das fibras de bagaço pré-tratados, os processos de purificação causaram uma redução significativa no diâmetro de $93 \mu \mathrm{m}$ para $10 \pm 1,7 \mu \mathrm{m}$ conforme as Figuras 4.13 (C) a (D) resultando na polpa branqueada. Comparando a fibra in natura com as tratadas é possível observar a eficiência dos tratamentos devido à mudança na 
morfologia das fibras. LAVORATTI et al., (2016) observaram uma diminuição no tamanho das fibras depois das fases de tratamento. Além disso, observou-se uma maior remoção das células de parênquima. Por outro lado, depois do branqueamento as fibras celulósicas apresentaram forma fitas e achatada, a desfibrilação das fibras foi notada, causando uma diminuição no comprimento e diâmetro. A forma cilíndrica dessas fibras aumenta a sua área específica e favorece as reações químicas tais como a hidrólise ácida (MORAIS et al., 2013; BRÍGIDA et al., 2010; PEREIRA et al., 2011; ROSLI et al., 2013; SIRÓ; PLACKETT, 2010; PANTHAPULAKKAL; SAIN, 2012). Todas as micrografias mostraram os mesmos perfis conforme o apêndice $D$.
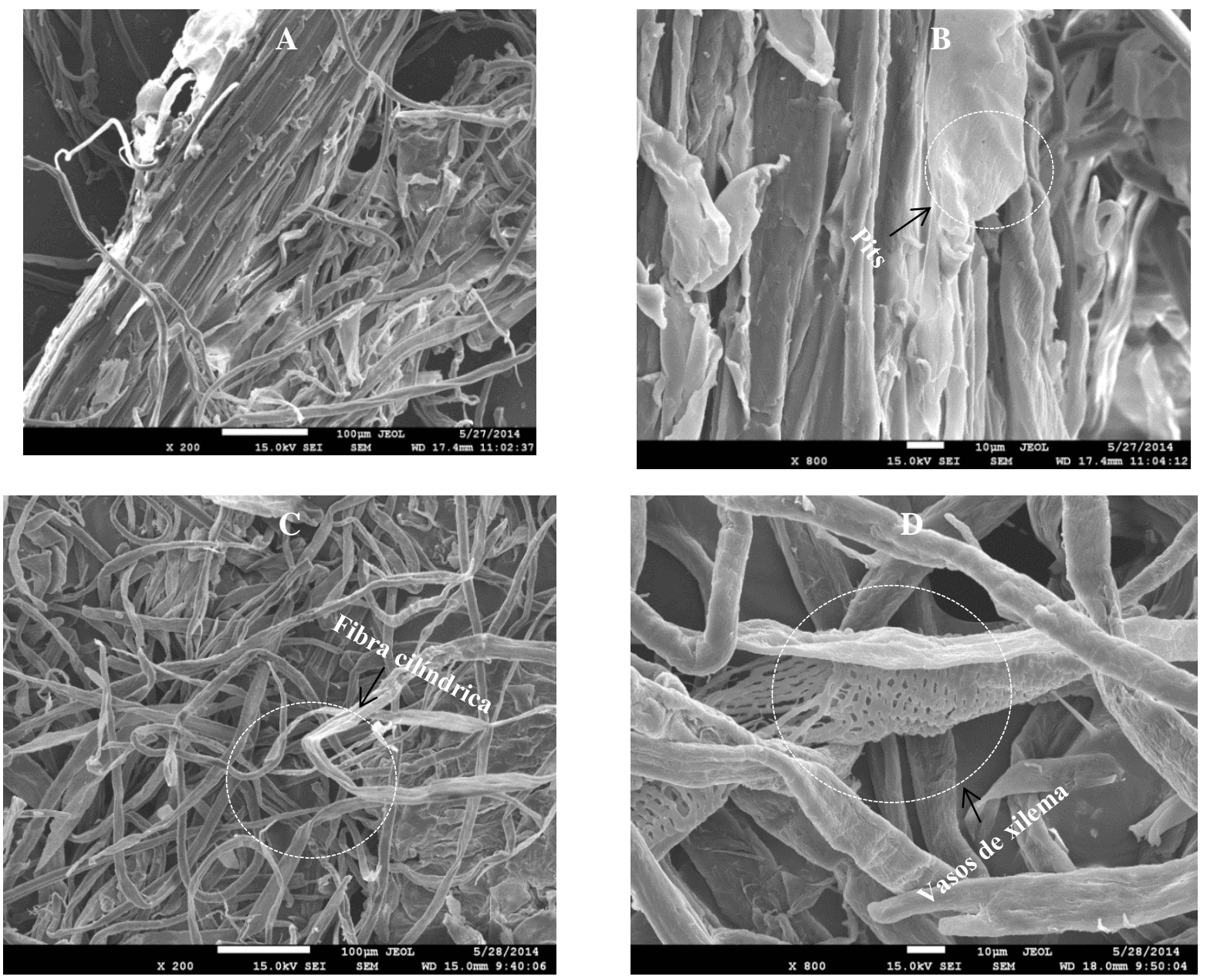

Figura 4.13: Micrografias obtidas em MEV do processo IX: (A e B) bagaço pré-tratados; (C e D) polpa branqueada. 
As micrografias das holocelulose e $\alpha$-celulose são apresentadas na Figura 4.14 (A). (B) e apêndice E dos processos V e IX, é possível observar que as micrografias são semelhantes, ou seja, não há mudança nas morfologias das fibras, depois dos diferentes tipos de tratamentos.
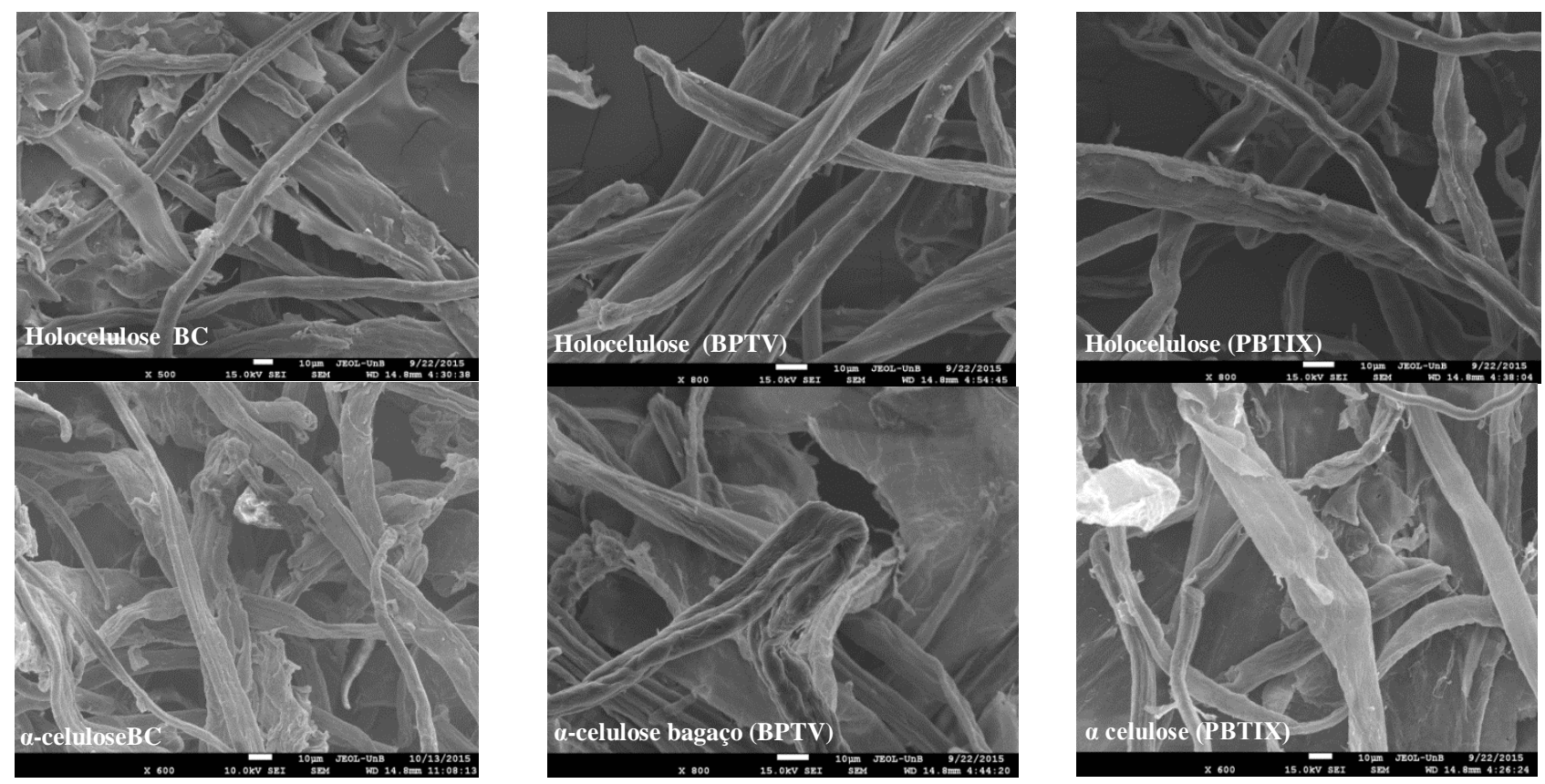

Figura 4.14: Micrografias obtidas em MEV das fibras holocelulose e $\alpha$-celulose: bagaço de cana (BC); bagaço pré-tratados (BPT); polpa branqueada (PB) dos processos V e IX.

\subsubsection{Caracterização dos NCC por microscopia eletrônica de transmissão (MET)}

Os nanocristais de celulose podem apresentar diferentes formas e tamanhos e terem características físicas específicas. O material nessa condição se encontra na forma polidispersa, ou seja, está constituído por um conglomerado de nanopartículas fisicamente diferentes conforme a Figura 4.15 e o apêndice F (FENGEL; WEGENER, 2003). As imagens de TEM retratam a aglomeração de feixes de nanocristais, como também cristalitos dispersos e individuais (KUMAR et al., 2014; MORAIS et al., 2013; BECK-CANDANEDO et al., 2005; KAMAL; KHOSHKAVA, 2015). 


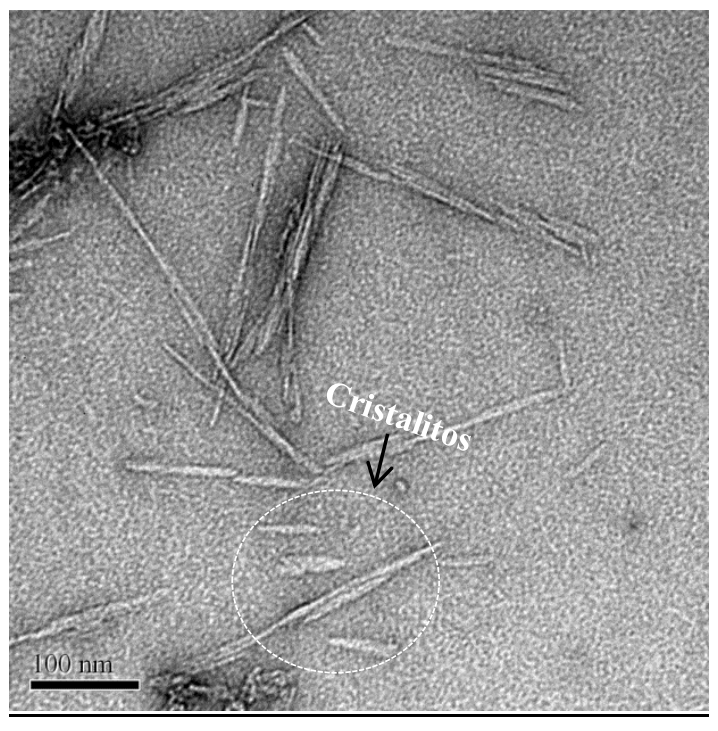

Nanocristais de celulose (NCCV)

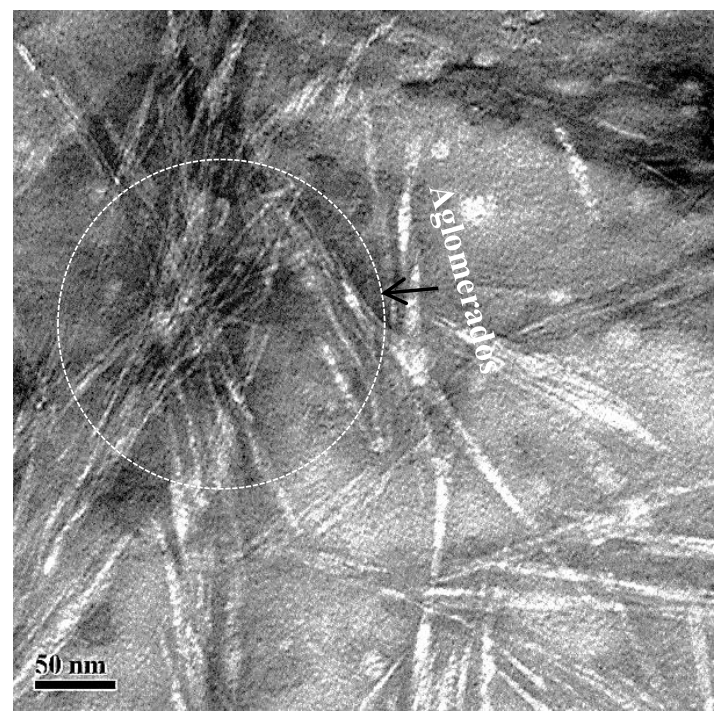

Nanocristais de celulose (NCCIX)

Processo $\mathrm{V}\left(\mathrm{NaClO}_{2} 2 \% / \mathrm{NaOH} 2 \% / 1 \mathrm{x}\right)$; e processo IX $\left(\mathrm{NaOH} 5 \% / \mathrm{NaClO}_{2} 3,3 \% / 1 x\right)$.

Figura 4.15. Microscopia eletrônica de transmissão dos nanocristais de celulose a partir de bagaço da cana de açúcar.

Para determinar as dimensões exatas dos nanocristais de celulose é complicado devido as limitações especificas dos diferentes métodos analíticos usados. Segundo Kumar et al. (2014), a aglomeração compacta dos nanocristais se refere as cadeias de celulose onde possui ligações de hidrogênio intermolecular e uma forte interação hidrofílica entre as cadeias de celulose. Os nanocristais de celulose tende a se aglomerar devido as ligações de hidrogênio. A aglomeração dos nanocristais de celulose dificulta avaliar o comprimento e o diâmetro. Os nanocristais de celulose ficaram entre torno de 44-300 (nm) de comprimento (L), o diâmetro (D) entre 10 a 30 $(\mathrm{nm})$, e a razão de aspecto (L/D) entre 5,8 a 10,2 (nm), conforme a Figura 4.16 (A e B). MANDAL; CHAKRABARTY, (2011) determinaram o L e o D das nanopartículas $170 \mathrm{~nm} \times$ $35 \mathrm{~nm}$; nanocristais de celulose a partir do bagaço apresentou um L de $255 \mathrm{~nm}$ e um D de $8 \mathrm{~nm}$ (TEIXEIRA et al., 2011;); LI et al. (2012) apresentaram um D de 10-20 nm. O valor do L e o D deste estudo estão de acordo com a literatura. Portanto, o L e o D vão depender do tipo da fibra, o pré-tratamento e a hidrólise. 

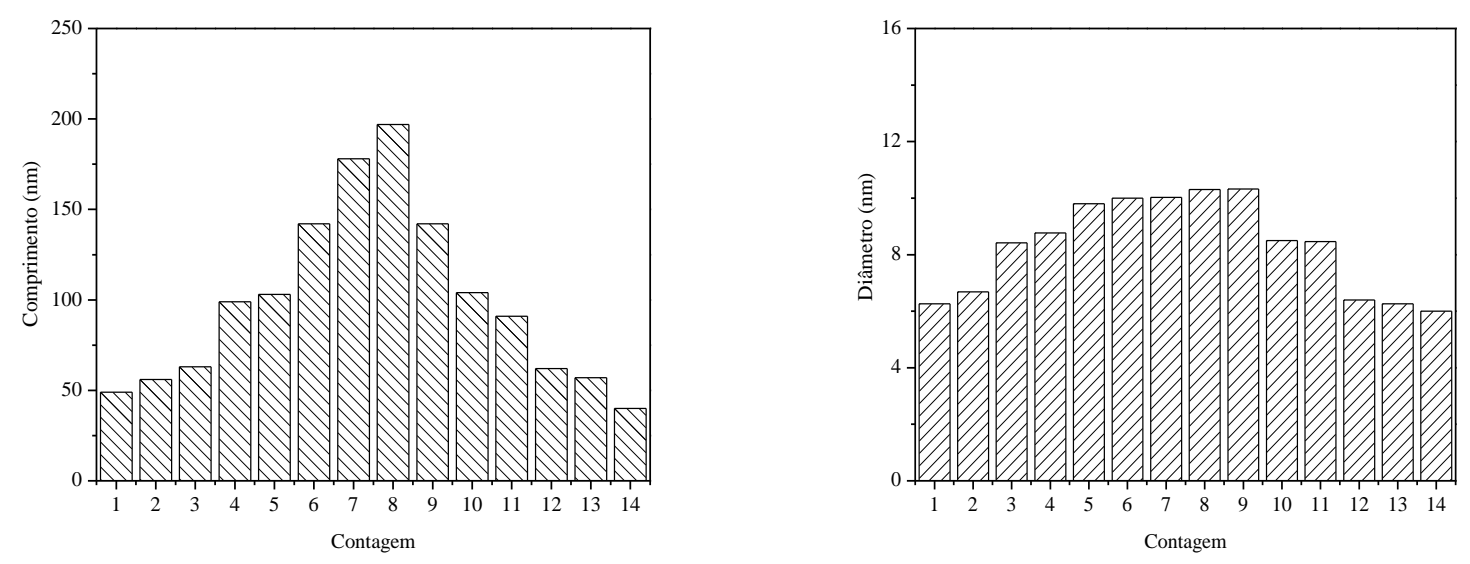

Nanocristais de celulose (NCCV)
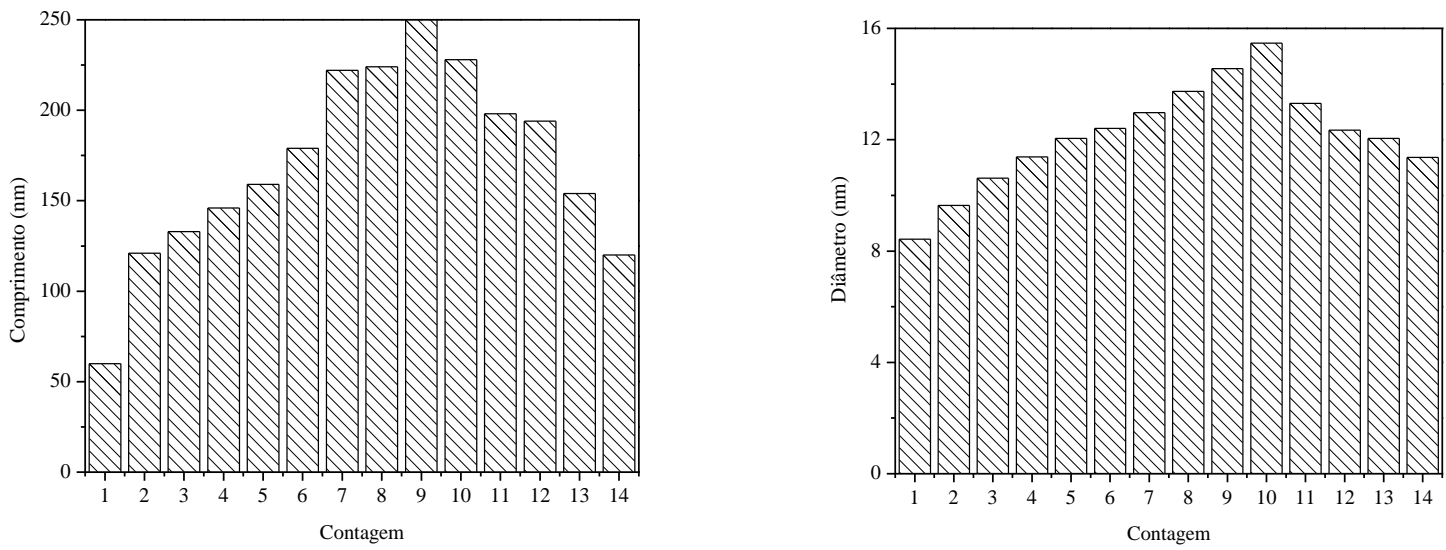

Nanocristais de celulose (NCCIX)

Figura 4.16: Distribuição de tamanho das nanopartículas dos nanocristais de celulose.

\subsubsection{Caracterização dos NCC por microscopia de força atômica (MFA)}

A análise dos nanocristais de celulose por microscopia de força atômica tem como objetivo avaliar o diâmetro, comprimento e forma dos nanocristais de celulose, mas devido aglomeração não foi possível. Somente foi possível visualizar as estruturas alongadas, cristalitos individuais e a presença de agregados, semelhante aos resultados encontrados por microscopia eletrônica de transmissão. A amostra $\mathrm{V}$ mostrou cristais aglomerados com uma estrutura mais ordenados e a 
amostra IX mostrou uma estrutura mais aleatório. A Figura 4.17 mostra as imagens de MFA obtidas dos NCCV e NCCIX, respectivamente.

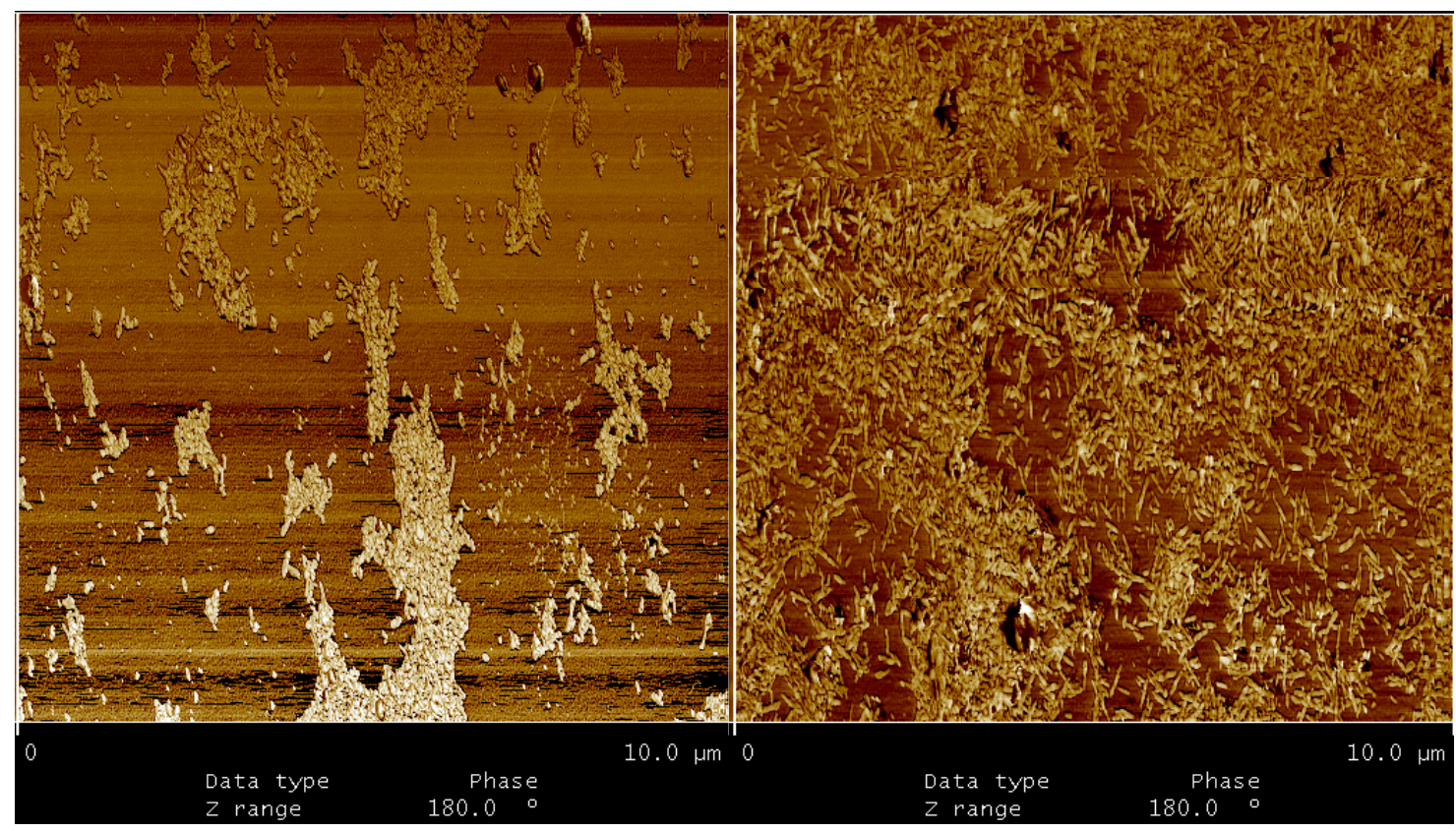

Nanocristais de celulose (NCCV) Nanocristais de celulose (NCCIX)

Processo V $\left(\mathrm{NaClO}_{2} 2 \% / \mathrm{NaOH} 2 \% / 1 \mathrm{x}\right)$; e processo IX $\left(\mathrm{NaOH} 5 \% / \mathrm{NaClO}_{2} 3,3 \% / 1 \mathrm{x}\right)$.

Figura 4.17: Microscopia de força atômica de transmissão dos nanocristais de celulose a partir de bagaço da cana de açúcar.

\subsection{CARACTERIZAÇÃO TÉRMICA DAS FIBRAS}

4.5.1. Caracterização das fibras, nanocristais de celulose, holocelulose e $\alpha$-celulose a partir da análise térmica e TGA/FTIR acoplado

Os materiais lignocelulósicos in natura, provenientes dos tratamentos e nanocristais de celulose foram analisados por análise termogravimétrica. Esta análise é utilizada para avaliar o nível de estabilidade térmica da amostra. A Figura 4.18 (A) e (B) mostra o comportamento típico das curvas TGA/DTG de degradação térmica das fibras de bagaço pré-tratado (BPT), polpa branqueada (PB), nanocristais de celulose (NCC) em relação ao bagaço in natura (BC). A estabilidade térmica ficou na faixa de temperatura entre 206 e $247^{\circ} \mathrm{C}$. A baixa estabilidade dos nanocristais de celulose pode ser explicada, devido à substituição dos grupos hidroxila, pelos grupos sulfatos ácidos na fase de hidrólise diminuem a energia de ativação para a degradação da 
celulose, tornando a amostra menos resistente à pirólise, ocorrendo reações de desidratação, liberando água e catalisando a decomposição da celulose (KARGARZADEH et al., 2012; KUMAR et al., 2014; MARIANO et al., 2014).

Segundo MORAIS et al. (2013), a presença de grupos sulfato nestes materiais pode ser verificada pelas bandas características em 1350 e $1175 \mathrm{~cm}^{-1}$, confirmado pelo FTIR. Neste estudo é observado dois picos um na região de $1360 \mathrm{~cm}^{-1}$ e outro na região1175 $\mathrm{cm}^{-1}$, atribuídos à celulose sulfatada (SILVÉRIO et al., 2013; KARGARZADEH et al., 2012).

Os resíduos resultantes após as análises do bagaço in natura e provenientes dos tratamentos (temperatura máxima do TGA de $600^{\circ} \mathrm{C}$ ) ficaram em torno de 20 e $46 \%$. De um modo geral, os resíduos aumentam de acordo com os tratamentos. Alguns fatores podem alterar a quantidades de resíduos, tais como: nanopartículas e um maior número das extremidades livres das cadeias dos nanocristais de celulose que se decompõem em baixa temperatura; a natureza altamente cristalina dos nanocristais de celulose aumenta a proporção de carbono, portanto, a formação de resíduos aumenta na medida em que aumenta o teor de carbono (ROMAN; WINTER, 2004).

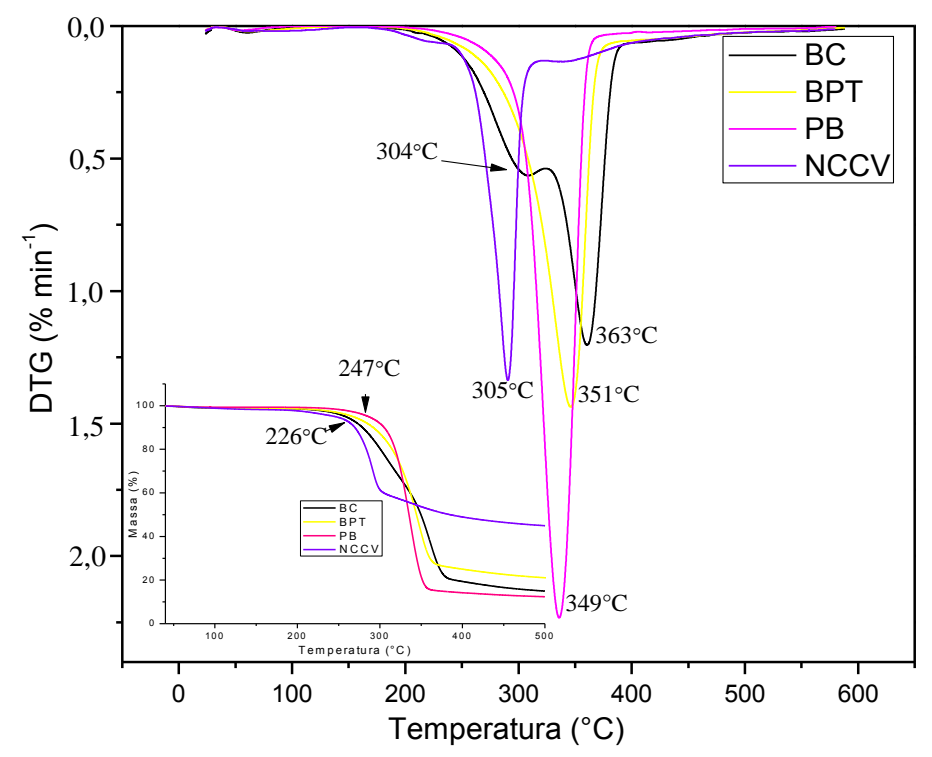

Processo V 


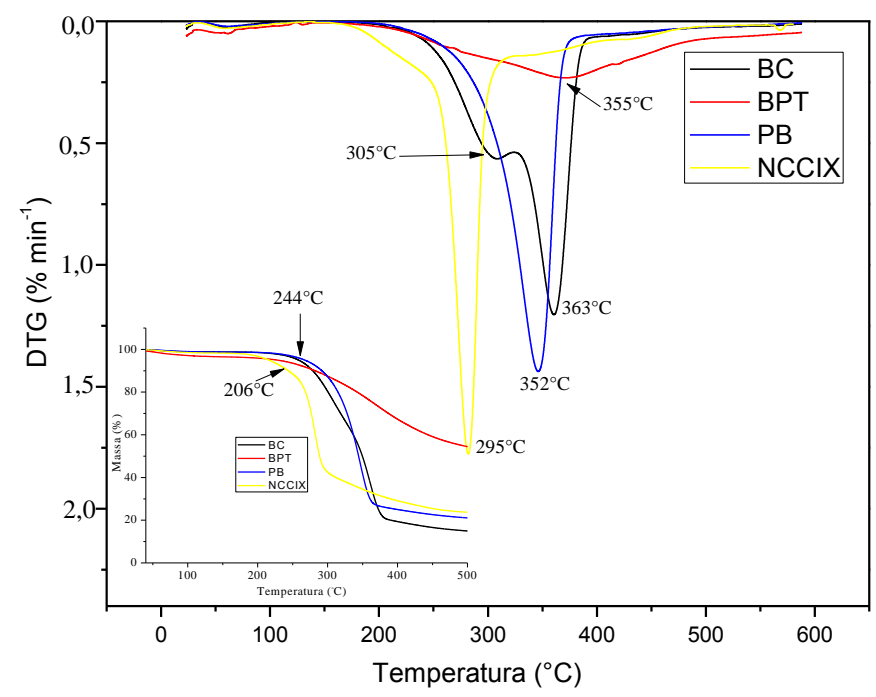

Processo IX

Processo $\mathrm{V}\left(\mathrm{NaClO}_{2} 2 \% / \mathrm{NaOH} 2 \% / 1 \mathrm{x}\right)$; e processo IX $\left(\mathrm{NaOH} 5 \% / \mathrm{NaClO}_{2} 3,3 \% / 1 \mathrm{x}\right)$.

Figura 4.18: Comportamento das curvas de degradação térmica das fibras de bagaço de cana-deaçúcar (BC); bagaço pré-tratado (BPT); polpa branqueada (PB); nanocristais (NCCV); nanocristais (NCCIX).

Devido às diferenças da estrutura química entre celulose, hemicelulose e lignina, estes se decompõem em diferentes temperaturas (ABRAHAM et al., 2011). As diferenças de comportamento térmico entre o bagaço in natura e as fibras tratadas podem ser mais facilmente visualizadas a partir das curvas DTG. Esta diferença pode ser devido à remoção dos extrativos que são solúveis em água, constituídos por carboidratos, gomas, proteínas e sais inorgânicos. A decomposição do bagaço in natura foi caracterizada por dois picos distintos, o bagaço prétratado, as polpas branqueadas e os nanocristais foram caracterizados por um pico distinto, que podem ser observados nas curvas DTG da Figura 4.18 (A) e (B). A primeira perda de massa ocorreu a $304^{\circ} \mathrm{C}$ para o bagaço in natura. Alguns autores atribuem essa perda à degradação de lignina. Esta perda é atribuída à degradação da lignina, que está relacionada com a quebra das ligações éter e carbono-carbono. Deste modo, o desaparecimento deste pico com os tratamentos, indicou que os constituintes amorfos foram removidos (JOSEPH et al., 2003; LEÃO et al., 
2012). Segundo Kumar et al. (2014), a lignina, hemicelulose e outros segmentos não celulósicos se decompõem em baixa temperatura. No caso, do FTIR mostram sinais de comprimentos de onda em 1700-1510 $\mathrm{cm}^{-1}$ referente à lignina/hemicelulose, como também pode ser observado no difração de raios-X, apresentando menor índice de cristalinidade devido a grande quantidade de constituintes amorfos. Este pico não é observado para as amostras tratadas.

O pico na faixa de 300 a $400^{\circ} \mathrm{C}$, onde atinge a velocidade de decomposição máxima, é atribuído à despolimerização da hemicelulose e a clivagem das ligações glicosídicas da celulose, apresentando $\mathrm{T}_{\text {pico }} \mathrm{em} 295^{\circ} \mathrm{C}$, com $\mathrm{T}_{\text {onset }}$ de $200^{\circ} \mathrm{C}$ e $\mathrm{T}_{\text {pico }}$ em $305^{\circ} \mathrm{C}$, com $\mathrm{T}_{\text {onset }}$ de $186^{\circ} \mathrm{C}$ para nanocristais; $\mathrm{T}_{\text {pico }}$ em $363^{\circ} \mathrm{C}$, com $\mathrm{T}_{\text {onset }}$ de $208^{\circ} \mathrm{C}$ para o bagaço in natura; e $\mathrm{T}_{\text {pico }} \mathrm{em} 352^{\circ} \mathrm{C}$, com $\mathrm{T}_{\text {onset }}$ de $238^{\circ} \mathrm{C}$ e $\mathrm{T}_{\text {pico }}$ em $349^{\circ} \mathrm{C}$ com $\mathrm{T}_{\text {onset }}$ de $247^{\circ} \mathrm{C}$, para as polpas branqueadas, respectivamente (LAVORATTI et al., 2016). Para nanocristais de celulose, $\mathrm{T}_{\text {onset }}$ é reduzido em comparação ao bagaço, bagaço pré-tratado e polpa branqueada, isso é devido à inserção de grupos sulfato na superfície dos nanocristais de celulose durante a hidrólise com ácido sulfúrico (EL MIRI et al., 2015). Desse modo, a literatura reporta a redução $T_{\text {onset }}$ e a degradação máxima dos nanocristais de celulose. Este fato também é observado nos nanocristais de celulose obtido a partir casca de coco (FAHMA et al., 2010), fibras de algodão (TEIXEIRA et al., 2010), e bagaço de cana-de-açúcar (TEIXEIRA et al., 2011). Segundo Yang et al. (2007), a hemicelulose degrada na faixa entre 220 a $315^{\circ} \mathrm{C}$; a celulose 315 a $400^{\circ} \mathrm{C}$ e a lignina começa a degradar à $300^{\circ} \mathrm{C}$, onde a degradação ocorre lentamente. No caso, do FTIR mostram sinais de comprimentos de onda em 1175 - $1110-890 \mathrm{~cm}^{-1}$ que corresponde à celulose, como também pode ser observado no difração de raios- $X$, apresentando maior índice de cristalinidade devido a grande quantidade de celulose cristalina.

A Tabela 4.6 mostra as porcentagens de perda em massa nas temperaturas de 100 a $500^{\circ} \mathrm{C}$ para o bagaço in natura e para as fibras tratadas. A perda de massa das polpas branqueadas após $400^{\circ} \mathrm{C}$ é mais elevada do que o bagaço in natura. Podendo concluir, que essa fase de branqueamento contribui para a formação de uma estrutura mais suscetível a degradação em altas temperaturas, atribuída às clivagens de ligações químicas das ligações glicosídicas da celulose. Sendo assim, a partir de $300^{\circ} \mathrm{C}$ os materiais lignocelulósicos analisados começam a degradação das estruturas químicas dos componentes das fibras seguidas da carbonização (LEÃO et al., 2015). 
Tabela 4.6. Perda de massa a diferentes temperaturas e picos de temperatura de degradação do bagaço in natura e das fibras tratadas.

\begin{tabular}{lrccccc}
\hline \multirow{7}{*}{\multicolumn{1}{c}{ Amostra }} & \multicolumn{7}{c}{ Temperaturas } \\
\cline { 2 - 7 } & $100^{\circ} \mathrm{C}$ & $200^{\circ} \mathrm{C}$ & $300^{\circ} \mathrm{C}$ & $400^{\circ} \mathrm{C}$ & $500^{\circ} \mathrm{C}$ & $\mathrm{T}_{\text {onset }}$ \\
\hline Bagaço in natura & 1,0 & 1,4 & 19 & 80 & 85 & 208 \\
Bagaço pré-tratados V & 0,9 & 1,3 & 10 & 74 & 78 & 210 \\
Polpa branqueada V & 0,6 & 0,7 & 4,9 & 85 & 87 & 238 \\
Nanocristais V & 0,8 & 2,0 & 21 & 49 & 54 & 200 \\
Bagaço pré-tratados IX & 3,0 & 4,2 & 13 & 34 & 46 & 224 \\
Polpa branqueada IX & 0,6 & 0,6 & 9 & 84 & 87 & 247 \\
Nanocristais IX & 1,2 & 2,3 & 46 & 69 & 75 & 186 \\
\hline
\end{tabular}

Processo V $\left(\mathrm{NaClO}_{2} 2 \% / \mathrm{NaOH} 2 \% / 1 \mathrm{x}\right)$; e processo IX $\left(\mathrm{NaOH} 5 \% / \mathrm{NaClO}_{2} 3,3 \% / 1 \mathrm{x}\right)$.

As Figuras 4.19 apresentam os espectros dos gases da pirólise do bagaço, bagaço pré-

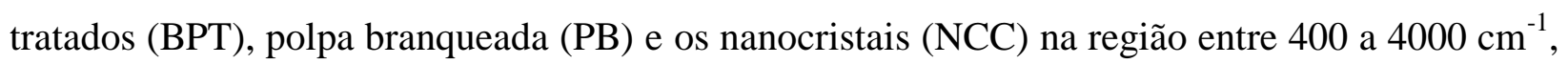
usando TGA-FTIR. A DTG apresentou para todas as amostras o ponto da máxima razão de perda de massa foi em torno de $350^{\circ} \mathrm{C}$ com o tempo médio de $30 \mathrm{~min}$. Os principais produtos dos gases da pirólise da biomassa em função do comprimento de onda e da temperatura são: $\mathrm{CO}_{2}, \mathrm{CH}_{4}, \mathrm{CO}$ e alguns compostos orgânicos (aldeídos $\mathrm{C}=\mathrm{O}$; alcanos $\mathrm{C}-\mathrm{C}$; éter $\left(\mathrm{C}-\mathrm{O}-\mathrm{C}\right.$ ) e $\mathrm{H}_{2} \mathrm{O}$ ). $\mathrm{O}$ espectro mostra que na região do infravermelho entre $3017-1600 \mathrm{~cm}^{-1}$ ocorre liberação da $\mathrm{H}_{2} \mathrm{O}$, ou seja, umidade na estrutura das fibras. Esta banda é mais intensa nas fibras pré-tratadas e nanocristais, podendo ser absorção de $\mathrm{H}_{2} \mathrm{O}$ devido à pirólise da celulose, atribuída possivelmente a maior quantidade de $\mathrm{OH}$ devido o teor de celulose. Pode também existir alguns produtos gasosos que são indetectáveis usando FTIR, tais como $\mathrm{H}_{2}$ (YANG et al., 2007; LIU et al., 2011).

As absorções nos comprimentos de onda na região de $2350 \mathrm{~cm}^{-1}$ são devidos a liberação de $\mathrm{CO}_{2}$ apresentando pico mais intenso para a fibra de bagaço. A presença de $\mathrm{CO}_{2}$ é perfil de hemicelulose, lignina e celulose, confirmado pela DTG, exibindo picos em torno $\left(304-363^{\circ} \mathrm{C}\right)$; em 3500- $690 \mathrm{~cm}^{-1}$ há absorção típica da liberação de $\mathrm{CH}_{4}$, ou seja, a celulose, hemicelulose e lignina contribuíram para a liberação de $\mathrm{CH}_{4}$ a partir da pirólise de biomassa, respectivamente em baixa, média e alta temperatura; em $2060 \mathrm{~cm}^{-1}$ ocorrem à liberação de CO. Os grupos orgânicos contendo carboidrato $\mathrm{C}=\mathrm{O} 1719 \mathrm{~cm}^{-1}$ e $\mathrm{C}-\mathrm{O}-\mathrm{C} / \mathrm{C}-\mathrm{C} 1167 \mathrm{~cm}^{-1}$ são atribuídos à hemicelulose e celulose (YANG et al., 2007; LIU et al., 2011). 


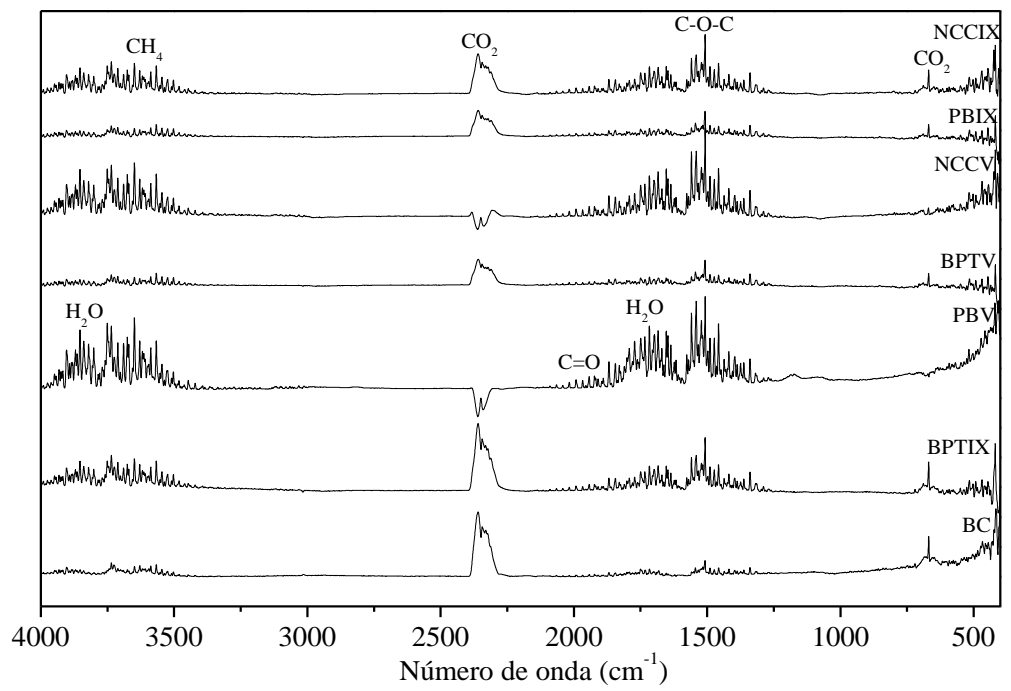

Processo $\mathrm{V}\left(\mathrm{NaClO}_{2} 2 \% / \mathrm{NaOH} 2 \% / 1 x\right)$; e processo IX ( $\left.\mathrm{NaOH} 5 \% / \mathrm{NaClO}_{2} 3,3 \% / 1 x\right)$.

Figura 4.19: Espectro característico dos gases liberados durante a pirólise em uma temperatura de $400^{\circ} \mathrm{C}$ das fibras de bagaço de cana-de-açúcar (BC); bagaço pré-tratado (BPT); polpa branqueada (PB); nanocristais (NCCV); nanocristais (NCCIX) dos processos V e IX.

Os materiais lignocelulósicos in natura e holocelulose, $\alpha$-celulose, hemicelulose e lignina foram analisados por análise termogravimétrica. A Figura 4.20 (A) mostra o comportamento típico das curvas TGA/DTG de degradação térmica das holoceluloses dos processos V e IX em relação holocelulose do bagaço. A estabilidade térmica ficou na faixa de temperatura de $200^{\circ} \mathrm{C}$ para holocelulose de bagaço e $246^{\circ} \mathrm{C}$ para holocelulose polpa branqueada IX. A Figura 4.20 (B) mostra a degradação térmica das $\alpha$-celulose do processo V e IX. A estabilidade térmica ficou na faixa de temperatura $232^{\circ} \mathrm{C}$ para todas $\alpha$-celulose do processo V e IX. A Figura 4.20 (C) mostra a degradação térmica da lignina do processo V e IX. A estabilidade térmica ficou na faixa de temperatura $196^{\circ} \mathrm{C}$ para todas as ligninas do processo V e IX.

O pico na faixa de 300 a $400^{\circ} \mathrm{C}$, onde atinge a velocidade de decomposição máxima da holocelulose das curvas DTG da Figura 4.20 (A), é atribuído à despolimerização da hemicelulose e a clivagem das ligações glicosídicas da celulose, apresentando pico em $333^{\circ} \mathrm{C}$, com $\mathrm{T}_{\text {onset }}$ de $202^{\circ} \mathrm{C}$ para holocelulose de bagaço e $347^{\circ} \mathrm{C}$, com $\mathrm{T}_{\text {onset }}$ de $232^{\circ} \mathrm{C}$ para holocelulose polpa branqueada IX. Para as curvas DTG da Figura 4.20 (B) onde atinge a velocidade de 
decomposição máxima da $\alpha$-celulose é atribuído à celulose, devido, a clivagem das ligações glicosídicas da celulose, apresentando pico em $350^{\circ} \mathrm{C}$, com $\mathrm{T}_{\text {onset }}$ de $232^{\circ} \mathrm{C}$ para todas $\alpha$-celulose do processo V e IX. A DTG da Figura 4.20 (C) onde atinge a velocidade de decomposição máxima da lignina, apresentando pico em $377^{\circ} \mathrm{C}$, com $\mathrm{T}_{\text {onset }}$ de $220^{\circ} \mathrm{C}$ para lignina de bagaço e $360^{\circ} \mathrm{C}$, com $\mathrm{T}_{\text {onset }}$ de $194^{\circ} \mathrm{C}$ para lignina de bagaço pré-tratado processo $\mathrm{V}$, a degradação da lignina, está relacionada com a quebra das ligações éter e carbono-carbono (LEÃO et al., 2015).

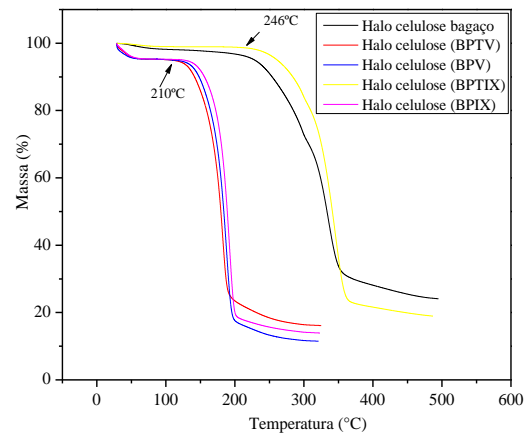

A
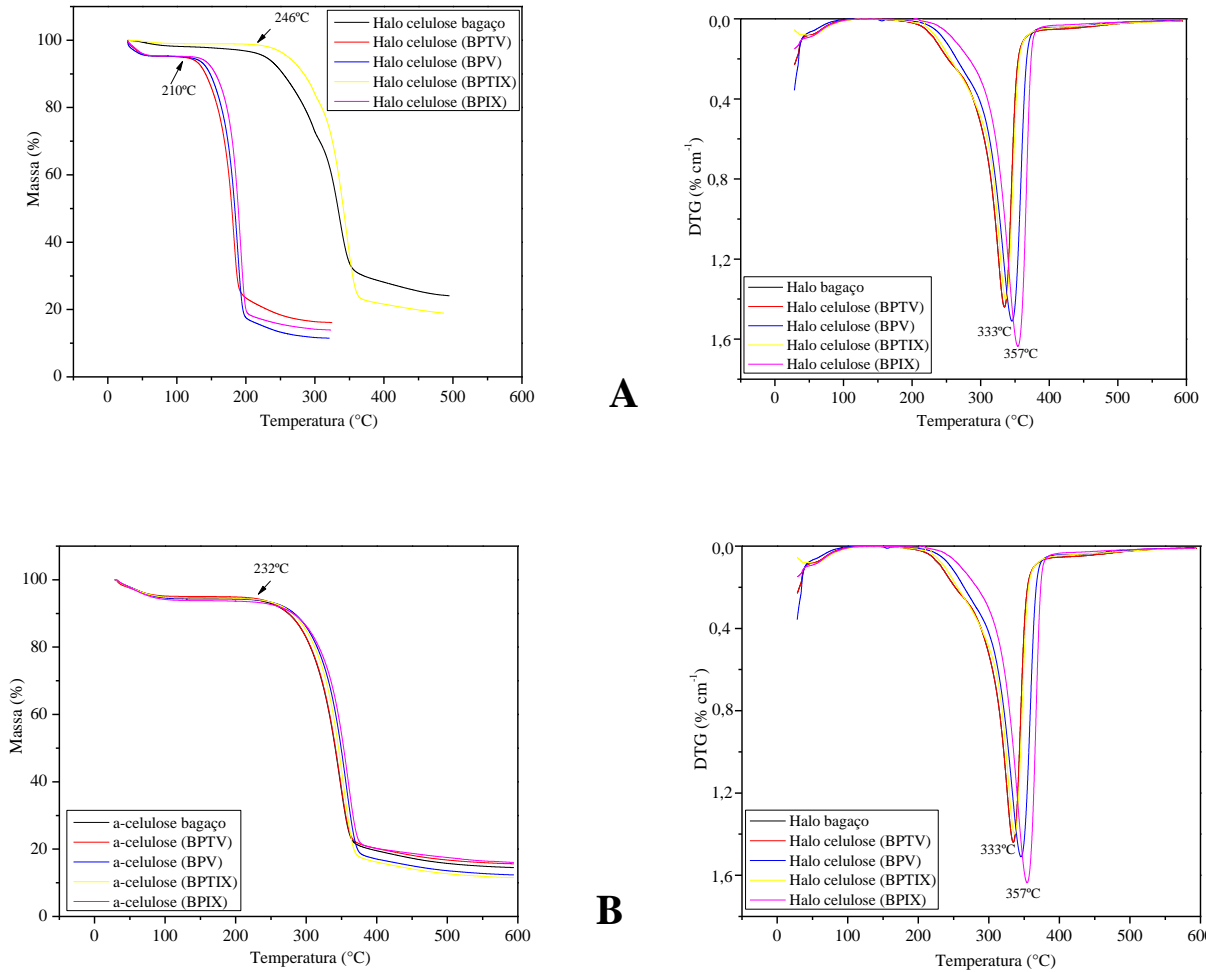

B
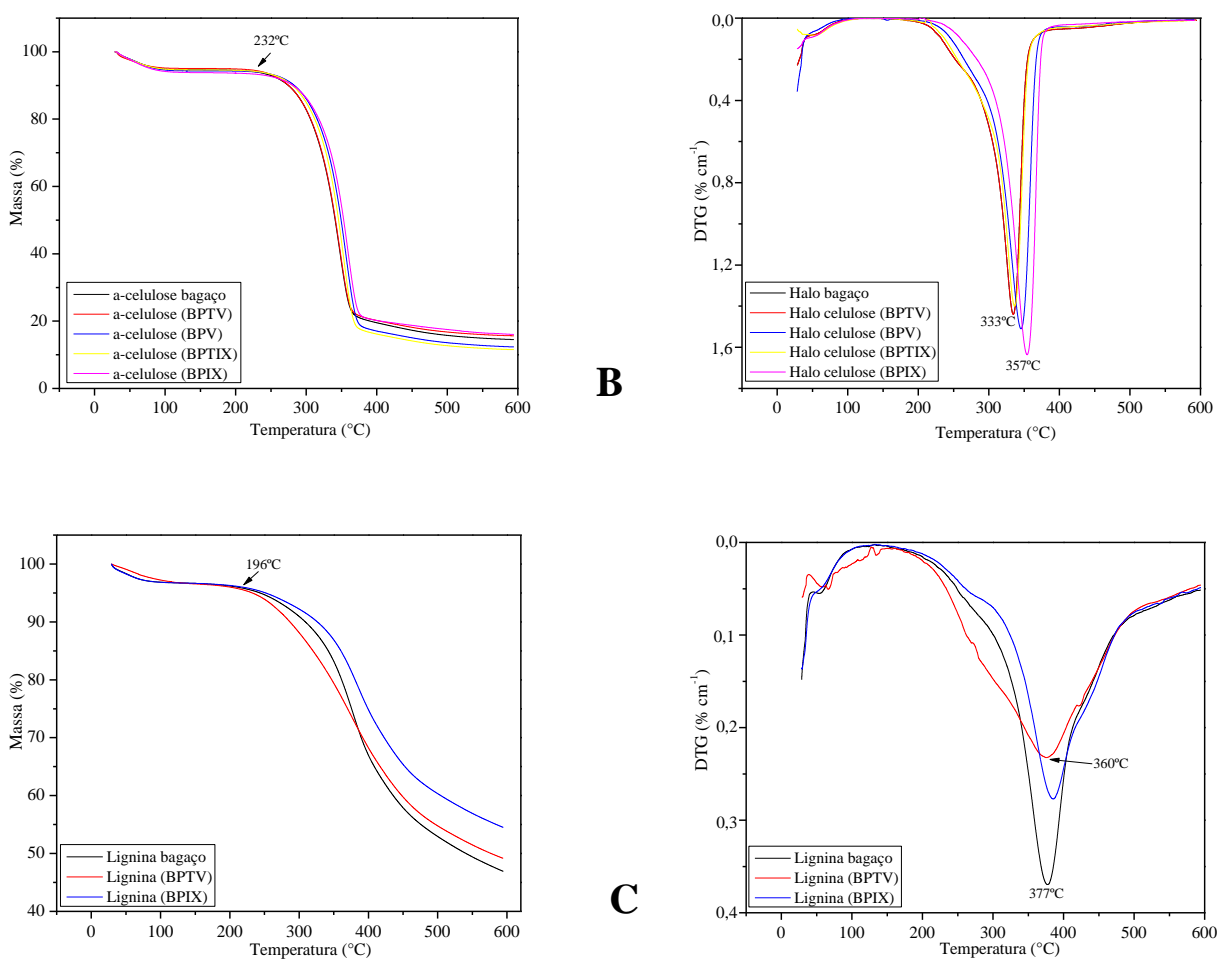

Figura 4.20: Comportamento das curvas de degradação térmica: (A) holocelulose; (B) $\alpha$ celulose; (C) lignina; Bagaço pré-tratado (BPT); Polpa branqueada (PB) dos processo V e IX. 


\subsubsection{Caracterização das fibras por calorimetria exploratória diferencial (DSC)}

Comparando as curvas DSC do bagaço in natura e tratadas, o bagaço in natura mostra pico endotérmico em $366^{\circ} \mathrm{C}$ com entalpia $\left(\Delta \mathrm{H}_{\text {evap }}\right) 282 \mathrm{J.g}^{-1} \mathrm{e}$ as polpas branqueadas os picos endotérmicos foram a 354 e $353^{\circ} \mathrm{C}$ com entalpia $\left(\Delta \mathrm{H}_{\text {evap }}\right) 722 \mathrm{J.g}^{-1}$ e $475 \mathrm{J.g}^{-1}$, respectivamente do processo V e IX conforme a Tabela 4.7 evidenciando a presença da celulose. Desta forma, quanto maior o tratamento das fibras, maior é o consumo de energia para a degradação. Isso pode ser devido à remoção dos extrativos ou de outros constituintes que se degradou. Como também a área superficial, pode diminuir a energia necessária para ocorrer a degradação.

Tabela 4.7: Dados das curvas DSC das fibras não tratadas, tratadas e nanocristais de celulose.

\begin{tabular}{lcc}
\hline \multicolumn{1}{c}{ Amostras } & Pico de Temperatura $\left({ }^{\circ} \mathbf{C}\right)$ & $\Delta \mathbf{H}\left(\mathbf{J . g}^{\mathbf{- 1}}\right)$ \\
\hline Bagaço in natura & 366 & 282 \\
Bagaço pré-tratado V & 339 & 48 \\
Polpa branqueada V & 354 & 722 \\
Nanocristais V & 299 & 249 \\
Bagaço pré-tratado IX & 357 & 226 \\
Polpa branqueada IX & 353 & 475 \\
Nanocristais IX & 308 & 173 \\
\hline
\end{tabular}

Processo V $\left(\mathrm{NaClO}_{2} 2 \% / \mathrm{NaOH} 2 \% / 1 \mathrm{x}\right)$; e processo IX ( $\left.\mathrm{NaOH} 5 \% / \mathrm{NaClO}_{2} 3,3 \% / 1 \mathrm{x}\right)$.

\subsection{OBTENÇÃO DOS NANOCOMPÓSITOS E CARACTERIZAÇÃO POR ANÁLISES TÉRMICAS, MORFOLÓGICA, ENSAIOS MECÂNICOS, ANÁLISE ESTATÍSTICA E REOLOGIA}

\subsubsection{Descrição dos processos de obtenção dos nanocompósitos}

O tipo de processo pode influenciar as propriedades dos nanocompósitos, alterando a resistência mecânica, propriedades térmicas, dinâmico-mecânicas e reológicas. Outro fato importante é a secagem do material, segundo Bledski; Gassan (1999), a secagem dos nanocristais 
de celulose deve ser feita antes do processamento. Esta etapa é muito importante, porque a água na superfície dos nanocristais de celulose pode agir como agente de separação na interface entre os nanocristais de celulose e a matriz. Após o processamento, os nanocompósitos apresentaram uma coloração amarelada e o ABS apresentou uma coloração branca, conforme mostra a Figura 4.21 (A e B), respectivamente. Segundo os estudos ROSA et al. (2009), a uniformidade da cor, entretanto, é uma boa indicação de que a mistura NCC/ABS foi bem homogeneizada.

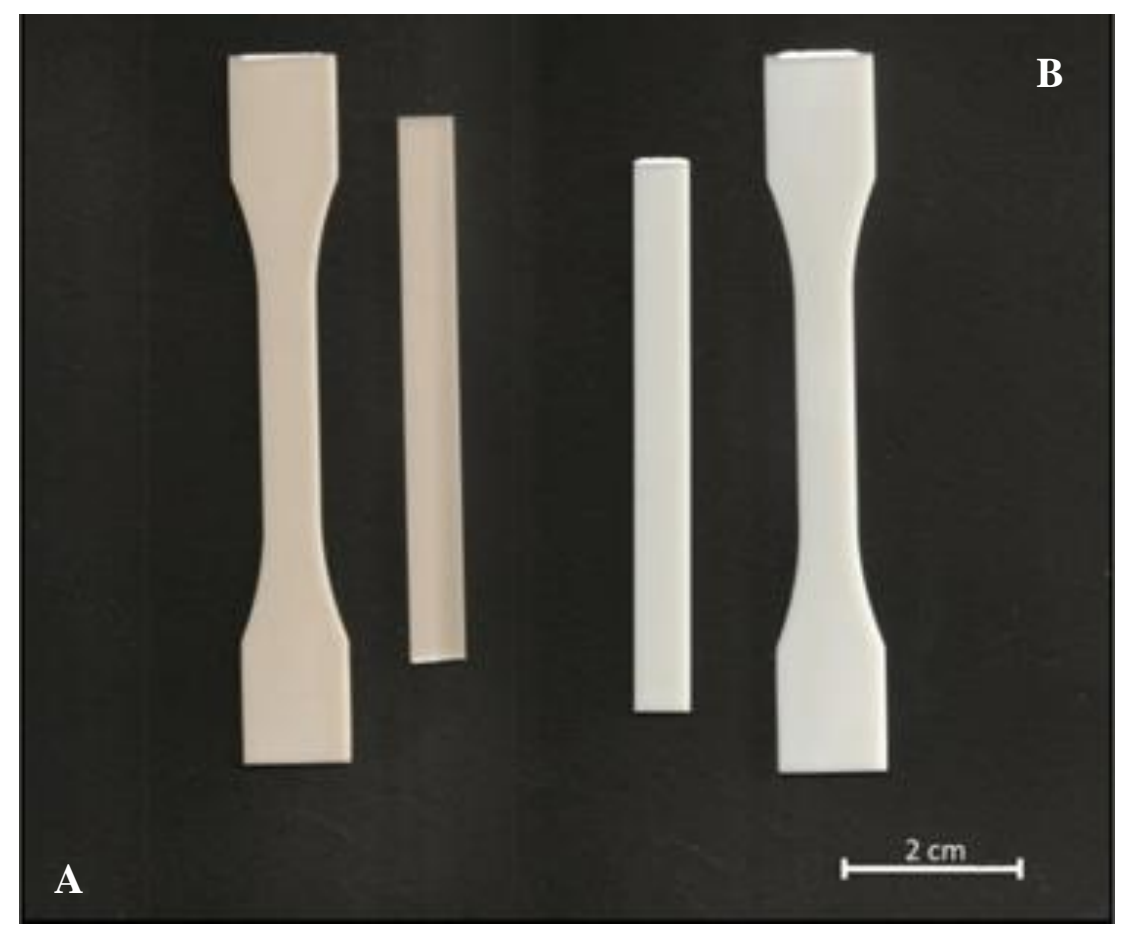

Figura 4.21: Corpos de prova de tração e flexão (A) NCC 1,5\%/ABS processo V; (B) ABS.

\subsubsection{Caracterização dos nanocompósitos a partir das análises térmicas}

A Figura 4.22 (A) mostra as curvas TGA/DTG para os nanocompósitos reforçados com 0,5\% (m/m) de NCC/ABS e NCC em relação ao ABS puro. Já, a Figura 4.22 (B) mostra simultaneamente as curvas TGA/DTG dos nanocompósitos reforçados com $1,5 \%(\mathrm{~m} / \mathrm{m})$ de NCC/ABS e NCC em relação ao ABS.

A estabilidade térmica do ABS puro foi de $347^{\circ} \mathrm{C}$. Para os nanocompósitos NCCIX 0,5\%/ABS, a estabilidade térmica foi semelhante ao do $\mathrm{ABS}$ puro de $347^{\circ} \mathrm{C}$ e para os nanocompósitos $\mathrm{NCCV}$ 0,5\%/ABS foi cerca de $321^{\circ} \mathrm{C}$. A estabilidade térmica para os 
nanocompósitos NCCV 1,5\%/ABS e NCCIX 1,5\%/ABS foram semelhantes em torno de $307^{\circ} \mathrm{C}$. Foi observado que com o aumento da adição de nanocristais de celulose a estabilidade térmica diminui. Este fato pode ser explicado devido o excesso de NCC, eles não conseguem dispersar na matriz ocorrendo assim aglomeração e consequentemente, diminuição da estabilidade.

As curvas DTG dos nanocompósitos apresentaram um pico distinto, que podem ser observado na Figura 4.22 (A) e (B). Tanto para o ABS puro quanto para os nanocompósitos de nanocristais de celulose/ABS, a faixa de decomposição ocorreu em uma única etapa. A curva DTG do ABS e NCCIX 0,5\%/ABS, mostra a velocidade de decomposição máxima, apresentando $\mathrm{T}_{\text {pico }}$ em $421^{\circ} \mathrm{C}$, com $\mathrm{T}_{\text {onset }}$ em $349^{\circ} \mathrm{C}$; NCCV 0,5\%/ABS apresentando $\mathrm{T}_{\text {pico }} \mathrm{em}$ $402^{\circ} \mathrm{C}$, com $\mathrm{T}_{\text {onset }}$ em $329^{\circ} \mathrm{C}$; NCCV 1,5\%/ABS ou NCCIX 1,5\%/ABS apresentando $\mathrm{T}_{\text {pico }}$ em $398^{\circ} \mathrm{C}$, com $\mathrm{T}_{\text {onset }}$ em $314^{\circ} \mathrm{C}$. Portanto, a amostra NCCIX 0,5/ABS segue a degradação do ABS, isso se deve ao fato do ABS blindar os NCC termicamente, podendo sugerir que os NCC estão mais dispersos, mostrando assim melhor desempenho de compatibilidade, afinidade química e sugerindo melhor interação com os NCC (MOTHÉ; AZEVEDO, 2009).

Embora a estabilidade térmica dos nanocompósitos seja maior que os nanocristais de celulose, decompõe-se mais facilmente que o ABS puro. Os nanocompósitos unem as características térmicas tanto do material de reforço quanto da matriz, ocorrendo alteração tanto nas propriedades térmicas como nas propriedades mecânicas do material. 


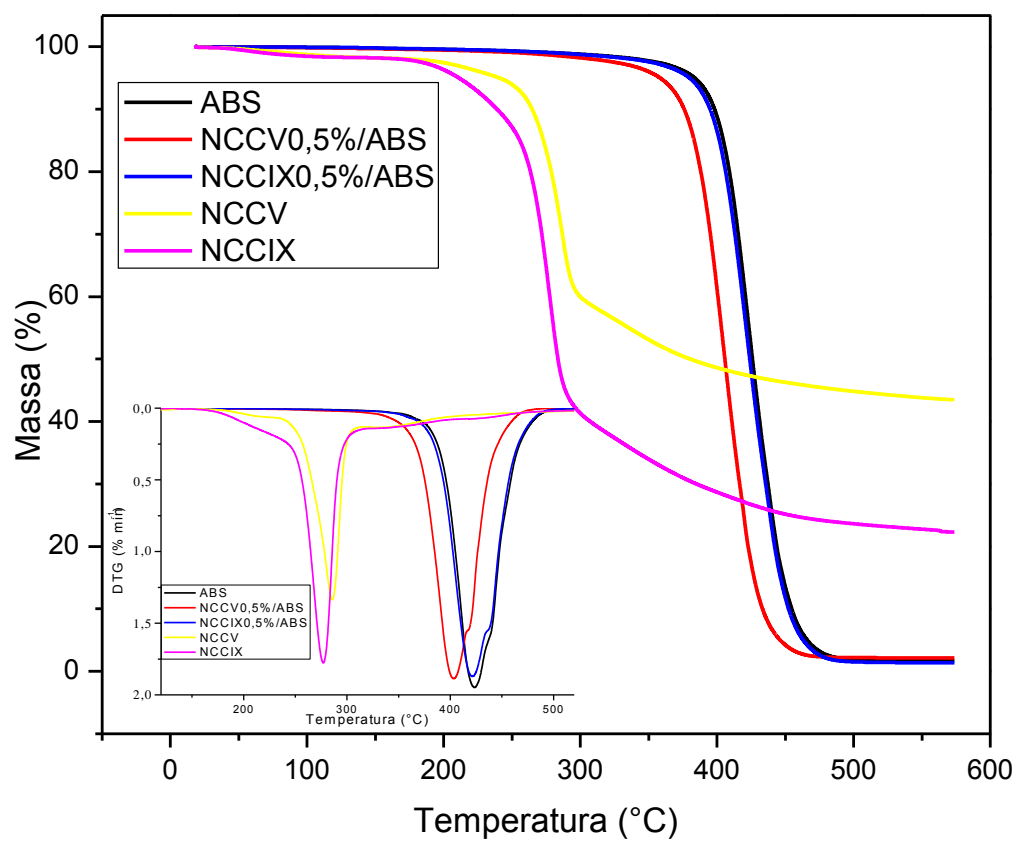

A

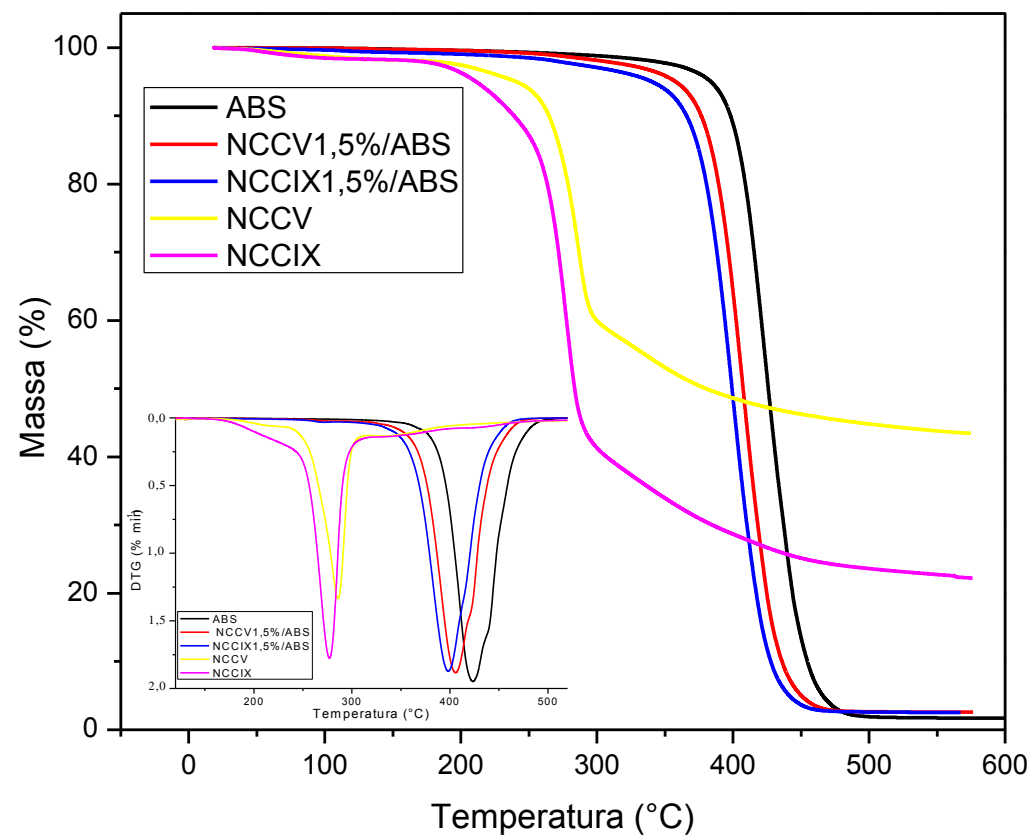

B

Figura 4.22. Comportamento das curvas de degradação térmica dos nanocompósitos de nanocristais de celulose/ABS: (A) NCC 0,5\%/ABS; (B) NCC 1,5\%/ABS dos processos V e IX. 
A partir das curvas de TGA e das curvas de derivadas (DTG), pôde-se relacionar os resultados de perda de massa entre 100 e $500^{\circ} \mathrm{C}$, como também os picos de temperatura de degradação térmica dos nanocompósitos e do ABS, conforme a Tabela 4.8.

A partir de $100^{\circ} \mathrm{C}$ já se observa a perda de massa para os nanocompósitos e somente a partir de $200^{\circ} \mathrm{C}$, a perda de massa do ABS é observada. A perda de massa após $400^{\circ} \mathrm{C}$ diminui com o aumento do teor de nanocristais adicionadas à matriz. Os picos de temperatura de degradação térmica dos nanocompósitos surgem em torno de $395^{\circ} \mathrm{C}$ e a temperatura de degradação térmica da matriz (ABS) foi em torno de $421^{\circ} \mathrm{C}$.

Tabela 4.8. Perda de massa nanocompósitos de nanocristais de celulose/ABS dos processos V e IX e ABS puro em atmosfera de $\mathrm{N}_{2}$.

\begin{tabular}{|c|c|c|c|c|c|c|}
\hline \multirow{2}{*}{ Amostras } & \multicolumn{5}{|c|}{ Perda de Massa (\%) } & \multirow{2}{*}{$\begin{array}{c}\text { Picos de } \\
\text { Degradação } \\
\text { Térmica }\left({ }^{\circ} \mathrm{C}\right)\end{array}$} \\
\hline & $100^{\circ} \mathrm{C}$ & $200^{\circ} \mathrm{C}$ & $300^{\circ} \mathrm{C}$ & $400^{\circ} \mathrm{C}$ & $500^{\circ} \mathrm{C}$ & \\
\hline ABS & 0,0 & 0,4 & 1,1 & 11,2 & 98,0 & 421 \\
\hline NCCV 0,5\%/ABS & 0,1 & 0,5 & 1,7 & 38,8 & 97,8 & 402 \\
\hline NCCV $1,0 \% / A B S$ & 0,1 & 0,3 & 1,8 & 46,5 & 97,9 & 395 \\
\hline NCCV 1,5\%/ABS & 0,0 & 0,4 & 1,8 & 35,8 & 97,3 & 398 \\
\hline NCCIX 0,5\%/ABS & 0,0 & 0,3 & 1,2 & 13,5 & 98,4 & 421 \\
\hline NCCIX $1,0 \% / A B S$ & 0,2 & 0,6 & 1,8 & 25,0 & 98,0 & 407 \\
\hline NCCIX $1,5 \% / A B S$ & 0,3 & 0,9 & 2,9 & 51,5 & 97,3 & 396 \\
\hline
\end{tabular}

\subsubsection{Caracterização dos nanocompósitos e nanocristais de celulose por calorimetria exploratória diferencial (DSC)}

A Tabela 4.9 mostra os dados das curvas DSC dos nanocompósitos de nanocristais de celulose/ABS e ABS. Os nanocompósitos de nanocristais de celulose/ABS apresentaram um

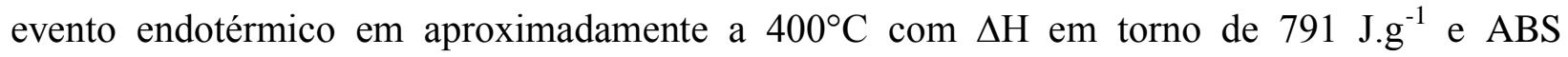

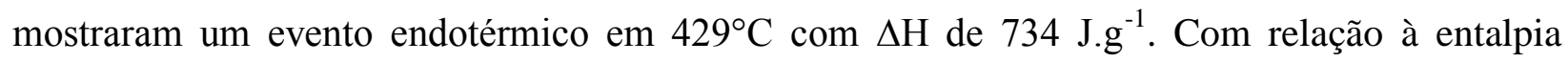
envolvida nos processos, a adição de nanocristais de celulose no ABS acarretou em maior consumo de energia para a degradação, isso se deve a interação entre carga/matriz. 
Tabela 4.9: Dados das curvas DSC dos nanocompósitos de nanocristais de celulose/ABS dos processos V e IX.

\begin{tabular}{lcc}
\hline & Pico de Temperatura $\left({ }^{\circ} \mathbf{C}\right)$ & $\Delta \mathbf{H}\left(\mathbf{J . g}^{\mathbf{- 1}}\right)$ \\
\hline ABS & 429 & 734 \\
NCCV 0,5\%/ABS & 402 & 770 \\
NCCV 1,0\%/ABS & 402 & 777 \\
NCCV 1,5\%/ABS & 399 & 791 \\
NCCIX 0,5\%/ABS & 409 & 740 \\
NCCIX 1,0\%/ABS & 408 & 791 \\
NCCIX 1,5\%/ABS & 400 & 778 \\
\hline
\end{tabular}

Foi estudado o comportamento térmico do ABS puro como também dos nanocompósitos de nanocristais de celulose/ABS, como pode ser observado na Figura 4.23. Nas curvas DSC do ABS puro e dos nanocompósitos de nanocristais de celulose/ABS, os resultados apresentaram um evento térmico (endotérmico $402-421^{\circ} \mathrm{C}$ ). A degradação desses materiais nessa faixa de temperatura está relacionada à decomposição dos NCC/ABS, corroborando com a perda de massa nesta mesma faixa observada na análise termogravimétrica.

E para os nanocristais o pico térmico endotérmico foi cerca de $275^{\circ} \mathrm{C}$. A diferença entre o comportamento das curvas (DTG/DSC) do NCCV 0,5\%/ABS e NCCIX 0,5\%/ABS pode ser justificada pela morfologia do NCC. 


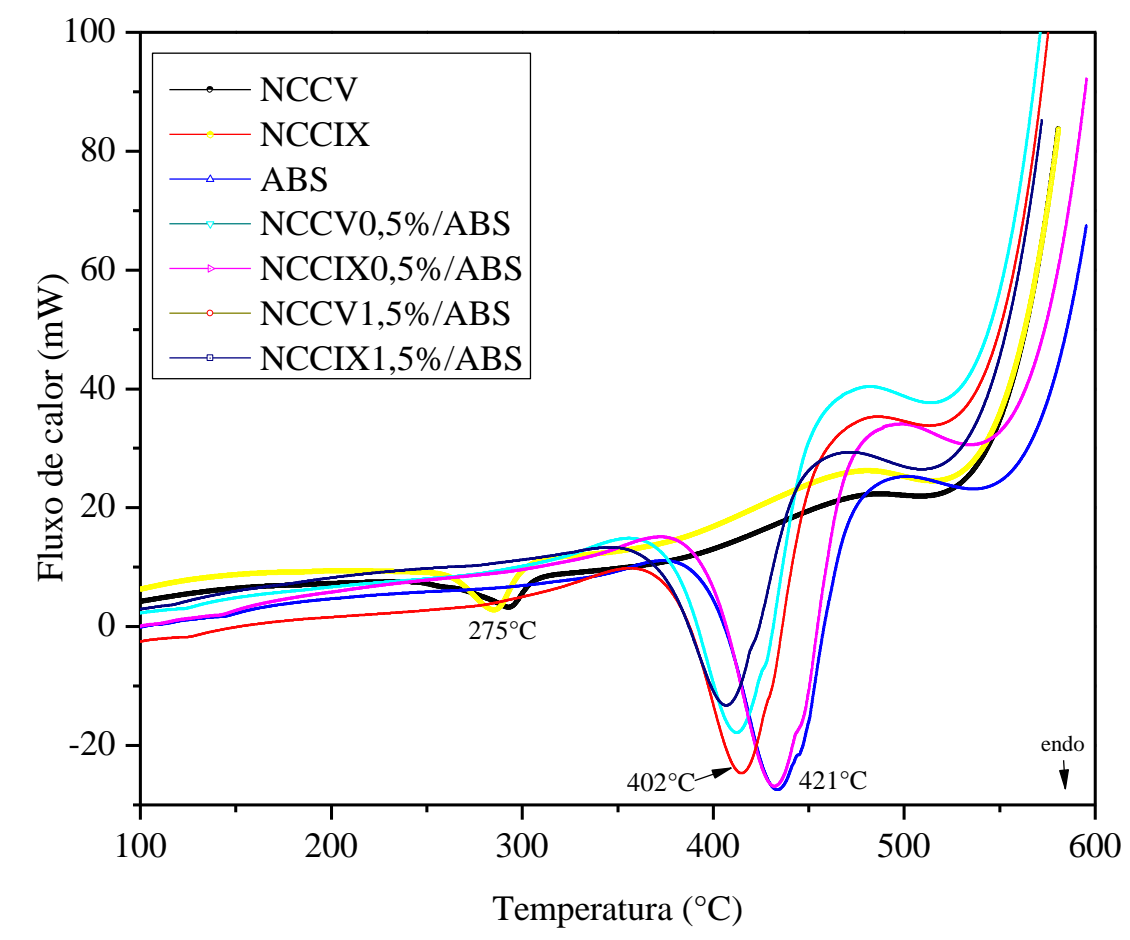

Figura 4.23: Curvas de DSC para os nanocompósitos de nanocristais de celulose/ABS dos processos V e IX.

\subsubsection{Caracterização dos nanocompósitos por análise dinâmica mecânica (DMA)}

As propriedades dinâmico-mecânicas de nanocompósitos reforçados com nanocristais de celulose dependem da distribuição e orientação dos NCC, a natureza da interface entre NCC/matriz e da região da interfase. Recentes investigações, a técnica de DMA foi usada para avaliar a interação interfacial entre nanocristais e matriz. A Figura 4.24 mostra o comportamento das curvas DMA para o ABS puro e para nanocompósitos reforçados com diferentes concentrações de NCC. Observa-se um aumento no módulo de armazenamento (E') com adição dos nanocristais de celulose. Ou seja, os nanocompósitos com NCC apresentaram E' superior ao ABS. Este comportamento está associado ao aumento da restrição molecular imposta pela adição dos nanocristais de celulose na matriz polimérica. Assim, a presença dos NCC dificultou a mobilidade das moléculas do ABS, provavelmente devido às interações entre NCC/ABS. Essa dificuldade na movimentação das moléculas da matriz fez com que houvesse um aumento 
significativo do módulo de armazenamento para os nanocompósitos em relação ao ABS puro (MA et al., 2015).

O módulo de armazenamento de NCC/ABS no estado vítreo $\left(50^{\circ} \mathrm{C}\right)$ é de $1,59 \mathrm{GPa}$ é $14 \%$ mais elevado do que o ABS puro $(1,40 \mathrm{GPa})$, enquanto que no estado elastomérico $\left(110^{\circ} \mathrm{C}\right) \mathrm{o}$ módulo de armazenamento de NCC/ABS é $327 \mathrm{MPa}$ é 59\% maior do que a observado no ABS puro (206 MPa). Isto significa que o NCC pode induzir um efeito de maior reforço, no estado de elastômeros do que no estado vítreo devido ao seu elevado módulo de elasticidade. Assim, a adição de cargas na matriz pode alterar o módulo na região elastomérica. Portanto, quanto maior o valor do módulo nessa região mais rígido é o nanocompósito, devido à maior restrição que as NCC impõem ao movimento livre das moléculas do polímero (ORNAGHI et al., 2010; CHIRAYIL et al., 2014; LAVORATTI et al., 2016). O mesmo comportamento foi observado por Lavorrati et al., 2016. Assim, este comportamento pode ser atribuído à morfologia dos NCC, como discutido na análise térmica da Figura 4.23.

$\mathrm{O}$ aumento do módulo armazenamento pode ser atribuído ao reforço $\mathrm{NCC}$, mas não o efeito da cristalização, devido à natureza amorfa do ABS (MA et al., 2015). Além disso, o aumento do módulo de armazenamento está relacionado com a diminuição da mobilidade molecular em função do módulo. Segundo Fim et al. (2014), o aumento no valor de módulo de armazenamento está relacionado com aumento da rigidez do polímero. Isso quer dizer que a adição dos NCC torna o ABS mais rígido, diminui a mobilidade molecular e aumenta a temperatura da região borrachosa. No entanto, o módulo de armazenamento de NCC/ABS apresentou melhora, comprovado pelas propriedades mecânicas e reologia. 


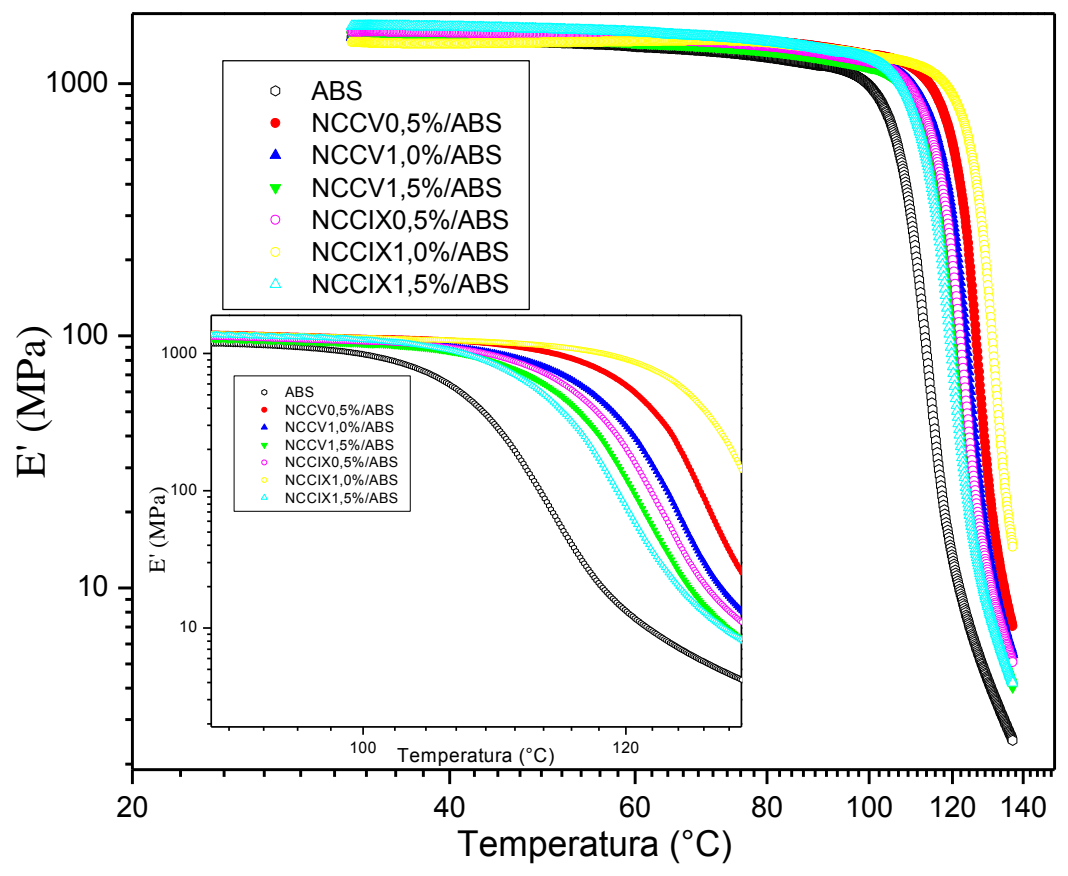

Figura 4.24: Módulo de armazenamento (E') para o ABS e os nanocompósitos de nanocristais de celulose/ABS dos processos V e IX.

Os valores dos nanocompósitos de nanocristais de celulose/ABS para o módulo de perda são maiores que o ABS puro para todos os nanocompósitos analisados e um deslocamento da temperatura foi observado. Segundo Lavoratti et al. (2016), a intensidade do pico do módulo de perda está relacionado com a dissipação de energia da interface entre NCC/ABS, devido à fricção interna e o aumento da temperatura está relacionado com a interação entre carga/matriz. O módulo de perda está mais sensível aos movimentos das cadeias moleculares dos polímeros. O valor de E" maior quer dizer que há maior restrição na mobilidade das cadeias poliméricas. Essa restrição na mobilidade das cadeias pode estar associada à maior rigidez do ABS devido à presença dos NCC conforme a Figura 4.25 (FIM et al., 2014; DIEZ-PASCUAL et al., 2014). Assim, a maior altura do pico de E" foi encontrada para o nanocompósito NCCV 0,5\%/ABS < NCCIX 1,5\%/ABS < NCCIX 0,5\%/ABS < NCCIX 1,0\%/ABS < NCCV 1,5\%/ABS < NCCV $1,0 \% / \mathrm{ABS}<\mathrm{ABS}$. 


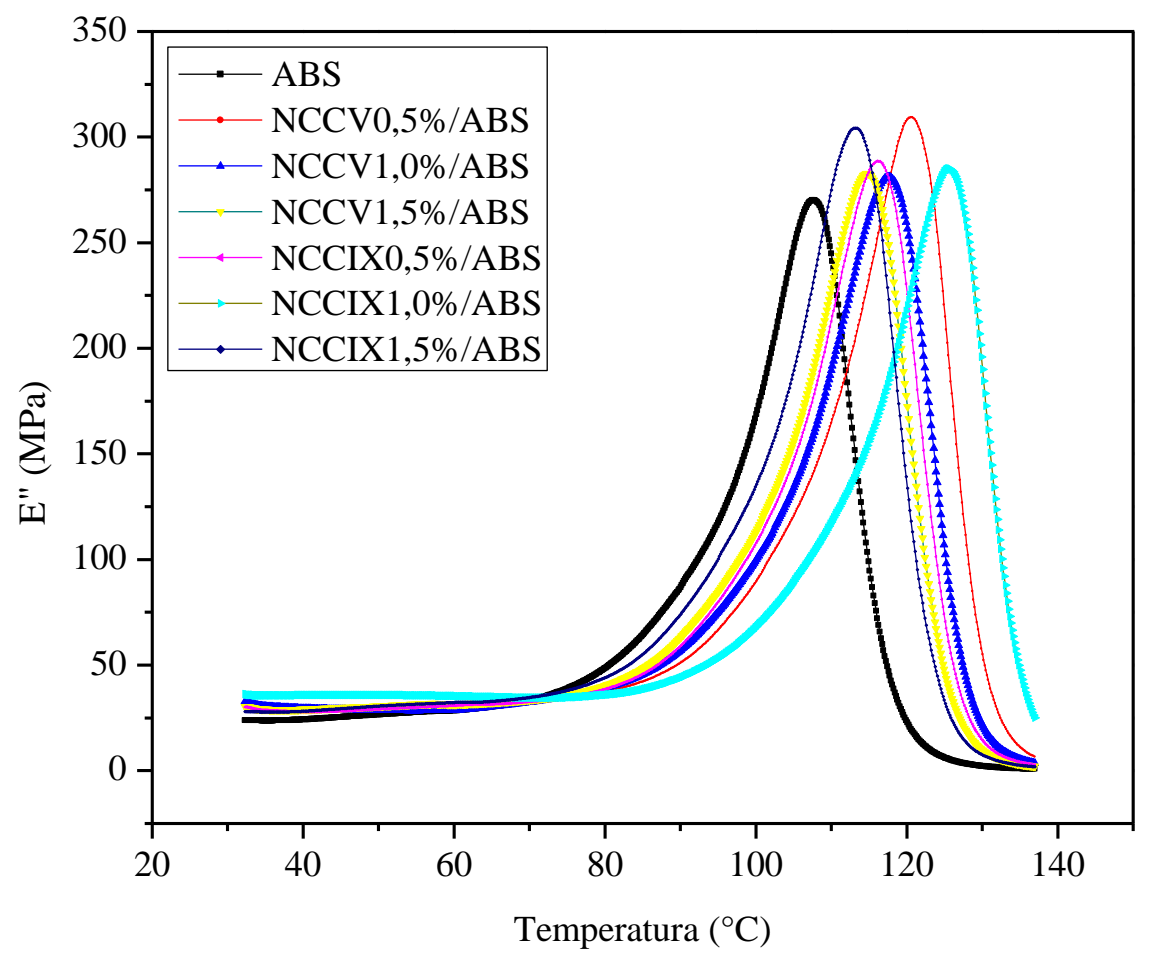

Figura 4.25: Módulo de perda (E") para o ABS e os nanocompósitos de nanocristais de celulose/ABS dos processos V e IX.

Adicionalmente, o pico de transição vítrea abaixo ou acima da $T_{\mathrm{g}}$ (temperatura de transição vítrea) da matriz devido à formação de uma interfase (região de contato interfacial entre NCC e matriz). Neste estudo, as temperaturas de transição vítrea foram determinadas a partir das curvas do módulo de perda. As temperaturas de transição vítrea de NCC/ABS estão apresentadas na Tabela 4.10, a maior $\mathrm{T}_{\mathrm{g}}$ foi encontrada para o nanocompósito NCCIX 0,5\%/ABS $<$ NCCIX 1,5\%/ABS. O aumento da $\mathrm{T}_{\mathrm{g}}$ é atribuído à maior restrição de movimentação das cadeias podendo resultar em melhor adesão na interface $\mathrm{NCC} /$ matriz, como também devido elevado índice de cristalinidade e afinidade química (SOARES, 2011; LAVORATTI et al., 2016).

Vale ressaltar que a $T_{g}$ da matriz polimérica amorfa, é muito importante, pois é nessa região que a cadeia do polímero está com movimentos restritos e acima da $\mathrm{T}_{\mathrm{g}}$ o nanocompósito adquire mobilidade para que a cadeia atue conjuntamente e ocorra mudança nas conformações 
carbônica. A presença de uma fase mais rígida com as NCC pode deslocar a $\mathrm{T}_{\mathrm{g}}$ da fase borrachosa para valores maiores. O aumento da rigidez pode ser obtido pelo próprio aumento da rigidez da cadeia polimérica, através da inclusão de NCC com alto grau de cristalinidade. Outro fator que influencia a $\mathrm{T}_{\mathrm{g}}$ é o aumento da massa molar (BORSOI et al., 2011).

Tabela 4.10: Temperatura de transição vítrea do ABS e dos nanocompósitos de nanocristais de celulose/ABS dos processos V e IX.

\begin{tabular}{cc}
\hline Amostras & $\mathbf{T}_{\mathbf{g}}\left({ }^{\circ} \mathbf{C}\right)$ \\
\hline ABS & 107 \\
NCCV 0,5\%/ABS & 120 \\
NCCV 1,0\%/ABS & 115 \\
NCCV 1,5\%/ABS & 114 \\
NCCIX 0,5\%/ABS & 116 \\
NCCIX 1,0\%/ABS & 125 \\
NCCIX 1,5\%/ABS & 112 \\
\hline
\end{tabular}

A Figura 4.26 apresenta as curvas de $\tan \delta$ em função da temperatura para diferentes frações volumétricas de NCC. Observou-se que com a adição dos NCC ocorre a diminuição da intensidade do pico tan $\delta$ e um deslocamento da temperatura. Nestes materiais poliméricos, o tan $\delta$ é alterado, pela incorporação dos NCC. Dessa forma, o valor do pico está associado com a movimentação da estrutura do polímero, em que pequenos grupos e segmentos de cadeia inicialmente "congelados" começam a se movimentar, assim, menores valores para o pico de $\tan \delta$ indica uma melhor adesão interfacial. Isso pode ser justificado pela restrição da movimentação das moléculas do polímero pela incorporação de cargas rígidas. Além disso, como a dissipação de energia, irá ocorrer na interface carga/matriz, então uma interface mais forte é caracterizada pela menor dissipação de energia (BORSOI et al., 2011; GEHLEN et al., 2014).

Portanto, quanto maior a interação entre NCC/matriz menor é a dissipação de energia, que resulta em deslocamento da temperatura do pico $\tan \delta$. Por outro lado, o valor de $\tan \delta$ indica o grau de amortecimento mecânico, quanto mais flexível o sistema, maior o grau de amortecimento (PISTOR et al., 2010).

Para os nanocompósitos analisados, foi observada uma sensível redução no grau de amortecimento em relação ao ABS, ou seja, quanto mais rígido for o sistema menor será o grau 
de amortecimento. Assim, com a adição dos NCC diminui-se a porcentagem da matriz, componente de maior ductilidade e, consequentemente, o grau de amortecimento. Estes resultados corroboram com as análises dos ensaios mecânicos (BORSOI et al., 2011).

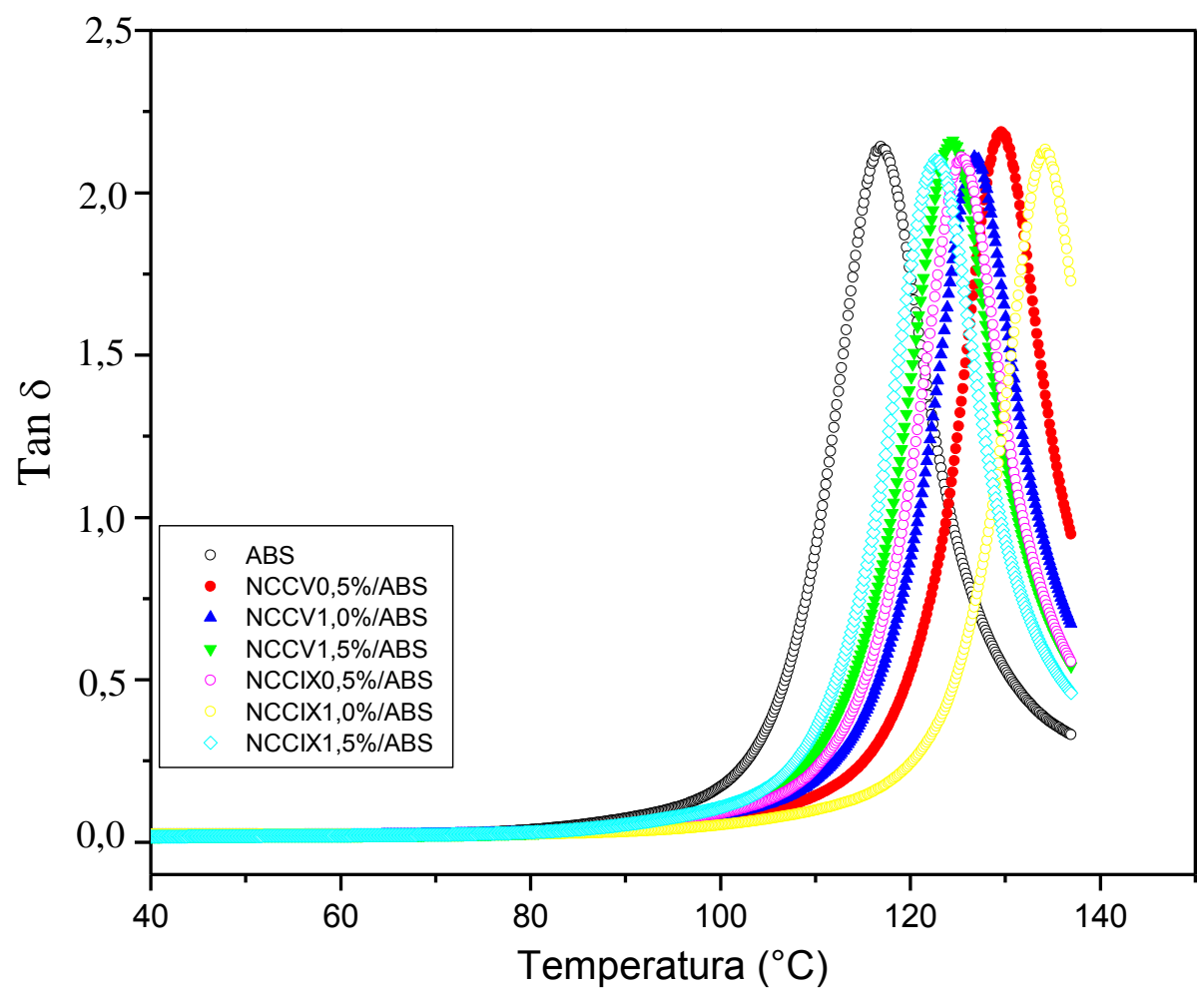

Figura 4.26: Tan $\delta$ do ABS e dos nanocompósitos de nanocristais de celulose/ABS dos processos V e IX.

\subsection{MORFOLOGIA E INTERFACE DOS NANOCOMPÓSITOS DE NANOCRISTAIS DE CELULOSE/ABS}

As micrografias das superfícies de fratura dos nanocompósitos submetidos ao ensaio de impacto são apresentadas na Figura 4.27 para os materiais NCC/ABS. O ABS é mostrado na Figura 4.27 (A), para uma análise comparativa. As Figuras 4.27 (B) (C) e (D) indicaram uma boa distribuição do reforço na matriz e homogeneidade. Ou seja, uma boa adesão entre carga e a matriz foi evidenciada, como também arrancamento das mesmas da matriz "pull out". Foi observado também que após a adição de carga à matriz, material fica poroso, essa alteração se 
deve a presença dos NCC. Os resultados determinados neste estudo estão de acordo com a literatura (PRACELLA et al., 2012).

Através das micrografias do Anexo $G$ pode-se observar que os nanocompósitos obtidos apresentam fluxo da matriz, isto é, deformação plástica do ABS. E os NCC são muitas vezes puxados da matriz deixando orifícios vazios, quebra dos NCC e aglomerados.

Os mecanismos de falhas em nanocompósitos fraturados podem ser decorrentes de uma sobrecarga mecânica que causa uma fratura frágil da matriz e do NCC; o NCC pode ser puxado para fora da matriz sem haver a ruptura; pode haver delaminação entre NCC e matriz; há a deformação plástica e ruptura da matriz (HEARLE et al., 1998).
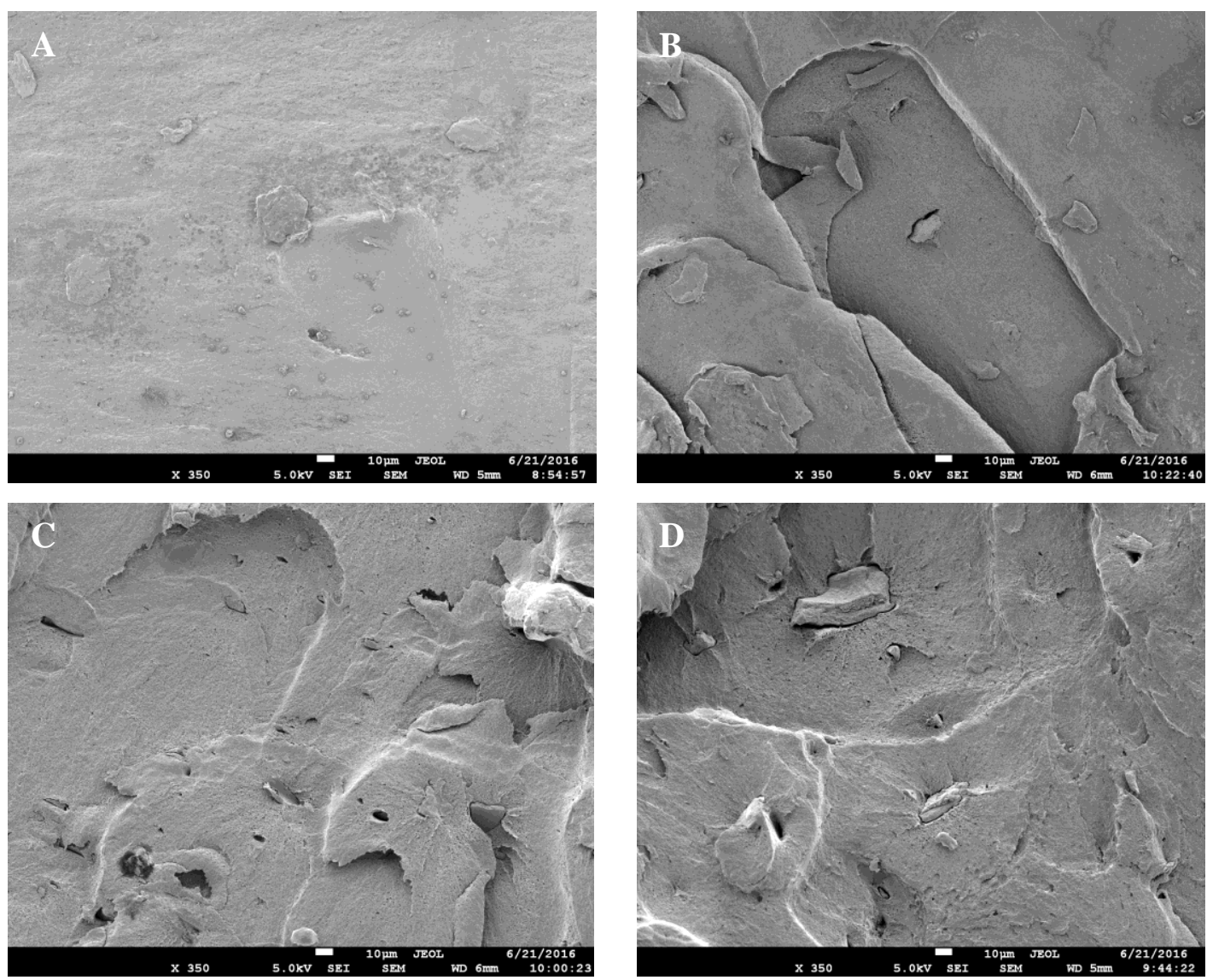

Figura 4.27. Micrografias obtidas dos nanocompósitos de nanocristais de celulose/ABS: (A) ABS; (B) NCCV 0,5\%/ABS; (C) NCCV 1,5\%/ABS; (D) NCCIX 1,5\%/ABS dos processos V e IX. 


\subsection{PROPRIEDADES MECÂNICAS DOS NANOCOMPÓSITOS DE NANOCRISTAIS DE CELULOSE/ABS}

\subsubsection{Resistência à tração dos nanocompósitos de nanocristais de celulose/ABS}

As propriedades mecânicas dos nanocompósitos são altamente influenciadas pela boa dispersão e pela compatibilidade interfacial entre carga e matriz. Assim, a resistência à tração depende da compatibilidade entre a carga e a matriz, e o módulo Young é influenciado pela impregnação da carga na matriz (FERREIRA et al., 1997).

Pode-se observar na Figura 4.28 o comportamento das curvas $\sigma$ versus $\varepsilon$ para os nanocompósitos obtidos em extrusora, reforçados com 0,$5 ; 1,0 ; 1,5 \%$ de nanocompósitos de nanocristais de celulose/ABS. Os ensaios de tração foram realizados utilizando o extensomêtro em velocidade de $2 \mathrm{~mL} / \mathrm{min}$, para todas as amostras $\mathrm{ABS}$ puro e nanocompósitos de nanocristais de celulose/ABS (ABS; NCCV 0,5\%/ABS; NCCV 1,0\%/ABS; NCCV 1,5\%/ABS; NCCIX 0,5\%/ABS; NCCIX 1,0\%/ABS; NCCIX 1,5\%/ABS).

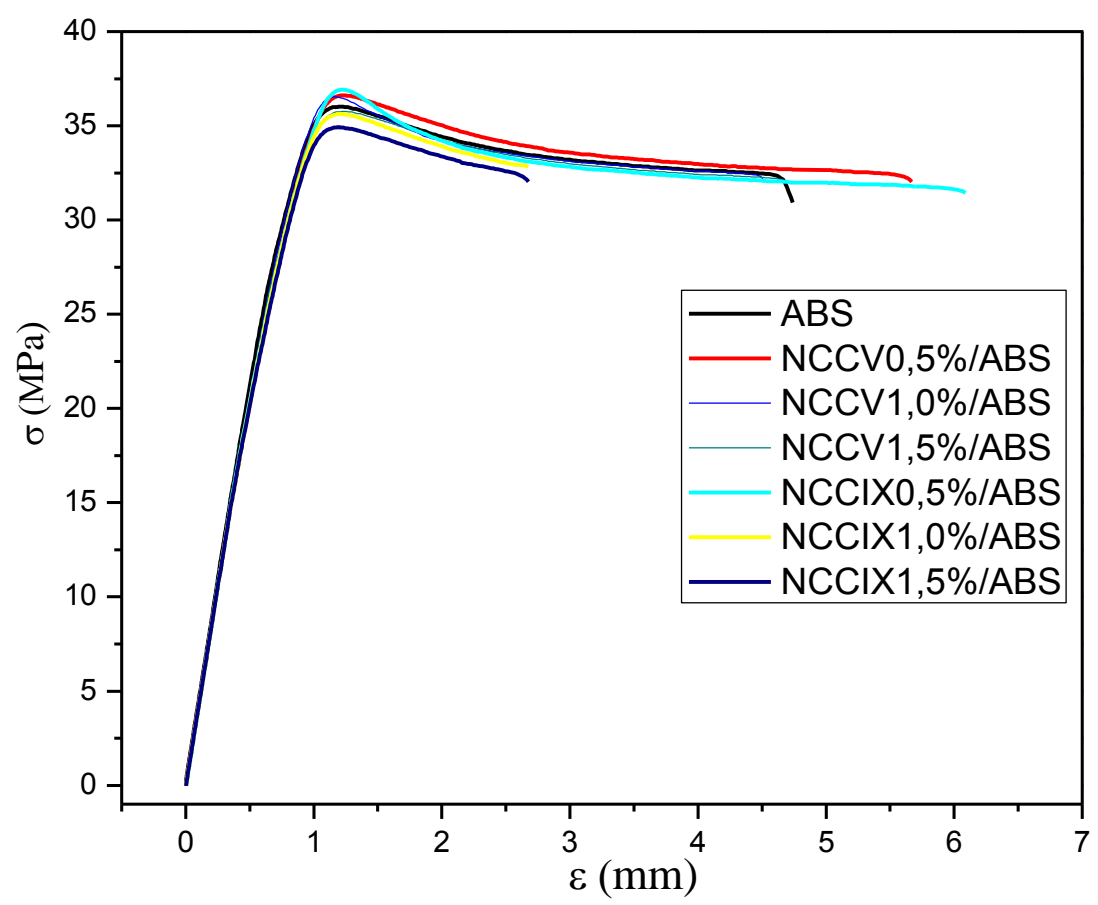

Figura 4.28. Comportamento das curvas de resistência à tração versus deformação de nanocompósitos de nanocristais de celulose/ABS dos processos V e IX. 
O comportamento da curva tensão $(\sigma)$ versus deformação $(\varepsilon)$ do ABS puro apresentou um polímero dúctil e a resistência máxima de 36,0 $\mathrm{MPa}$ e com a adição de NCC, a resistência à tensão aumenta para NCCIX 0,5\%/ABS < NCCV 0,5\%/ABS < NCCV 1,0\%/ABS (37,0; 36,6; $36,5 \mathrm{MPa}$ ), cerca de 3\%, em relação ao ABS puro. Isso ocorre, porque a adesão desses materiais pode se dar pela: elevada área superficial, razão de aspecto, elevada cristalinidade, atração eletrostática, ligação de hidrogênio, forças de van der Waals (BURADOWSKI; REZENDE, 2001). Portanto, uma forte ligação na interface carga/matriz é importante para uma eficiente transferência de carga aplicada sobre a matriz para os NCC, melhora da resistência do material nanocompósito. Assim, os NCC, são responsáveis por suportarem a maior parte da carga aplicada, são mais resistentes que a matriz. Sob a aplicação de uma tensão, a ligação NCC/matriz cessa nas extremidades dos NCC. Dessa forma, para que exista uma boa interação na interface $\mathrm{NCC} /$ matriz são necessários grupos funcionais atuando na região interfacial, ou seja, sítios ativos ácido-base de Lewis. A força de adesão existente em uma interface é dada pelo trabalho termodinâmico da adesão, que está relacionado à energia da superfície da carga e da matriz (DILSIZ; WIGHTMAN, 2000; CLINT, 2001).

Dessa forma, o aumento da resistência à tração demonstrou que o NCC/ABS formou uma forte ligação interfacial, maior afinidade e maior compatibilidade entre a carga e a matriz como também melhor dispersão dos NCC na matriz ABS, assim, favorecendo as propriedades mecânicas de tração, como também filtro de barreira. Portanto, os grupos de acrilonitrila (CN) do ABS têm átomos de nitrogênio $(\mathrm{N})$, que são eletronegativos, podendo forma ligações de hidrogênio com o átomo de hidrogênio da hidroxila $(\mathrm{OH})$ dos NCC (MA et al., 2015). A adesão interfacial do material foi confirmada pelo MEV.

A resistência à tração dos nanocompósitos de nanocristais de celulose/ABS variou dependendo da quantidade dos NCC. A resistência à tração dos nanocompósitos de nanocristais de celulose/ABS mostraram uma tendência de diminuição quando aumenta o teor NCC NCCIX 1,5\%/ABS < NCCIX 1,0\%/ABS < NCCV 1,5\%/ABS (34,9; 35,6 e 35,7 MPa).

No entanto, a resistência à tração diminui com aumento do teor NCC. Ou seja, um material resistente e rígido perde a flexibilidade, confirmado pela diminuição das propriedades mecânicas e DMA. Uma explicação para este fato é porque, há muitas hidroxilas no interior da estrutura química dos NCC. Assim, quando aumenta teor dos NCC, ocorre uma mudança nas 
hidroxilas adjacentes que irá aumentar a formação das ligações de hidrogênio. Uma vez que essas ligações de hidrogênio são formadas nas estruturas dos NCC, a sua área superficial irá diminuir, e consequentemente, o contato da área entre NCC/ABS também diminui. Então, a eficiência da interface entre NCC/ABS diminuirá. Alterações semelhantes têm sido relatadas para nanocompósitos de NCC/PVAC e NCC/ABS (PRACELLA et al., 2012; MA et al., 2015). Vale ressaltar, quando o nanocompósitos de nanocristais de celulose/ABS possui propriedades inferiores à matriz, o teor de reforço encontra-se abaixo da concentração crítica ou quando este forma aglomerados que fragilizam o sistema, portanto, a redução na resistência dos nanocompósitos com a incorporação dos NCC pode ter sido provocada pela formação de aglomerados. A MEV confirma a formação de aglomerados para os nanocompósitos com maiores concentrações (PĂRPĂRITĂ et al., 2014; NETO et al., 2007; BEZERRA et al., 2015).

Segundo HASSAN et al. (2014), estudaram as propriedades mecânicas dos nanocompósitos de nanofibras/PP a partir de bagaço da cana-de-açúcar, ocorrendo uma diminuição da resistência a tração entre 20 a $21 \%$ e o módulo Young aumenta de aproximadamente $10 \%$ para os nanocompósitos nanofibras/PP. Este fato pode ser atribuído à maior rigidez das nanofibras de celulose quando comparada ao PP puro.

Para o módulo Young é observado um aumento para todos os nanocompósitos de nanocristais de celulose/ABS em relação ao ABS puro conforme a Figura 4.29. A adição de nanocristais de celulose aumentou o módulo elasticidade de tração em até $28 \%$ para os nanocompósitos de nanocristais de celulose/ABS em relação ao ABS puro. 


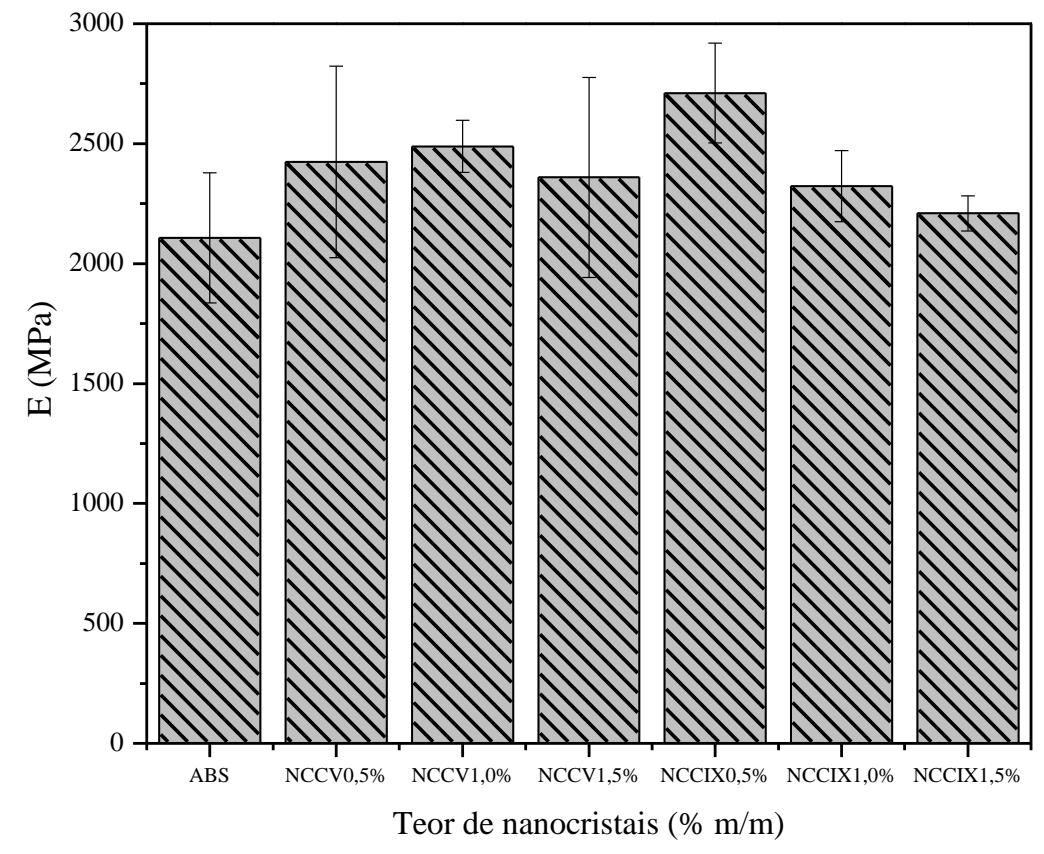

Figura 4.29: Módulo de Young versus nanocompósitos de nanocristais de celulose/ABS dos processos V e IX.

Isso ocorre porque os NCC tem um excelente módulo, e esta propriedade pode ser transferida para os nanocompósitos (NCC/ABS). Os nanocompósitos com NCCIX 0,5/ABS < NCCV 1,0/ABS < NCCV 0,5/ABS proporcionou melhor ancoragem em relação ao nanocompósitos NCCV 1,5/ABS < NCCIX 1,0/ABS < NCCIX 1,5/ABS. A mesma situação foi observada no estudo de nanocompósitos nanofibras/acetato de polivinila. Portanto, este estudo mostra que o maior módulo obtido, foi quando utilizou um menor teor de NCC (GONG et al., 2011), o mesmo foi observado nos estudos MA et al., (2015).

Os NCC possui elevado grau de cristalinidade que lhe confere um alto módulo. Dessa forma, o elevado grau de cristalinidade dificulta que os NCC se deformem. Esta característica é retida nos NCC quando é introduzido no ABS. Assim, a mobilidade molecular do ABS nos nanocompósitos é restrita e com concentrações elevadas de NCC na matriz, o espaço da mobilidade molecular diminui. Em resumo, a capacidade de deformação de nanocompósitos de nanocristais de celulose/ABS foi restringida após a adição de NCC. Uma mudança semelhante 
foi observada para nanocompósitos NCC/Poliamida6 (CORRÊA et al., 2014). Além disso, considerando que a carga é a fase rígida que não pode ser deformada. $O$ efeito da interação da carga/matriz é atribuído a morfologia da carga no polímero e a natureza química da matriz. A interação borracha-carga pode ser atribuída as ligações físicas (van der Waals), bem como ligações químicas ou ambas (BEZERRA et al., 2013). Segundo Jesus et al. (2015), a incorporação de uma segunda fase cristalina, como os NCC, em uma matriz vítrea (formada por copolímero acrilonitrila e estireno), aumenta sua tenacidade (FERREIRA et al., 1997).

Assim, foram evidenciadas melhoras nas propriedades dos nanocompósitos de nanocristais de celulose/ABS, podendo ser confirmado pela DMA devido aumento do módulo de armazenamento que está relacionado com o aumento da rigidez do material; podendo ser confirmado também pela reologia devido o aumento da viscosidade dos NCC/ABS sugerindo compatibilidade ou interação entre NCC/matriz.

Em vista disso, o tipo de NCC interfere no desempenho do material, mesmo que seja uma sensível diferença. A literatura reporta várias formas de obtenção de nanocompósitos, casting e master batch utilizando vários solventes e depois a extrusão. Além do impacto ambiental na produção dos NCC, mostra também o impacto no processamento, devido a grande utilização de solvente, para melhorar a compatibilidade entre carga e matriz. Então, levando em consideração que o processamento destes materiais foi amigavelmente sustentável, ou seja, não foi utilizado solvente e nem agente compatibilizante para melhorar a compatibilidade de interface entre NCC/ABS, como reporta a literatura, pode-se considerar melhora propriedades mecânicas.

\subsubsection{Resistência à flexão dos nanocompósitos de nanocristais de celulose/ABS}

A Tabela 4.11 mostra as propriedades mecânicas de flexão (resistência à flexão e módulo de elasticidade) dos vários nanocompósitos de nanocristais de celulose/ABS. Comparando os resultados da resistência em flexão para os nanocompósitos em relação ao ABS puro, todos os nanocompósitos de nanocristais de celulose/ABS apresentaram resistência inferior à matriz pura.

A adição de NCC resultou em um maior módulo de elasticidade para o nanocompósito (NCCIX 0,5\%/ABS), quando comparados ao ABS puro. Para os nanocompósitos de nanocristais de celulose/ABS, módulo de elasticidade à flexão aumentou em até 5\%. A inserção dos NCC na matriz fez com que os nanocompósitos apresentassem valores inferiores de resistência e módulos de elasticidade em flexão, assim, este comportamento pode ser atribuído à morfologia dos NCC. 
Tabela 4.11. Propriedades mecânicas de flexão dos nanocompósitos de nanocristais de celulose/ABS dos processos V e IX.

\begin{tabular}{ccc}
\hline Amostras & $\begin{array}{c}\text { Resistência à flexão } \\
(\mathbf{M P a})\end{array}$ & $\begin{array}{c}\text { Módulo de elasticidade } \\
(\mathbf{M P a})\end{array}$ \\
\hline ABS & $63,14 \pm 0,8$ & $2355,2 \pm 24,1$ \\
NCCV 0,5\%/ABS & $56,96 \pm 0,8$ & $2283,0 \pm 65,7$ \\
NCCV 1\%/ABS & $56,17 \pm 0,5$ & $2354,3 \pm 18,7$ \\
NCCV 1,5\%/ABS & $54,49 \pm 0,7$ & $2343,5 \pm 59,7$ \\
NCCIX 0,5\%/ABS & $59,85 \pm 1,8$ & $2464,3 \pm 26,8$ \\
NCCIX 1\%/ABS & $56,86 \pm 0,1$ & $2395,3 \pm 41,9$ \\
NCCIX 1,5\%/ABS & $56,81 \pm 0,1$ & $2364,1 \pm 19,7$ \\
\hline
\end{tabular}

\subsubsection{Resistência a impacto dos nanocompósitos de nanocristais de celulose/ABS}

A resistência ao impacto dos nanocompósitos é um fator importante na seleção destes materiais para aplicações de engenharia e, sobretudo, existe a necessidade de identificação de uma fratura prematura do material. As propriedades de resistência ao impacto do ABS e dos nanocompósitos de nanocristais de celulose/ABS são apresentadas nas Figuras 4.30. 


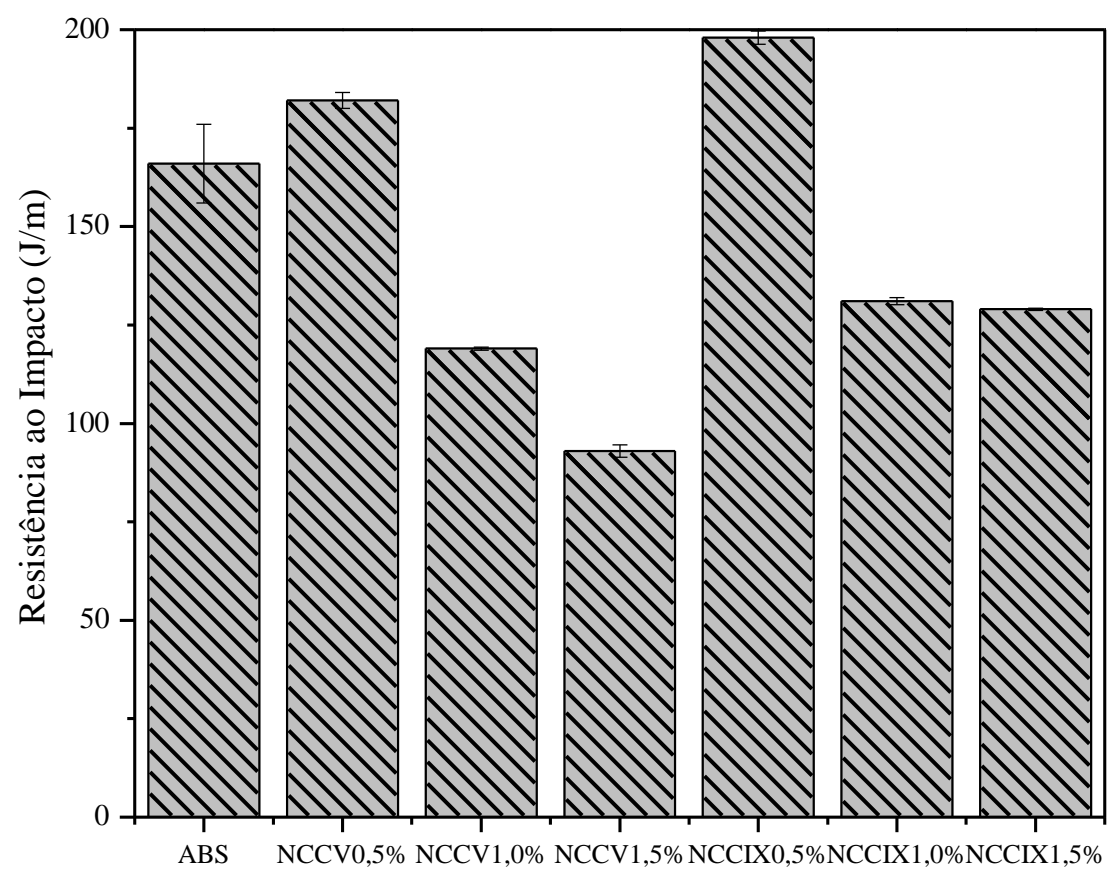

Teor de nanocristais $(\% \mathrm{~m} / \mathrm{m})$

Figura 4.30: Resistência ao impacto dos nanocompósitos de nanocristais de celulose/ABS do processo V e IX.

Os resultados encontrados para os ensaios mecânicos de impacto Izod para o ABS puro foi de $166 \mathrm{~J} / \mathrm{m}$. Os nanocompósitos reforçados com $0,5 \%$ de NCC foram os que apresentaram a maiores resistências ao impacto, os nanocompósitos NCCV 0,5\%/ABS e NCCIX 0,5\%/ABS (182 e $198 \mathrm{~J} / \mathrm{m}$ ), apresentando um aumento de 19\% em relação ao ABS puro, assim, confirmado boa interação entre NCC/matriz (fase elastomérica é a fase mais sensível ao reforço). Este fato se deve através de interações favoráveis entre os sítios ácidos e básicos de Lewis destes materiais, possibilitando as ligações de hidrogênio na interface NCC/matriz. Portanto, a afinidade entre ambas intensifica a adesão entre NCC/matriz. Entretanto, sabe-se que o NCC 0,5\%/ABS possui maior afinidade (podendo ser por interações físicas e químicas entre (NCC/matriz) com ABS (forte interface) melhorando, assim, a adesão NCC 0,5\%/ABS, fator determinante para o sucesso da aplicação desses materiais. Assim, a adesão entre carga/matriz pode ser atribuída a cinco mecanismos principais que podem ocorrer na interface: adsorção e molhamento; interdifusão; atração eletrostática; ligação química e adesão mecânica (BURAKOWSKI; REZENDE, 2001). 
Por outro lado, foi observado que na medida em que aumenta o teor de carga a resistência ao impacto diminui para os nanocompósitos com NCCV 1,5\%/ABS e NCCIX 1,5\%/ABS (93 e $129 \mathrm{~J} / \mathrm{m}$ ) sofreu uma redução de energia, indicando que um aumento na adição dos NCC tornou o material mais frágil. Quanto menor for à energia absorvida, mais frágil será o comportamento do material. Além disso, os NCC poderiam absorver a energia do impacto e reduzir a propagação de microfissuras (LANDI; SILVA, 2004; PAIVA et al., 2006).

Segundo Martins et al. (2014), a adição de cargas na matriz polimérica implica em redução nos valores da resistência ao Impacto Izod e, com aumento do teor de cargas, há uma diminuição nas propriedades mecânicas, uma vez que os nanocompósitos de matriz polimérica com cargas particuladas (com dimensões micrométricas), geralmente não apresentam melhorias em suas propriedades mecânicas, em relação matriz pura, exceto o módulo de elasticidade. Nos estudos Cui et al., (2007) e Sohn et al. (2011), também observaram uma redução do valor da resistência ao impacto com o aumento do teor de NCC.

\section{Análise de dados}

Foi realizado o teste Dunnett's com nível de significância de 5\%, em comparação as médias entre ABS e nanocompósitos, em pares e Anova fatorial (Tabela 1 do apêndice H). $\mathrm{O}$ resultado do teste de Dunnett (para todas as propriedades) compara o ABS com cada tratamento, par em par, foi observado que quando se adiciona os nanocristais na matriz, ocorre alteração do polímero. Esta avaliação foi comprovada estatiscamente, para resistência a tração, a flexão e impacto conforme observado na Figura 4.31.

Houve diferença entre os nanocompósitos e o ABS, podendo aferir que os nanocristais teve influência sobre esta variável. Foram encontrados a partir do teste de Dunnett valores significativos para todas nanocompósitos conforme a Tabela 2 do apêndice I. 

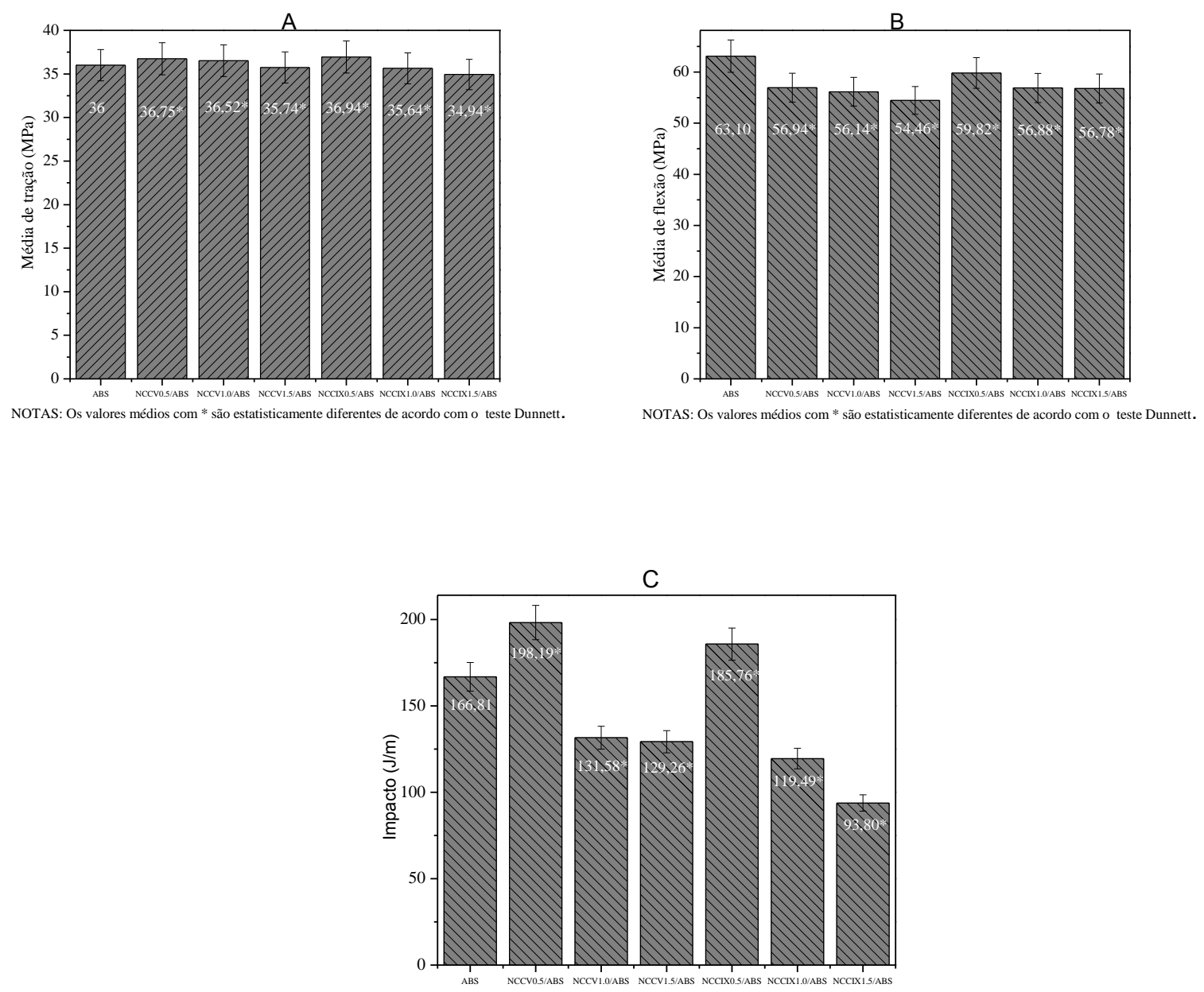

NOTAS: Os valores médios com * são estatisticamente diferentes de acordo com o teste Dunnett.

Figura 4.31: Propriedades físicas dos nanocompósitos pelo teste Dunnet.

Como visto na análise anterior, a adição de NCC alterou as propriedades do ABS, e a seguir foi analisado qual dos dois fatores (processo, concentração ou ambos) afetou essas propriedades. Analisando a Figura 4.32 (A); (C) e (E), têm-se as mesmas classificações de grupos dos nanocompósitos, em que NCCV/ABS e NCCIX/ABS são diferentes estatiscamente em todas as amostras analisadas, onde o NCCV/ABS apresentou melhor performance em relação a tração; NCCIX/ABS apresentou melhor propriedade de flexão; e o NCCV/ABS apresentou melhor desempenho em relação ao impacto. Ou seja, quando aumenta o teor de NCC as propriedades diminuem, deixando claro que os nanocompósitos é influenciado pelo teor de NCC. Assim, obtendo três classificações de grupo para os teores de NCC, mostrando as diferenças 
significativa (Tabela 3 do Apêndice H). Ou seja, a fase do butadieno até certo ponto ele reforça o material, depois fica mais rígido e as propriedades diminui.
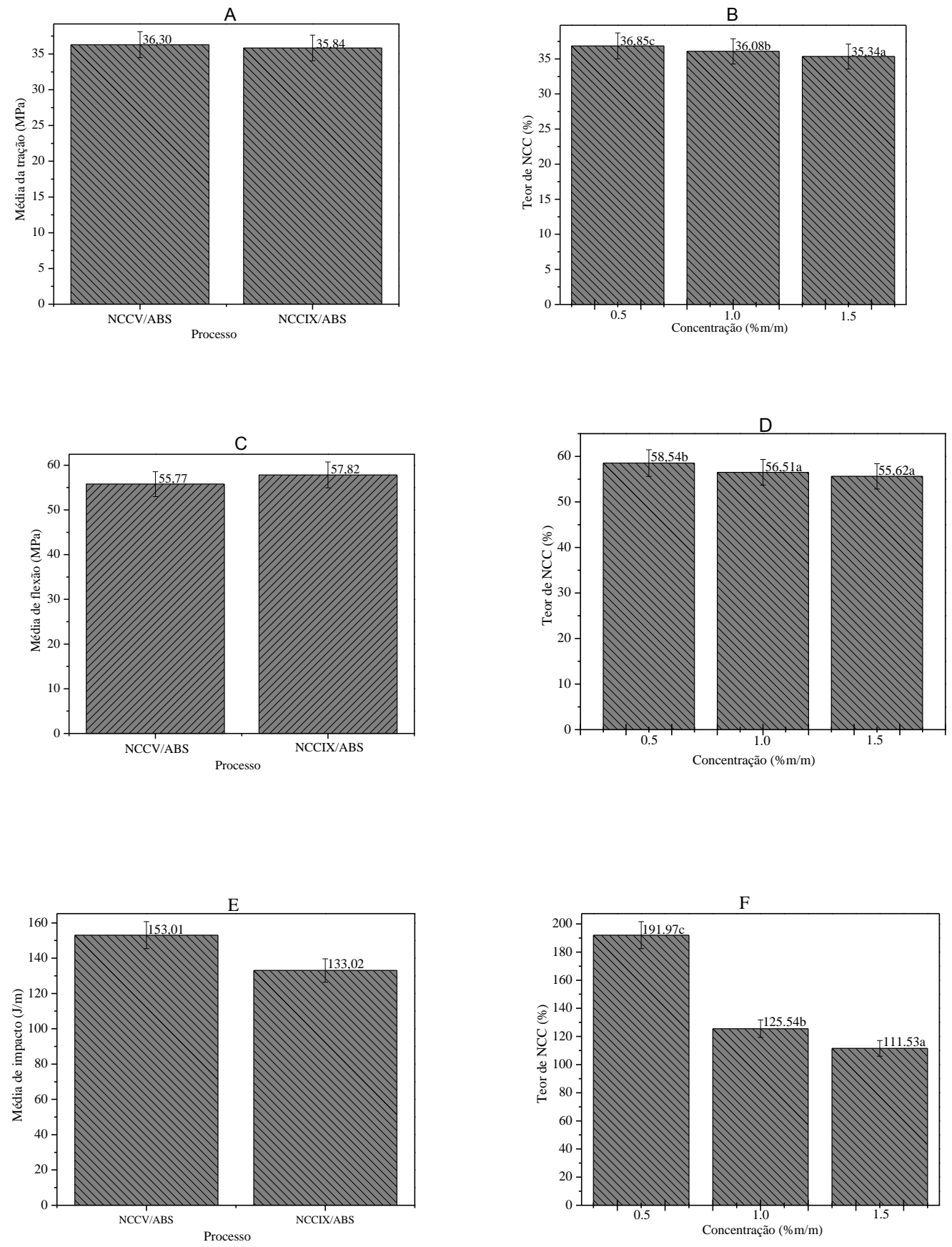

Figura 4.32: Média da resistência a tração, flexão e impacto por grupo em relação ao processo; teor de NCC em relação à concentração. 
A Figura 4.32 (B); (D) e (F), mostra que ao adicionar os NCC na matriz, o material foi alterado. Ou seja, quando aumenta o teor de NCC as propriedade diminui, deixando claro que os nanocompósitos é influenciado pelo teor de NCC. Assim, obtendo três classificações de grupo para os teores de NCC, que foi estatisticamente significativo conforme Tabela 3 do apêndice H.

O módulo de elasticidade de tração para os nanocompósitos foram iguais estatiscamente, portanto, não há diferença entre os nanocompósitos com pode ser observado na Figura 4.33 (A). O módulo de elasticidade de flexão para os nanocompósitos foram diferentes estatiscamente, portanto, há diferença significativa entre as amostras conforme a Figura 4.33 (B).
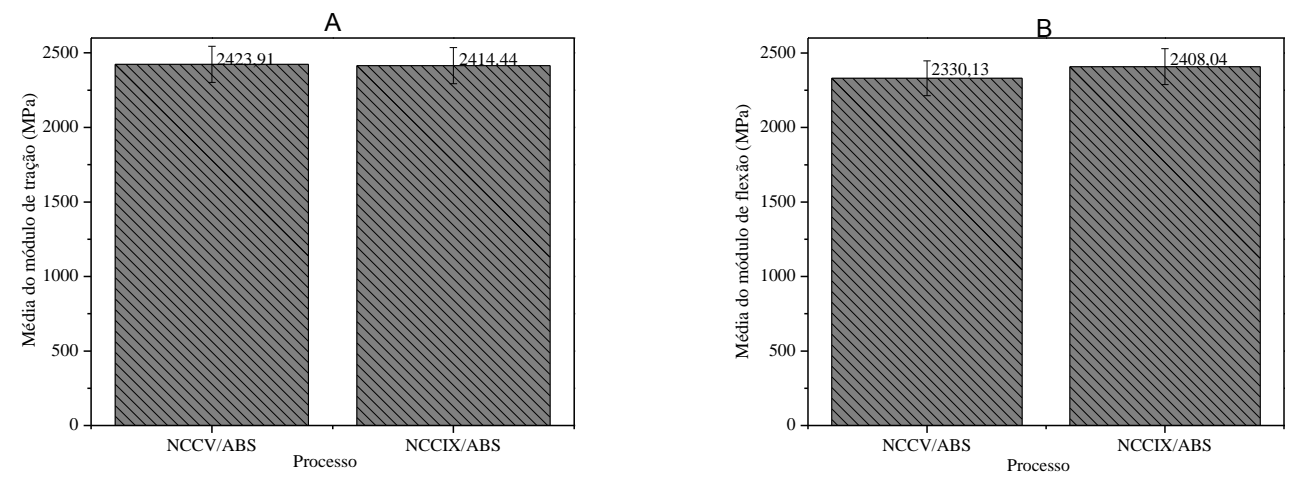

Figura 4.33: Média do módulo elástico tração (A) e flexão (B).

\subsubsection{Difração de raios-X dos nanocompósitos de nanocristais de celulose/ABS}

A dispersão dos nanocristais foi verificada com DRX para as seguintes amostras: NCCV; NCCIX; NCCV 0,5\%/ABS; NCCV 1,5\%/ABS; NCCIX 0,5\%/ABS; e NCCIX 1,5\%/ABS conforme a Tabela 4.12:

O NCCV apresentou difração em $2 \theta=22,6^{\circ}$ e o NCCIX apresentou difração em $2 \theta=$ $22,2^{\circ}$, que corresponde ao espaçamento basal de $3,82 \AA$ e $3,93 \AA$. O NCCV0,5\%/ABS apresentou difração de $2 \theta=19,0^{\circ}$ e NCCIX0,5\%/ABS apresentou difração de $2 \theta=19,15^{\circ}$, que corresponde ao espaçamento basal de 4,55 Å e 4,60 A. Para os NCCV1,5\%/ABS a difração foi de $2 \theta=19,4^{\circ}$ e para NCCIX1,5\%/ABS a difração foi de $2 \theta=19,50^{\circ}$ um espaçamento basal de $4,54 \AA$ e $4,55 \AA$, respectivamente. Estes resultados mostram que algumas moléculas intercalaram entre a estrutura dos nanocristais, mostrando assim, que os NCCIX tem uma maior afinidade com o ABS (CAO et al., 2005; GALVAN et al., 2011b). 
Para os nanocompósitos, a difração em $2 \theta$ dos nanocristais sofreram um ligeiro descolamento para valores menores, na presença do polímero, independentes das concentrações. Esse decaimento da intensidade do pico dos nanocristais em relação ao nanocompósitos sugere uma desorganização das lamelas dos nanocristais presente nos nanocompósitos. Isso indica uma provável formação de nanocompósitos de estruturas intercaladas e/ou esfoliadas (MORELLI; FILHO, 2010).

Tabela 4.12: Espaçamento basal dos nanocristais e nanocompósitos de nanocristais de celulose/ABS dos processos V e IX.

\begin{tabular}{lcc}
\hline \multicolumn{1}{c}{ Amostras } & $\mathbf{2 \theta}\left({ }^{\circ}\right)$ & Espaçamento basal $(\mathbf{A})$ \\
\hline NCCV & 22,6 & 3,82 \\
NCCIX & 22,2 & 3,93 \\
NCCV 0,5\%/ABS & 19,2 & 4,54 \\
NCCV 1,5\%/ABS & 19,5 & 4,54 \\
NCCIX 0,5\%/ABS & 19,1 & 4,60 \\
NCCIX 1,5\%/ABS & 19,3 & 4,54 \\
\hline
\end{tabular}

\subsubsection{Reometria de placas paralelas dos nanocompósitos de nanocristais de celulose/ABS}

Sendo a reologia a ciência que estuda o escoamento e a deformação da matéria sob a ação de uma força. Se uma pequena tensão é aplicada a um material sólido, a deformação se inicia. O material irá continuar a se deformar até que as tensões moleculares (internas) se estabeleçam e se equilibrem com as tensões externas. A maioria dos sólidos exibe algum grau de resposta elástica, onde existe uma completa recuperação da deformação após a remoção das tensões de deformação. Vale ressaltar que nem todos os materiais atingem uma deformação de equilíbrio. Quando uma tensão externa for aplicada a um fluido, a deformação ocorre, e continua a ocorrer indefinidamente até que a tensão seja removida, pois o fluido não apresenta nenhuma resistência à deformação. As forças de fricção internas, ou seja, a viscosidade do fluido retarda a taxa de deformação. Todavia, um equilíbrio pode ser estabelecido onde a taxa de deformação é constante quando relacionada com as propriedades do fluido. O mais simples destes fluidos é o Newtoniano, em que a taxa de deformação é diretamente proporcional à tensão aplicada (GUERRA et al., 2004). 
Assim, a fase de processamento dos polímeros é muito importante, as propriedades reológicas dependem dos parâmetros operacionais (temperatura, pressão, vazão, etc.) e estruturais (massa molar, distribuição de massa molar). Dessa forma, é recomendável medir propriedades, como a viscosidade, nas condições mais próximas às condições de processamento (ITO et al., 2004). No momento do processamento dos polímeros, estes materiais sofrem diversos tipos de deformações em virtude da complexidade da geometria dos equipamentos utilizados, e respondem com um comportamento reológico viscoelástico, resultado da sobreposição de pelo menos dois regimes reológicos simples: um fluxo de cisalhamento simples e um fluxo de estiramento ou alongamento simples. O primeiro é produzido por forças de cisalhamento e o segundo é produzido por forças de tração e o terceiro em uma única direção. Assim, torna-se necessário conhecer o comportamento desses materiais quando em situações de escoamento, para poder prever e compreender o desempenho final (GUERRA et al., 2004; SOLOMON et al., 2001). As medidas de viscosidade complexas foram feitas nas mesmas condições para ABS puro e os nanocompósitos de nanocristais de celulose/ABS.

A Figura 4.34 mostra as curvas de viscosidade complexa versus frequência angular das amostras ABS puro e dos nanocompósitos de nanocristais de celulose/ABS. Pode ver-se que o nanocompósitos de nanocristais de celulose/ABS apresentou um comportamento pseudoplástico semelhante e os nanocompósitos apresentaram uma maior viscosidade em relação ao ABS puro. As nanopartículas quando dispersas na matriz polimérica promovem as alterações nas suas propriedades devido a interações químicas que podem influenciar na dinâmica molecular do polímero resultando em significativas alterações de suas propriedades físicas, térmicas e/ou mecânicas e reológicas (OLIVEIRA; DEMARQUETTE, 2009). Como também a forma das partículas, tamanho de partícula e rigidez das partículas (fibras, por exemplo, rígidas ou flexíveis), topologia da superfície, propriedades químicas da superfície (tratamento da superfície), energia interfacial (molhabilidade), densidade e a fração do volume ou concentração. Ou seja, o aumento da viscosidade em baixa frequência pode estar relacionado com a geometria da carga ou tamanho das partículas, afinidade química e a elevada área superficial (RIDES, 2005). Segundo As'habi et al. (2011), um aumento na viscosidade pode esta relacionado à incorporação de NCC indicando interação entre NCC/ABS ou pode ser efeito da adição da carga. O aumento da viscosidade dos nanocompósitos de nanocristais de celulose/ABS em relação ao ABS puro, sugere compatibilidade ou interação entre carga/matriz. A carga da superfície é um 
importante parâmetro que controla as interações entre NCC e se reflete no comportamento reológico das suspensões.

Mas, o ABS e NCCV 1,5\%/ABS mostraram um comportamento pseudonewtoniano com um regime de baixa de frequência angular. Isso ocorre por que a adesão não é muito boa, e o polímero não molha os NCC como deveria, dando origem a um fenômeno de escorregamento entre NCC/ABS, havendo pouca afinidade química e fraca interação entre carga/matriz. O nanocompósito NCCV 1,5\%/ABS apresentou uma viscosidade muito próximo ao ABS puro em alta frequência, devido ao alinhamento preferencial dos NCC e das moléculas do polímero. Estes resultados são semelhantes aos resultados encontrados por (MA et al., 2007; GEHLEN et al., 2014; GALVAN et al., 2011b).

Em termos dos valores dos parâmetros reológicos, as sequências dos nanocompósitos de nanocristais de celulose/ABS foram NCCIX 1,5\%/ABS < NCCIX 0,5\%/ABS < NCCV 1,0\%/ABS < NCCV 0,5\%/ABS. O nanocompósito NCCIX1,5\%/ABS mostrou boa adesão entre carga/matriz comprovado pelo DMA, melhorou as propriedades térmica confirmada pelo (TGA/DSC), apresentou maior viscosidade e módulo de armazenamento confirmado pela reologia. Mas, o nanocompósto NCC 1,5\%/ABS não teve bom desempenho nas propriedades mecânicas. Este fato pode ser explicado, que devido a grande quantidade de NCC facilitou as ligações de hidrogênio e dificultando o contato entre carga/matriz ocorrendo assim aglomerações dos NCC e consequentemente não ocorrendo uma distribuição ou dispersão homogênea da carga na matriz. O nanocompósito NCCIX 0,5\%/ABS mostrou boa adesão entre carga/matriz comprovado pelo DMA, melhorou as propriedades térmica confirmada pelo (TGA/DSC), maior viscosidade e módulo de armazenamento confirmado pela reologia e apresentou melhoras nas propriedades mecânicas. Este fato está provavelmente relacionado à forte interação entre o $\mathrm{OH}$ (NCC) e N (ABS) e boa dispersão da carga na matriz (GEHLEN et al., 2014). 


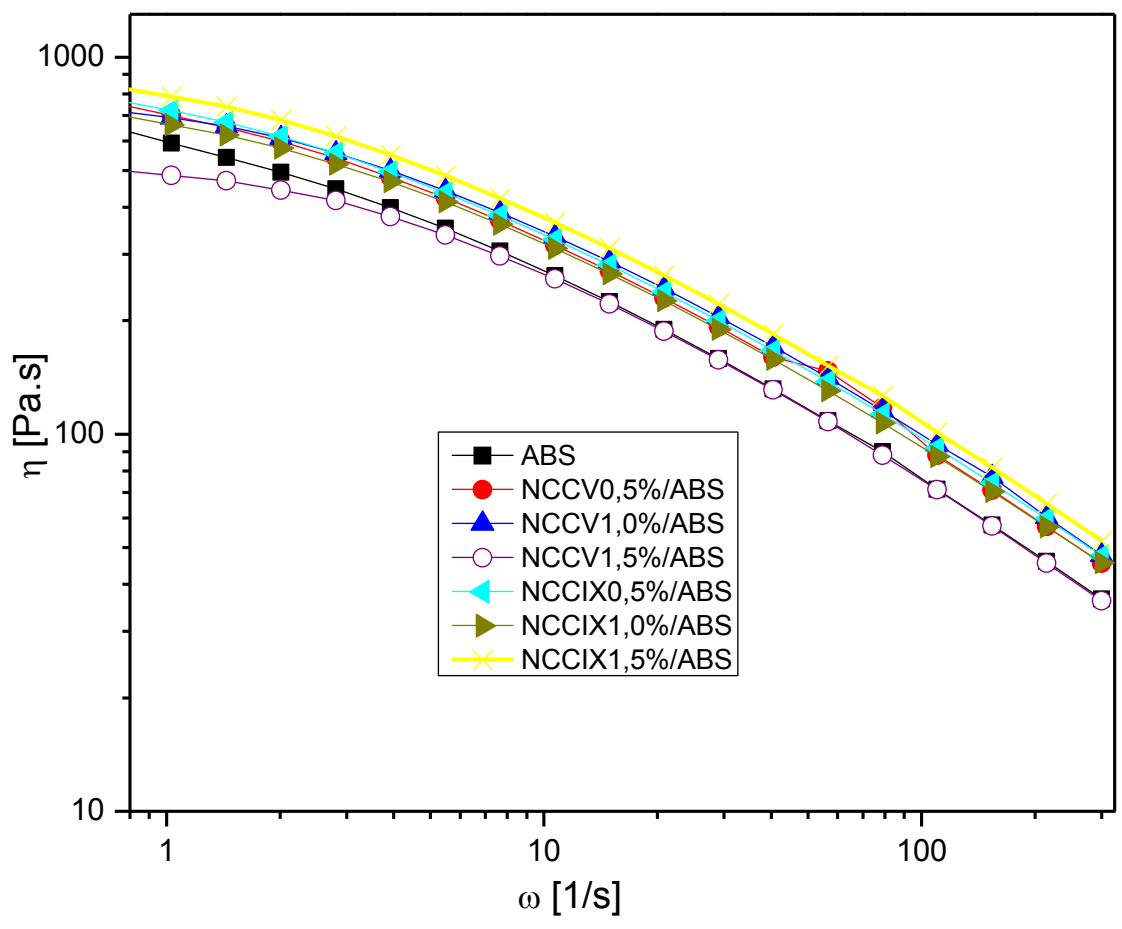

Figura 4.34: Viscosidade complexa versus frequência angular do ABS puro e dos nanocompósitos de nanocristais de celulose/ABS dos processos V e IX.

Na Figura 4.35 mostra os nanocompósitos NCCV/ABS e NCCIX/ABS em relação ao ABS. Portanto, na região terminal a baixa frequência, esta curva para um homopolímero o declínio é de 2. Assim, G' aumenta quadraticamente com frequência e o G" aumenta linearmente. Quando coloca um em função do outro tem que dá um declínio de 2. Mas, o ABS é um copolímero, portanto, o declínio é menor que 2.

Foi observado que o processo $\mathrm{V}$ apresentou a mesma resposta viscoelástica que o $\mathrm{ABS}$, portanto, não há modificação de estrutura. Assim, a resposta viscoelástica em relação à resposta elástica G' e a viscosa G", quer dizer que não há diferença na resposta viscoelática e não há nada de estruturalmente diferente, portanto, a resposta viscoelástica é sempre a mesma, indicando fraca interação.

Os nanocompósitos do processo IX tem um aumento contínuo da viscosidade. É observado, que quando coloca a carga a viscosidade aumenta, parte desse aumento esta 
relacionado com adição do sólido no líquido e a outra parte devido à interação NCC/ABS. Assim, o declinio médio para o processo IX é quase 2, isso quer dizer que $\mathrm{G}^{\prime}$ aumenta mais rapidamente que o G", ou seja, a elasticidade aumenta mais rapidamente que a viscosidade, isso ocorre por que há interação e possivelmente há uma modificação de estrutura. Assim, processo IX apresentou em uma melhor adesão, mostrando que não há diminuição da viscosidade (ABDULHADI; AL-JUHANI, 2015). As diferentes rotas de obtenção de nanocristais, gerou nanocristais com diferente composição química, áreas superficiais como também diferente interação entre carga matriz

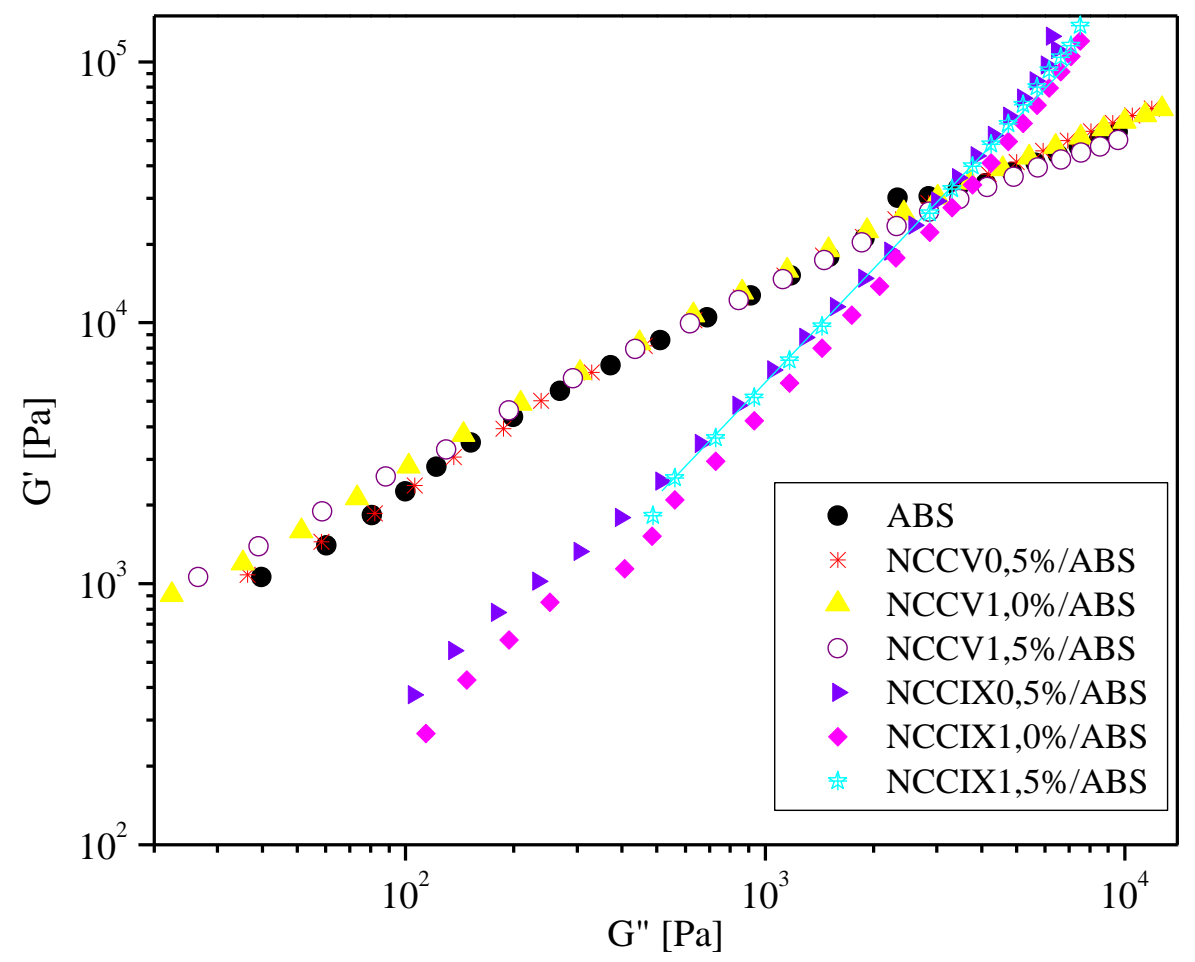

Figura 4.35: Módulo de armazenamento (G') versus módulo de perda (G") do ABS puro e dos nanocompósitos de nanocristais de celulose/ABS dos processos V e IX. 


\section{CAPÍTULO IV Conclusões}

A composição química da fibra, a metodologia empregada e o rendimento da produção dos nanocristais de celulose influenciam diretamente nos impactos ambientais. Considerando todos os cenários, conclui-se que o processo de extração de nanocristais pelo processo I é o que apresenta o maior consumo de energia e insumos, assim, evidenciando o maior potencial de aquecimento global, acidificação e eutrofização dentro das rotas avaliadas. Portanto dentre de todas as rotas avaliadas os processos $\mathrm{V}$ (tratados com: $\mathrm{NaClO}_{2} 2 \% / \mathrm{NaOH} 2 \% / 1 \mathrm{x}$ ) e IX (tratados com: $\mathrm{NaOH} 5 \% / \mathrm{NaClO}_{2} 3,3 \% / 1 \mathrm{x}$ ) apresentaram menores impactos ambientais. Contudo, os nanocristais de celulose, possuem grande potencial para ser usado como agentes de reforço em nanocompósitos.

Por fim, para que os nanocristais de celulose obtidos a partir da fibra de bagaço de canade-açúcar possam ter um melhor desempenho ambiental, deve-se investigar possibilidades de redução no consumo de energia e água, seja com a redução no tempo de processo e diminuição do uso de solventes ou trocar estes solventes por outros na fase de pré-tratamento. Ainda, devese avaliar possibilidades de recuperação de efluentes como uma maneira de diminuir o consumo de energia. Assim, simples queima para geração de energia eliminaria boa parte da emissão de $\mathrm{CH}_{4}$ e diminuiria sua contribuição ao potencial de aquecimento global. A reutilização da água deve ser explorada, considerando água dentro dos padrões de qualidade em cada fase da extração de nanocristais. Novas tecnologias para produzir nanocristais, tais como tratamentos enzimáticos, processos mecânicos, ultrassom e solventes são alternativas que também pode levar a um melhor desempenho ambiental.

Os efeitos das condições de preparação, tais como branqueamento e tempo de hidrólise, influenciaram sobre os comportamentos térmicos e morfológicos dos nanocristais de celulose. Portanto, pode-se afirmar mudanças significativas entre as fibras de bagaços pré-tratados, polpas branqueadas e nanocristais pelos espectros de infravermelho, MEV, difração de raios-X e também análises térmicas. Os tratamentos (1B) foram considerados mais apropriados para obtenção dos nanocristais de celulose. Este estudo também mostra que os nanocristais de celulose podem ser preparados com êxito a partir de cana-de-açúcar por hidrólise ácida, estimulando o uso de fibras naturais para a produção dos nanocristais de celulose. A preparação 
ou rota de obtenção dos cristais, pode gerar cristais com diferentes afinidades químicas e isto pode ser observado pela diferença resposta reológica.

As propriedades mecânicas dos nanocompósitos foram alteradas com a adição dos nanocristais de celulose a partir de bagaço de cana-de-açúcar. Estatisticamente ficou comprovado que a partir do momento que aumenta o teor de nanocristais no polímero, ocorre redução das propriedades mecânicas. Portanto, para escolher o melhor material a ser usado, vai depender das suas propriedades e sua aplicação, se é necessário, maior tração (nanocompósito de nanocristais do processo V/ABS); maior flexão (nanocompósito de nanocristais do processo IX/ABS); maior impacto (nanocompósito de nanocristais do processo V/ABS), o melhor material pra corresponder a análise térmica (nanocompósito de nanocristais do processo IX/ABS); ou ambientalmente correto (nanocompósito de nanocristais do processo IX/ABS); maior viscosidade (nanocompósito de nanocristais do processo IX/ABS). Assim, há uma melhora ou aumento das propriedades até $0,5 \%$, posteriormente ocorre perdas das propriedades. 


\section{PERSPECTIVAS FUTURAS E RECOMENDAÇÕES}

Este trabalho gerou uma grande quantidade de dados que podem ser utilizados para correlacionar estudos econômicos e aspectos técnicos que envolvam a produção de componentes baseados em nanocompósitos reforçados com nanocristais de celulose a partir de bagaço-decana-de-açúcar.

Recomenda-se para trabalhos futuros, novas rotas para produção dos nanocristais, como também estudar outros métodos para obtenção de nanocompósitos, a fim de melhorar ainda mais a dispersão das nanocargas na matriz polimérica.

Com isso acredita-se que com todos esses estudos adicionais somando-se a este trabalho, os materiais nanocompósitos NCC/ABS poderão ser amplamente aplicados na engenharia. 


\section{REFERÊNCIAS BIBLIOGRÁFICAS}

ABDUL KHALIL, A. H. et al. 2012. Green composites from sustainable cellulose nanofibrils: A review. Carbohydrate Polymers, v. 87, p.963- 979.

ABDULHADI, A.; AL-JUHANI. 2015. Rheology, Mechanical Properties, and Thermal Stability of Maleated Polyethylene Filled with Nanoclays. Journal of Nanomaterials, v. 2015, p.112.

ABRAHAM, et al. 2011. Extraction of nanocellulose fibrils from lignocellulosic fibres: A novel approach. Carbohydrate Polymers, v. 86, p.1468- 1475.

ADEL, A. M. et al. 2010. Characterization of microcrystalline cellulose prepared from lignocellulosic materials. Part I. Acid catalyzed hydrolysis. Bioresource Technology v.101 p.4446-4455.

AKERHOLM, M. et al. 2004. Characterization of the crystalline structure of cellulose using static and dynamic FT-IR spectroscopy. Carbohydrate Research, v. 339, p.569-578.

ALBINANTE, S. R. et al. 2013. Revisão dos tratamentos químicos da fibra natural para mistura com poliolefinas. Química Nova, v. 36, p.114-122.

ARAKI, R. et al. 1998. Flow properties of microcrystalline cellulose suspension prepared by acid treatment of native cellulose. Colloids and Surfaces A: Physicochemical and Engineering, v. 142, p.75-82.

ARAUJO, A. A. S. et al. 2006. Determinação dos teores de umidade e cinzas de amostras comerciais de guaraná utilizando métodos convencionais e análise térmica. Química Nova, v.42, p.2.

ARRIETA, M. O. et al. 2014. Multifunctional PLA-PHB/cellulose nanocrystal films: Processing, structural and thermal properties. Carbohydrate Polymers, v. 107, p.16-24.

ARSÈNEA M-A et al. 2013.Treatments of Non-wood Plant Fibres Used as Reinforcement in Composite Materials. Materials Research, v. 16, p.903-923.

ARVIDSSON, R. et al. 2015. Life cycle assessment of cellulose nanofibrils production by mechanical treatment and two different pretreatment processes. Environmental Science Technology, v. 49, p.6881-6890. 
AS'HABI, L. et al. 2011. Morphological, rheological and thermal studies in melt processed compatibilized PA6/ABS/clay nanocomposites. Journal Polymer Research, v. 18, p.197205.

ASTM D256-10. 2010. Standard Test Methods for Determining the Izod Pendulum Impact Resistance of Plastics. West Conshohocken Pennsylvania - United States : s.n., 2010.

ASTM D638. Association Standards Testing Materials. Standard Test Methods for Tensile Properties of Plastics. In: Annual Book of Standards ASTM. Philadelphia, 2003.

ASTM D790. Association Standards Testing Materials. Standard Test Methods for Flexural Properties of Unreinforced and Reinforced Plastics and Electrical Insulating Materials. In: Annual Book of Standards ASTM. Philadelphia, 2003.

BARNES, H. A. 2000. A handbook of elementary rheology. Institute of Non-Newtonian Fluid Mechanics, University of Wales, p. 210.

BAYART , J. B. et al. 2010. A framework for assessing off-stream freshwater use in LCA.

International Journal of Life Cycle Assessment, v. 15, p.439-453

BECK-CANDANEDO, S. et al. 2005. Effect of Reaction Conditions on the Properties and Behavior of Wood Cellulose Nanocrystal Suspensions. Biomacromolecules, v. 6, p. 10481054.

BERGENSTRÅHLE, M. et al. 2010. Cellulose crystal structure and force fields. International Conference on Nanotechnology for the Forest Products Industry, p.3.

BERNIER, E. et al. 2012. Life cycle assessment of kraft lignin for polymer applications. International Journal of Life Cycle Assessment, v. 18, p 520-528.

BEYLER, C. L.; HIRSCHLER, M. M. 2002. Thermal decomposition of polymers. SFPE Handbook of Fire Protection Engineering, Section 1, Chapter 7, p.111-131.

BEZERRA, E. B. et al. 2015. Estudo das propriedades mecânicas e termomecânicas de compósitos de Poli(ع-caprolactona)/Nanolínter. Revista Eletrônica de Materiais e Processos, v. 10, p.16-20.

BEZERRA, F. O. et al. 2013. Efeito Payne em Nanocompósitos de NBR com Montmorilonita Organofílica. Polímeros, v. 23, p.223-228.

BHASKAR, T. et al. 2003. Studies on thermal degradation of acrylonitrile butadiene styrene copolymer (ABS-Br) containing brominated flame retardant. Journal of Analytical and Applied Pyrolysis, v. 70, p.369-381. 
BLAKER, J. J. et al. 2014. Aligned unidirectional PLA/bacterial cellulose nanocomposite fibre reinforced PDLLA composites. Reactive \& Functional Polymers, v. 85, p.185-192.

BLEDSKI, A. K.; GASSAN, J. 1999. Composites reinforced with cellulose based fibres. Progress in Polymers Science Sci. v.24 p.221-274.

BLOM, H.; et al. 2006. Detection of degradation of ABS materials via DSC. Thermochimica Acta, v. 442, p.64-66.

BORSOI, C. et al. 2011. Obtainment and characterization of composites using polystyrene as matrix and fiber waste from cotton textile industry as reinforcement. Polímeros, v. 21, p.271-279.

BOTAN, R. et al. 2011. Síntese e caracterização de nanocompósitos esfoliados de poliestireno hidróxido duplo lamelar via polimerização In Situ. Polímeros Ciência e Tecnologia, v. 21, p.34-38.

BOUFI, S. et al. 2014. Mechanical performance and transparency of nanocellulose reinforced polymer nanocomposites. Macromolecular Materials and Engineering., v. 299, p. 560568

BRASIL. 2010. Segunda Comunicação Nacional do Brasil á Convenção-Quadro das Nações Unidas sobre Mudança do Clima, MCTI, p.1-56.

BRETAS, R. E. S.; SCURACCHIO, C. H. 2007. Técnicas de caracterização de polímeros, Artliber, $1^{\text {a }}$ edição, p.385-404.

BRÍGIDA, A. I. S. et al. 2010. Effect of chemical treatments on properties of green coconut fiber. Carbohydrate Polymers, v.79 p.832-838.

BRINCHI, L. et al. 2013. Production of nanocrystalline cellulose from lignocellulosic biomass: Technology and applications. Carbohydrate Polymers, v. 94, p. 154- 169.

BRITO, B. S. L. et al. 2012. Preparation, morphology and structure of cellulose nanocrystals from bamboo fibers. Cellulose, v. 19, p.1527-1536.

BURADOWSKI, L.; REZENDE, M.C. 2001. Modificação da rugosidade de fibras de carbono por método químico para aplicação em compósitos poliméricos. Polímeros: Ciência e Tecnologia, v. 11, p. 51-57.

CAESB. Disponível em < https://www.caesb.df.gov.br/como-a-agua-e-tratada.html >Acesso em 24 fevereiro de 2016. 
CALLISTER Jr. W.D; RETHWISCH. D.G; Ciência e engenharia de materiais, $8^{a}$ edição, LTC, 2012. 128-161 p.

CAMARGO, P. H. C. et al. 2009. Nanocomposites: synthesis, structure, properties and new application opportunities. Materials Research, v.12.

CAMPOS, A. et al. 2013. Obtaining nanofibers from curaua' and sugarcane bagasse fibers using enzymatic hydrolysis followed by sonication. Cellulose, v. 20, p.1491-1500.

CANEVAROLO Jr. S. V, Técnicas de caracterização de polímeros, Artliber, 2007, $1^{\text {a }}$ edição, 263 p á 284 p.

CANeVarolo JUnior, S. V. 2006. Ciência dos Polímeros: Um texto Básico para Tecnólogos e Engenheiros. São Paulo: Artliber, 183 p.

CANTO, L. B.; PESSAN, L. A. 2007. Técnicas de caracterização de polímeros, Artliber, 2007, $1^{a}$ edição, 341 pá 360 p.

CAO, X. et al. 2005. Polyurethane/clay nanocomposites foams: processing, structure and properties. Polymer, v. 46, 775-783.

CAVALCANTE, A. C. et al. 2.10. Inventário ambiental do processo de obtenção de nanocristais de celulose a partir da fibra de coco verde. $2^{\circ}$ Congresso Brasileiro em Gestão de Ciclo de Vida em Produtos e Serviços.

CHAPAGAIN, A. K. et al. 2006. The water footprint of cotton consumption: An assessment of the impact of worldwide consumption of cotton products on the water resources in the cotton producing countries. Ecological Economics, v.6 0, 186 - 203.

CHEN, W. et al. 2011. Individualization of cellulose nanofibers from wood using high-intensity ultrasonication combined with chemical pretreatments. Carbohydrate Polymers, v.83, p. 1804-1811.

CHENG, Q. et al. 2011. Advanced Cellulosic Nanocomposite Materials. Advances in Composite Materials for Medicine and Nanotechnology, p.547-564.

CHERIAN, B. M. et al. 2011. Cellulose nanocomposites with nanofibres isolated from pineapple leaf fibers for medical applications. Carbohydrate Polymers, v 86, p1790-1798.

CHEHEBE, J. R. Análise do Ciclo de Vida de produtos: ferramenta gerencial da ISSO 14000. Rio de Janeiro: Qualitymark Ed., CNI, 1997. 120 p. 
CHIRAYIL, C.J. et al. 2014. Rheological behaviour of nanocellulose reinforced unsaturated polyester nanocomposites. International Journal of Biological Macromolecules, v. 69, p. 274-281.

CHRISSAFIS, K.; BIKIARIS, D. 2011. Can nanoparticles really enhance thermal stability of polymers? Part I: An overview on thermal decomposition of addition polymers. Thermochimica Acta, v. 523, p.1-24.

Cisneros, B. J. Energia e aquecimento global. Disponível em http://www.ipcc.ch/report/ar5/wg3/ > Acesso em 22 fevereiro 2016.

CLINT, J. H. Adhesion and components of solid surface energies. Colloid \& Interface Science,

COCCIA, V. et al. 2014. Cellulose Nanocrystals Obtained from Cynara Cardunculus and Their Application in the Paper Industry. Sustainability, v 6, p.5252-5264.

COLTRO, L. 2007. Avaliação do ciclo de vida como instrumento d Gestão: CETEA/ITAL, ISBN 978-85-7029-083-0, P.70.

COLTRO, L.; KARASKI, T. U. 2015. Pegada hídrica: do conceito à normatização. Boletim de tecnologia e desenvolvimento de embalagens, v. 27, p.1.

CORRADINI, E. et al. 2009. Composição química, propriedades mecânicas e térmicas da fibra de frutos de cultivares de coco verde. Revista Brasileira de Fruticultura, v. 31 p.837-846.

CORRÊA, A. C. 2010. Cellulose nanofibers from curaua fibers. Cellulose, v. 17, p.1183-1192.

CORREAA, A. C. et al. 2014. Obtaining nanocomposites of polyamide 6 and cellulose whiskers via extrusion and injection molding. Cellulose, v. 21, p.311-322.

CORREA, C. A. 2007a. Técnicas de caracterização de polímeros, Artliber, 2007, $1^{\text {a }}$ edição, $177-200 \mathrm{p}$.

CORREA, C. A. et al. 2007b. Role of maleated coupling agents on the interface adhesion of polypropylene-wood composites. Journal of Thermoplastic Composite Materials, v. 20, p. 323-339.

COUTINHOL. F. C. et al. Sistema capaz de reaproveitar a água utilizada para a produção de água destilada no laboratório integrado de águas residuais e de mananciais. LIAMAR do IFCE. Disponível em <http://melhorespraticas.mec.gov.br/arquivos/ceara.pdf> Acesso em 24 fevereiro 2016.

CUI, W. et al. 2007. Preparation and properties of flame retardant high impact polystyrene. Fire Safety Journal. 2007, Vol. 42, p. 232-239. 
DIEZ-PASCUAL, A. M.; DIEZ-VICENTE, A. L. 2014. Poly(3-hydroxybutyrate)/ZnO Bionanocomposites with Improved Mechanical, Barrier and Antibacterial Properties. International Journal Molecular Science, v.15, p.10950-10973.

DILSIZ, N.; WIGHTMAN, J.P. Effect of acid-base properties of unsized and sized carbon fibers on fiber/epoxy matrix adhesion. Colloids and Surfaces A, v. 164, p. 325-336, 2000.

DUFRESNE, A. 2010. Processing of Polymer Nanocomposites Reinforced with Polysaccharide Nanocrystals. Molecules, v. 15, p.4111-4128.

DUFRESNE, A. 2013. Nanocellulose: a new ageless bionanomaterial. Materials Today, v.16, p. 6.

EL MIRI, N. et al. 2015. Bio-nanocomposite films based on cellulose nanocrystals filled polyvinyl alcohol/chitosan polymer blend. Journal Applied Polymer Science, v. 132, p.22.

EMPINOTTI, V. L. 2013. Análise crítica da Pegada Hídrica Cinza na produção de celulose.

ENDES, C. et al. 2013. Risk assessment of released cellulose nanocrystals - mimicking inhalatory exposure. Journal of Physics: Conference Series, v. 429, p.1-11.

EPA - ENVIRONMENTAL PROTECTION AGENCY / UNITED STATES. ¿Qué es la lluvia

EUROPEAN COMISSION. International Reference Life Cycle Data System (ILCD) Handbook

- General guide for Life Cycle Assessment - Detailed guidance. Joint Research Center, Institute for Environment and Sustainability: Luxembourg. 2010, 1-417.

FAHMA, F. et al. 2010. Effect of pre-acid-hydrolysis treatment on morphology and properties of cellulose nanowhiskers from coconut husk. Cellulose, v. 18, p.443-450.

FENGEL, D.; WEGENER, G. 2003. Wood: Chemistry, Ultrastructure, Reactions. Germany: Walter de Gruyter, 612 p.

FERREIRA, L. A. S. et al. 1997. Comportamento Mecânico e Termo-Mecânico de Blendas Poliméricas PBT/ABS. Ciência e Tecnologia, v. 7, p. 67-90.

FIGUEIRÊDO, M. C. B et al. Life cycle assessment of cellulose nanowhiskers. Journal of Cleaner Production, v. 35, p.130-139.

FIM, F. C. et al. 2014. Comparison between Polyethylene/Carbon Nanotubes and Polyethylene/Graphene Nanosheets Nanocomposites Obtained by In Situ Polymerization. Polímeros, v. 24, p.373-380. 
FORTUNATI, E. et al. 2015. Processing of PLA nanocomposites with cellulose nanocrystals extracted from Posidonia oceanica waste: Innovative reuse of coastal plant. Industrial Crops and Products, v. 67, p.439-447.

FRONE, A. N. et al. 2013. Morphology and thermal properties of PLA-cellulose nanofibers composites. Carbohydrate Polymers, v. 91, p.377- 384.

GALGALI, G. et al. 2001. A rheological study on the kinetics of hybrid formation in polypropylene nanocomposites. Macromolecules, v. 34, p.852-858.

GALLI, C. S.; ABE, D. S. 2009. Disponibilidade, poluição e eutrofização das águas. In book: Águas do Brasil. Análises Estratégicas., Chapter: 10, Editors: Academia Brasileira de Ciências, Instituto de Botânica, p.165-174.

GALVAN, D. et al. 2011a. Estudo das condições de processamento nas propriedades de nanocompósitos de ABS e argilas organofílicas. 11 $^{\circ}$ Congresso Brasileiro de Polímeros, p. 1946-1951.

GALVAN, D. et al. 2011b. Reologia de nanocompósitos de ABS e mistura binária de argilas montmorilonita organofílicas. 11 $^{\circ}$ Congresso Brasileiro de Polímeros, p. 1587-1592.

GAMA, A. F. et al. 2013. Inventário de agrotóxicos e risco de contaminação química dos recursos hídricos no semiárido cearense. Quím. Nova, v. 36, p.3.

GAVANKAR, S. et al. 2014. The Role of Scale and Technology Maturity in Life Cycle Assessment of Emerging Technologies. Journal of Industrial Ecology, v. 19, p.51-60.

GEHLEN, A. et al. 2014. Influence of different organomodified clays on the viscoelastic response of ethylene vinyl acetate//poly(vinyl chloride)/organoclay nanocomposites. Journal of Elastomers \& Plastics, v. 47, p.636-646.

GHANTA, M. et al. 2014. Environmental impacts of ethylene production from diverse feedstocks and energy sources. Applied Petrochemical Research, v. 4, p.167-179.

GILFILLAN, W. N. et al. 2014. Preparation and characterization of composites from starch with sugarcane bagasse nanofibres. Cellulose, v. 21, p.2695-2712.

GONG, G. et al. 2011. Tensile behavior, morphology and viscoelastic analysis of cellulose nanofiber-reinforced (CNF) polyvinyl acetate (PVAc). Composites Part A: Applied Science and Manufacturing, v. 42, p.1275-1282.

GONZALEZ, P. S.; VEJA, M. C. 2016. Effect of water recovery on the water footprint of cellulose production in Chile. Red ACV Chile, 2p. 
GUERRA, B. B. et al. 2004. Avaliação Reológica de Elastômeros e suas Composições. Polímeros: Ciência e Tecnologia, v. 14, p.289-294.

GUIMARÕES, J. L. et al. 2009. Characterization of banana, sugarcane bagasse and sponge gourd fibers of Brazil. Industrial Crops and Products, v. 30, p.407-415.

GUIMARÕES, M. J. O. C. et al. 2003. Reologia de polietileno de alta densidade tenacificado com polietileno elastomérico. Polímeros, v. 13, p.2.

HASSAN, M. et al. 2014. Improving cellulose/polypropylene nanocomposites properties with chemical modified bagasse nanofibers and maleated polypropylene. Journal of Reinforced Plastics and Composites, v. 33, p.26-36.

HATAKEYAMA, T.; LIU, Z. 2000. Handbook of thermal analysis. 452 p.

HEARLE, J.W.S. et al. 1998. Atlas of Fibre Fracture and Damage to Textiles. Boca Raton: CRC Press, 468 p.

HELBERT, W. et al. 1996. Polymers Composites, v. 17, p.604-611.

HENRIQUE, M. A. et al. 2013. Valorization of an agro-industrial waste, mango seed, by the extraction and characterization of its cellulose nanocrystals. Journal of Environmental Management, v. 121, p. 202-209.

HERRERA-FRANCO, P. J.; VALADEZ-GONZÁLEZ, A. 2005. A study of the mechanical properties of short natural-fiber reinforced composites. Composites: Part B - v.36 p.597608.

HOEKSTRA, A. Y. et al. 2011. Manual de avaliaç !ão de pegada hidríca. Editora Earthscan.

HOOK, B. A. et al. Extraction of $\alpha$-cellulose from mummified wood for stable isotopic analysis. Chemical Geology, v. 405, p. 19-27, 2015.

HORVATH, A. L. 2006. Solubility of Structurally Complicated Materials: I. Wood. Journal of Physical and Chemical Reference Data, v. 35, p. 77-92.

HOSOYA, T.; SAKAKI, S. 2014. Levoglucosan formation from crystalline cellulose: Importance of Hydrogen Bonding Network in the Reaction. Chem Sus Chem, v. 6, p.235668.

HUG, T. et al. 2012. Nanocrystalline cellulose (NCC) reinforced alginate based biodegradable nanocomposite film. Carbohydrate Polymers, v. 90, p.1757- 1763. 
IBAMA. Instituto Brasileiro de Meio Ambiente e Recursos Naturais Renováveis. Programa de controle da poluição do ar por veículos automotores - PROCONVE/PROMOT, 3 ed. Brasília: IBAMA/DIQUA, 2011. 584 p.

Institute for Environment and Sustainability, I. 2010. ILCD Handbook: General guide for Life Cycle Assessment - Detailed guidance. União Européia: Joint Research Centre (JRC).

IPCC - Intergovernmental Panel on Climate Change. 2006. Disponível em <http://www.ipccnggip.iges.or.jp/public/2006gl/pdf/2_Volume2/V2_1_Ch1_Introduction.pd f> Acesso em 22 março 2016.

ISO 14044:2006. Environmental management life cycle assessment Requirements and Guidelines. International Organization for Standardization.

ISO. International Standard 14040:2006 Environmental management - Life cycle assessment

ISO. International Standard 14046:2014. Environmental management -- Water footprint -Principles, requirements and guidelines. Geneva, Switzerland, 33p.

ITO, E. N. et al. 2004. Análise do desenvolvimento morfológico da blenda polimérica pbt/abs durante as etapas de mistura por extrusão e moldagem por injeção. Polímeros: Ciência e Tecnologia, v. 14, p. 83-92.

JESUS, L. C. C. et al. 2015. Propriedades mecânicas de compósitos de poliestireno reforçado com celulose de bagaço de cana. Revista interdisciplinar de pesquisa em engenharia, v. 1, p.1-14.

JIANG, F.; HSIEH, Y. L. 2013. Chemically and mechanically isolated nanocellulose and their self-assembled structures. Carbohydrate Polymers, v. 95, p.32-40.

JIN, Y. et al. 2015. Ultrasonic assisted cross-flow ultrafiltration of starch and cellulose nanocrystals suspensions: characterization at multi-scales. Carbohydrate Polymers, v. 124, p.66-76.

JOHAR, N. et al. 2012. Extraction, preparation and characterization of cellulose fibres and nanocrystals from rice husk. Industrial Crops and Products, v. 37, p.93- 99.

JONOOBI, M. et al. 2009. Chemical composition, crystallinity, and termal degradation of bleached end unbleached kenaf bast (Hibiscus cannabinus) pulp and nanofibers. BioResouces, v.4(2) p.26-639.

JONOOBI, M. et al. 2010. Characteristics of nanofibers extracted from kenaf core. Bioresources, v. 5, p.2556-2566. 
JONOOBI, M. et al. 2012. Producing low-cost cellulose nanofiber from sludge as new source of raw materials. Industrial Crops and Products, v. 40, p.232- 238.

JOSEPH K. et al. 1999. A review on sisal fiber reinforced polymer composites. Revista Brasileira de Engenharia Agricola e Ambiental, v.3, p.379.

JOSEPH, P.V. et al. The thermal and crystallisation studies of short sisal fibre reinforced polypropylene composites. Composites: Part A - Applied Science and Manufacturing, v.34, p. 253-266, 2003.

KADLA, J. F.; GILBERT, R. D. 2000. Cellulose structure: a review. Cellulose Chemical Technology, v. 34, p. 197.

KAHN, S. Energia e aquecimento global. Disponível em http://www.ipcc.ch/report/ar5/wg3/ > Acesso em 22 fevereiro 2016.

KALIA, S. et al. 2011. Cellulose-Based Bio- and Nanocomposites: A Review. International Journal of Polymer Science, v. 2011, p.35.

KAMAL, M.; KHOSHKAVA, V. 2015.Effect of cellulose nanocrystals (CNC) on rheological and mechanical properties and crystallization behavior of PLA/CNC nanocomposites. Carbohydrate Polymers, v. 123, p.105-114.

KARGARZADEH, H. et al. 2012. Effects of hydrolysis conditions on the morphology, crystallinity, and thermal stability of cellulose nanocrystals extracted from kenaf bast fibers. Cellulose, v.19 p.855-866.

KHAN, A. et al. 2012. Mechanical and barrier properties of nanocrystalline cellulose reinforced chitosan based nanocomposite films. Carbohydrate Polymers, v. 90, p.1601- 1608.

KHANNA, V. et al. 2008. Carbon Nanofiber Production: Life Cycle Energy Consumption and Environmental Impact. Journal of Industrial Ecology, v.12, Number 3.

KING, P. L. et al. 2002. Laboratory fourier transform infrared spectroscopy methods. Department of Earth Sciences.

KLOCK, U. et al. 2005. Química da madeira. 86 f. Departamento de Engenharia e Tecnologia Florestal. Setor de Ciências Agrárias. Universidade Federal do Paraná.

KOEHLER, A. 2008. Water use in LCA: managing the planet's freshwater resources. Int J Life Cycle Assess, v. 13, p.451-455.

KONTTURI, E. J. 2005. Surface chemistry of cellulose. From natural fibres to model surfaces. Library Technische Universiteit Eindhoven, 149 p. 
KOUNINA, A. et al. 2013. Review of methods addressing freshwater use in life cycle inventory and impact assessment. International Journal Life Cycle Assessement, v. 18, p.707-721.

KOWALCZYK, M. et al. 2011. Mechanical and thermal properties of PLA composites with cellulose nanofibers and standard size fibers. Composites: Part A, v. 42, p.1509-1514.

KUMAR, A. et al. 2014. Characterization of Cellulose Nanocrystals Produced by AcidHydrolysis from Sugarcane Bagasse as Agro-Waste. Journal of Materials Physics and Chemistry, v. 2, p.1-8.

KUMAR, A. et al. 2013. Synthesis and characterization of cellulose nanocrystals/PVA based bionanocomposite. Advanced Materials Letters, v. 4, p.626-631.

KUMAR, A. et al. 2014. Characterization of Cellulose Nanocrystals Produced by AcidHydrolysis from Sugarcane Bagasse as Agro-Waste. Journal of Materials Physics and Chemistry, (2), 1-8.

KUMAR, P. et al. 2009. Methods for Pretreatment of Lignocellulosic Biomass for Efficient Hydrolysis and Biofuel Production. Industrial Engineering Chemical Research, XXXX, $\mathrm{xxx}, 000$.

KUMAR, R. et al. 2011. Chemical modifications of natural fiber for composite material. Pelagia Research Library: Der Chemica Sinica, v.2, p.219-228.

LANDI, T. R. L.; SILVA, L. G. A. 2004. Estudo do efeito da radiação ionizante com feixe de elétrons sobre o terpolímero acrilonitrila butadieno estireno - ABS. Revista Mackenzie de Engenharia e Computação, v. 4, p.107-117.

LAVOINE, N. et al. 2012. Microfibrillated cellulose - Its barrier properties and applications in cellulosic materials: A review. Carbohydrate Polymers, v. 90, p.735- 764.

LAVORATTI, A. et al. 2016. Dynamic-mechanical and thermomechanical properties of cellulose nanofiber/polyester resin composites. Carbohydrates Polymers, v. 136, p.955963.

LEÃO R. M. et al. 2015a. Surface Treatment of Coconut Fiber and its Application in Composite Materials for Reinforcement of Polypropylene. Journal of Natural Fiber, v. 12, p. 574-586.

LEÃO, R. M et al. 2016b. Statistical Analysis and Mechanical Behavior for Polypropylene Composites Reinforced with Benzoylated Sugarcane Fibres. Journal of Bioprocess and Biotechniques, v. 6, p. 1-6. 
LEÃO, R. M et al. 2016c. The Recycling of Sugarcane Fiber/Polypropylene Composites. Materials Research, v. 18, p.690-697.

LEMMET, S. et al. 2012. Greening the economy through life cycle thinking. Ten years of the UNEP/SETAC Life Cycle Initiative, p.57.

LI, J. et al. 2012. Homogeneous isolation of nanocellulose from sugarcane bagasse by high pressure homogenization. Carbohydrate Polymers, v. 90, p.1609- 1613.

LI, Q. et al. 2013. Nanocellulose Life Cycle Assessment. ACS Sustainable Chemical Engineering, v. 1, p.919-928.

LI, X. Z. et al. 1999. Ammonium removal from landfill leachate by chemical precipitation. Waste Management, v. 19, p. 409-415.

LI, X. et al. 2007. Chemical Treatments of Natural Fiber for Use in Natural Fiber-Reinforced Composites: A Review. Journal Polymer Environment, v. 15, p.25-33.

LIMA, M. M. S, BORSALI, R. Rodlike 2004. Cellulose Microcrystals: Structure, Properties, and Applications. Macromolecular Rapid Communications, v.25, p.771-787.

LIU, D. et al. 2010. Starch composites reinforced by bamboo cellulosic crystals. Bioresource Technology, v.101, p.2529-2536.

LIU, Q. et al. 2011. Interactions of biomass components during pyrolysis: A TG-FTIR study. Journal of Analytical and Applied Pyrolysis, v. 90, p.213-218.

LOPES, A. S. et al. 1991. Acidez do solo e calagem. ANDA Associação Nacional para Difusão de Adubos. Boletim técnico, 1-14p.

LU, P. et al. 2012. Preparation and characterization of cellulose nanocrystals from rice straw. Carbohydrate Polymers, v 87, p.564- 573.

LUONG, N. D. et al. 2011. Graphene/cellulose nanocomposite paper with high electrical and mechanical performances. Journal Material Chemical, v. 21, p.13991.

LUZ, S. M. et al. 2010. Environmental benefits of substituting talc by sugarcane bagasse fibers as reinforcement in polypropylene composites: Ecodesign and LCA as strategy for automotive components. Resources, Conservation and Recycling, $\mathrm{xxx} \mathrm{xxx}-\mathrm{xxx}$.

MA, H. et al. 2011. Green composite films composed of nanocrystalline cellulose and a cellulose matrix regenerated from functionalized ionic liquid solution. Carbohydrate Polymers, v. 84, p.383-389. 
MA, H. et al. 2007. Clay network in ABS-graft-MAH nanocomposites: Rheology and flammability. Polymer Degradation and Stability, v. 92, p.1439e1445.

MA, L. et al. 2015. Preparing cellulose nanocrystal/acrylonitrile-butadiene-styrene nanocomposites using the master-batch method. Carbohydrate Polymers, v. 125, p.352359.

MADSEN, B. 2004. Properties of plant fiber yarn polymer composites: An experimental study. 151 p. Technical University of Denmark.

MALISKA, A. M. Microscopia eletrônica de varredura. Disponível em <http: www.materiais.ufsc.br/lcm/web-MEV/MEV_Apostila.pdf>. Acesso em 14 janeiro 2011.

MAMLEEV, V., BOURBIGOT, S., \& YVON, J. 2007. Kinetic analysis of the thermal decomposition of cellulose: The main step of mass loss. Journal of Analytical and Applied Pyrolysis, v. 88, p.151-165.

MANDAL, A.; CHAKRABARTY, D. 2011. Isolation of nanocellulose from waste sugarcane bagasse (SCB) and its characterization. Carbohydrate Polymers, v. 86, p.1291- 1299.

MARIANO, M. et al. 2014. Cellulose Nanocrystals and Nanocomposites: Review of some Properties and Challenges. Journal of Polymer Science, Part B: Polymer Physics, v. 52, p.791-806.

MARTINS, P. A. 2014. Estudo de Sistemas Retardantes de Chama sem Bromo para ABS. Polímeros, vol. 24, n. 5, p. 572-578.

MARTINS, P. A. et al. 2012. Obtenção e caracterização do abs com adição de tio2 e argila. $\mathbf{6 7}^{\circ}$ congresso internacional - ABM.

MAURYA, D. P. et al. 2015. An overview of key pretreatment processes for biological conversion of lignocellulosic biomass to bioethanol. Biotechnology, v. 5, p.597-609.

MESQUITA, J. P. et al. 2010. Biobased nanocomposites from layer-by-layer assembly of cellulose nanowhiskers with chitosan. Biomacromolecules, v. 11, p. 2.

MOON, R. J. et al. 2011. Cellulose nanomaterials review: structure, properties and nanocomposites. Cite this: Chemical Society Reviews, v. 40, p.3941-3994.

MORAIS, J. P. S. et al. 2013. Extraction and characterization of nanocellulose structures from raw cotton linter. Carbohydrate Polymers, v. 91, p.229- 235.

MORÁN J. I. et al. 2008. Extraction of cellulose and preparation of nanocellulose from sisal fibers. Cellulose, v. 15, p.149-159. 
MORELLI, F. C.; FILHO, A. R. 2010. Nanocompósitos de Polipropileno e Argila Organofílica: Difração de Raio X, Espectroscopia de Absorção na Região do Infravermelho e Permeação ao Vapor D’água. Polímeros, v. 20, nº 2, p. 121-125.

MOSIER, N. et al. 2005. Features of promising technologies for pretreatment of lignocellulosic biomass. Bioresource Technology, v. 96, p.673-686.

MOTHÉ, C. G.; AZEVEDO, A. D. 2009. Análise térmica de materiais. São Paulo: ed. Artliber. $324 \mathrm{p}$.

MOTHÉ, C. G.; MIRANDA, I. C. 2009. Characterization of sugarcane and coconut fibers by thermal analysis and FTIR. J Therm Anal Calorim v.97 p.661-665.

MOURAD, A. L. et al. 2007. Avaliação do ciclo de vida como instrumento de gestão. Centro de Tecnologia de Embalagem. CETEA/ITAL, 75p.

MORAIS, J. P. S. et al. 2010. Procedimentos para analise lignocelulosica. Embrapa, 54p.

MULINARI, D. R. et al. 2009. Sugarcane bagasse cellulose/HDPE composites obtained by extrusion. Composites Science and Technology, v. 69, p.214-219.

NAHLA, A. et al. 2015. Development of wheat gluten/nanocellulose/titanium dioxide nanocomposites for active food packaging. Carbohydrate Polymers, v. 124, p.337-346.

NEHER, B. et al. 2014. Study of Mechanical and Physical Properties of Palm Fiber Reinforced Acrylonitrile Butadiene Styrene Composite. Materials Sciences and Applications, v. 5, p.39-45.

NETO, J. R. A. et al. 2007a. Influência da Adição de uma Carga Nanoparticulada no Desempenho de Compósitos Poliuretano/Fibra de Juta. Polímeros: Ciência e Tecnologia, v. 17, p. 10-15.

NETO, R. B. 2007b. Técnicas de caracterização de polímeros, Artliber, 2007, $1^{\text {a }}$ edição, 41 p á $60 \mathrm{p}$.

NG, H-M. et al. 2015. Extraction of cellulose nanocrystals from plant sources for application as reinforcing agent in polymers. Composites Part B, v. 75, p.176 -200.

NIELSEN, P. H. et al. 2007. Cradle-to-Gate Environmental Assessment of Enzyme Products Produced Industrially in Denmark by Novozymes A/S. International Journal LCA, p.1-7.

NISHIYAMA, Y. et al. 2003. Crystal Structure and Hydrogen Bonding System in Cellulose I $\alpha$ from Synchrotron X-ray and Neutron Fiber Diffraction. J. American Chemical Society, v. 125, p.14300-14306. 
OGEDA, T. L.; PETRI, D. F.S. 2010. Hidrólise enzimática de biomassa. Química Nova, v. 33, p.1549-1558.

OH YOUN, S. et al. 2005. Crystalline structure analysis of cellulose treated with sodium hydroxide and carbon dioxide by means of X-ray diffraction and FTIR spectroscopy. Carbohydrate Research, 340, p.2376-2391.

OKAMURA, K. 1991. Structure of cellulose. In Wood and Cellulosic Chemistry (D. N.-S. Hon and N. Shiraishi, eds). New York: Marcel Dekker, p. 89-111.

OLAD, A. 2011. Polymer/Clay Nanocomposites. Advances in Diverse Industrial Applications of Nanocomposites. Edited by Boreddy Reddy, 588 p.

OLIVEIRA, C. F. P.; DEMARQUETTE, N. R. 2009. Propriedades reológicas de nanocompósitos de polipropileno. Anais do $\mathbf{1 0}^{\circ}$ Congresso Brasileiro de Polímeros, p.108.

ORNAGHI JR., H. L. et al. 2010. Mechanical and Dynamic Mechanical Analysis of Hybrid Composites Molded by Resin Transfer Molding. Journal of Applied Polymer Science, v. 118 , p. 887-896.

O'SUllivan, A. C. 1997. Cellulose: the structure slowly unravels. Cellulose, v. 4, p.173-207.

OUDIANI, A. El. et al. 2011. Transition from cellulose I to cellulose II in $\mathrm{NaOH}$ treated Agave americana L. fibre. Carbohydrate Polymers, v. 86, p.1221- 1229.

PAIVA, L. B. et al. 2006. Propriedades mecânicas de nanocompósitos de polipropileno e montmorilonita organofílica. Polímeros: Ciência e Tecnologia, v. 16, p. 136-140.

PALMQVIST, E.; HAHN-HAGERDAL, B. 2000. Fermentation of lignocellulosic hydrolysates. II: inhibitors and mechanisms of inhibition. Bioresource Technology, v. 74, p. 25-33.

PANTHAPULAKKAL, S.; SAIN, M. 2012. Preparation and characterization of cellulose nanofibril films fromwood fibre and their thermoplastic polycarbonate composites. International Journal of Polymer Science, v. 2012, p. 6.

PĂRPĂRITĂ, E. et al. 2014. Structuremorphology mechanical properties relationship of some polypropylene/lignocellulosic composites. Materials and Design, v.56, p.763-772.

PELTOLA et al. 2006. Effect of rotational speed of twin screw extruder on the microstructure and rheological and mechanical properties of nanoclay-reinforced polypropylene nanocomposites. Polymer Engineering and Science, v. 46, p.995-1000. 
PEREIRA, P. H. F. et al. 2011. Sugarcane bagasse pulping and bleaching: Thermal and chemical characterization. BioResources, v. 6, p.2471-2482.

PEREIRA, P. H. F. et al. 2014. Sugarcane bagasse cellulose fibres and their hydrous niobium phosphate composites: synthesis and characterization by XPS, XRD and SEM. Cellulose, v. 21, p.641-652.

PICCOLI, R. et al. 2006. Características das principais técnicas analíticas aplicadas à caracterização de materiais. $17^{\circ}$ Congresso Brasileiro de Engenharia e Ciência dos Materiais.

PICKERING, K.L. et al. 2016. A review of recent developments in natural fibre composites and their mechanical performance. Composites: Part A 83, 98-112.

PISTOR, V. et al. 2010. Influence of physical interaction between organoclay and poly(ethyleneco-vinylVacetate) matrix and effect of clay content on rheological melt state. Polymer, v. 51, p.5165-5171.

POUR, R. H. et al. 2014. Mechanical, Thermal, and Morphological Properties of Graphene Reinforced Polycarbonate/Acrylonitrile Butadiene Styrene Nanocomposites. Polymer Composites.

PRACELLA, M. et al. 2012. Preparation and characterization of PLA nanocomposites with nanocellulose filled PVAC. In The European conference on composite materials Venice, p. 24-28.

PRACELLA, M. et al. 2014. Morphology and properties tuning of PLA/cellulose nanocrystals bionanocomposites by means of reactive functionalization and blending with PVAc. Polymer, v. 55, p.3720-3728.

RAMOS, N. P.; JUNIOR, A. L. 2016. Disponível em < http://www.agencia.cnptia.embrapa.br/gestor/cana-de-acucar/arvore/CONT1.html > Acessado em 28 de março 2016.

REZENDE, C. A. et al. 2011. Chemical and morphological characterization of sugarcane bagasse submitted to a delignification process for enhanced enzymatic digestibility. Biotechnology for Biofuels, v. 4, p.54.

REZENDE, J. M.; OLIVEIRA, F. L.; MULINARI, D. R. 2010. Hybrid composites evaluation to be applied in Engineering. Cadernos UniFOA, n. 15. 
RICKERBY, D. G.; MORRISON, M. 2007. Nanotechnology and the environment: A European perspective. Science and Technology of Advanced Materials, v. 8, p.19-24.

RIDES, M. 2005. Rheological characterisation of filled materials: a review. National Phiscal Laboratory, p.1-35.

RIMDUSIT, S. et al. 2013. Characterizations of Poly(vinyl chloride)/Acrylonitrile Styrene Acrylate Blends for Outdoor Applications. Engineering Journal, v. 18, p.105-118.

ROCHA, T. C. J. et al. 2007. Principais copolímeros elastoméricos à base de butadieno utilizados na indústria automobilística. Polímeros: Ciência e Tecnologia, v. 17, p.299-307.

ROES, A. L. et al. 2007. Environmental and cost assessment of a polypropylene nanocomposite. Journal Polymer Environmental, v. 15, p.212-226.

ROMAN, M.; WINTER, W. T. 2004. Effect of sulfate groups from sulfuric acid hydrolysis on the thermal degradation behavior of bacterial cellulose. Biomacromolecules, v. 5, p.16711677.

ROMANZINI, D. et al. 2013. Influence of fiber content on the mechanical and dynamic mechanical properties of glass/ramie polymer composites. Materials \& Design, v. 47, p. 915.

ROSA, M. F. et al. 2009. Nanocompósitos de borracha natural reforçados com nanowhiskers de fibra de coco imaturo. V Workshop de Rede de Nanotecnologia Aplicada ao Agronegócio, p. 1-4.

ROSA, M. F. et al. 2010. Cellulose nanowhiskers from coconut husk fibers: Effect of preparation conditions on their thermal and morphological behavior. Carbohydrate Polymers, v. 81, p.83-92.

ROSA, S. L. et al. 2012. Chlorine-free Extraction of Cellulose from Rice Husk and Whisker Isolation. Carbohydrate Polymers, 87, p.1131-1138.

ROSLI, N. A. et al. 2013. Isolation and characterization of cellulose nanocrystals from agave angustifolia fibre. BioResources, v. 8, p.1893-1908.

ROUSSEAUX, P. Analyse du cycle de vie - Évaluation des Impacts. In: Techniques de l'ingénieur. Disponível em: <techniques-ingenieur.fr/base-documentaire/environnementsecurite-th5/systeme-de-management-environnemental-produits-et-acv-42627210/analysedu-cycle-de-vie-g5610/> acessado em 23 de março de 2016.

RUSSEL, J. B. 2015. Química Geral. São Paulo; Makron Books, v. 1, 9ª edição, 662 p.. 
SABA, N. et al. 2014. A Review on potentiality of nano filler/natural fiber filled polymer hybrid composites. Polymers, v. 6, p.2247-2273.

SANCHEZ, E. M. S. et al. 1999. Avaliação da degradação térmica e fotooxidativa do abs automotivo. Polímeros: Ciência e Tecnologia, p. 116-122.

SANTOS, R. B. et al. 2011. Wood based lignina reactions importante to the biorefinery and pulp and paper industries. BioResources, v. 8, p.1455-1477.

SANTOS, R. M. et al. 2013. Cellulose nanocrystals from pineapple leaf, a new approach for the reuse of this agro-waste. Industrial Crops and Products, v. 50, p.707- 714.

SCHADLER L. S. 2003. Polymer-based and polymer-filled nanocomposites. In: Ajayan PM, Schadler LS, Braun PV, editors. Nanocomposite science and technology. Weinheim: Wiley-VCH Verlag.

SEGAL, L. et al. (1959). An empirical method for estimating the degree of crystallinity of native cellulose using the X-ray diffractometer. Textile Research Journal, v. 29, p.786-794.

SHEN, L.; PATEL, M. K. 2008. Life Cycle Assessment of Polysaccharide Materials: A Review. Journal Polymer Environmental, v. 16, p154-167.

SHEN, L.; PATEL, M. K. 2010. LIFE CYCLE ASSESSMENT OF MAN-MADE CELLULOSE FIBRES. Lenzinger Berichte, 88, 1-59

SILVA, E. C. et al. 2007. Análise térmica aplicada à cosmetologia. Revista Brasileira de Ciências Farmacêuticas, v.43, n.3.

SILVA, E. S.; LUZ, S. M. 2012. Avaliação de impactos econômicos ao longo de todo o ciclo da produção de etanol. $6^{\circ}$ Congresso Internacional de Bioenergia.

SILVA, R. et al. 2009. Aplicações de fibras lignocelulósicas na química de polímeros e em compósitos. Química Nova, v.32, n³, p.661-671.

SILVÉRIO, F. O. et al. 2006. Metodologia de extração e determinação do teor de extrativos em madeiras de eucalipto. Revista Árvore, v.30, p.6.

SILVERIO, H. A. et al. 2013. Extraction and characterization of cellulose nanocrystals from corncob for application as reinforcing agent in nanocomposites. Industrial Crops and Products, v. 44, p.427- 436.

SIRÓ, I. PLACKETT, D. 2010. Microfibrillated cellulose and new nanocomposite materials: a review. Cellulose, v. 17, p.459-494. 
SOARES, I. L. et al. 2011. Caracterização da dispersão dos nanocompósitos de $\mathrm{PP} / \mathrm{TiO}_{2}$ não modificados. $11^{\circ}$ Congresso Brasileiro de Polímeros, 1-6p.

SOARES, L. H. B. et al. 2009. Mitigação das emissões de gases estufa pelo uso de etanol da cana-de-açúcar produzido no Brasil. Circular Técnica, 1-14.

SOHN, K. et al. 2011. Flame Retarding PC/ABS Resins having Superior Thermomechanical Properties. Fibers and Polymers. 2011, Vol. 12. nº 4, p. 451-456.

SOLOMON, M. J. et al. 2001. Rheology of polypropylene/clay hybrid materials. Macromolecules, v. 34, p.1864-1872.

SPINELLA, S. et al. 2015. Polylactide/cellulose nanocrystal nanocomposites: Efficient routes for nanofiber modification and effects of nanofiber chemistry on PLA reinforcement. Polymer, v. 65 , p. $9-17$.

STEPHAN, P. et al. 2009. Assessing the Environmental Impacts of Freshwater Consumption in LCA. Environmental Science Technology, 43, 4098-4104.

STRYER, L. et al. 2014. Bioquimica. Editora: GUANABARA KOOGAN, p.1184.

SUMMERSCALES, J. et al. 2010. A review of bast fibres and their composites. Part 1- Fibres as reinforcements. Composites: Part A, In Press.

TEIXEIRA, E. M. et al. 2010. Cellulose nanofibers from white and naturally colored cotton fibers. Cellulose, v. 17, p.595-606.

TEIXEIRA, E. M. et al. 2011. Sugarcane bagasse whiskers: Extraction and characterizations. Industrial Crops and Products, v. 33, p. 63-66.

TEIXEIRA, F. L. S. Disponível em <http://www.assocana.com.br/custo.php> Acessado em 26 de fevereiro de 2016.

VASCONCELLOS, E. A. 2006 Transporte e meio ambiente: conceitos e informações para análise de impactos. São Paulo: Ed. do Autor, 200p.

VERARDI, A. et al. 2005. Hydrolysis of Lignocellulosic Biomass:Current Status of Processes and Technologies and Future Perspectives. News on: Science Focus Direct on Catalysts, p.290.

VIDAL, R. et al. 2009. Life cycle assessment of composite materials made of recycled thermoplastics combined with rice husks and cotton linters. Int J Life Cycle Assess, v.14, p.73-82. 
VILA, C. et al. 2011. Extracting value from Eucalyptus wood before kraft pulping: Effects of hemicelluloses solubilization on pulp properties. Bioresource Technology, v. 102, p. 52515254.

VILELA, F. S. V et al. 2012. Análise de desempenho ambiental da cadeia de suprimentos do etanol anidro no Brasil. $6^{\circ}$ Congresso Internacional de Bioenergia.

WANG, Q. et al. 2014. Kinetics of Strong Acid Hydrolysis of a Bleached Kraft Pulp for Producing Cellulose Nanocrystals (CNCs). Ind. Eng. Chem. Res, v. 53, p.11007-11014.

WATER FOOTPRINT NETWORK. Disponível em <http://waterfootprint.org/en/> Acesso em 18 de fevereiro de 2016.

WILlERS, C. D.; RODRIGUES, B. L. 2014. A critical evaluation of Brazilian life cycle assessment studies. International Journal Life Cycle Assessment, v. 19, p.144-152.

WYMAN, C. E. et al. 2005. Polysaccharides: Strutural Diversity and Functional Versatility; Dumitriu, S., ed.; Dekker: New York, 2005, cap. 43.

XU, F. et al. 2013. Qualitative and quantitative analysis of lignocellulosic biomass using infrared techniques: A mini-review. Applied Energy, v. 104, p.801-809.

YANG, H. et al. 2007. Characteristics of hemicellulose, cellulose and lignin pyrolysis. Fuel, v. 86, p.1781-1788.

YANG, J. et al. 2015. Design of cellulose nanocrystals template-assisted composites hydrogels: Insights from static to dynamic alignment. Macromolecules, XXXX, XXX, XXX-XXX.

YANG, S. et al. 2004. Thermal analysis of an acrylonitrile-butadiene-styrene/SWNT composite. Polymer Degradation and Stability, v. 83, p.383-388.

YU, M. et al. 2012. Preparation and characterization of bamboo nanocrystalline celulose. BioResources, v. 7, p.1802-1812.

ZAINI, L. H. et al. 2013. Isolation and Characterization of Cellulose Whiskers from Kenaf (Hibiscus cannabinus L.) Bast Fibers. Scientific Research, v. 4, p.37-44.

ZHAO, J. et al. 2005. Rheological characterization of polystyrene-clay nanocomposites to compare the degree of exfoliation and dispersion. Polymer, v. 46, p.8641-8660.

ZHOU, Y. M. et al. 2012. Effect of nanocellulose isolation techniques on the formation of reinforced poly(vinyl alcohol) nanocomposite films. eXPRESS Polymer Letters, v. 6, p.794-804. 
ZUGENMAIER, P. 2001. Conformation and packing of various crystalline cellulose fibers. Progress in Polymer Science, v. 26, p.1342-1417. 
APÊNDICE A: Consumo de água e energia e Emissões potenciais impactos ambientais na fase produção de nanocristais.

Tabela 1: Emissões do potencial de aquecimento global ( $\mathrm{kg}$ de $\mathrm{CO}_{2}$ eq.) na fase de produção dos NCC

\begin{tabular}{|c|c|c|c|c|c|c|c|c|c|}
\hline \multicolumn{10}{|c|}{ Consumo } \\
\hline Processos & $\mathrm{NaOH}$ & $\mathrm{C}_{2} \mathrm{H}_{4} \mathrm{O}_{2}$ & $\mathrm{H}_{2} \mathrm{SO}_{4}$ & $\mathrm{HNO}_{3}$ & $\mathrm{H}_{2} \mathrm{O}_{2}$ & $\begin{array}{l}\text { Água } \\
\text { Tap }\end{array}$ & $\begin{array}{l}\text { Água } \\
\text { dest }\end{array}$ & Energia & Total \\
\hline I & 544 & 51,70 & 644 & - & - & $2,4 \times 10^{3}$ & $2,8 \times 10^{3}$ & 11,18 & $3,95 \times 10^{3}$ \\
\hline II & 51,60 & 1,23 & 71,10 & - & - & 105 & 207,30 & 5,45 & 195 \\
\hline III & 14,20 & 1,69 & 39,10 & - & - & 52 & 131,50 & 6,46 & 158 \\
\hline IV & 1,02 & 0,24 & 6,19 & - & - & 11,20 & 20,23 & 6,72 & 28 \\
\hline V & 9,31 & 0,55 & 24,80 & & & 63,80 & 78,50 & 6,38 & 23,5 \\
\hline VI & 28,90 & 0,68 & 37,80 & 52,80 & - & 100 & 62,90 & 6,83 & 158 \\
\hline VII & 26,80 & 2,15 & 28,40 & 49 & & 137 & 97,10 & 13,40 & 231 \\
\hline VIII & 3,50 & 0,28 & 3,39 & 6,38 & - & 12,80 & 12,44 & 14,41 & 30,3 \\
\hline IX & 4,10 & 0,08 & 4,31 & 7,61 & - & 8,37 & 8,30 & 8,01 & 13,7 \\
\hline $\mathbf{X}$ & 29,50 & - & 9,59 & - & 131 & 8,59 & 10,03 & 5,27 & 156 \\
\hline XI & 130 & - & 29,30 & - & $2,3 \times 10^{3}$ & 75,30 & 84,10 & 10,75 & $2,46 \times 10^{3}$ \\
\hline XII & 233 & 1,11 & 140 & - & 381 & 68 & 116 & 3,96 & 647 \\
\hline
\end{tabular}

Tabela 2: Emissões do potencial de acidificação ( $\mathrm{kg}$ de $\mathrm{SO}_{2}$ eq.) na fase de produção dos NCC

\begin{tabular}{|c|c|c|c|c|c|c|c|c|c|}
\hline \multicolumn{10}{|c|}{ Consumo } \\
\hline Processos & $\mathrm{NaOH}$ & $\mathrm{C}_{2} \mathrm{H}_{4} \mathrm{O}_{2}$ & $\mathrm{H}_{2} \mathrm{SO}_{4}$ & $\mathrm{HNO}_{3}$ & $\mathrm{H}_{2} \mathrm{O}_{2}$ & $\begin{array}{l}\text { Água } \\
\text { Tap }\end{array}$ & $\begin{array}{l}\text { Água } \\
\text { dest }\end{array}$ & Energia & Total \\
\hline I & 1,1800 & 0,0583 & 14,200 & - & - & 4,0600 & 7,0300 & 0,0557 & 26,66 \\
\hline II & 0,1120 & 0,0013 & 1,5700 & - & - & 0,1320 & 0,5920 & 0,0271 & 2,43 \\
\hline III & 0,0310 & 0,0019 & 0,8630 & - & - & 0,0886 & 0,3750 & 0,0322 & 1,39 \\
\hline IV & 0,0203 & 0,0006 & 0,5490 & - & - & 0,1090 & 0,2049 & 0,0318 & 0,91 \\
\hline V & 0,0090 & $9,4 e-5$ & 0,0953 & 0,0049 & - & 0,0143 & 0,02368 & 0,0399 & 0,18 \\
\hline VI & 0,0630 & 0,0007 & 0,8360 & 0,0343 & - & 0,1710 & 0,17890 & 0,0341 & 1,32 \\
\hline VII & 0,0584 & 0,0024 & 0,6270 & 0,0318 & - & 0,2340 & 0,27710 & 0,0666 & 1,29 \\
\hline VIII & 0,0022 & 0,0002 & 0,1370 & - & - & 0,0190 & 0,05230 & 0,0334 & 0,24 \\
\hline IX & 0,0076 & 0,0003 & 0,0075 & 0,0041 & - & 0,0218 & 0,03540 & 0,0715 & 0,14 \\
\hline $\mathbf{X}$ & 0,2830 & - & 0,6480 & - & 2,6300 & 0,1280 & 0,24000 & 0,0536 & 3,98 \\
\hline XI & 0,0642 & - & 0,2120 & - & 0,1500 & 0,0146 & 0,02860 & 0,0263 & 0,49 \\
\hline XII & 0,5060 & 0,0012 & 3,0900 & - & 0,4350 & 0,1160 & 0,33000 & 0,0197 & 4,50 \\
\hline
\end{tabular}


Tabela 3: Emissões do potencial de eutrofização (kg de fosfato eq.) na fase de produção dos

$\mathrm{NCC}$

\begin{tabular}{llllllllll}
\hline \multicolumn{1}{c}{ Processos } & $\mathbf{N a O H}$ & $\mathbf{C}_{\mathbf{2}} \mathbf{H}_{\mathbf{4}} \mathbf{O}_{\mathbf{2}}$ & $\mathbf{H}_{\mathbf{2}} \mathbf{S O}_{\mathbf{4}}$ & $\mathbf{H N O} \mathbf{H}_{\mathbf{3}}$ & $\mathbf{H}_{\mathbf{2}} \mathbf{O}_{\mathbf{2}}$ & $\begin{array}{l}\text { Água } \\
\text { Tap }\end{array}$ & $\begin{array}{l}\text { Água } \\
\text { dest }\end{array}$ & Energia & Total \\
\hline I & 0,1700 & 0,00625 & 0,1350 & - & - & 0,9780 & 1,2990 & $2,8 \mathrm{e}-3$ \\
II & 0,0161 & 0,00014 & 0,0149 & - & - & 0,0493 & 0,1001 & $1,4 \mathrm{e}-3$ & 0,59 \\
III & 0,0044 & 0,00020 & 0,0081 & - & - & 0,0214 & 0,0635 & $1,6 \mathrm{e}-3$ & 0,09 \\
IV & 0,0029 & $6,7 \mathrm{e}-5$ & 0,0051 & - & - & 0,0262 & 0,0365 & $1,7 \mathrm{e}-3$ & 0,07 \\
V & 0,0003 & $2,9 \mathrm{e}-5$ & 0,0012 & - & - & 0,0045 & $9,4 \mathrm{e}-3$ & $1,6 \mathrm{e}-3$ & 0,01 \\
VI & 0,0090 & $8,3 \mathrm{e}-5$ & 0,0079 & 0,0361 & - & 0,0412 & 0,0336 & $1,7 \mathrm{e}-3$ & 0,12 \\
VII & 0,0083 & 0,0002 & 0,0059 & 0,0334 & - & 0,0563 & 0,0468 & $3,3 \mathrm{e}-3$ & 0,15 \\
VIII & 0,0010 & $3,4 \mathrm{e}-5$ & 0,0007 & 0,0043 & - & 0,0052 & $6,0 \mathrm{e}-3$ & $3,6 \mathrm{e}-3$ & 0,02 \\
IX & 0,0013 & $1,0 \mathrm{e}-5$ & 0,0009 & 0,0051 & - & 0,0034 & $4,0 \mathrm{e}-3$ & $2,0 \mathrm{e}-3$ & 0,01 \\
X & 0,0407 & - & 0,0061 & - & 0,3200 & 0,0309 & 0,0405 & $2,7 \mathrm{e}-3$ & 0,44 \\
XI & 0,0092 & - & 0,0020 & - & 0,0183 & 0,0035 & $4,8 \mathrm{e}-3$ & $1,3 \mathrm{e}-3$ & 0,03 \\
XII & 0,0728 & 0,0001 & 0,0293 & - & 0,0530 & 0,0279 & 0,0560 & $9,9 \mathrm{e}-4$ & 0,24 \\
\hline
\end{tabular}

Fluxos da produção dos nanocristais

Pretreatment generic met8 $\mathrm{H} 2 \mathrm{O} 2 \mathrm{1B}$

GaBi process plan:Reference quantities

The names of the basic processes are shown

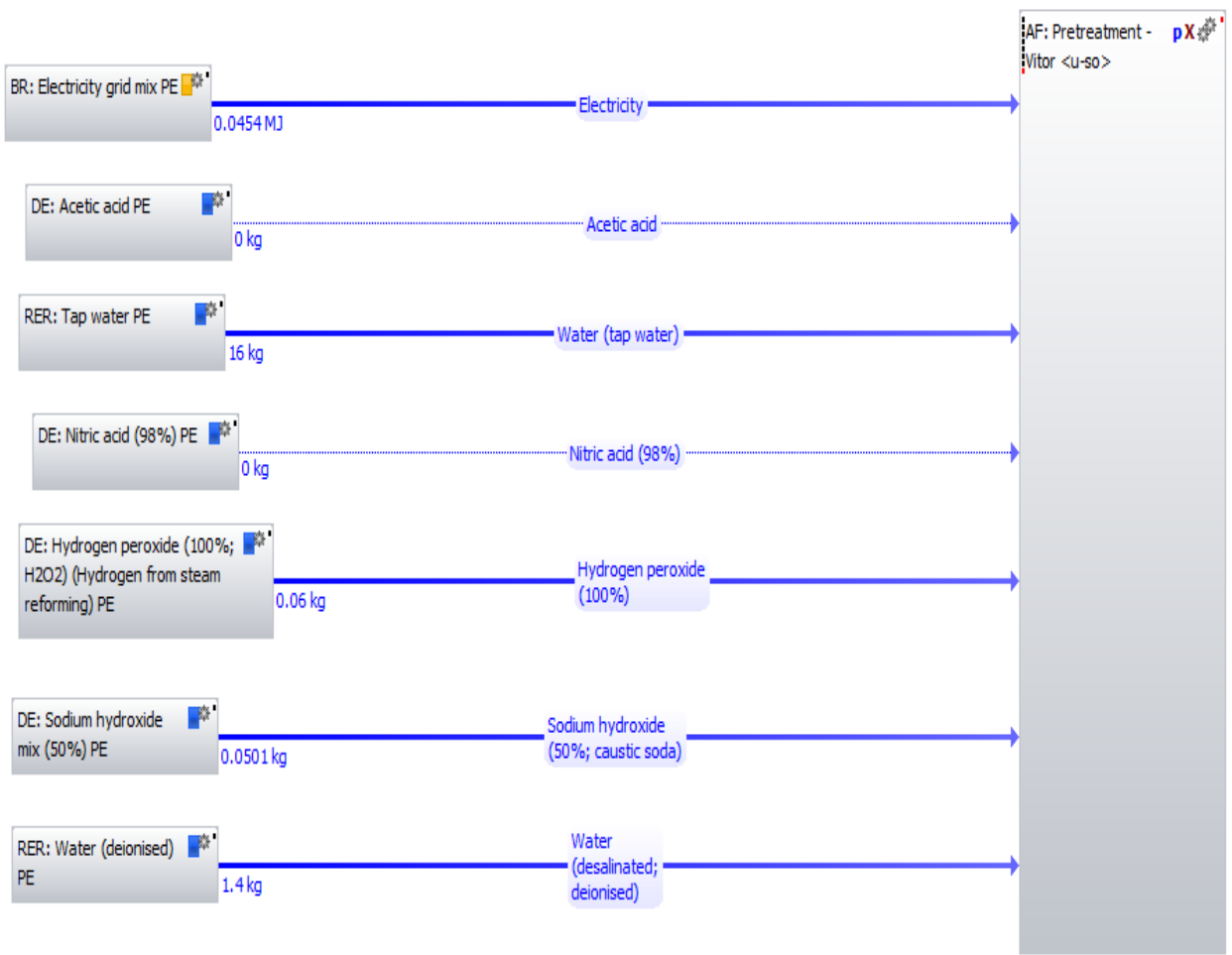


Hydrolysis_generic met8 H2O2 1B

Gabi process plan:Reference quantities
The names of the basic processes are shown.

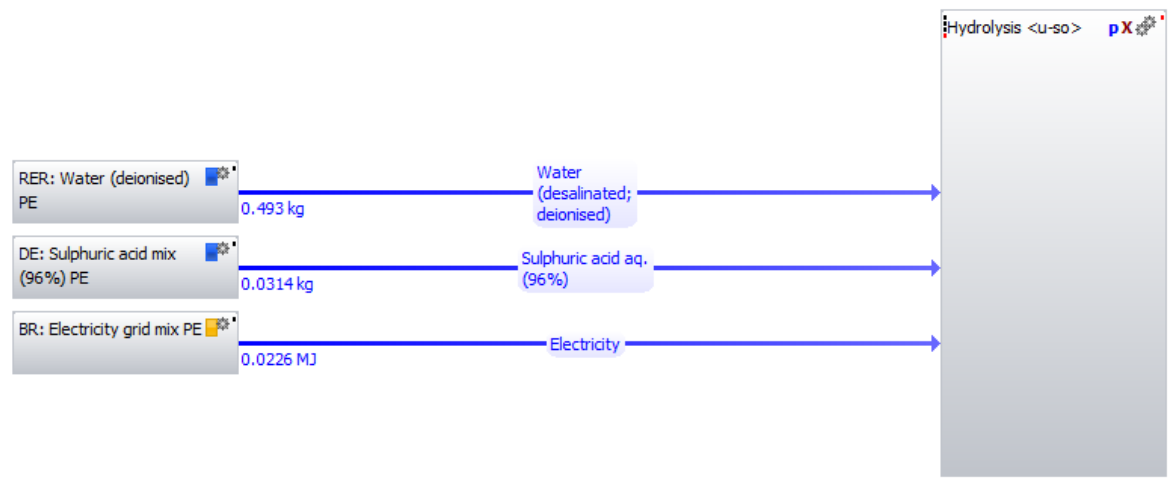


APÊNDICE B: Caracterização das fibras de bagaço de cana-de açúcar in natura
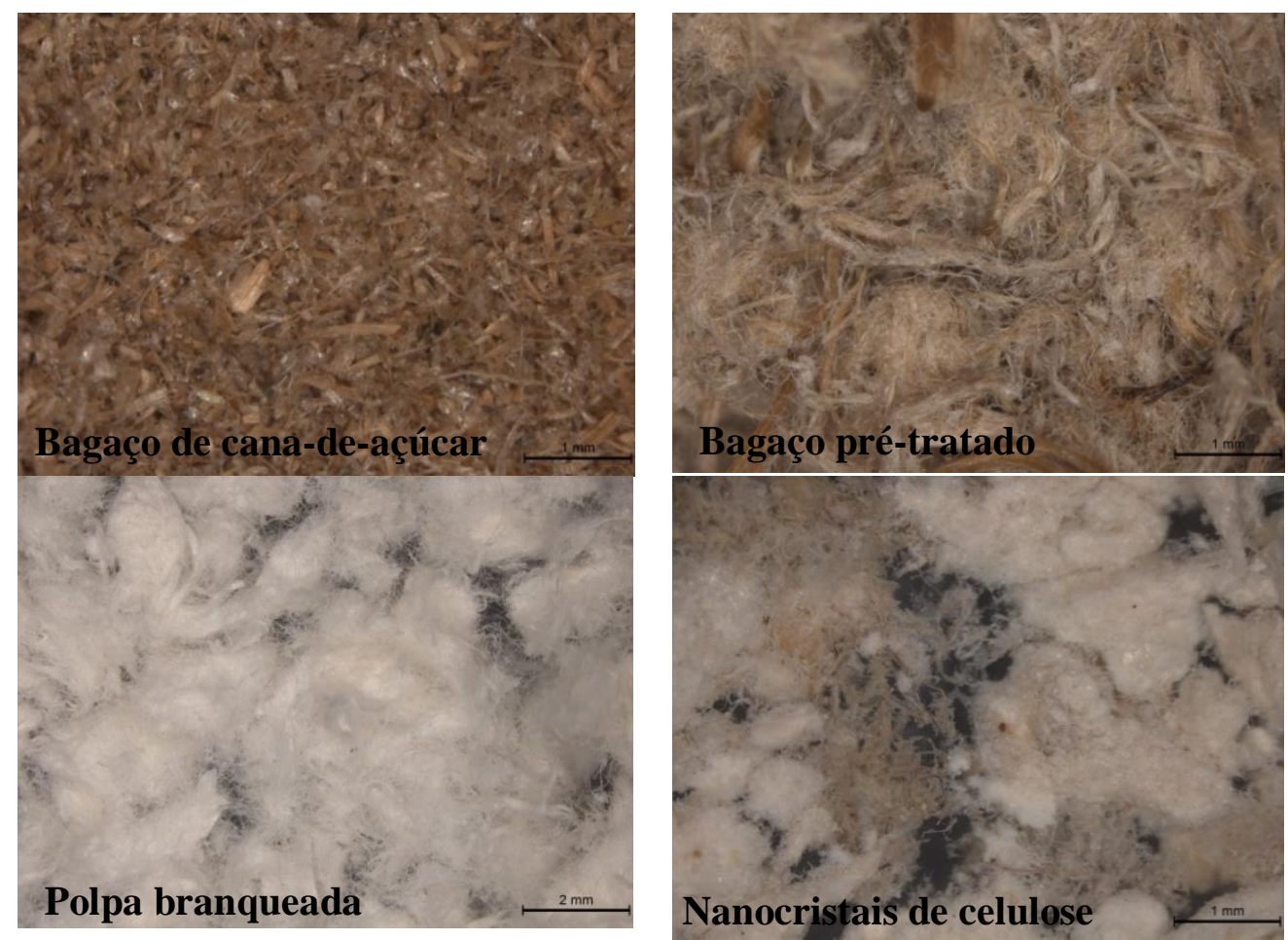

Figura 1: Imagens estereomicroscópio $(20$ x $)$ de bagaço de-cana-de-açúcar do processo I.
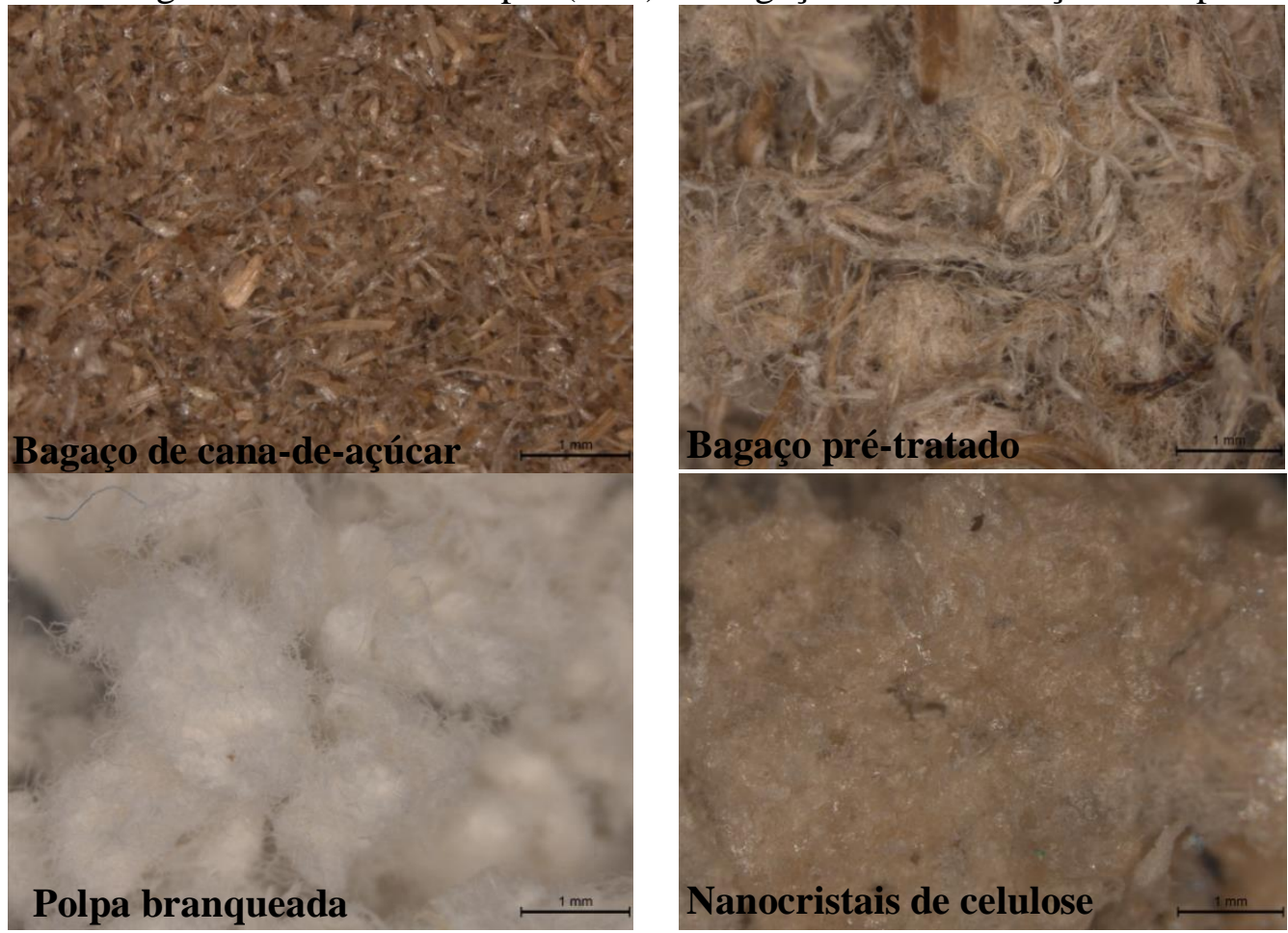

Figura 2: Imagens estereomicroscópio $(20$ x) de bagaço de-cana-de-açúcar do processo II. 

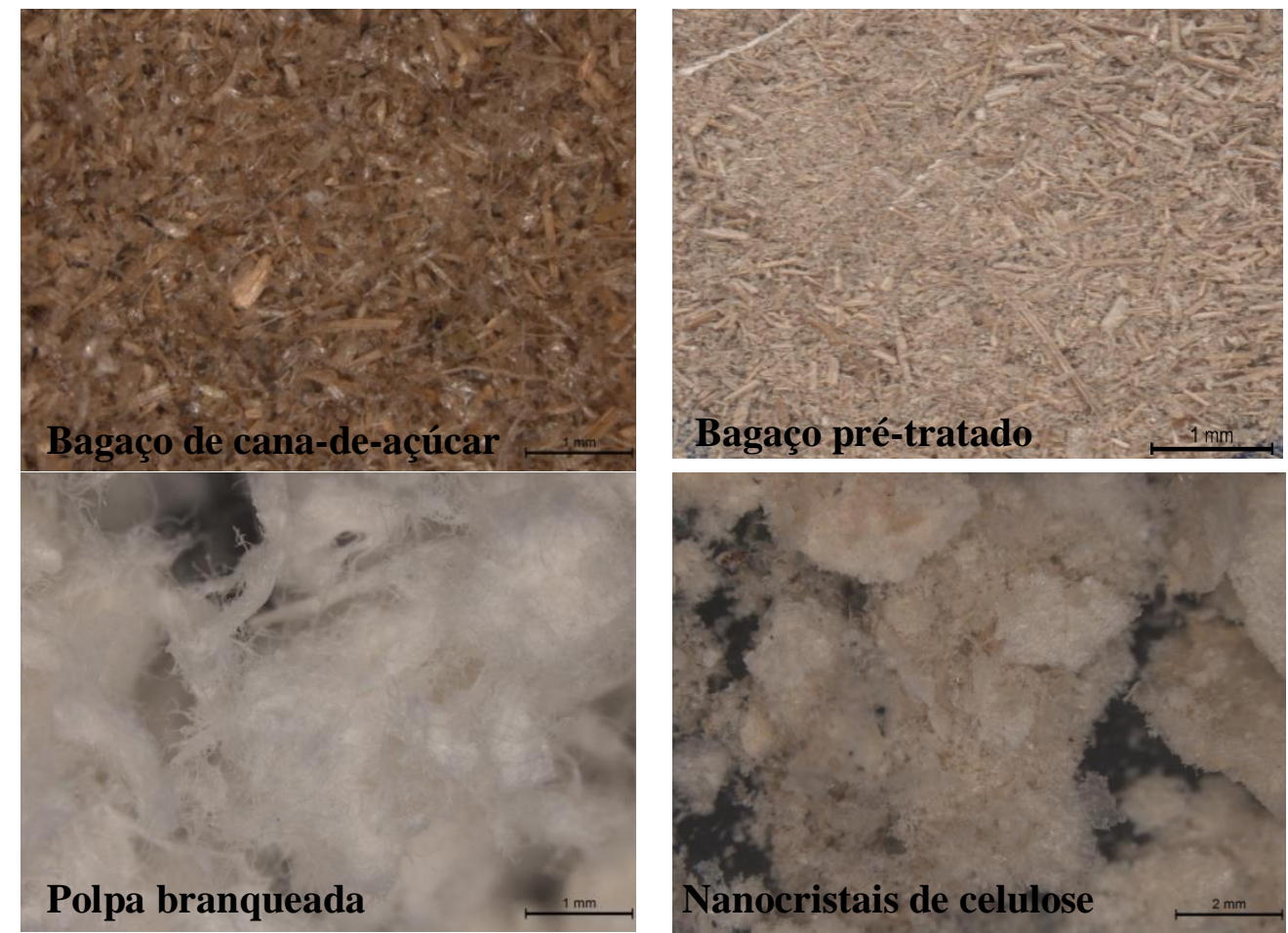

Figura 3: Imagens estereomicroscópio $(20$ x) de bagaço de-cana-de-açúcar do processo III.
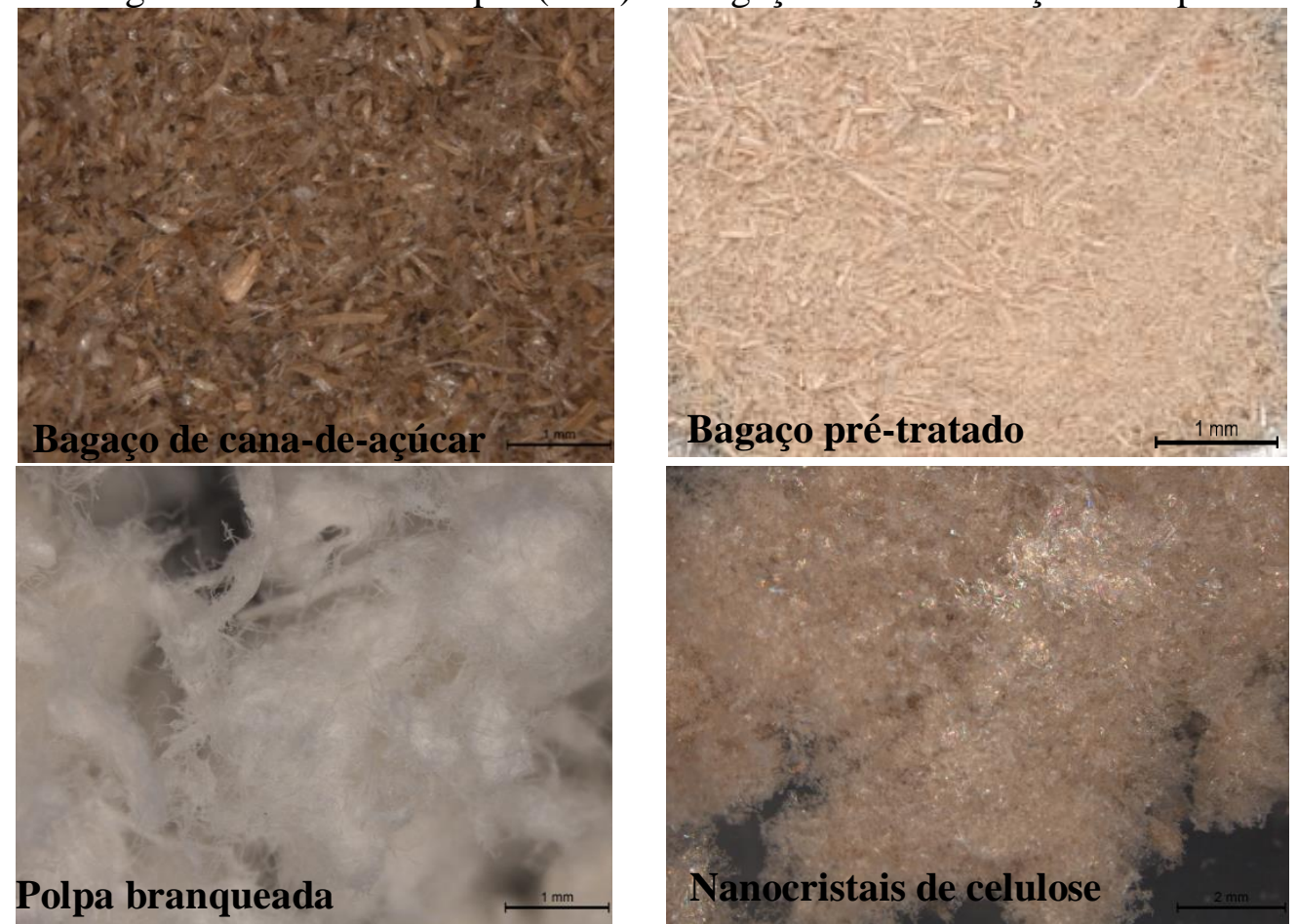

Figura 4: Imagens estereomicroscópio $(20$ x) de bagaço de-cana-de-açúcar do processo IV. 


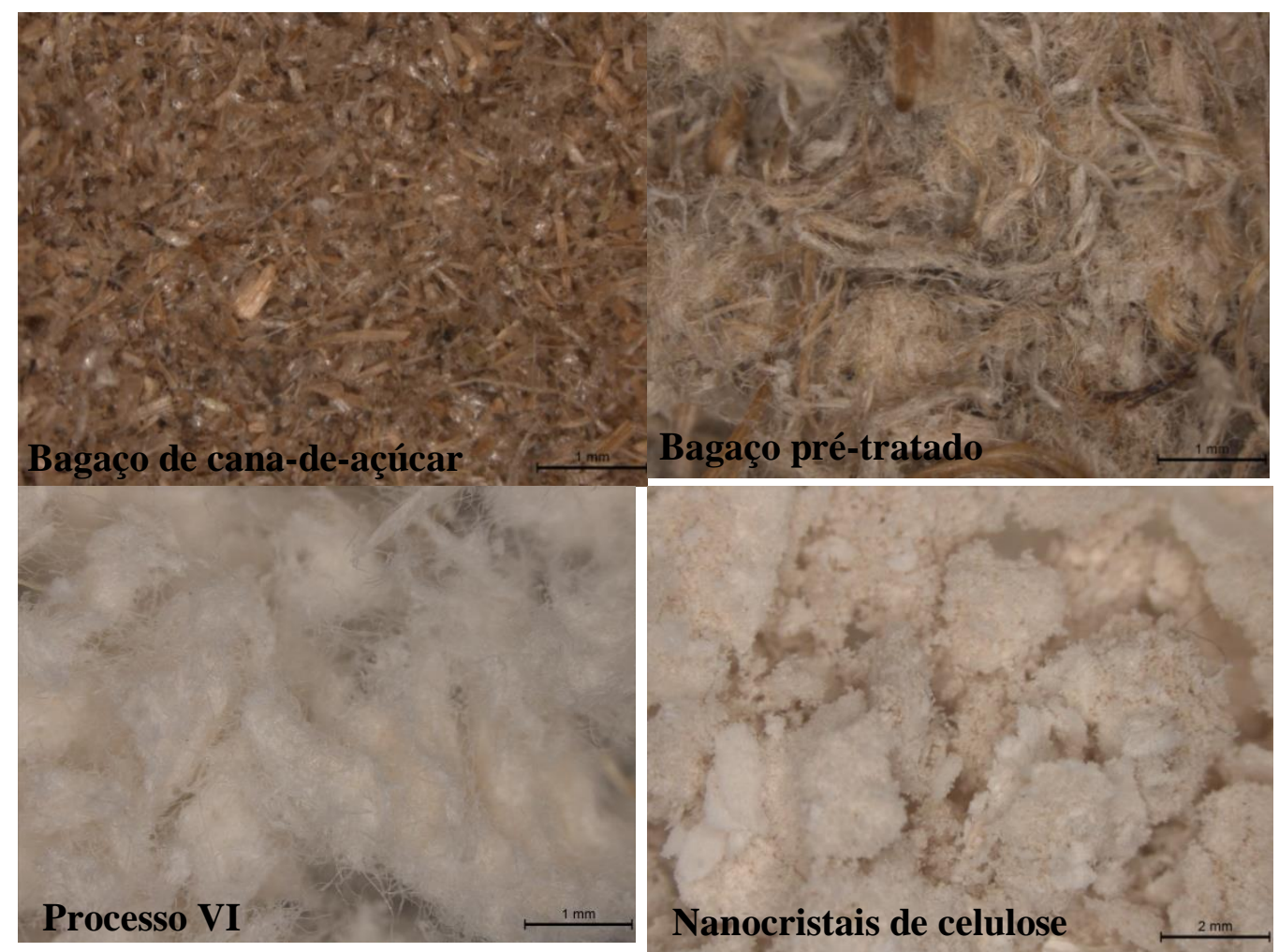

Figura 5: Imagens estereomicroscópio $(20$ x) de bagaço de-cana-de-açúcar do processo VI
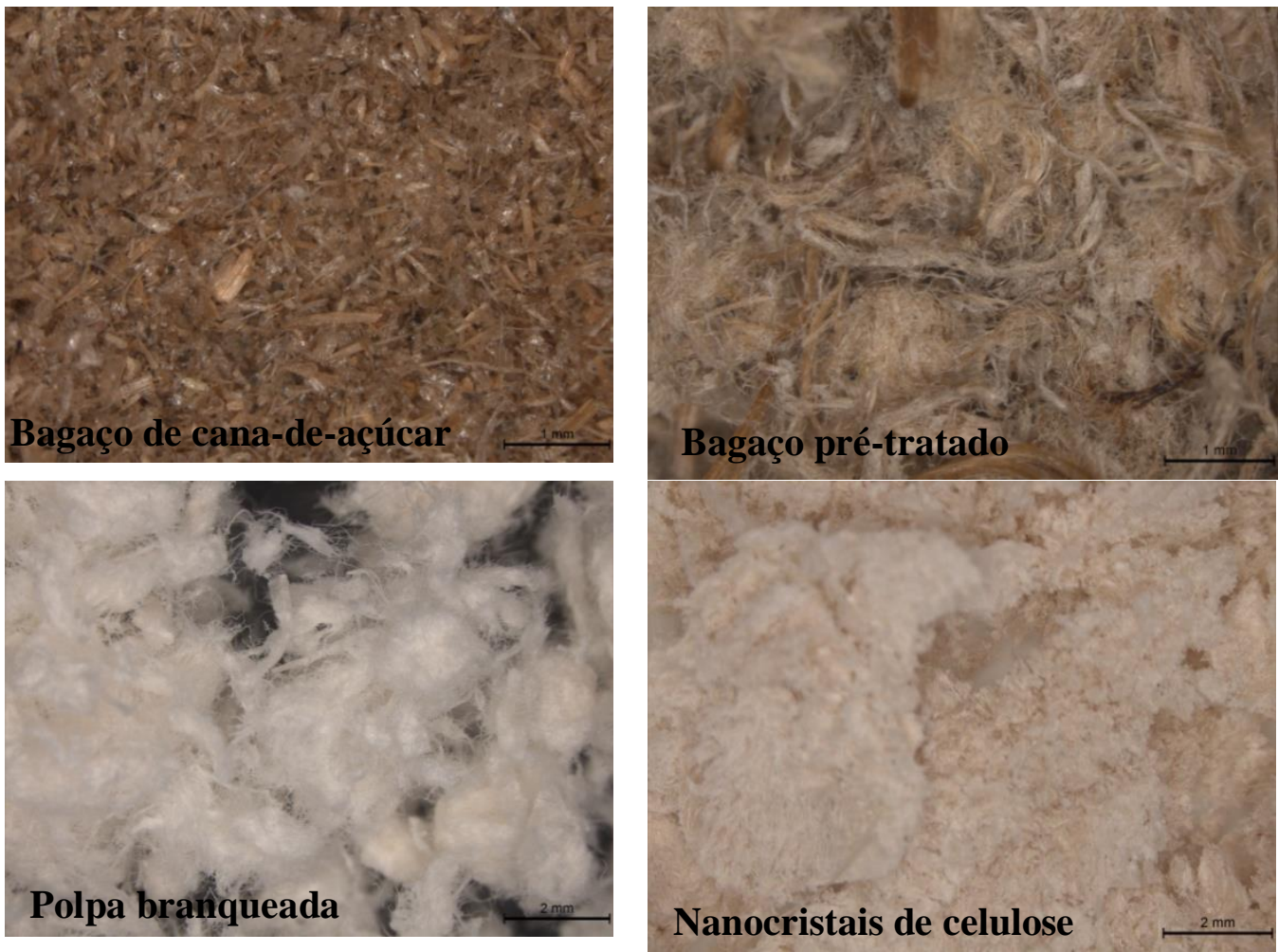

Figura 6: Imagens estereomicroscópio (20 x) de bagaço de-cana-de-açúcar do processo VII. 


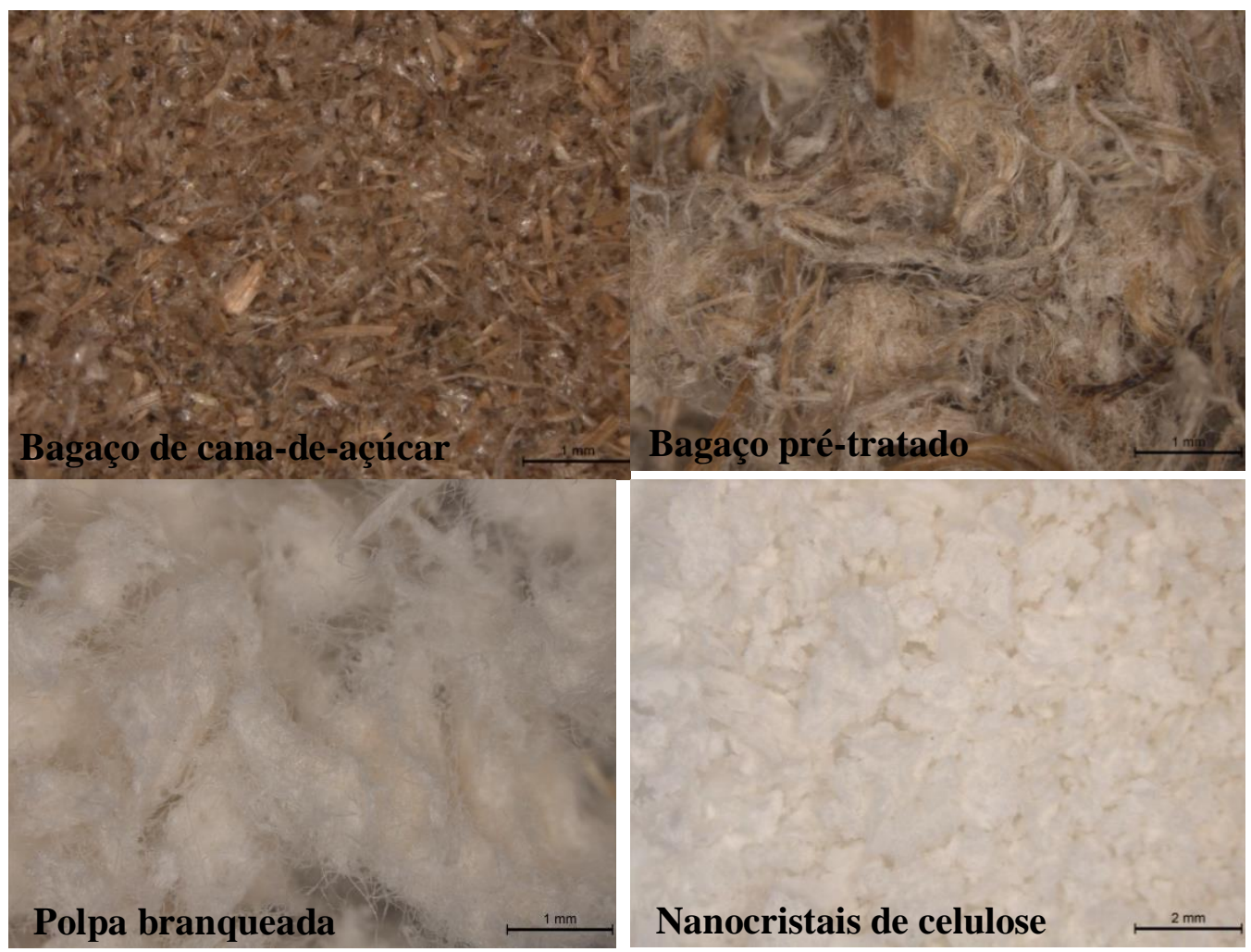

Figura 7: Imagens estereomicroscópio $(20$ x) de bagaço de-cana-de-açúcar do processo VIII.
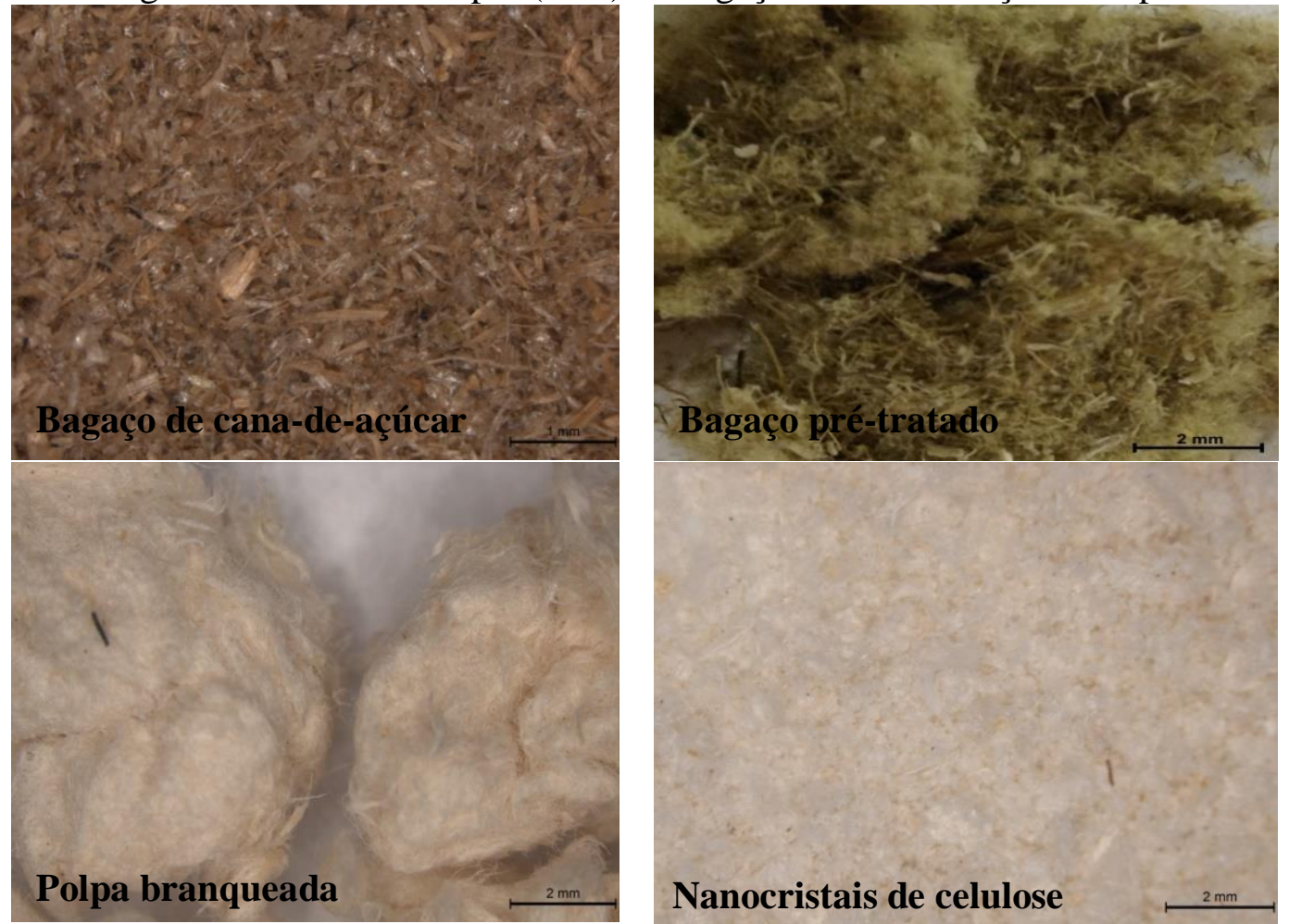

Figura 8: Imagens estereomicroscópio $(20$ x) de bagaço de-cana-de-açúcar do processo X. 

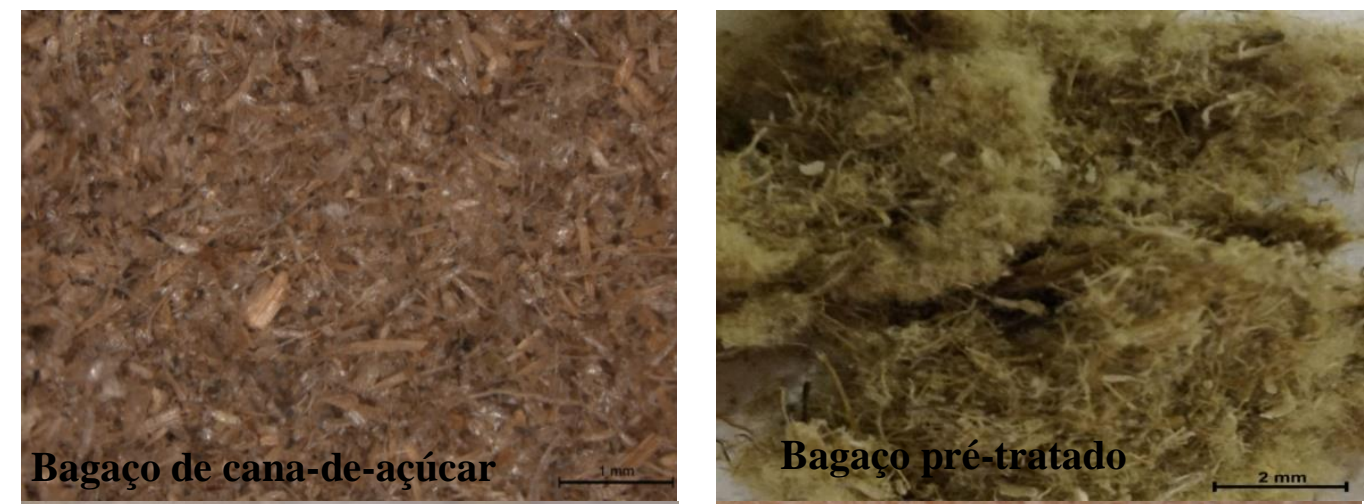

Polpa branqueada

Nanocristais de celulose

Figura 9: Imagens estereomicroscópio $(20$ x $)$ de bagaço de-cana-de-açúcar do processo XI.
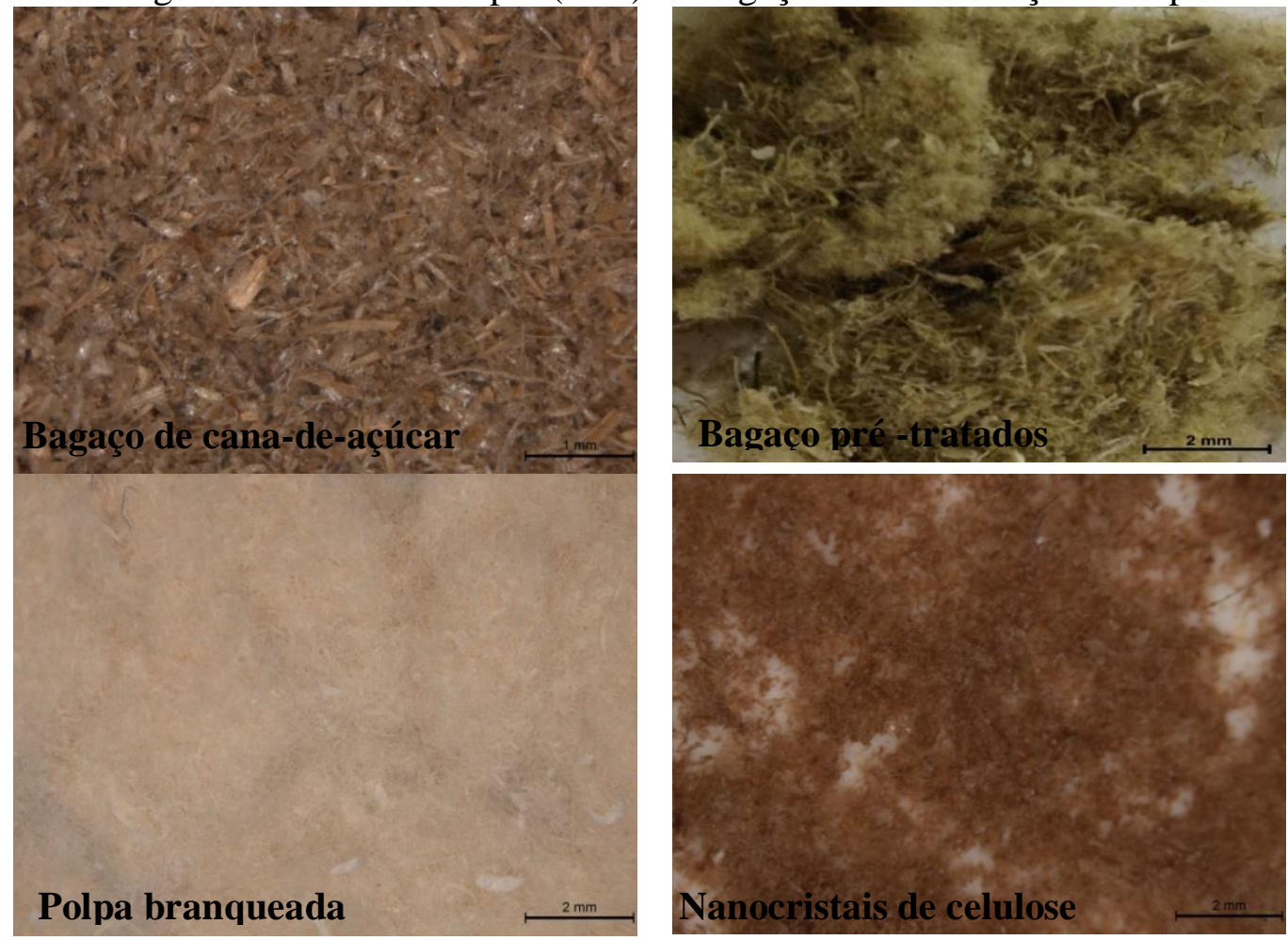

Figura 10: Imagens estereomicroscópio $(20$ x) de bagaço de-cana-de-açúcar do processo XII. 
APÊNDICE C: Caracterização das fibras e dos nanocristais de celulose por FTIR

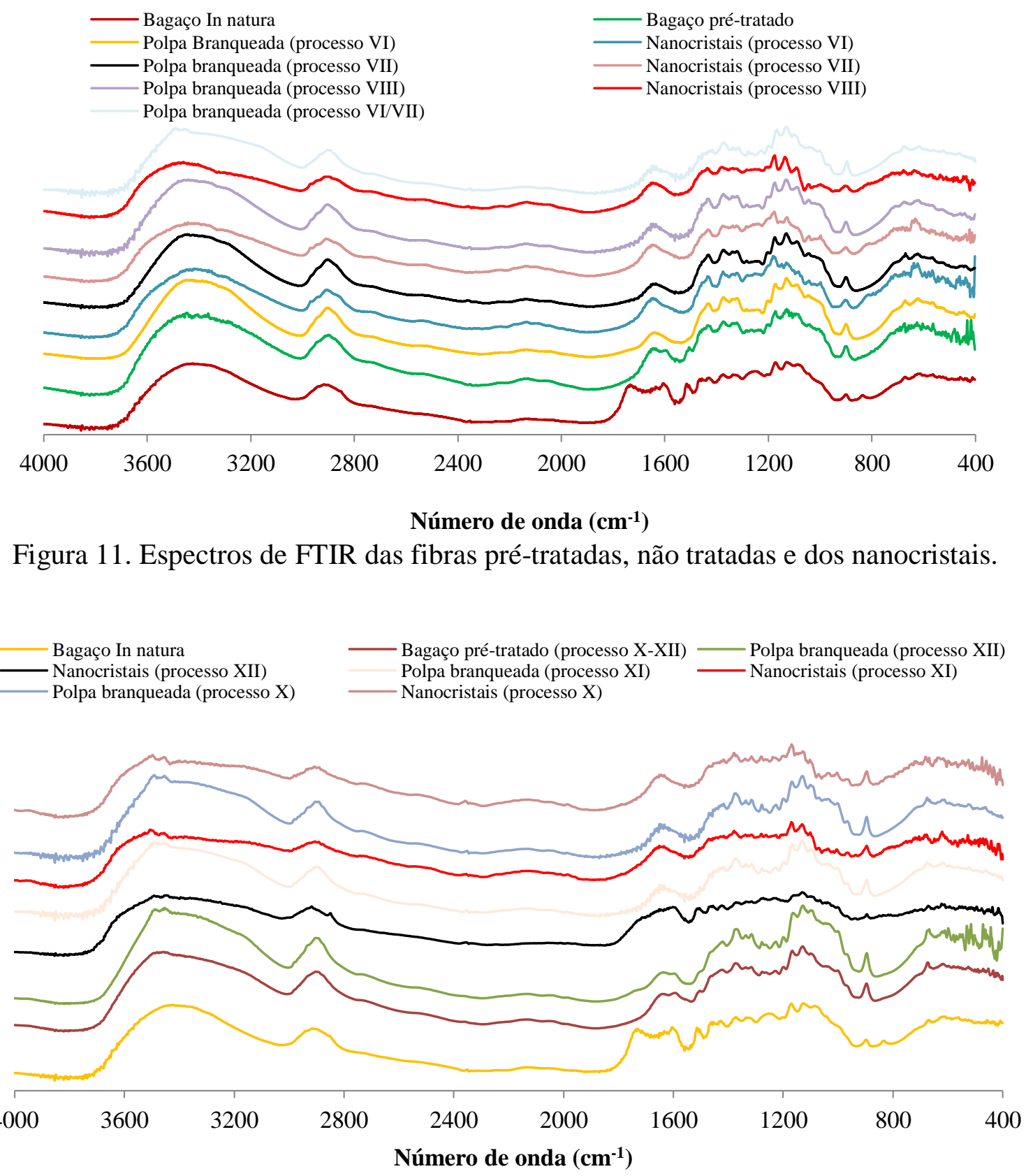

Figura 12. Espectros de FTIR das fibras pré-tratadas, não tratadas e dos nanocristais. 
APÊNDICE D: Caracterização das fibras tratadas por microscopia SEM
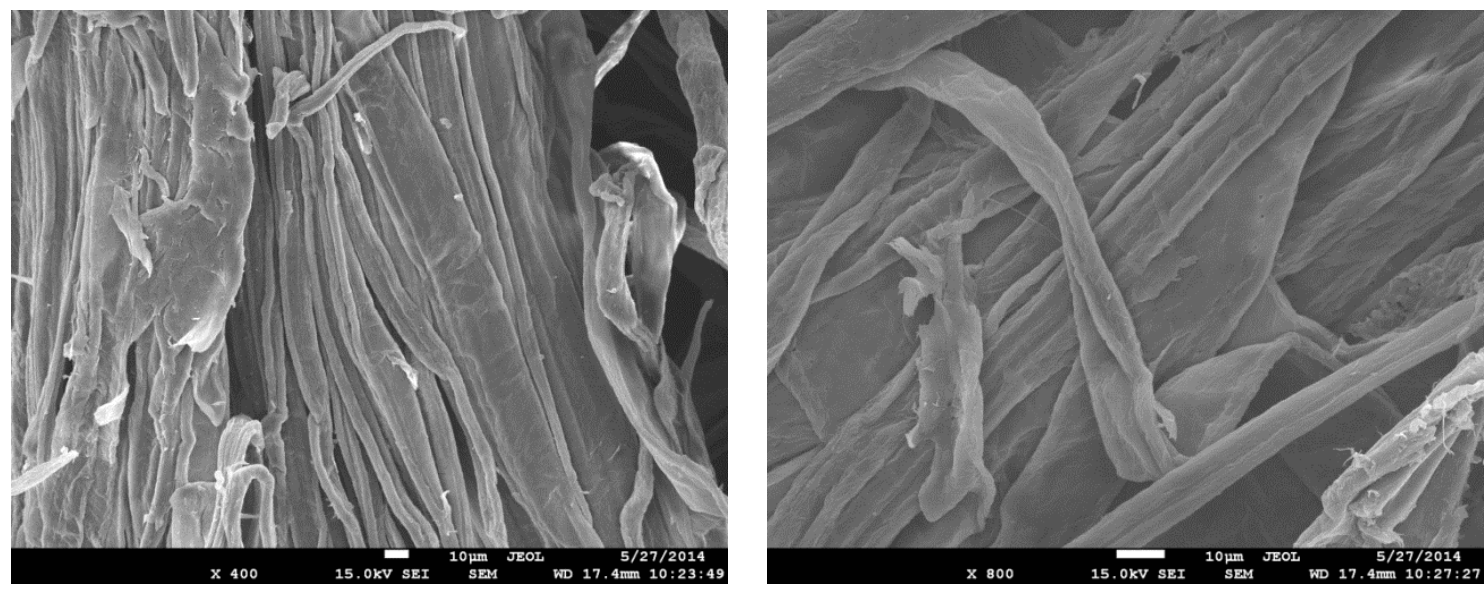

Figura 13: Micrografias obtidas em MEV do processo I: polpa branqueada.
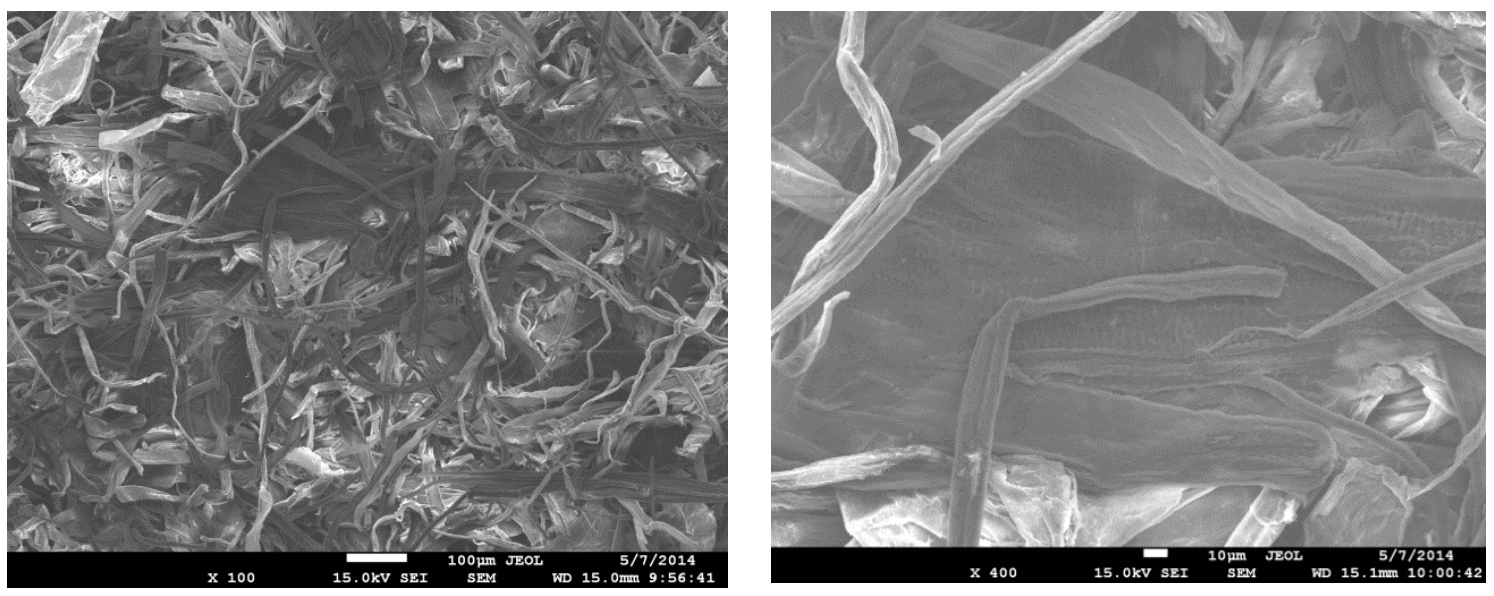

Figura 14: Micrografias obtidas em MEV do processo II: polpa branqueada
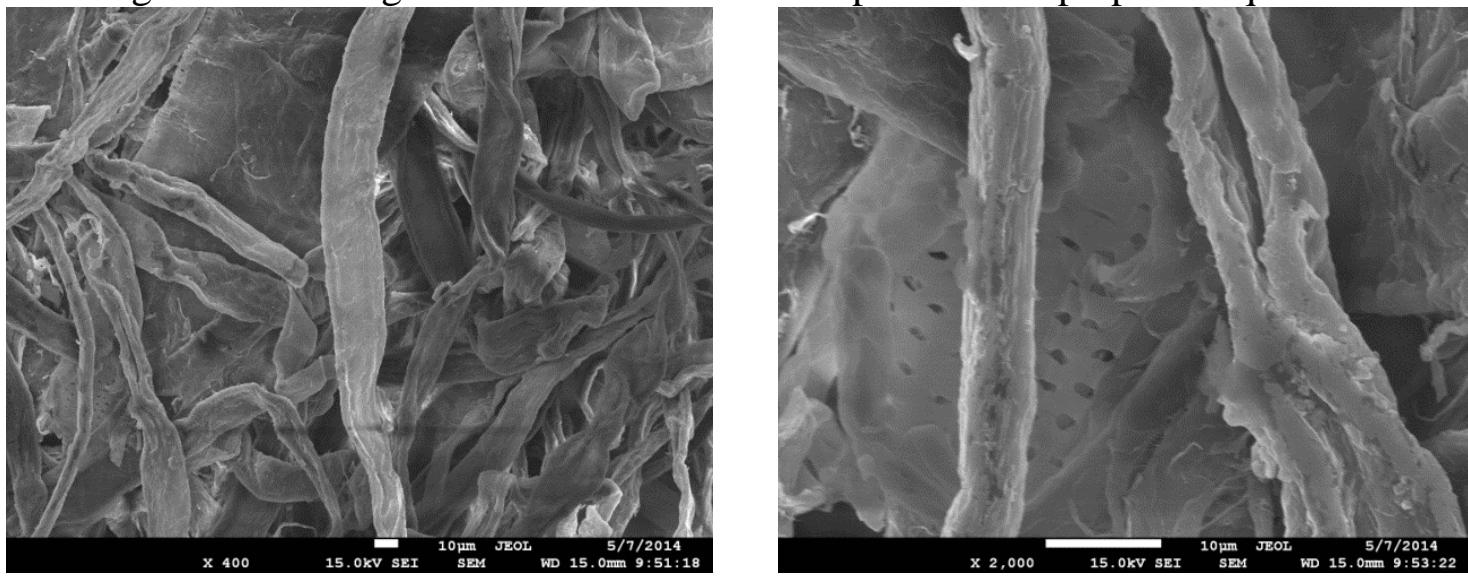

Figura 15: Micrografias obtidas em MEV do processo III: polpa branqueada 

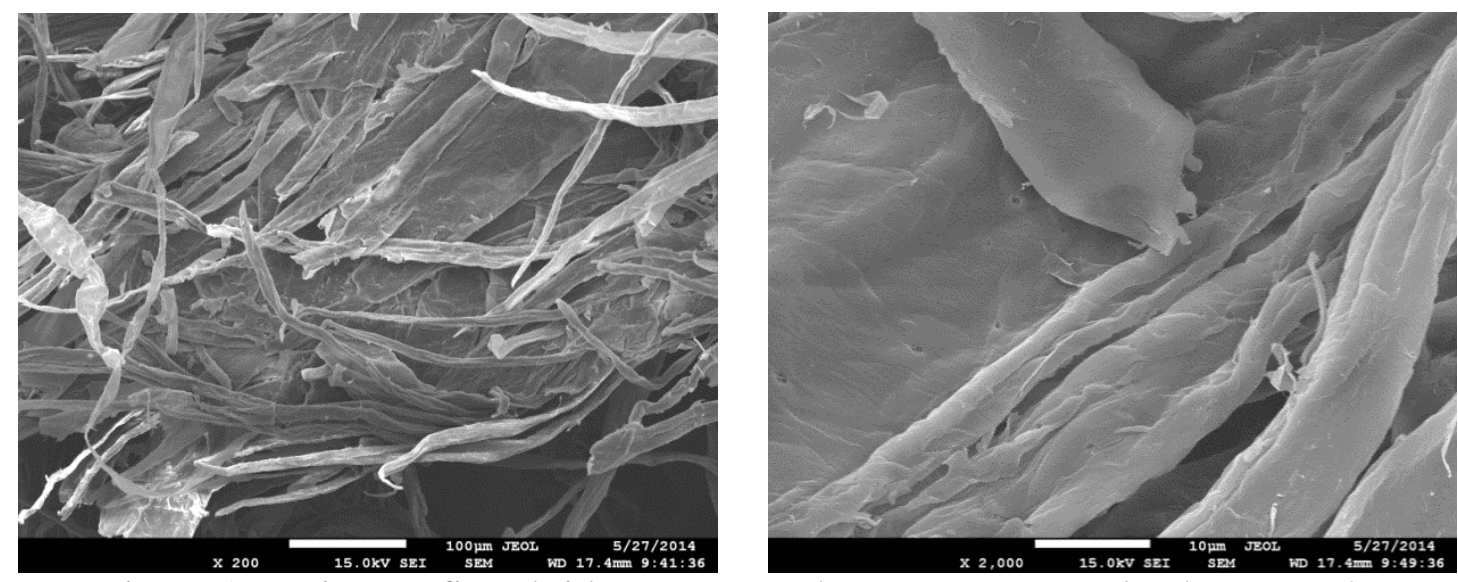

Figura 16: Micrografias obtidas em MEV do processo IV: polpa branqueada
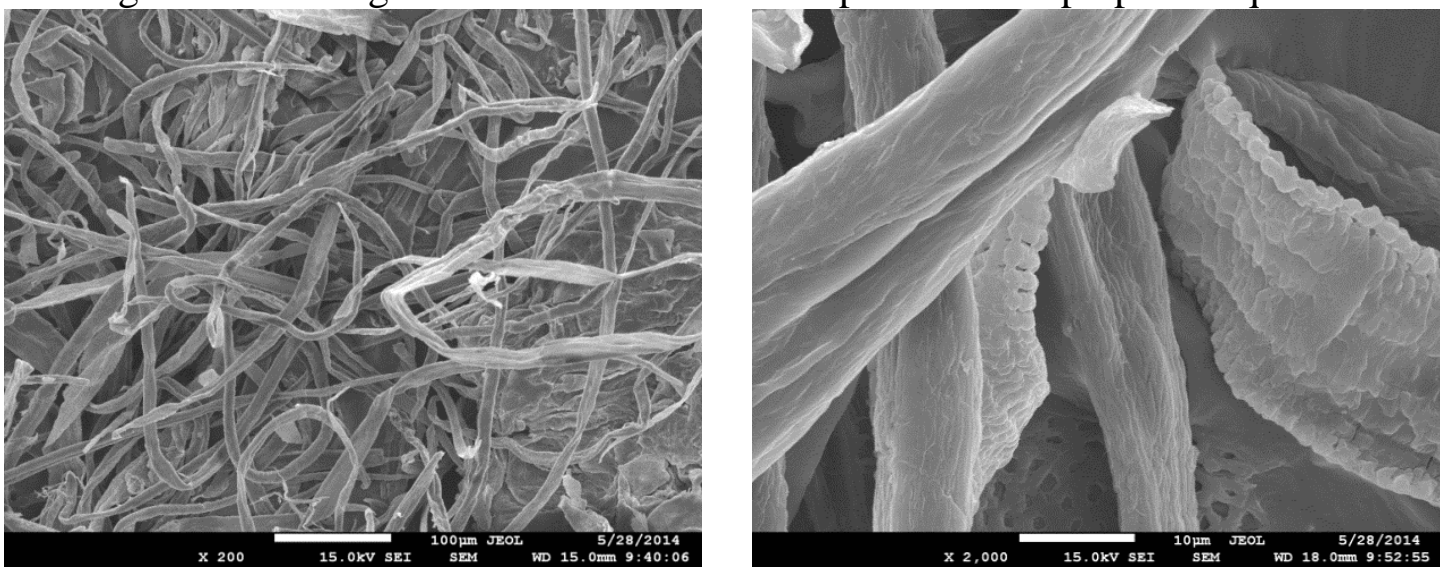

Figura 17: Micrografias obtidas em MEV do processo VI: polpa branqueada
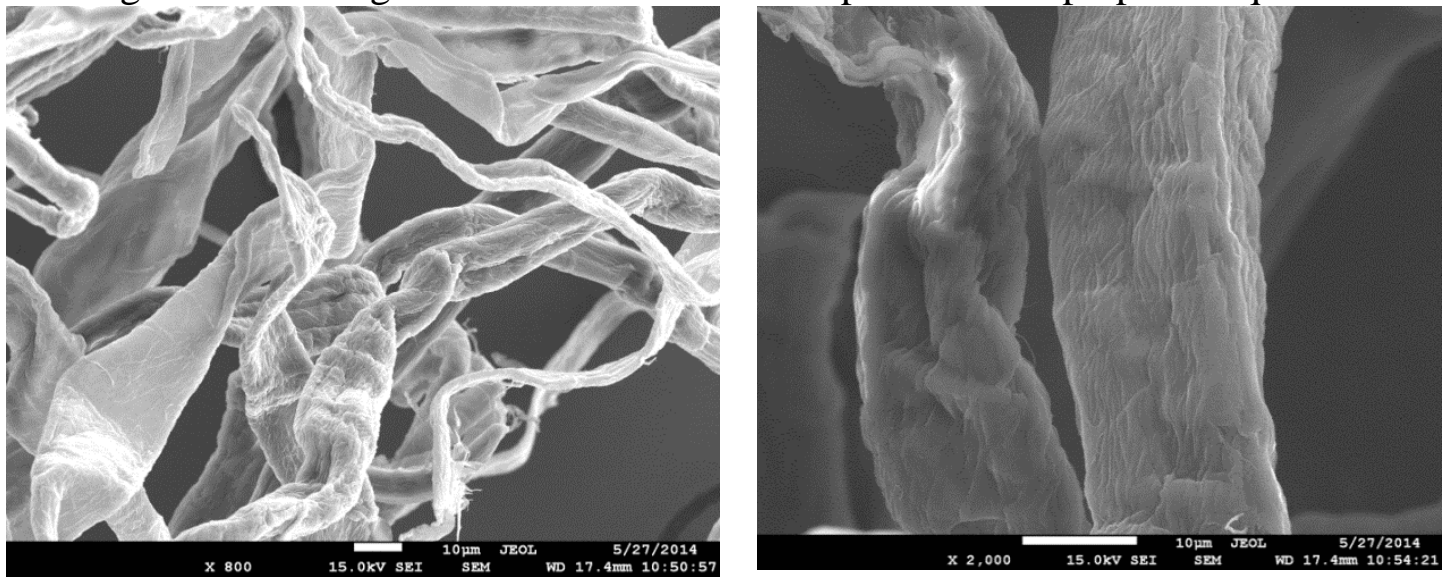

Figura 18: Micrografias obtidas em MEV do processo VII: polpa branqueada 

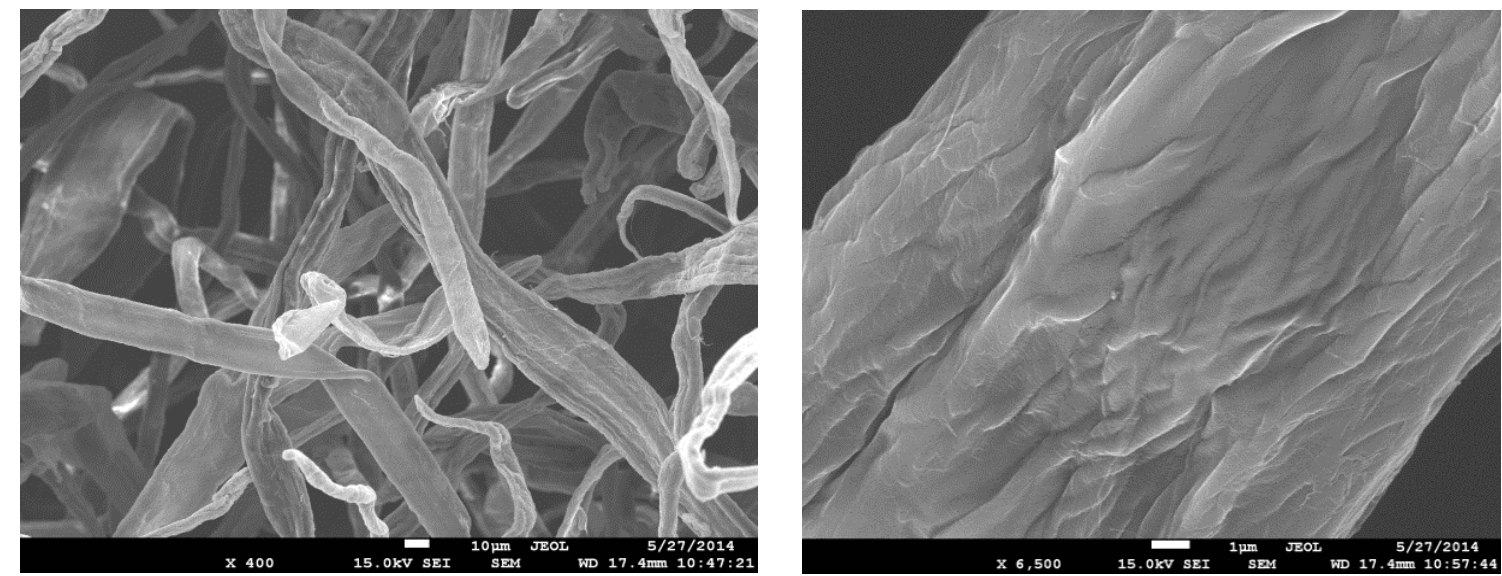

Figura 19: Micrografias obtidas em MEV do processo VIII: polpa branqueada.
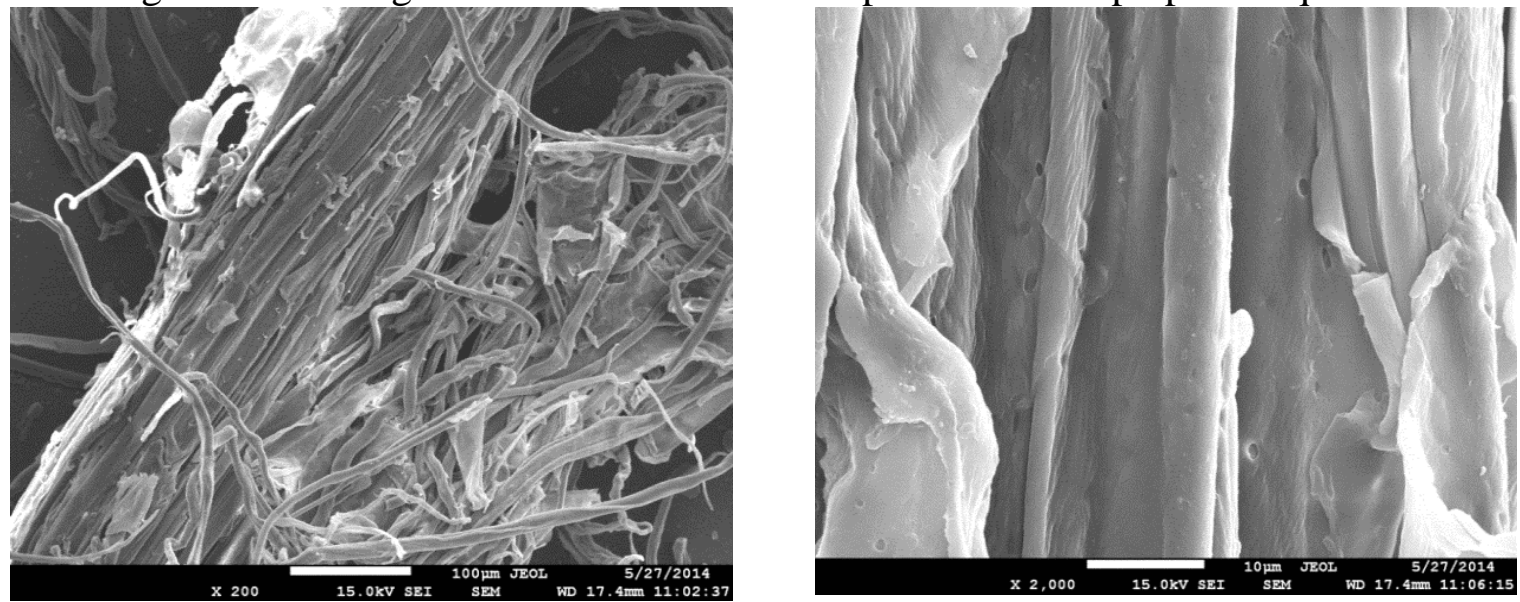

Figura 20: Micrografias obtidas em MEV do processo X: polpa branqueada
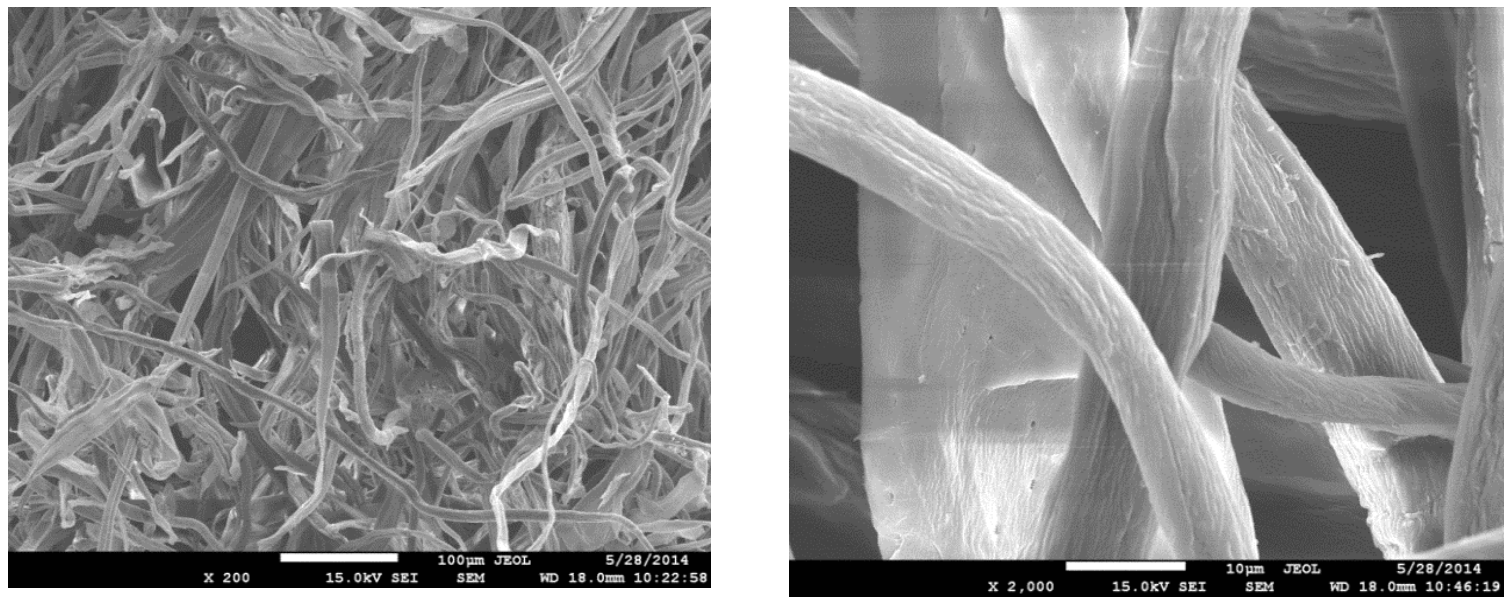

Figura 21: Micrografias obtidas em MEV do processo XI: polpa branqueada 

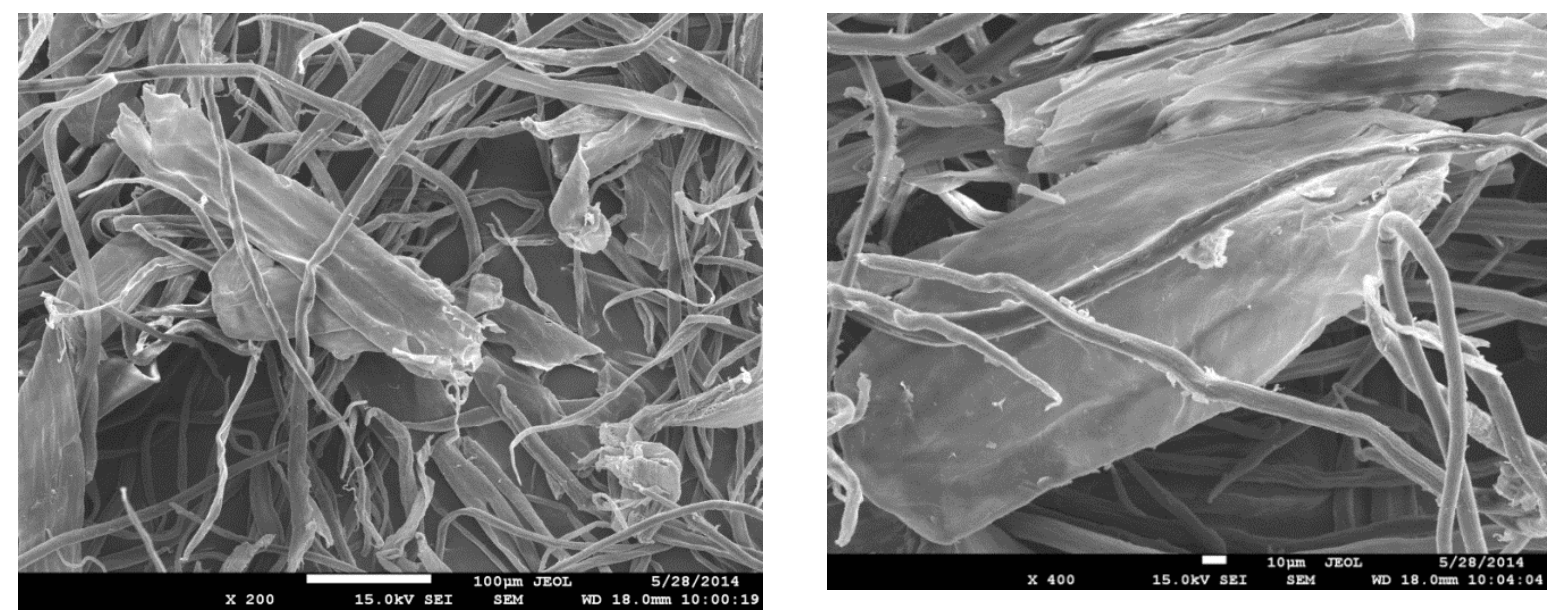

Figura 22: Micrografias obtidas em MEV do processo XII: polpa branqueada 
APÊNDICE E: Caracterização da holocelulose. $\alpha$-celulose e lignina por microscopia SEM

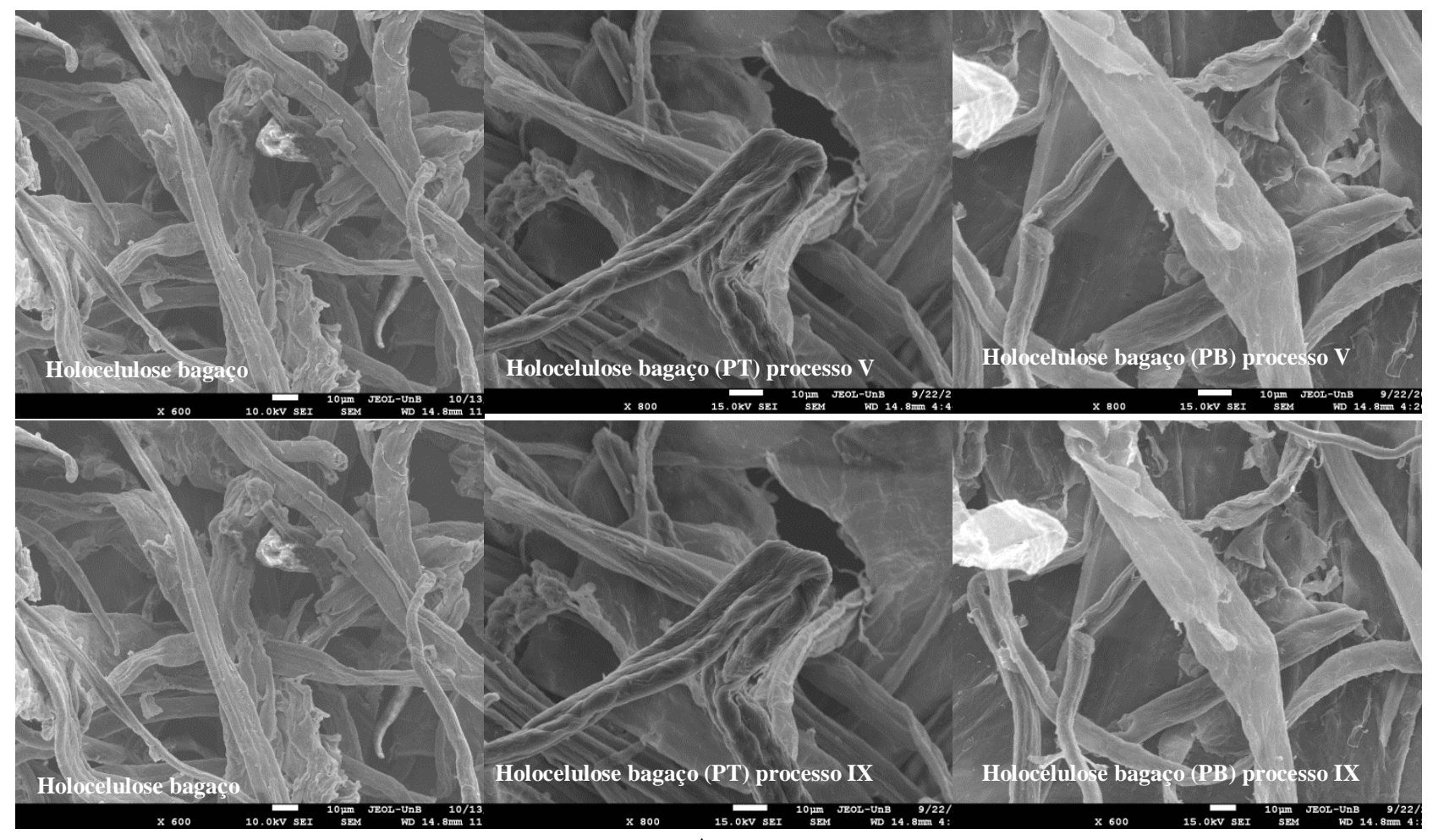

A

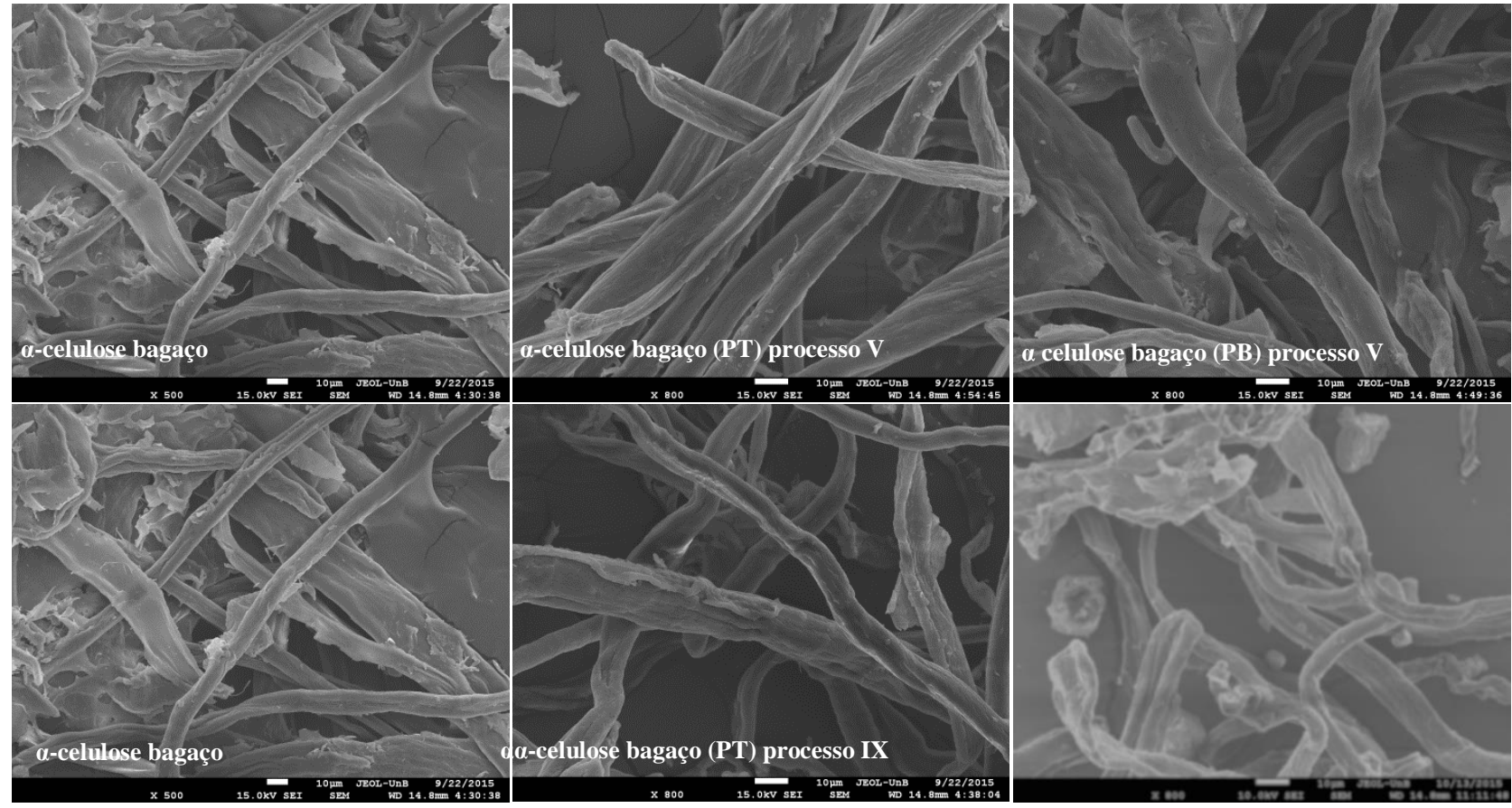

B

Figura 23: Micrografias obtidas em MEV das fibras holocelulose processo V e IX (A); (B); $\alpha$ celulose processo $\mathrm{V}$ e IX. 
APÊNDICE F: Caracterização por microscopia MET
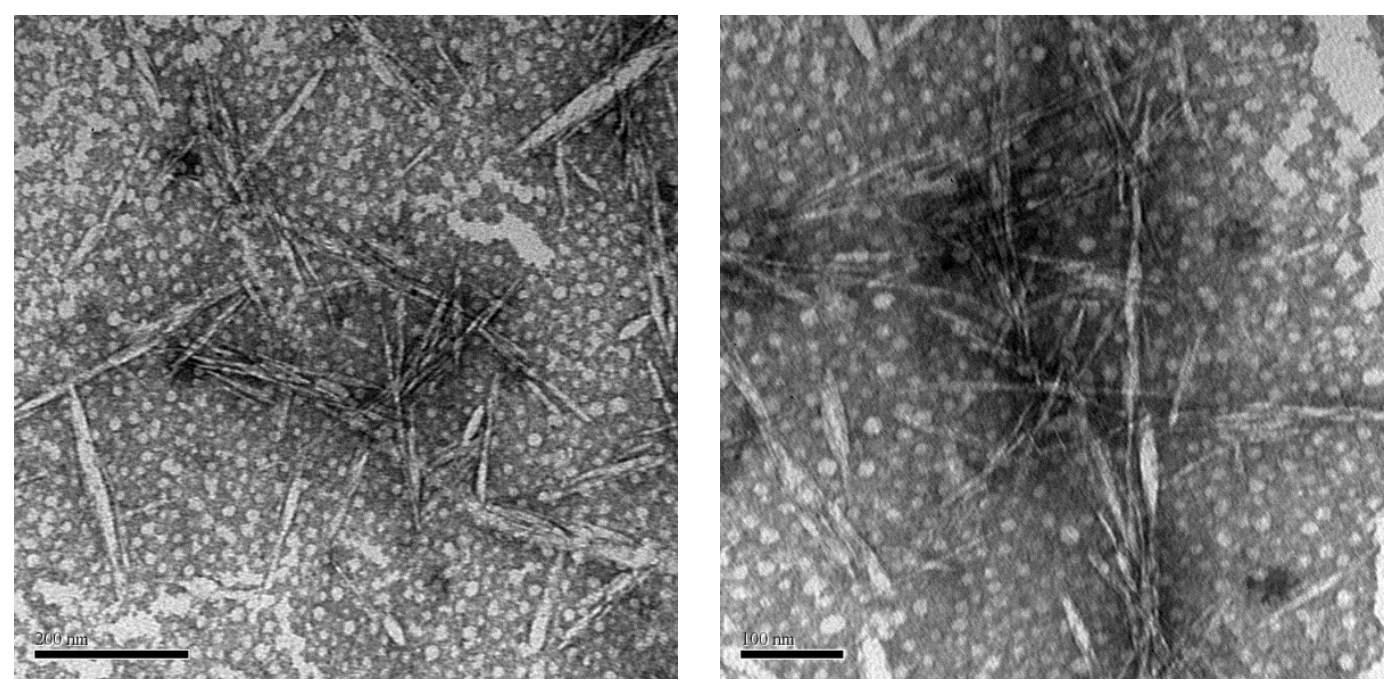

Figura 24. Microscopia eletrônica de transmissão dos nanocristais de celulose a partir de bagaço da cana de açúcar isolados com 30 minutos de hidrólise ácida (processo I).
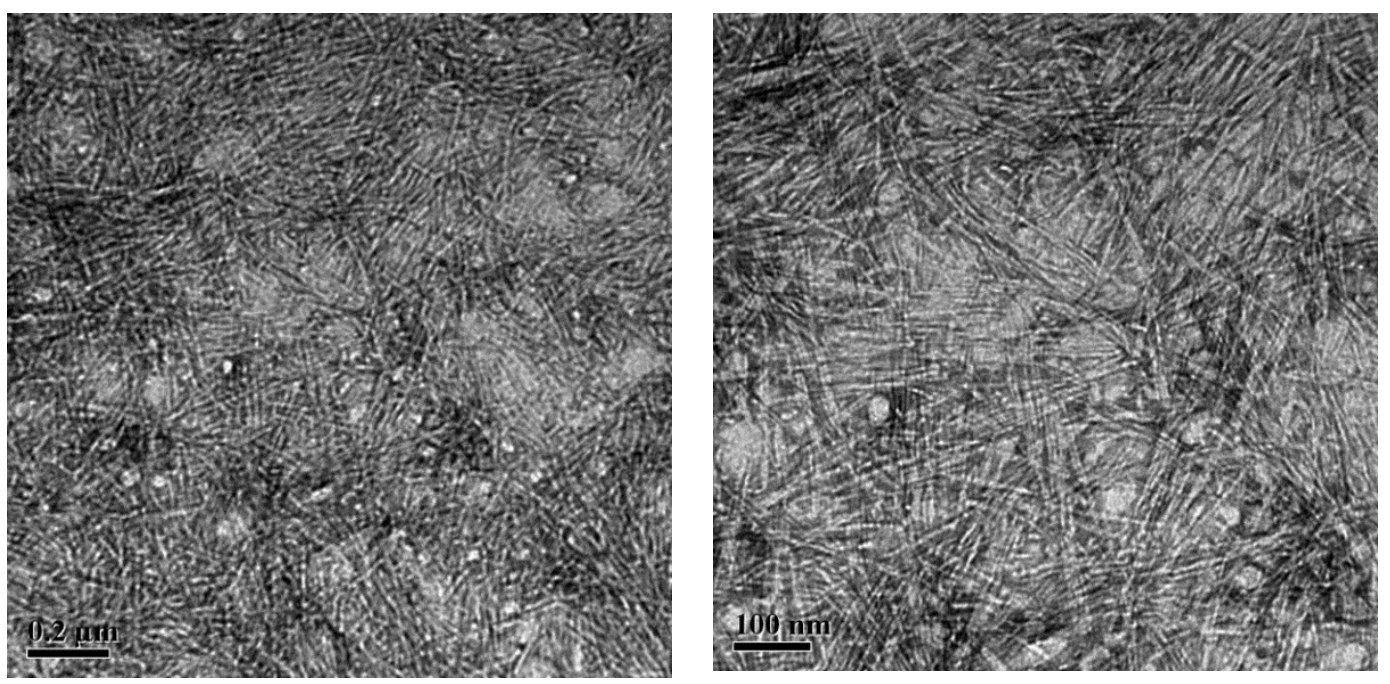

Figura 25. Microscopia eletrônica de transmissão dos nanocristais de celulose a partir de bagaço da cana de açúcar isolados com 30 minutos de hidrólise ácida (processo II). 

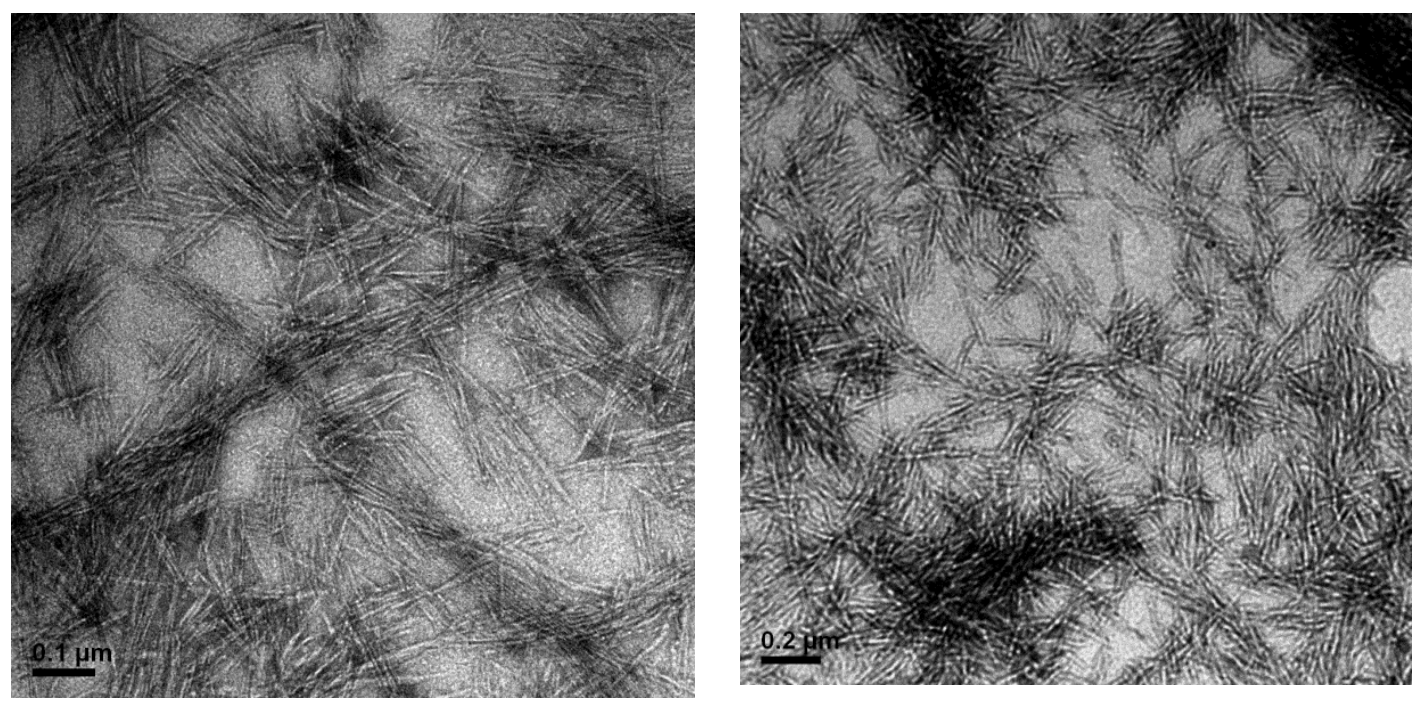

Figura 26. Microscopia eletrônica de transmissão dos nanocristais de celulose a partir de bagaço da cana de açúcar isolados com 30 minutos de hidrólise ácida (processo III).
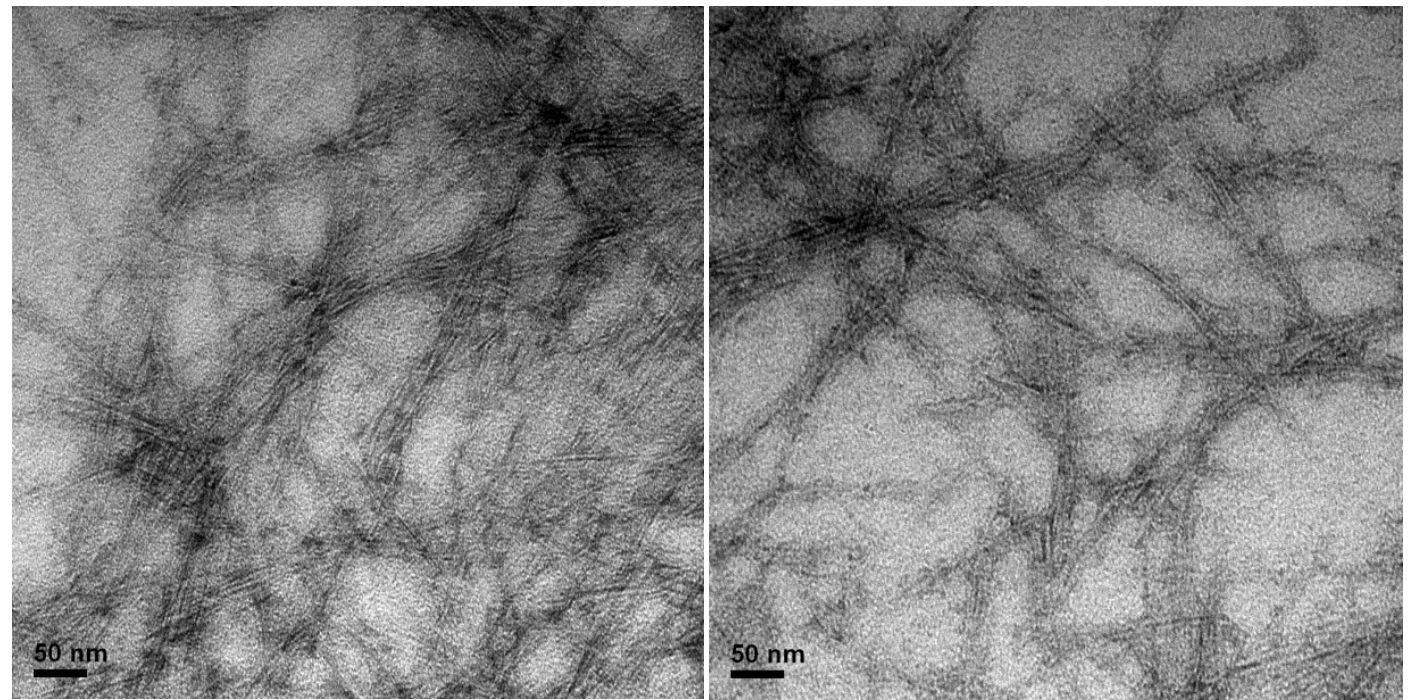

Figura 27. Microscopia eletrônica de transmissão dos nanocristais de celulose a partir de bagaço da cana de açúcar isolados com 30 minutos de hidrólise ácida (processo IV). 

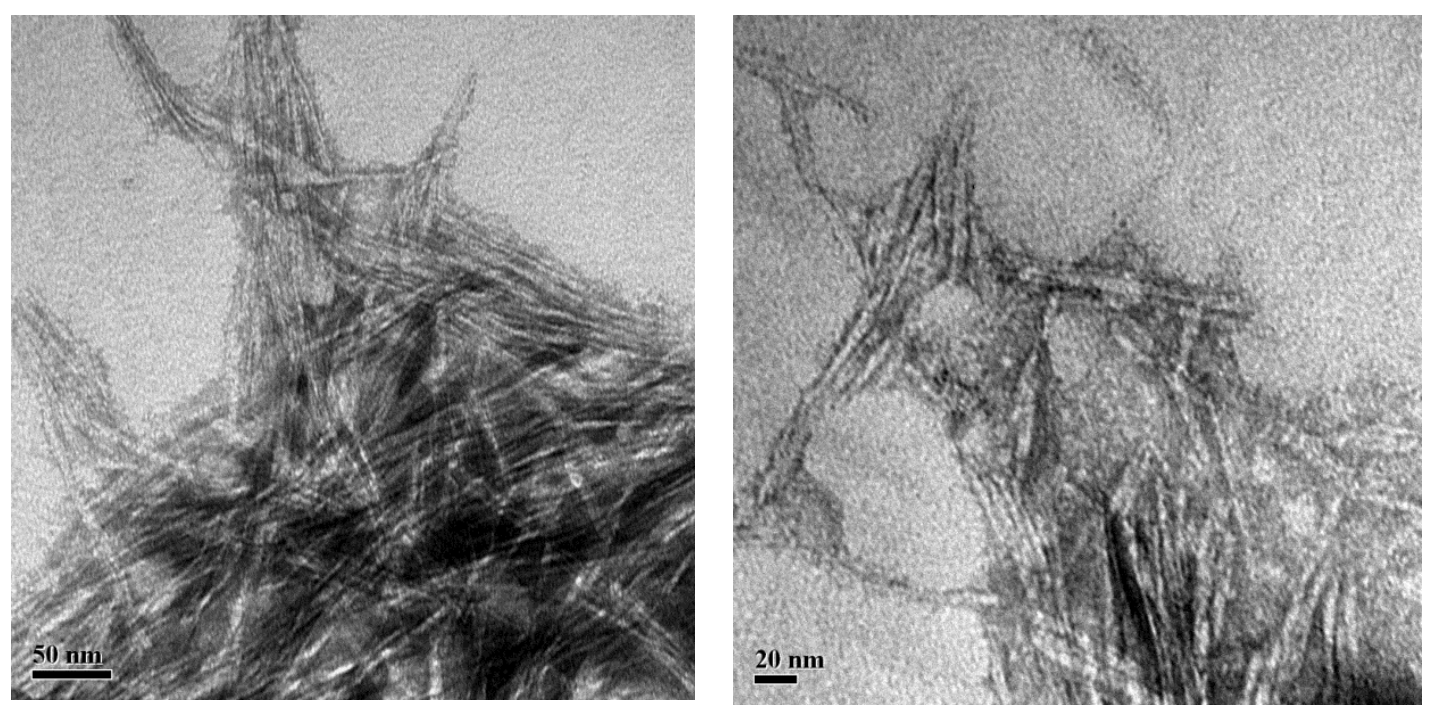

Figura 28. Microscopia eletrônica de transmissão dos nanocristais de celulose a partir de bagaço da cana de açúcar isolados com 30 minutos de hidrólise ácida (processo VI).
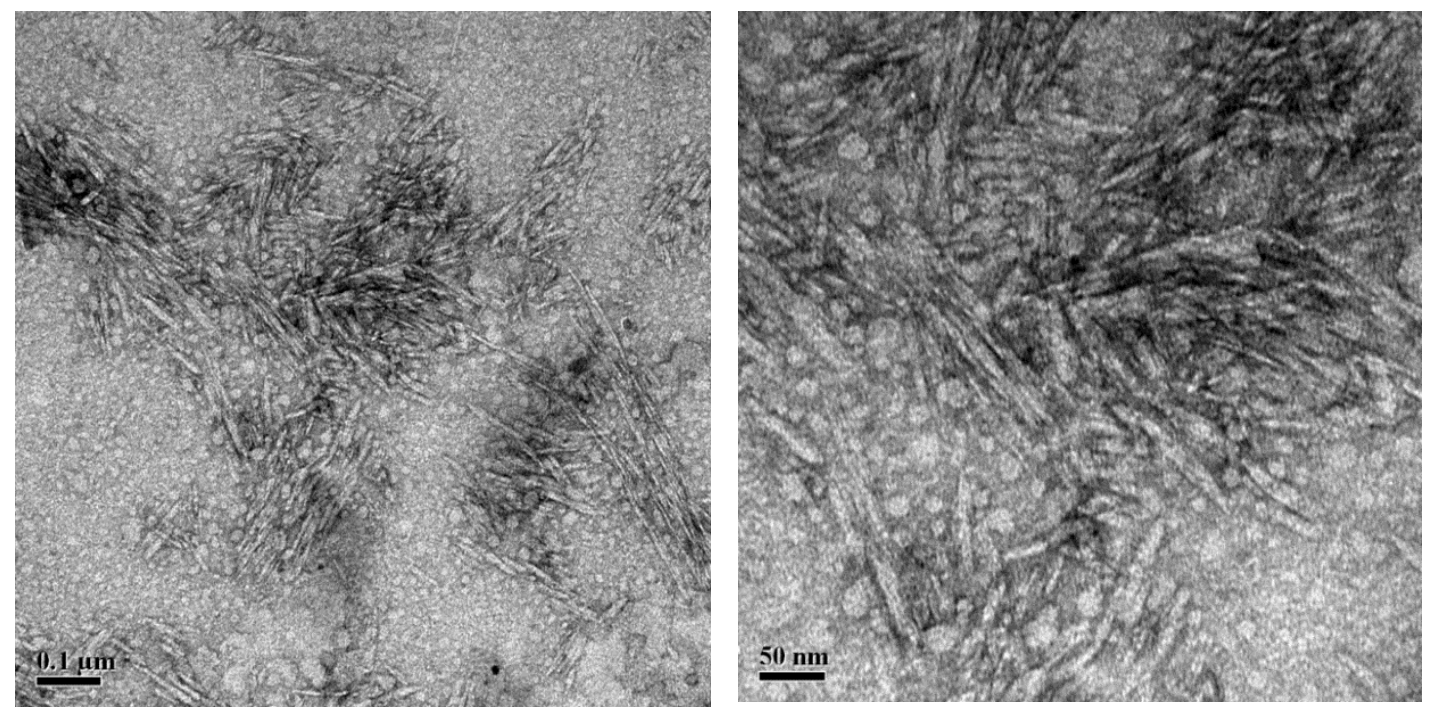

Figura 29. Microscopia eletrônica de transmissão dos nanocristais de celulose a partir de bagaço da cana de açúcar isolados com 30 minutos de hidrólise ácida (processo VII). 

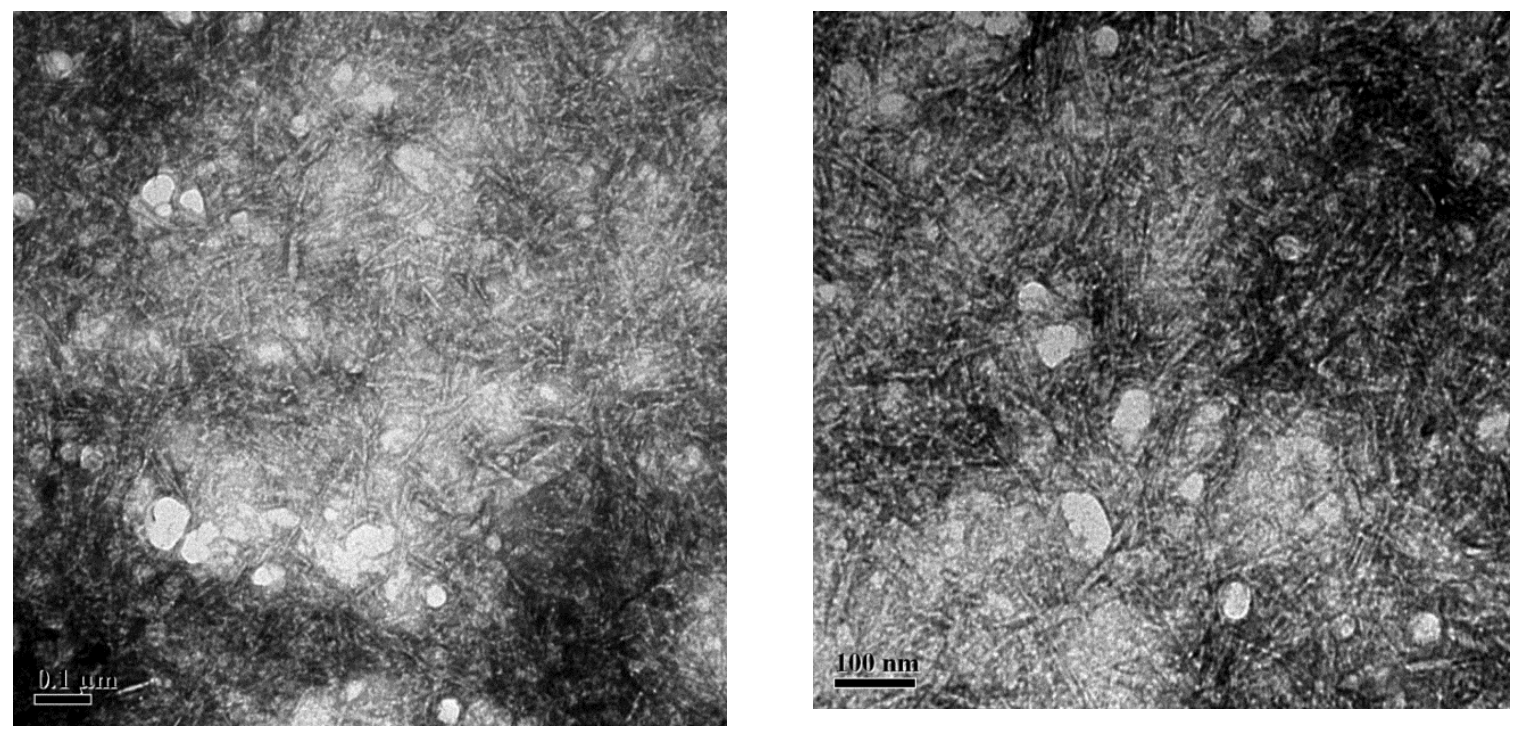

Figura 30. Microscopia eletrônica de transmissão dos nanocristais de celulose a partir de bagaço da cana de açúcar isolados com 30 minutos de hidrólise ácida (processo VIII).
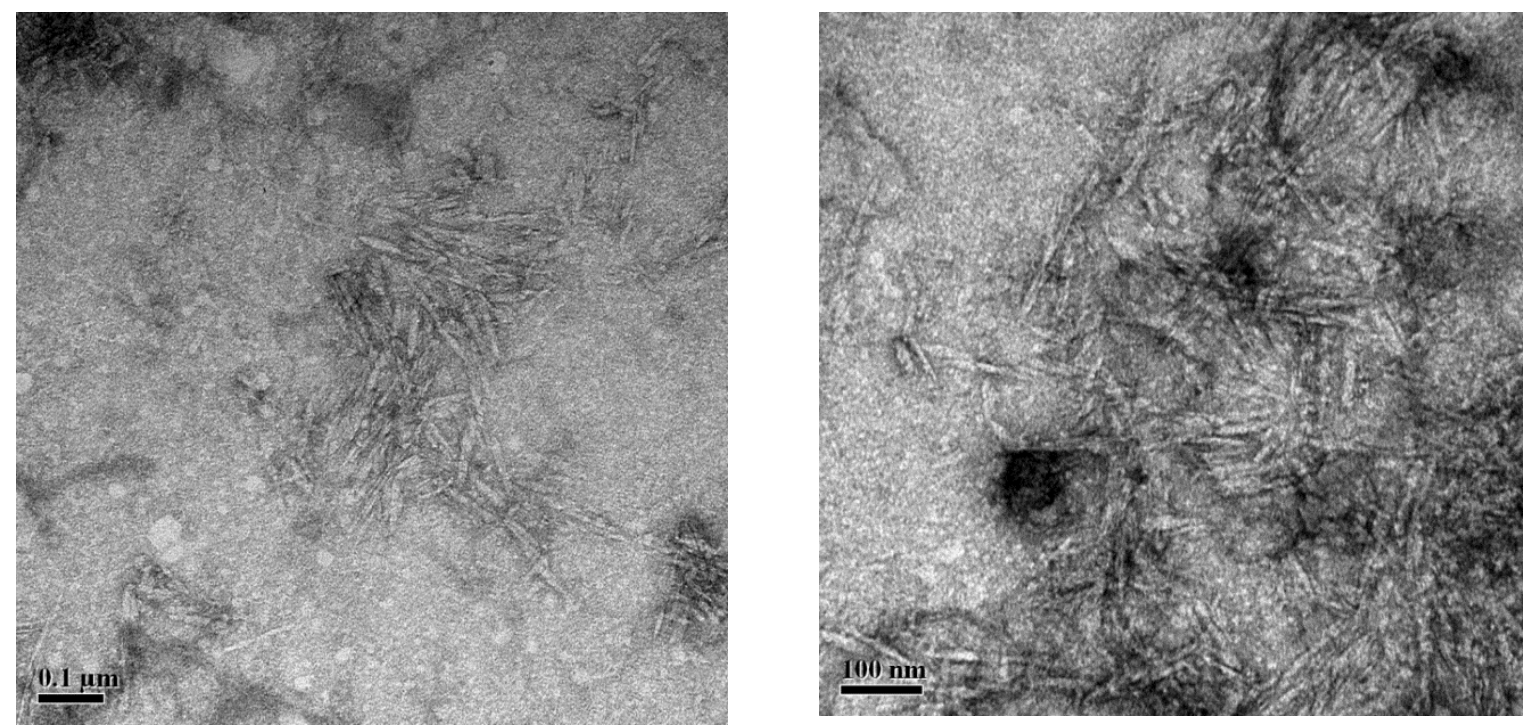

Figura 31. Microscopia eletrônica de transmissão dos nanocristais de celulose a partir de bagaço da cana de açúcar isolados com 30 minutos de hidrólise ácida (processo X). 

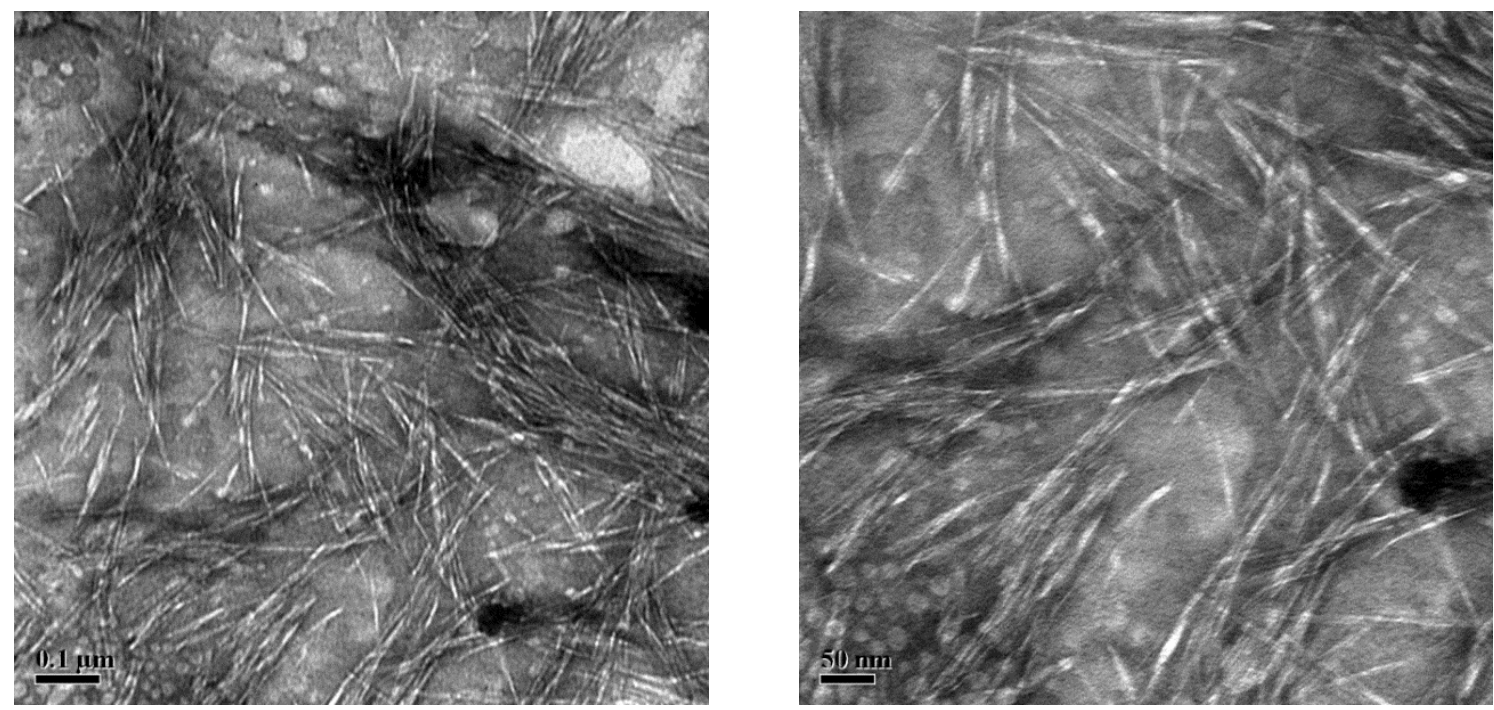

Figura 32. Microscopia eletrônica de transmissão dos nanocristais de celulose a partir de bagaço da cana de açúcar isolados com 30 minutos de hidrólise ácida (processo XI).
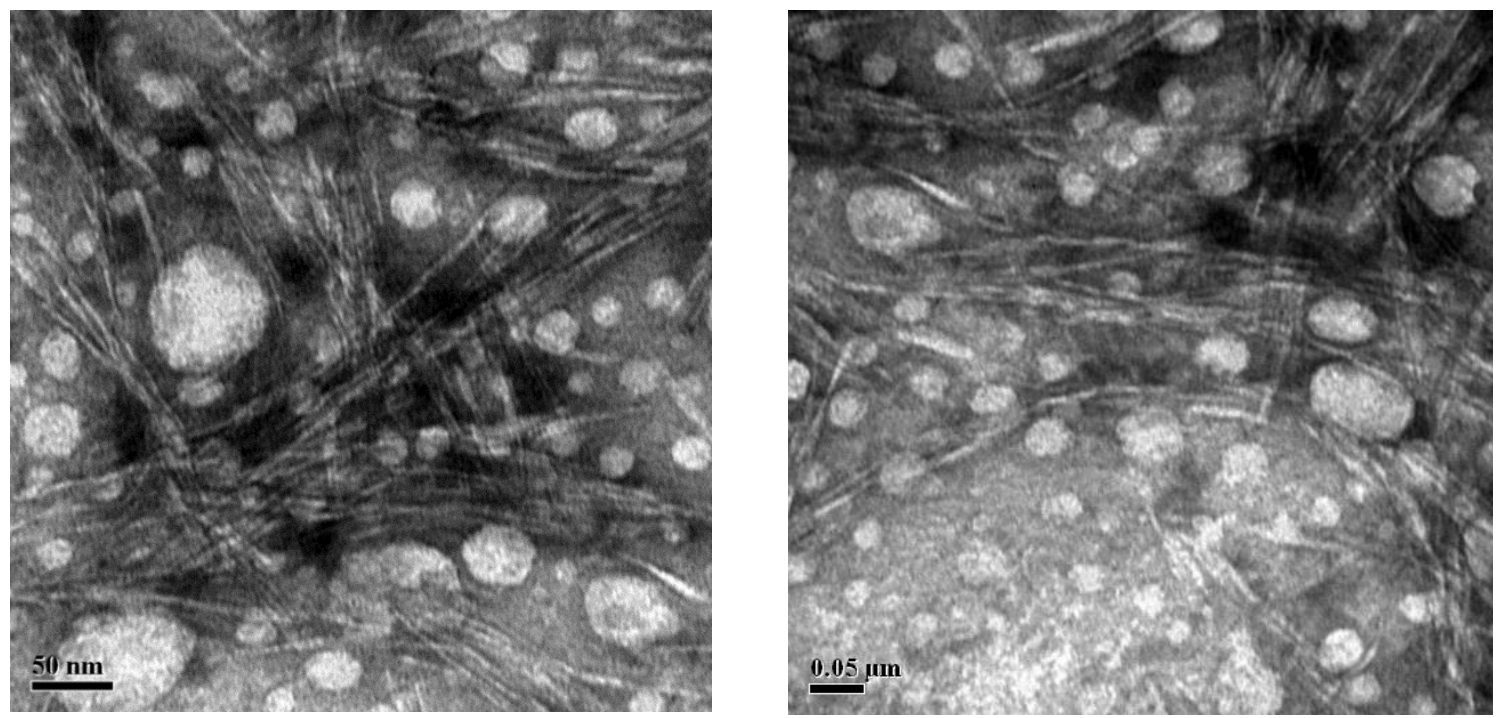

Figura 33. Microscopia eletrônica de transmissão dos nanocristais de celulose a partir de bagaço da cana de açúcar isolados com 30 minutos de hidrólise ácida (processo XII). 
APÊNDICE G: Caracterização por microscopia MEV
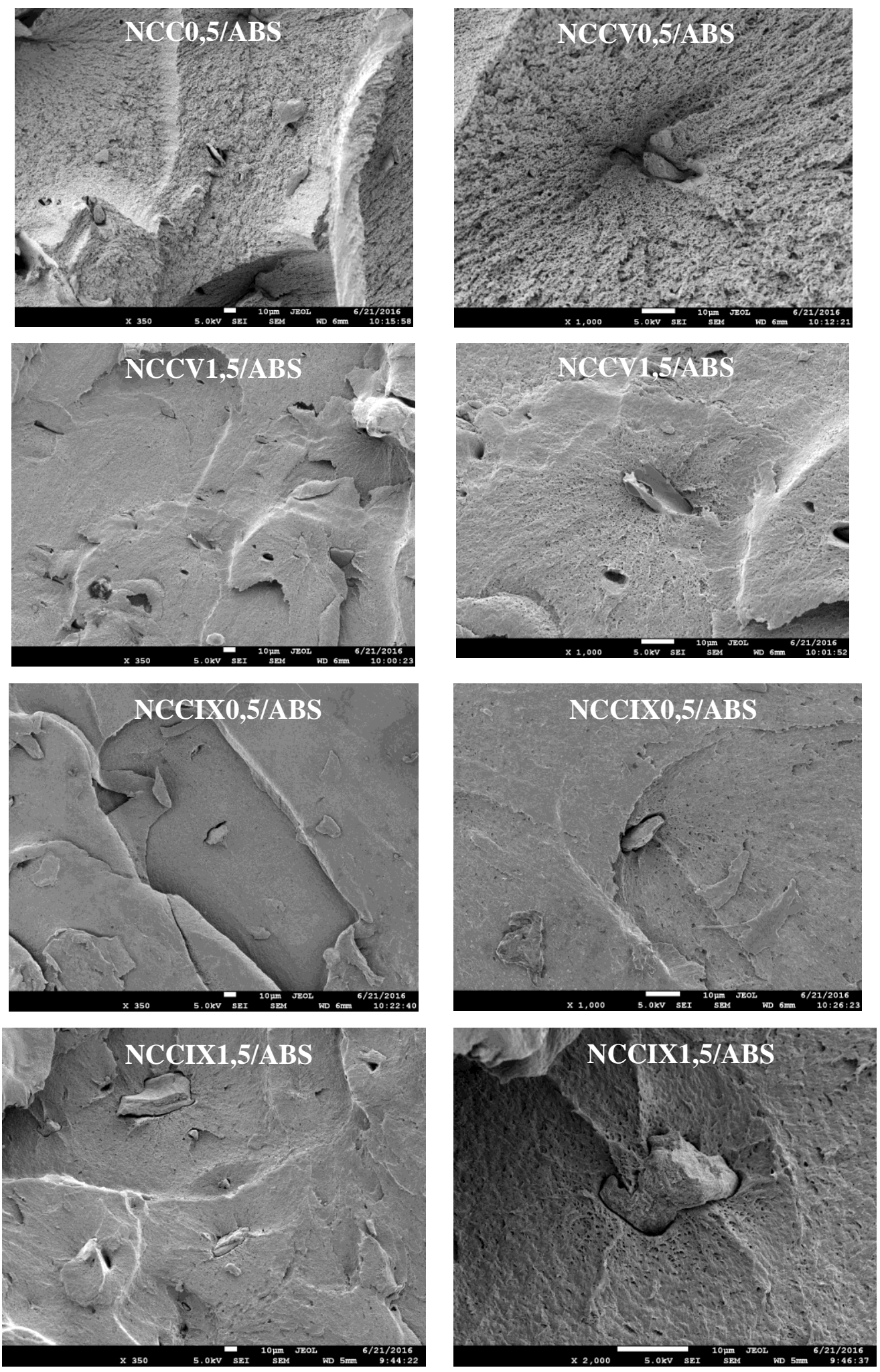
APÊNDICE H: Análise estatística

Tabela 1: ANOVA das propriedades mecânicas.

\begin{tabular}{|c|c|c|c|c|c|c|}
\hline & & Soma & $\mathrm{df}$ & Média & $\mathrm{F}$ & Sig. \\
\hline \multirow[t]{3}{*}{ Flexão } & & 243,375 & 6 & 40,563 & 38,112 & 0,000 \\
\hline & & 29,800 & 28 & 1,064 & & \\
\hline & Total & 273,175 & 34 & & & \\
\hline \multirow[t]{3}{*}{ FlexãoMOE } & & 90348,067 & 6 & 15058,011 & 8,412 & 0,000 \\
\hline & & 50121,132 & 28 & 1790,040 & & \\
\hline & Total & 140469,199 & 34 & & & \\
\hline \multirow[t]{3}{*}{ Tração } & & 14,518 & 6 & 2,420 & 7,981 & 0,000 \\
\hline & & 8,186 & 27 & 0,303 & & \\
\hline & Total & 22,704 & 33 & & & \\
\hline \multirow[t]{3}{*}{ TraçãoMOE } & & 1147347,691 & 6 & 191224,615 & 29,108 & 0,000 \\
\hline & & 177378,570 & 27 & 6569,577 & & \\
\hline & Total & 1324726,261 & 33 & & & \\
\hline
\end{tabular}


Tabela 2: Análise descritiva das propriedades mecânicas.

\begin{tabular}{|c|c|c|c|c|c|c|c|c|}
\hline \multirow{2}{*}{\multicolumn{2}{|c|}{ Variável dependente }} & & & \multirow{3}{*}{$\begin{array}{c}\text { Média (I-J) } \\
-6,16000^{*}\end{array}$} & \multirow{3}{*}{$\begin{array}{r}\text { Std. Erro } \\
.65247\end{array}$} & \multirow{3}{*}{$\begin{array}{l}\text { Sig. } \\
.000\end{array}$} & \multicolumn{2}{|c|}{ 95\% Intervalo de confiança } \\
\hline & & & & & & & Limite inferior & Limite superior \\
\hline \multirow[t]{6}{*}{ Flexão } & Dunnett & P5-0,5 & ABS Puro & & & & -7.9421 & -4.3779 \\
\hline & & P5-1,0 & ABS Puro & $-6,96000^{*}$ & .65247 & .000 & -8.7421 & -5.1779 \\
\hline & & P5-1,5 & ABS Puro & $-8,64000^{*}$ & .65247 & .000 & -10.4221 & -6.8579 \\
\hline & & P9-0,5 & ABS Puro & $-3,28000^{*}$ & .65247 & .000 & -5.0621 & -1.4979 \\
\hline & & $\mathrm{P} 9-1,0$ & ABS Puro & $-6,22000^{*}$ & .65247 & .000 & -8.0021 & -4.4379 \\
\hline & & $\mathrm{P} 9-1,5$ & ABS Puro & $-6,32000^{*}$ & .65247 & .000 & -8.1021 & -4.5379 \\
\hline \multirow[t]{6}{*}{ FlexãoMOE } & Dunnett & P5-0,5 & ABS Puro & -72.00000 & 26.75848 & .055 & -145.0848 & 1.0848 \\
\hline & & $\mathrm{P} 5-1,0$ & ABS Puro & -1.24000 & 26.75848 & 1.000 & -74.3248 & 71.8448 \\
\hline & & P5-1,5 & ABS Puro & -12.04000 & 26.75848 & .995 & -85.1248 & 61.0448 \\
\hline & & P9-0,5 & ABS Puro & $108,74000^{*}$ & 26.75848 & .002 & 35.6552 & 181.8248 \\
\hline & & $\mathrm{P} 9-1,0$ & ABS Puro & 39.72000 & 26.75848 & .492 & -33.3648 & 112.8048 \\
\hline & & P9-1,5 & ABS Puro & 8.88000 & 26.75848 & .999 & -64.2048 & 81.9648 \\
\hline \multirow[t]{6}{*}{ Tração } & Dunnett & P5-0,5 & ABS Puro & .75000 & .36937 & .210 & -.2625 & 1.7625 \\
\hline & & P5-1,0 & ABS Puro & .52000 & .34824 & .490 & -.4346 & 1.4746 \\
\hline & & P5-1,5 & ABS Puro & -.26000 & .34824 & .941 & -1.2146 & .6946 \\
\hline & & P9-0,5 & ABS Puro & .94000 & .34824 & .055 & -.0146 & 1.8946 \\
\hline & & P9-1,0 & ABS Puro & -.36000 & .34824 & .802 & -1.3146 & .5946 \\
\hline & & P9-1,5 & ABS Puro & $-1,06000^{*}$ & .34824 & .025 & -2.0146 & -.1054 \\
\hline \multirow[t]{6}{*}{ TraçãoMOE } & Dunnett & P5-0,5 & ABS Puro & $317,13000^{*}$ & 54.37196 & .000 & 168.0890 & 466.1710 \\
\hline & & P5-1,0 & ABS Puro & $380,94000^{*}$ & 51.26237 & .000 & 240.4228 & 521.4572 \\
\hline & & P5-1,5 & ABS Puro & $251,82000^{*}$ & 51.26237 & .000 & 111.3028 & 392.3372 \\
\hline & & P9-0,5 & ABS Puro & $603,48000^{*}$ & 51.26237 & .000 & 462.9628 & 743.9972 \\
\hline & & P9-1,0 & ABS Puro & $215,48000^{*}$ & 51.26237 & .001 & 74.9628 & 355.9972 \\
\hline & & P9-1,5 & ABS Puro & 102.40000 & 51.26237 & .222 & -38.1172 & 242.9172 \\
\hline
\end{tabular}


Tabela 3: Testes entre as propriedades mecânicas.

\begin{tabular}{|c|c|c|c|c|c|c|}
\hline Fonte & & Tipo III Soma & $\mathrm{df}$ & Média & $\mathrm{F}$ & Sig. \\
\hline \multirow{4}{*}{$\begin{array}{l}\text { Modelo } \\
\text { corrigido }\end{array}$} & flexão & $75,248^{\mathrm{a}}$ & 5 & 15.050 & 12.859 & .000 \\
\hline & flexãoMOE & $82794,806^{\mathrm{b}}$ & 5 & 16558.961 & 8.270 & .000 \\
\hline & tração & $14,500^{\mathrm{c}}$ & 5 & 2.900 & 11.142 & .000 \\
\hline & traçãoMOE & $733018,632^{\mathrm{d}}$ & 5 & 146603.726 & 19.028 & .000 \\
\hline \multirow[t]{4}{*}{ Interceptar } & flexão & 93041.169 & 1 & 93041.169 & 79498.732 & .000 \\
\hline & flexãoMOE & 161428688.295 & 1 & 161428688.295 & 80618.549 & .000 \\
\hline & tração & 37508.193 & 1 & 37508.193 & 144117.680 & .000 \\
\hline & traçãoMOE & 168552128.103 & 1 & 168552128.103 & 21877.180 & .000 \\
\hline \multirow[t]{4}{*}{ processo } & flexão & 28.132 & 1 & 28.132 & 24.037 & .000 \\
\hline & flexãoMOE & 47295.593 & 1 & 47295.593 & 23.620 & .000 \\
\hline & tração & 1.776 & 1 & 1.776 & 6.824 & .016 \\
\hline & traçãoMOE & 651.169 & 1 & 651.169 & .085 & .774 \\
\hline \multirow[t]{4}{*}{ teorNC } & flexão & 37.083 & 2 & 18.541 & 15.843 & .000 \\
\hline & flexãoMOE & 2697.036 & 2 & 1348.518 & .673 & .520 \\
\hline & tração & 10.666 & 2 & 5.333 & 20.490 & .000 \\
\hline & traçãoMOE & 378377.102 & 2 & 189188.551 & 24.556 & .000 \\
\hline \multirow{4}{*}{$\begin{array}{l}\text { processo } * \\
\text { teorNC }\end{array}$} & flexão & 5.883 & 2 & 2.941 & 2.513 & .103 \\
\hline & flexãoMOE & 35267.549 & 2 & 17633.775 & 8.806 & .001 \\
\hline & tração & 1.640 & 2 & .820 & 3.151 & .062 \\
\hline & traçãoMOE & 303320.931 & 2 & 151660.466 & 19.685 & .000 \\
\hline \multirow[t]{4}{*}{ Erro } & flexão & 26.918 & 23 & 1.170 & & \\
\hline & flexãoMOE & 46054.659 & 23 & 2002.376 & & \\
\hline & tração & 5.986 & 23 & .260 & & \\
\hline & traçãoMOE & 177202.862 & 23 & 7704.472 & & \\
\hline \multirow[t]{4}{*}{ Total } & flexão & 93776.760 & 29 & & & \\
\hline & flexãoMOE & 163078678.940 & 29 & & & \\
\hline & tração & 37741.410 & 29 & & & \\
\hline & traçãoMOE & 170607425.700 & 29 & & & \\
\hline \multirow[t]{4}{*}{ Total corrigido } & flexão & 102.166 & 28 & & & \\
\hline & flexãoMOE & 128849.466 & 28 & & & \\
\hline & tração & 20.486 & 28 & & & \\
\hline & traçãoMOE & 910221.494 & 28 & & & \\
\hline
\end{tabular}


Tabela 4: ANOVA da resistência ao impacto.

\begin{tabular}{|c|c|c|c|c|c|}
\hline & Soma & df & Média & $\mathrm{F}$ & Sig. \\
\hline Entre grupos & 60566.365 & 6 & 10094.394 & 250.130 & .000 \\
\hline Dentro grupo & 1694.978 & 42 & 40.357 & & \\
\hline Total & 62261.344 & 48 & & & \\
\hline
\end{tabular}

Tabela 5: Comparações da resistência ao impacto.

\begin{tabular}{rllrrrrr}
\hline & & & & & \multicolumn{2}{c}{$95 \%$ Intervalo de confiança } \\
\cline { 5 - 7 } (I) tratamento & & Média (I-J) & Std. Erro & Sig. & Limite inferior & Limite superior \\
\hline Dunnett & P5-05 & ABS-Puro & $31,38429^{*}$ & 3.39565 & .000 & 22.3019 & 40.4667 \\
& P5-1,0 & ABS-Puro & $-35,22857^{*}$ & 3.39565 & .000 & -44.3110 & -26.1461 \\
& P5-1,5 & ABS-Puro & $-37,54714^{*}$ & 3.39565 & .000 & -46.6296 & -28.4647 \\
P9-0,5 & ABS-Puro & $18,94857^{*}$ & 3.39565 & .000 & 9.8661 & 28.0310 \\
P9-1,0 & ABS-Puro & $-47,31714^{*}$ & 3.39565 & .000 & -56.3996 & -38.2347 \\
P9-1,5 & ABS-Puro & $-73,01000^{*}$ & 3.39565 & .000 & -82.0924 & -63.9276 \\
\hline
\end{tabular}

Tabela 6: Testes entre a resistência ao impacto.

\begin{tabular}{lrrrrr}
\hline & & & & & \\
Fonte & Tipo III Soma & df & \multicolumn{1}{c}{ Média } & \multicolumn{1}{c}{ F } & \multicolumn{1}{l}{ Sig. } \\
\hline Modelo corrigido & $57169,153^{\mathrm{a}}$ & 5 & 11433.831 & 276.042 & .000 \\
Interceptar & 859072.513 & 1 & 859072.513 & 20740.203 & .000 \\
processo & 4198.200 & 1 & 4198.200 & 101.355 & .000 \\
teorNC & 51714.771 & 2 & 25857.386 & 624.263 & .000 \\
processo * teorNC & 1256.182 & 2 & 628.091 & 15.164 & .000 \\
Erro & 1491.143 & 36 & 41.421 & & \\
Total & 917732.810 & 42 & & & \\
Total corrigido & 58660.296 & 41 & & & \\
\hline
\end{tabular}

